\title{
Fundamental and experimental investigation of a Double Mechanism Sorptive Refrigeration (DMSR) system
}

\author{
by \\ Linghui Zhu \\ B. Eng. \\ A thesis submitted to the Faculty of Graduate Studies and Research in partial \\ fulfillment of the requirements for the degree of

\section{Master of Applied Science}

Ottawa-Carleton Institute for Mechanical and Aerospace Engineering Department of Mechanical and Aerospace Engineering

\author{
Carleton University
}

Ottawa, Ontario

Canada

August 2006

(C) Linghui Zhu, 2006 


$\begin{array}{ll}\begin{array}{l}\text { Library and } \\ \text { Archives Canada }\end{array} & \begin{array}{l}\text { Bibliothèque et } \\ \text { Archives Canada }\end{array} \\ \begin{array}{l}\text { Published Heritage } \\ \text { Branch }\end{array} & \begin{array}{l}\text { Direction du } \\ \text { Patrimoine de l'édition }\end{array} \\ \begin{array}{l}\text { 395 Wellington Street } \\ \text { Ottawa ON K1A ON4 }\end{array} & \begin{array}{l}\text { 395, rue Wellington } \\ \text { Ottawa ON K1A ON4 } \\ \text { Canada }\end{array}\end{array}$

Your file Votre référence ISBN: 978-0-494-18339-7 Our file Notre référence ISBN: 978-0-494-18339-7

NOTICE:

The author has granted a nonexclusive license allowing Library and Archives Canada to reproduce, publish, archive, preserve, conserve, communicate to the public by telecommunication or on the Internet, loan, distribute and sell theses worldwide, for commercial or noncommercial purposes, in microform, paper, electronic and/or any other formats.

The author retains copyright ownership and moral rights in this thesis. Neither the thesis nor substantial extracts from it may be printed or otherwise reproduced without the author's permission.
AVIS:

L'auteur a accordé une licence non exclusive permettant à la Bibliothèque et Archives Canada de reproduire, publier, archiver, sauvegarder, conserver, transmettre au public par télécommunication ou par l'Internet, prêter, distribuer et vendre des thèses partout dans le monde, à des fins commerciales ou autres, sur support microforme, papier, électronique et/ou autres formats.

L'auteur conserve la propriété du droit d'auteur et des droits moraux qui protège cette thèse. $\mathrm{Ni}$ la thèse ni des extraits substantiels de celle-ci ne doivent être imprimés ou autrement reproduits sans son autorisation.
In compliance with the Canadian

Privacy Act some supporting forms may have been removed from this thesis.

While these forms may be included in the document page count, their removal does not represent any loss of content from the thesis.
Conformément à la loi canadienne sur la protection de la vie privée, quelques formulaires secondaires ont été enlevés de cette thèse.

Bien que ces formulaires aient inclus dans la pagination, il n'y aura aucun contenu manquant.

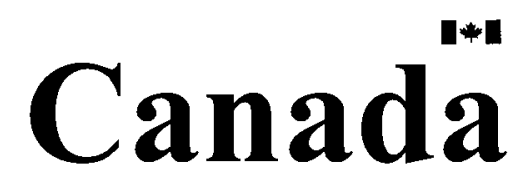




\begin{abstract}
This thesis work is to perform testing and theoretical analyses of a thermal-driven refrigeration system using a new sorbent-sorptive pair as the working pair.
\end{abstract}

The basic thermodynamic properties of the working solution and liquid or vapour ammonia were collected, compared and formulated, which include enthalpy, viscosity, density, thermal conductivity, specific heat and the crystallization line. The relationships among the temperature, solution concentration and other thermal properties were investigated.

Based on the thermodynamic properties analysis of the working solution, a detailed thermal-driven refrigeration system mathematical model is introduced, which include five correlative components: generator, condenser, evaporator, absorber, and solution heat exchanger. Two computational simulation programs are applied to analyze the thermal-driven refrigeration system characteristics and performance. These simulations involve a thermal network throughout the whole system, and the heat balance for every component.

A series of experiments are conducted. The experiments involve two different working conditions, normal refrigeration working condition and super-cooling working condition. Large amounts of temperature data are acquired based on experimental work. This data covers different generating temperature, cooling water temperature at different testing conditions.

This thesis also points out opportunities to improve the system performance and 
optimize the system structures and will greatly help the next generation prototype design. 


\section{Acknowledgement}

From the bottom of my heart, I thank Professor Junjie Gu, my thesis supervisor. It was his appreciation that led me to the opportunity with which I can do what I want and what I love. Today, I gratefully show the small piece of shell found on the beach; and thank the person who led me to this beach, and provided guidance to find the shell. I appreciate his knowledge and patience with guiding me on the right track of studying.

I would also like to thank Mr. David Li, the vice president of DY Refrigeration Inc, who provided support for me to perform research in Carleton University; and thanks Mr. Ruoxi Dong who helped me with experimental hardware. I will also thank Shujun Wang who helped me with technical papers and related information, and with wording in this thesis. I would like to thank the people working in the machine shop who provided assistance in the experimental device manufacturing process.

I would thank all of the people who have been helping me, directly and indirectly, or have been providing convenience in our work.

Here, I would thank my Alma Mater, Shandong University of Science and Technology, China. It is where I learned the fundamental engineering knowledge, laying the foundation for my future.

Finally, I remain sanity to the love and support of my family and friends. Thank You.

Linghui Zhu

Carleton University, Ottawa, Canada 


\section{Table of Contents}

ABSTRACT ...........................................................................................

ACKNOWLEDGEMENT ..................................................................... IV

LIST OF FIGURES .................................................................................. IX

LIST OF TABLES .................................................................................. XIV

NOMENCLATURE .............................................................................XV

CHAPTER 1 INTRODUCTION ............................................................

1.1 Introduction to thermal-driven refrigeration system technology ............................................... 1

1.2 Background.............................................................................................................................................

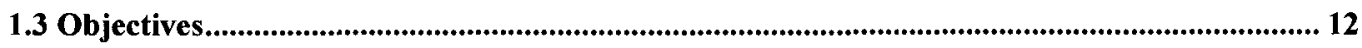

1.4 Organization ....................................................................................................................................... 13

\section{CHAPTER 2}

THERMAL-DRIVEN REFRIGERATION SYSTEM FUNDAMENTALS ..........14

2.1 Principle of operation ................................................................................................................ 14

2.2 Working fluid for absorption refrigeration systems....................................................................... 16

2.3 Various designs of absorption refrigeration cycles....................................................................... 20

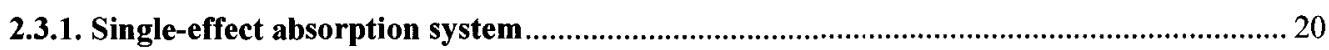

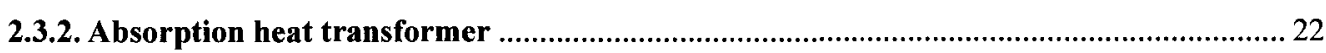

2.3.3. Multi-effect absorption refrigeration cycle ................................................................ 23

2.3.4. Absorption refrigeration cycle with GAX ............................................................... 27

2.3.5. Absorption refrigeration cycle with an absorber heat recovery .................................. 29

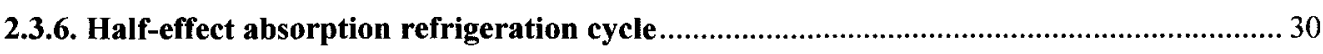

2.3.7. Combined vapor absorption-compression cycle .................................................... 31

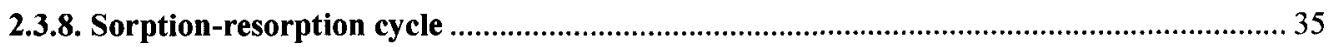

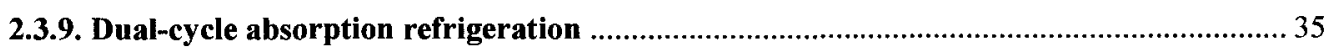

2.3.10. Combined ejector-absorption refrigeration cycle ................................................ 36

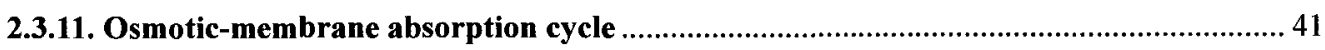

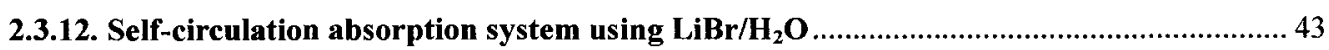




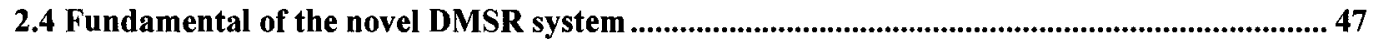

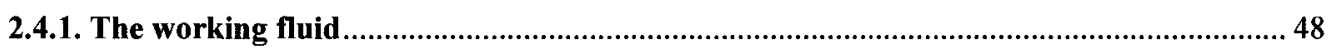

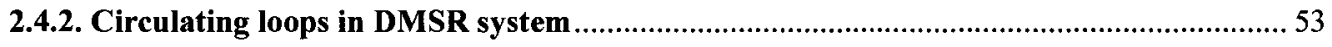

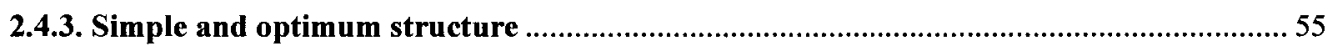

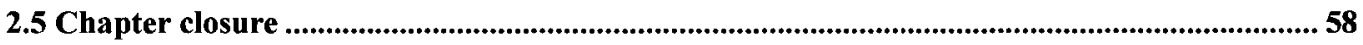

\section{CHAPTER 3}

\section{THERMODYNAMICS PROPERTIES OF WORKING FLUID AND}

MATHEMATICAL MODELING...............................................................60

3.1 Thermodynamic properties of the working fluid ........................................................................61

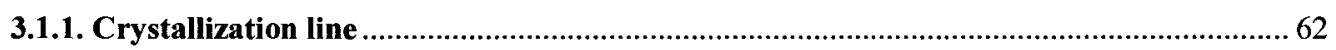

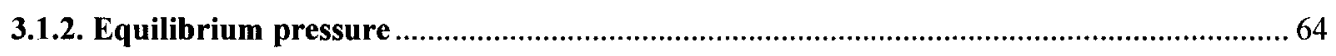

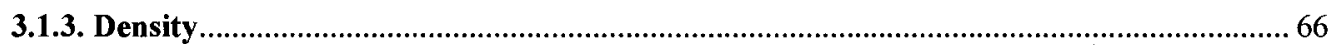

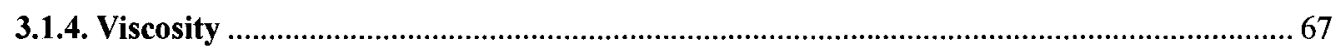

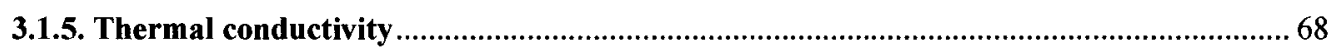

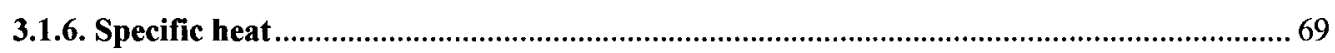

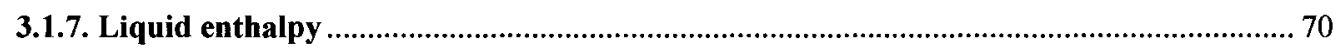

3.1.8. Thermodynamic properties of liquid and vapor ammonia........................................... 73

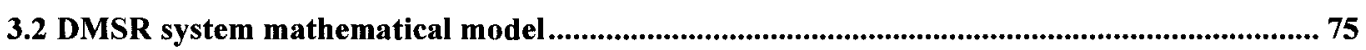

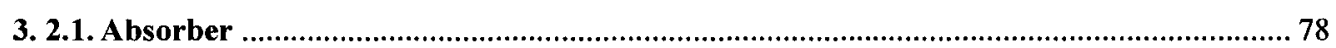

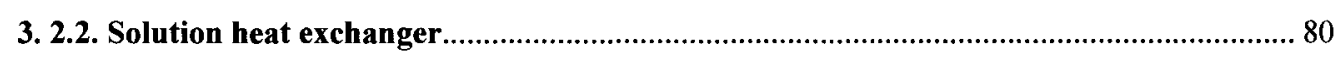

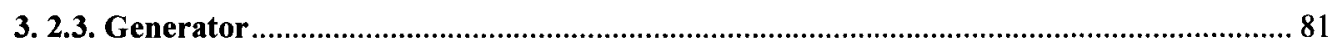

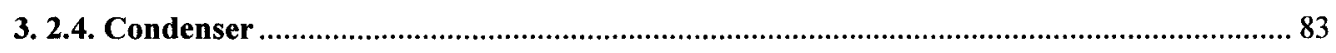

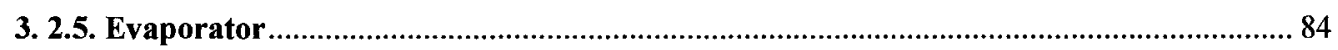

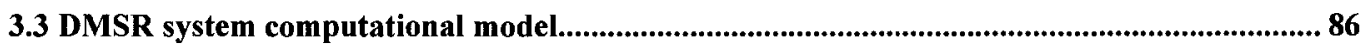

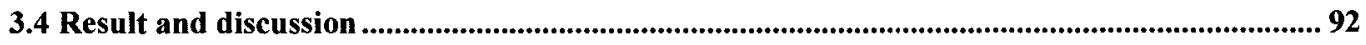

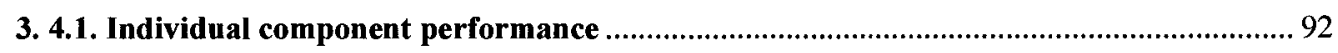

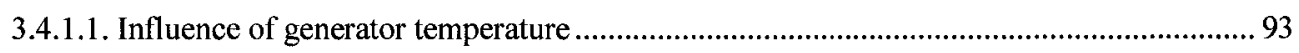

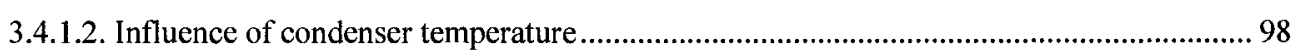

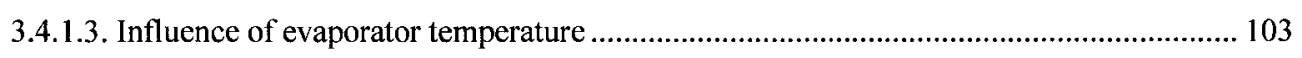

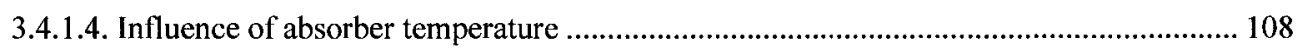

3.4.1.5. Influence of solution heat exchanger effectiveness..................................................111

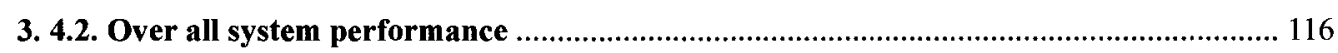

3.4.2.1. Influence of the heat source temperature ................................................................. 117

3.4.2.2. Influence of the partial pressure of hydrogen ............................................................. 122

3.4.2.3. Influence of cooling water inlet temperature to the condenser .................................... 127

3.4.2.4. Influence of the cooling water inlet temperature to absorber.................................... 133 


\section{CHAPTER 4}

\section{EXPERIMENTAL INVESTIGATION OF DMSR SYSTEM}

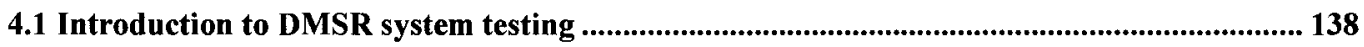

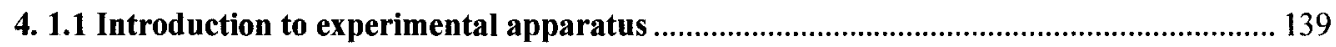

4.1.1.1 Double Mechanism Sorptive Refrigeration (DMSR) system ..................................... 140

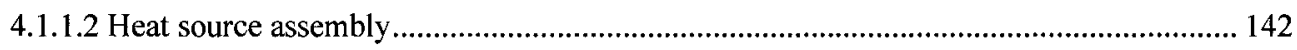

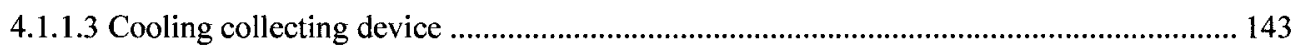

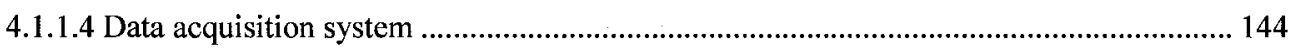

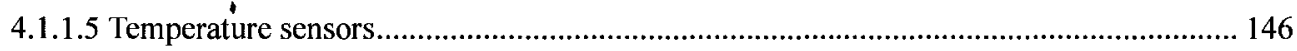

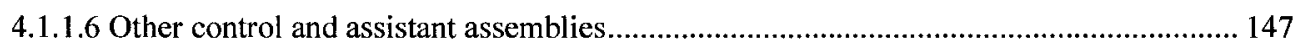

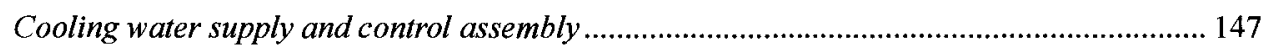

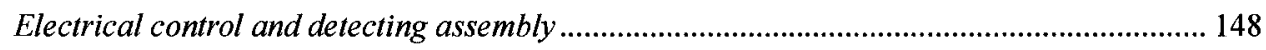

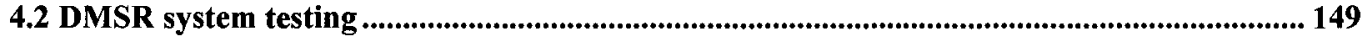

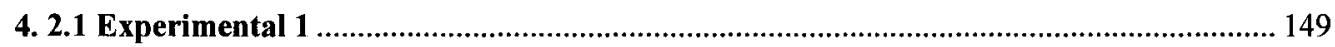

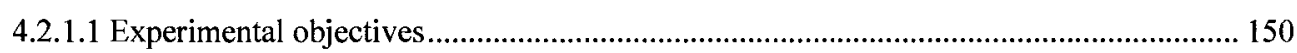

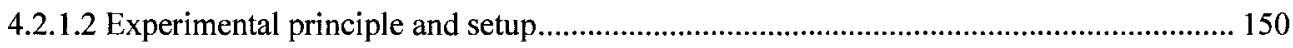

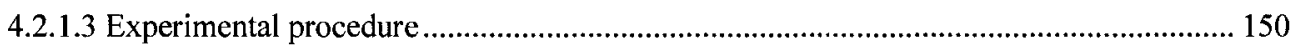

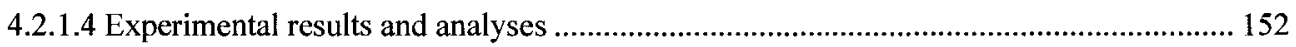

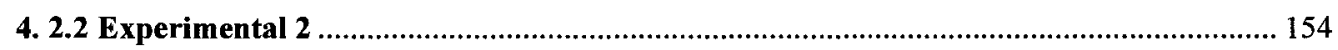

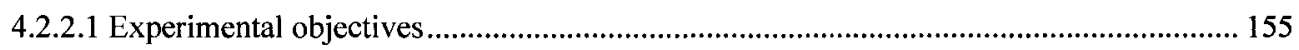

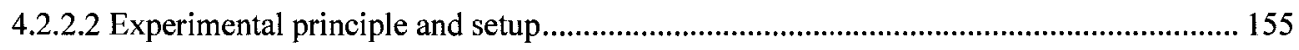

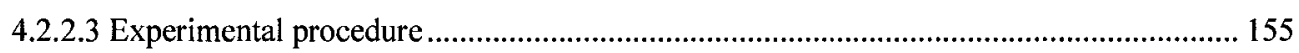

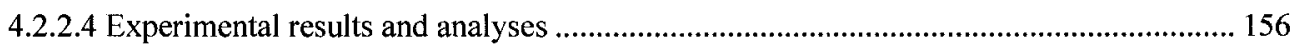

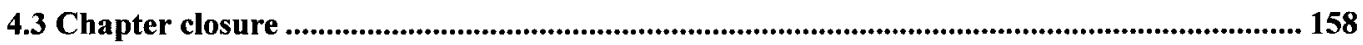

\section{CHAPTER 5}

CONCLUSIONS AND RECOMMENDATIONS .........................................159

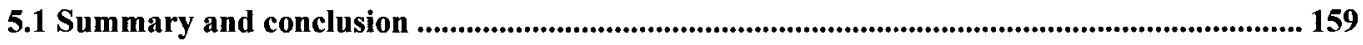

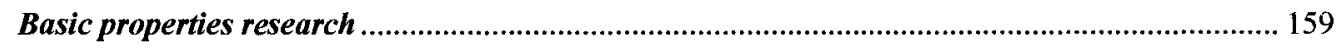

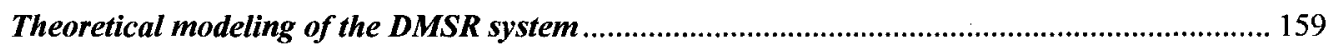

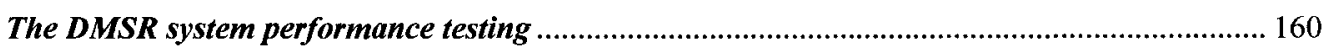

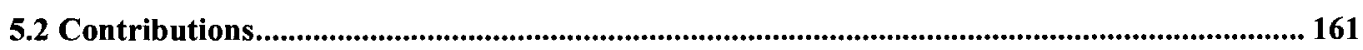

The first working prototype built at Carleton University ........................................................ 161

Theoretical analysis on DMSR system performance .............................................................. 161

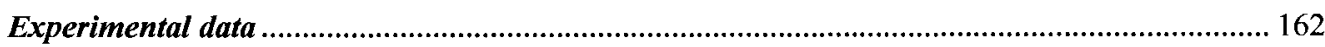




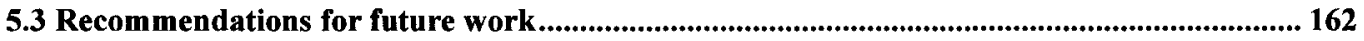

The Improvement of theoretical analysis method ............................................................. 162

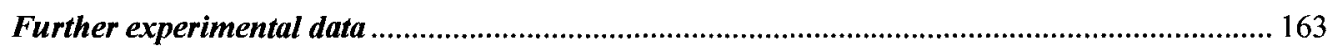

Comparison of experimental data and simulation ..................................................................... 163

The improvement of testing data acquisition system......................................................... 163

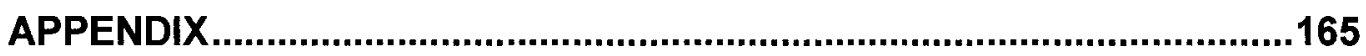

Appendix I: The computational simulation programs....................................................... 165

Program I.1 The single components simulation program 1 (Matlab) ...................................... 165

Program I.2 The overall system performance simulation program 2 (Matlab) ......................... 167

Appendix II: The experimental result recordings ................................................................ 170

Table II.1 Experimental result for normal refrigeration working conditions ............................. 170

Table II.2 Experimental result for super-cooling working conditions ................................ 173

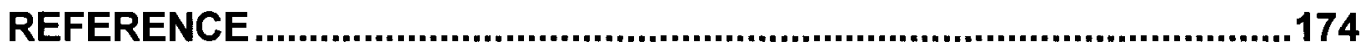




\section{List of Figures}

Figure 1.1 (a) Absorption process occurs in right vessel causing cooling effect in the other; (b) Refrigerant separation process occurs in the right vessel as a result of additional heat from outside heat source

Figure 2.1 A continuous absorption refrigeration cycle

Figure 2.2 A single-effect $\mathrm{LiBr} / \mathrm{H}_{2} \mathrm{O}$ absorption refrigeration system with a solution heat exchanger (HX) that helps decrease heat input at the generator.

Figure 2.3 Absorption heat transformer absorbs waste heat at the generator. Liquid refrigerant is pumped to the evaporator to absorb waste heat. High temperature useful heat from the absorber is heat of absorption

Figure 2.4 A double-effect $\mathrm{LiBr} / \mathrm{H}_{2} \mathrm{O}$ absorption cycle. Heat released from the condensation of refrigerant vapor is used as heat input in generator II. This cycle is operated with 3 pressure levels i.e. high, moderate and low pressure.

Figure 2.5 A double-effect absorption cycle operates with two pressure levels. Heat of absorption from Absorber II is supplied to the Desorber I for the refrigerant separation process ........ 26

Figure 2.6 A triple-effect absorption cycle operates at 4 pressure levels. Heat of condensation from the higher-pressure stage is used for refrigerant separation in the lower-pressure stage

Figure 2.7 The dotted loop shows secondary fluid used for transferring heat from high temperature section in the absorber to low temperature section in the generator 28

Figure 2.8 The cycle with absorber heat recovery uses heat of absorption to preheat the outgoing stream from the absorber to the generator

Figure 2.9 A half-effect absorption cycle is a combination of two single-effect cycles but working at different pressure levels. Letting heat source temperature be lower than the minimum temperature which is necessary for a single-effect cycle working at the same pressure level 31

Figure 2.10 Combined vapor absorption/compression heat pump

Figure 2.11 A double effect absorption-compression cycle is conFigured as a heat pump. Heat of absorption in the first stage will be supplied to the second stage for refrigerant separation 33 
Figure 2.12 A combined cycle proposed by Caccoila et al. [86], employing combination of two working fluids i.e. $\mathrm{NH}_{3} / \mathrm{H}_{2} \mathrm{O}$ and $\mathrm{H}_{2} \mathrm{O} / \mathrm{KHO}$. The rectifier is absent and also the highest pressure is decreased

Figure 2.13 A resorption cycle proposed by Altenkirch uses two solution circuits 35

Figure 2.14 Solar driven dual cycle absorption employs two different working fluids i.e. $\mathrm{NH}_{3} / \mathrm{H}_{2} \mathrm{O}$ and $\mathrm{H}_{2} \mathrm{O} / \mathrm{LiBr}$. Heat of absorption and condensation from $\mathrm{NH}_{3} /$ water cycle are supplied to the generator of $\mathrm{H}_{2} \mathrm{O} / \mathrm{LiBr}$ cycle 36

Figure 2.15 A modified double-effect combined ejector-absorption refrigeration cycle where there is no condenser included 38

Figure 2.16 A combined ejector/absorption system using DMETEG/R22 and DMETEG/R21 as working fluids. The strong solution in the returning leg from generator serves as primary fluid and refrigerant vapor from evaporator as second fluid

Figure 2.17 A combined ejector/absorption proposed by Aphornratana and Eames [92], was invented. High pressure refrigerant vapor from the generator enters the ejector as motive fluid to carry the refrigerant vapor from the evaporator

Figure 2.18 A combined cycle proposed by Eames and Wu [68]. The highest solution circuit temperature is maintained at about $80^{\circ} \mathrm{C}$. So the corrosion problem is alleviated 41

Figure 2.19 An osmotic membrane absorption cycle employs heat for refrigerant separation and producing pressure difference within the system... 42

Fig. 2.20 The diagram shows a bubble pump in a generator module. Heat input to the generator is used for both circulation of working fluid and evaporation of refrigerant. 44

Figure 2.21 A diffusion absorption refrigerator (DAR). This system was once widely used as a domestic refrigerator as no electricity is required in its operation. $\mathrm{NH}_{3} / \mathrm{H}_{2} \mathrm{O}$ /auxiliary gas is charged in the machine as the working fluid..........................................................................46

Figure 2.22 Comparison of the effect of COP values on generator temperatures [6] ....................50

Figure 2.23 Comparison of the effect of COP values on evaporator temperatures $[6] \ldots . . . . . . . . . . . . .551$

Figure 2.24 Comparison of the effect of COP values on condenser temperatures [6]................... 52

Figure 2.25 Comparison of the effect of COP values on absorber temperatures [6].....................53

Figure 2.26 Double Mechanism Sorptive Refrigeration (DMSR) system..................................56

Figure 3.1 The relationship among the $\mathrm{NH}_{3}-\mathrm{NaSCN}$ solution crystallization temperature, 
equilibrium pressure and solution concentration

Figure 3.2 The relationship among the $\mathrm{NH}_{3}-\mathrm{NaSCN}$ solution saturation equilibrium pressure, temperature and solution concentration (comparison between experimental data and equation 3.6) [18] 66

Figure 3.3 The relationship among the $\mathrm{NH}_{3}-\mathrm{NaSCN}$ solution viscosity, temperature and solution concentration (comparison between experimental data and equation 3.12) [18] 68

Figure 3.4 The relationship among the $\mathrm{NH}_{3}-\mathrm{NaSCN}$ solution specific heat, temperature and solution concentration (comparison between experimental data and equation 3.19) [18] ... 70

Figure 3.5 The relationship among the $\mathrm{NH}_{3}-\mathrm{NaSCN}$ solution liquid enthalpy, temperature and solution concentration (comparison between experimental data and equation 3.12) [18] .... 72

Figure 3.7 The flowchart of computational simulation program ..................................................87

Figure 3.8 The effect of generator temperature on COP value.....................................................95

Figure 3.9 The relation between generator temperature and circulation ratio.............................. 96

Figure 3.10 The relation between generator temperature and cooling capacity ...........................99

Figure 3.11 The relation between generator temperature and heating load...................................98

Figure 3.12 The relation between condenser temperature and COP ......................................... 100

Figure 3.13 The relation between condenser temperature and circulation ratio ......................... 101

Figure 3.14 The relation between condenser temperature and cooling capacity.......................... 102

Figure 3.15 The relation between condenser temperature and heating load ................................ 103

Figure 3.16 The relation between evaporator temperature and COP.......................................... 106

Figure 3.17 The relation between evaporator temperature and circulation ratio........................ 106

Figure 3.18 The relation between evaporator temperature and cooling capacity ....................... 107

Figure 3.19 The relation between evaporator temperature and heating load ............................... 107

Figure 3.20 The relation between absorber temperature and COP ......................................... 109

Figure 3.21 The relation between absorber temperature and circulation ratio ............................110

Figure 3.22 The relation between absorber temperature and cooling capacity.............................110

Figure 3.23 The relation between absorber temperature and heating load ...................................111

Figure 3.24 The relation between solution heat exchanger effectiveness and COP......................114

Figure 3.25 The relation between solution heat exchanger effectiveness and heating load..........115

Figure 3.26 The relation between solution heat exchanger effectiveness and heating rejection 
Figure 3.27 The relation between heat source temperature and heating load 118

Figure 3.28 The relation between heat source temperature and cooling capacity

Figure 3.29 The relation between heat source temperature and weak solution concentration ... 121

Figure 3.30 The relation between heat source temperature and strong solution concentration . 122

Figure 3.31 The relation between chilled liquid outlet temperature and system COP

Figure 3.32 The relation between chilled liquid outlet temperature and cooling capacity 125

Figure 3.33 The relation between chilled liquid outlet temperature and weak solution concentration

Figure 3.34 The relation between chilled liquid outlet temperature and strong solution concentration 127

Figure 3.35 The relation between condenser cooling water inlet temperature and system COP 129 Figure 3.36 The relation between condenser cooling water inlet temperature and cooling capacity

Figure 3.37 The relation between condenser cooling water inlet temperature and heat rejection from condenser. 131

Figure 3.38 The relation between condenser cooling water inlet temperature and weak solution concentration. 132

Figure 3.39 The relation between condenser cooling water inlet temperature and strong solution concentration. 133

Figure 3.40 The relation between absorber cooling water inlet temperature and circulation ratio

Figure 3.41 The relation between absorber cooling water inlet temperature and heat rejection from absorber.

Figure 3.42 The relation between absorber cooling water inlet temperature and weak solution concentration. 136

Figure 3.43 The relation between absorber cooling water inlet temperature and strong solution concentration 137

Figure 4.1 The Double Mechanism Sorptive Refrigeration (DMSR) system testing apparatus . 140 Figure 4.2 Droplet separator designed for condensing NaSCN entrainment in vapor ammonia 142 xii 
Figure 4.3 Heat source assembly for DMSR system testing ............................................... 143

Figure 4.4 Cooling collecting device and cooling water control and detect device...................... 144

Figure 4.5 Data acquisition system hardware for DMSR system testing .................................. 145

Figure 4.6 Data acquisition system interface for DMSR system testing...................................... 146

Figure 4.7 Cooling water supply and control assembly for DMSR system testing....................... 148

Figure 4.8 Electrical control and detecting assembly for DMSR system testing ......................... 149

Figure 4.9 The relation between evaporator outlet temperature and heat source temperature

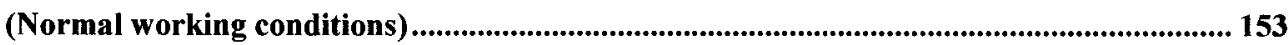

Figure 4.10 The relation between absorber cooling water outlet temperature and heat source temperature (Normal working conditions)

Figure 4.11 The relation between condenser cooling water outlet temperature and heat source temperature (Normal working conditions).

Figure 4.12 The relation between evaporator outlet temperature and heat source temperature (Super-cooling working conditions) 157

Figure 4.13 The relation between evaporator outlet temperature and cooling water inlet temperature (Super-cooling working condition). 158 


\section{List of Tables}

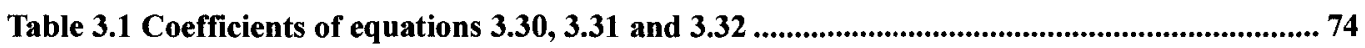

Table 3.2 The design condition for the single components simulation program ........................... 90

Table 3.3 The design condition for the whole system simulation program......................................90

Table 3.4 The calculated properties for design conditions of the whole system simulation program 


\section{Nomenclature}

$X$

XCRIS

$T$

$P$

$\dot{m}$

$\rho$

$\eta$

$\lambda$

$C p$

$h$

$h_{l}$

$h_{v}$

$h_{\text {superheated }}$

$h_{\text {saturated }}$

$Q e$

$Q_{g}$

$Q_{a}$

$Q_{c}$

$W_{\text {pump }}$

$T_{\text {hoa }}$

$T_{\text {cia }}$ liquid phase concentration, $\mathrm{kg} \mathrm{NH}_{3} / \mathrm{kg}$ solution

crystallization concentration, $\mathrm{kg} \mathrm{NH}_{3} / \mathrm{kg}$ solution

temperature, ${ }^{\circ} \mathrm{C}$

absolute pressure, $\mathrm{kPa}$

mass flow rate, $\mathrm{kg} / \mathrm{s}$

density, $\mathrm{kg} / \mathrm{m}^{3}$

viscosity, $\mathrm{kPa}$ sec.

thermal conductivity, $\mathrm{kW} / \mathrm{mK}$

specific heat, $\mathrm{kJ} / \mathrm{kgK}$

specific enthalpy, $\mathrm{kJ} / \mathrm{kg}$

specific enthalpy for liquid ammonia, $\mathrm{kJ} / \mathrm{kg}$

specific enthalpy for vapor ammonia, $\mathrm{kJ} / \mathrm{kg}$

specific enthalpy for superheated vapor ammonia, $\mathrm{kJ} / \mathrm{kg}$

specific enthalpy for saturated vapor ammonia, $\mathrm{kJ} / \mathrm{kg}$

cooling capacity, $\mathrm{kW}$

heating load, $\mathrm{kW}$

energy released from absorber, $\mathrm{kW}$

energy released from condenser, $\mathrm{kW}$

energy load by circulation pump, $\mathrm{kW}$

weak solution output temperature from absorber, ${ }^{\circ} \mathrm{C}$

cooling water input temperature from absorber, ${ }^{\circ} \mathrm{C}$ 


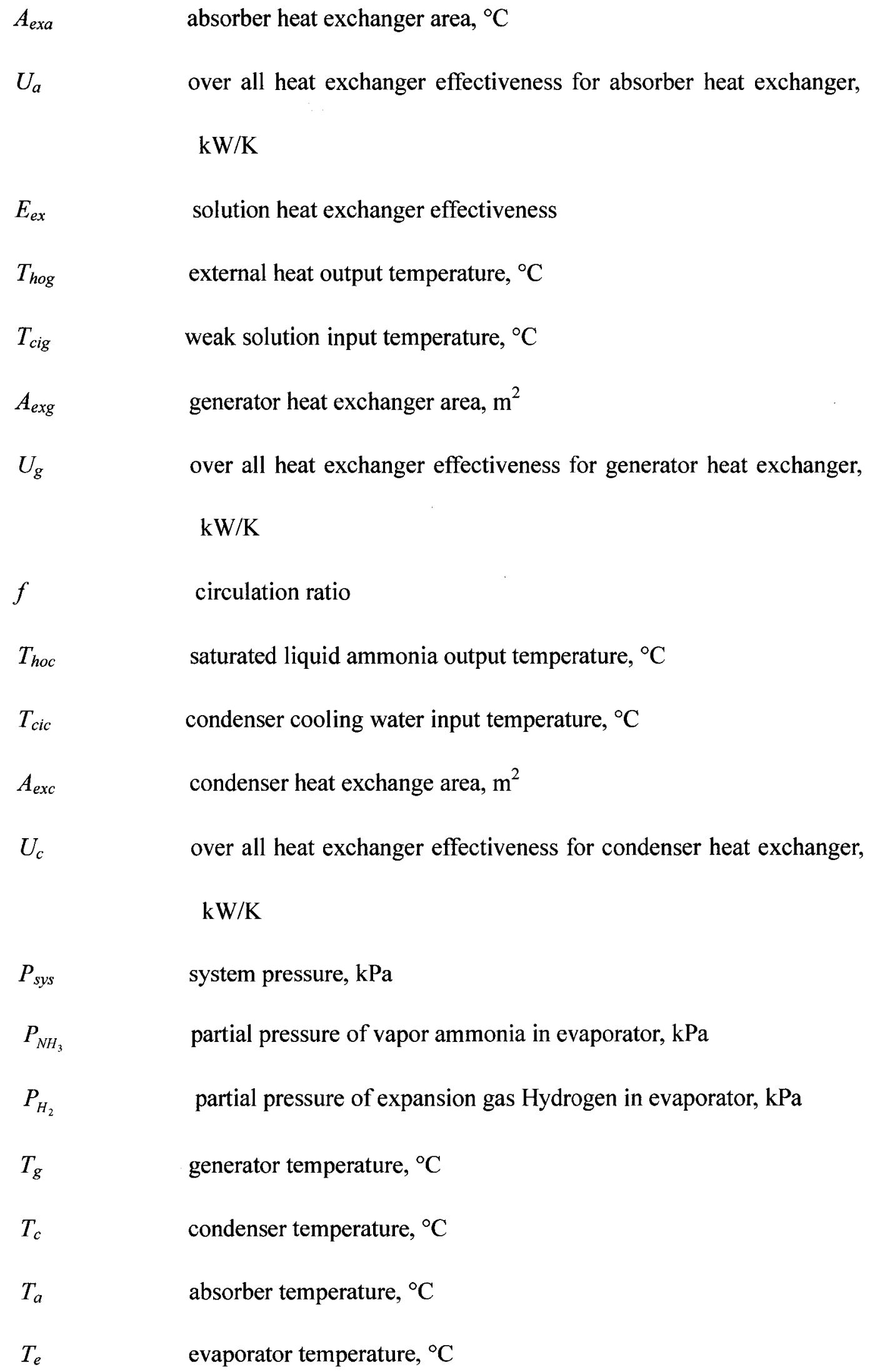




\section{Chapter 1 Introduction}

\subsection{Introduction to thermal-driven refrigeration system technology}

The absorption cycle is a process by which refrigeration effect is produced through the use of two fluids and some quantity of heat input, rather than electrical input as in the more familiar vapor compression cycle. Both vapor compression and absorption refrigeration cycles accomplish the removal of heat through the evaporation of a refrigerant at a low pressure and the rejection of heat through the condensation of the refrigerant at a higher pressure. The method of creating the pressure difference and circulating the refrigerant is the primary difference between the two cycles. The vapor compression cycle employs a mechanical compressor to create the pressure difference necessary to circulate the refrigerant. In the absorption system, a secondary fluid or absorbent is used to circulate the refrigerant.

The working fluid in an absorption refrigeration system is a binary solution consisting of refrigerant and absorbent. In Figure 1.1(a), two evacuated vessels are connected to each other. The left vessel contains liquid refrigerant while the right vessel contains a binary solution of absorbent/refrigerant. The solution in the right vessel will absorb refrigerant vapor from the left vessel causing pressure to reduce. While the refrigerant vapor is being absorbed, the temperature of the remaining refrigerant will reduce as a result of its vaporization. This causes a refrigeration effect 
to occur inside the left vessel. At the same time, solution inside the right vessel becomes more dilute because of the higher content of refrigerant absorbed. This is called the "absorption process". Normally, the absorption process is an exothermic process. Therefore, it must reject heat out to the surrounding in order to maintain its absorption capability. Whenever the solution cannot continue with the absorption process because of saturation of the refrigerant, the refrigerant must be separated out from the diluted solution. Heat is normally the key for this separation process. It is applied to the right vessel in order to dry the refrigerant from the solution as shown in Figure 1.1(b). The refrigerant vapor will be condensed by transferring heat to the surroundings. With these processes, the refrigeration effect can be produced by using heat energy [1].

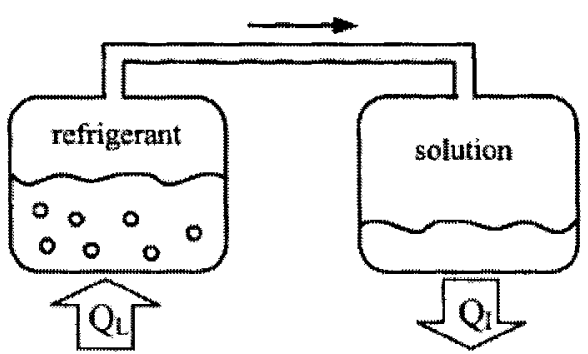

(a)

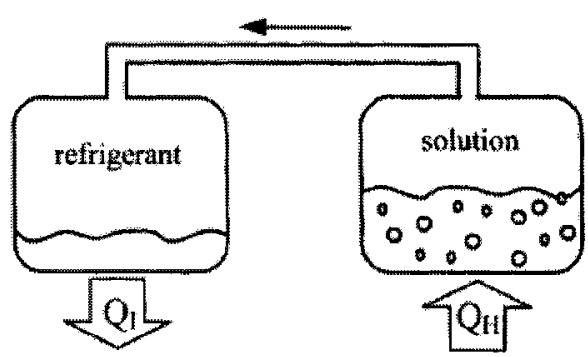

(b)

Figure 1.1 (a) Absorption process occurs in right vessel causing cooling effect in the other; (b) Refrigerant separation process occurs in the right vessel as a result of additional heat from outside heat source

In the early years of this century, sorption refrigeration was quite frequently used. The early development of an absorption cycle dates back to the 1700's. It was known that ice could be produced by an evaporation of pure water from a vessel contained within an evacuated container in the presence of sulfuric acid, $[2,3]$. In 1810 , ice could be made from water in a vessel, which was connected to another vessel 
containing sulfuric acid. As the acid absorbed water vapor, causing a reduction of temperature, layers of ice were formed on the water surface. The major problems of this system were corrosion and leakage of air into the vacuum vessel. In 1859 , Ferdinand Carre introduced a novel machine using water/ammonia as the working fluid. This machine took out a US patent in 1860. Machines based on this patent were used to make ice and store food. It was used as a basic design in the early age of refrigeration development. In the 1950 's, a system using lithium bromide/water as the working fluid was introduced for industrial applications. A few years later, a double-effect absorption system was introduced and has been used as an industrial standard for high performance heat-operated refrigeration cycle [1].

Later, with the development of cheap reliable compressors and electrical motors, the improvement in power station efficiency, and the introduction of CFCs (chlorofluorocarbons) and HCFCs (hydrochlorofluorocarbons), which have high coefficient of performance (COP), sorption refrigeration became a niche technology. However, refrigeration technology is required to continuously evolve due to new environmental regulations. The first regulation concerning the depletion of the ozone layer (Montreal Protocol, 1988) decided to phase-out chlorofluorocarbons and then hydrochlorofluorocarbons. In developed countries, the production of chlorofluorocarbons has been prohibited since 1995, and hydrochlorofluorocarbons will be banned in 2015 at the latest in the European Union depending on the country (they have been banned since 1998 in Sweden). The second regulation concerns the global warming effect and is being implemented according to the Kyoto Protocol 
(1997) [4]. Some of the refrigerants which fulfill the Montreal Protocol with zero 'ozone depletion potential', the hydrofluorocarbons, are concerned with this new regulation which prescribes a limitation of the emissions of greenhouse gases $\left(\mathrm{CO}_{2}\right.$, $\mathrm{CH}_{4}, \mathrm{~N}_{2} \mathrm{O}$, hydrofluorocarbons, perfluorocarbons, $\mathrm{SF}_{6}$ ). In refrigeration and air conditioning industry, a worldwide movement to find alternative refrigerants has been boomed since then.

The refrigeration professionals are improving their systems by: containment, recycling, recovery, qualification and ultimately by alternative technologies. Absorption technology is, obviously, one of the possible alternative technologies. Another important concern for refrigeration technology is the primary energy source with expanding of air-conditioning use. Air-conditioning systems requires large amount of electricity. Indeed, in some countries, such as the USA, China and other Far East countries, air-conditioning in summer time induces peaks in the electricity demand. Therefore, a global rational energy policy consists of promoting heat powered air-conditioning in summer time so as to cut down these peaks and make the electricity demand more uniform throughout the year.

Taking these considerations into account, some sorption technologies appear to be viable alternatives to vapour compression. First, sorption technology uses fluids with zero 'ozone depletion potential' which adhere to the Montreal Protocol. Second, the fluids have zero 'global warming potential' and fulfill the Kyoto Protocol. Third, they are heat-powered systems which need very little electricity. However, heat powered sorption units require energy which, in most cases, is provided by natural gas 
or fuel combustion, also resulting in $\mathrm{CO}_{2}$ emissions. Therefore, care must be taken that the efficiency of the sorption units is high enough to contribute less to global warming than the competing vapor compression systems. In the case of waste heat recovery, the problem of efficiency is not important for environmental impact since there are no emissions of greenhouse gases.

As sorption technology is a possible alternative to vapor compression refrigeration, it is important to compare the various sorption systems. Among them, liquid absorption units have been developed for a long time and present many references concerning their efficiency, cost, reliability, overall dimensions and weight. On the contrary, solid sorption systems have been scarcely developed up to now.

The most common absorption systems are $\mathrm{H}_{2} \mathrm{O}-\mathrm{LiBr}$ and $\mathrm{NH}_{3}-\mathrm{H}_{2} \mathrm{O}$ cycles. Within each of the two categories there are some differentiations between them but it is useful to divide the technology in this way to facilitate the discussion.

The absorption working fluid in $\mathrm{H}_{2} \mathrm{O}-\mathrm{LiBr}$ has been used widely since 1950 s when the technology was pioneered by several manufactures in the United States. This working fluid utilizes water as the refrigerant and is therefore limited to refrigeration temperatures above $0^{\circ} \mathrm{C}$. Absorption machines based on $\mathrm{H}_{2} \mathrm{O}-\mathrm{LiBr}$ are typically conFigured as water chillers for air-conditioning systems in large buildings. Machines are available in sizes ranging from 10 to 1500 Ton ( 1 Ton=12,000 $\mathrm{Btu} / \mathrm{hr}=3.517 \mathrm{~kW})$. The coefficient of performance $(\mathrm{COP})$ of these machines, defined as the refrigeration capacity divided by driving heat input, typically varies over the range $0.7<\mathrm{COP}<1.2$ depending on the particular cycle configuration. 
$\mathrm{NH}_{3}-\mathrm{H}_{2} \mathrm{O}$ absorption system has been used since the later 1800 s at which time it was used for ice production prior to the introduction of vapor compression technology. This working fluid utilizes ammonia as the refrigerant and water as the absorbent. One advantage of ammonia as refrigerant is that the allowable refrigeration temperature is much lower (the freezing temperature of ammonia is $-77.7^{\circ} \mathrm{C}$ ). However, the toxicity of ammonia is a factor that has limited its use to well-ventilated areas. $\mathrm{NH}_{3}-\mathrm{H}_{2} \mathrm{O}$ absorption chillers are commonly used as air-components and this use is regulated in some densely populated urban areas. The ability to provide direct gas-fired and air-cooled air-conditioning is the primary selling point of this technology. Machines are available in capacity ranging from 3 to 25 Ton (10 to 90 $\mathrm{kW})$ with coefficient of performance typically around $0.5[5]$.

For refrigeration, the $\mathrm{NH}_{3}-\mathrm{H}_{2} \mathrm{O}$ cycle is often used because of lower evaporation temperature of ammonia than water (i.e. from $-10^{\circ} \mathrm{C}$ to $0^{\circ} \mathrm{C}$ ) [6]. Research has been performed for $\mathrm{NH}_{3}-\mathrm{H}_{2} \mathrm{O}$ systems theoretically [7-9] and experimentally $[10,11]$. These studies show that the $\mathrm{NH}_{3}-\mathrm{H}_{2} \mathrm{O}$ system exhibits a relatively low COP. Further more, another disadvantage of the $\mathrm{NH}_{3}-\mathrm{H}_{2} \mathrm{O}$ system was its high water content in the vapor phase, resulting in a necessary requirement for an expensive dephlegmator, and resulting in the high vapor pressure at high temperature working conditions. Efforts are being made to search for better refrigerant-absorbent pairs that can improve system performance. It is proposed that $\mathrm{NH}_{3}-\mathrm{LiNO}_{3}$ and $\mathrm{NH}_{3}-\mathrm{NaSCN}$ cycles can be alternatives to $\mathrm{NH}_{3}-\mathrm{H}_{2} \mathrm{O}$ systems [12]. The advantages provided by these systems over the conventional $\mathrm{NH}_{3}-\mathrm{H}_{2} \mathrm{O}$ and $\mathrm{H}_{2} \mathrm{O}-\mathrm{LiBr}$ absorption 
units include: (a). lower generator temperatures, which allow operation with simple, flat-plate, solar collectors or waste heat, (b). lower evaporation temperatures in comparison with the $\mathrm{H}_{2} \mathrm{O}-\mathrm{LiBr}$ system, and (c). a higher coefficient of performance in comparison with the $\mathrm{NH}_{3}-\mathrm{H}_{2} \mathrm{O}$ system [13].

Among the first studies on the $\mathrm{NH}_{3}-\mathrm{NaSCN}$ system are those of Blytas and Daniels [14] and Sargent and Beckman [15]. Tyagi [16] and Aggarawal et al. [17] provide related studies and reviews on ammonia-salts absorption refrigeration systems. Thermodynamic and physical properties for the $\mathrm{NH}_{3}-\mathrm{LiNO}_{3}$, and $\mathrm{NH}_{3}-\mathrm{NaSCN}$ solutions have been presented by C. A. Infante Ferreira [18], while an interesting comparison between $\mathrm{NH}_{3}-\mathrm{H}_{2} \mathrm{O}, \mathrm{NH}_{3}-\mathrm{LiNO}_{3}$ and $\mathrm{NH}_{3}-\mathrm{NaSCN}$ absorption systems may be found in the works of Bourseau and Bugarel [19] and Dawen Sun [6].

\subsection{Background}

As introduced in the preceding section, there is a possibility of using low grade thermal energy such as waste heat from industries or solar energy, in refrigeration for food preservation, ice making and space conditioning of buildings, and some practical advantages such as quiet, long lasting, cheap to maintain and environmentally benign, so that sorption refrigeration system won great interesting and was widely used in a very long history.

An absorption cycle, in its simple form, is a process by which a cooling effect is produced through the use of two fluids and some quantity of heat. This cooling effect is accomplished with the removal of heat through evaporation of a fluid (refrigerant) 
at low pressure and the rejection of heat through the condensation of a fluid refrigerant) at a higher pressure.

The first element of the absorption principle, evaporation, can be traced back to the Egyptians. Pottery containers of wine and other liquids were set out at night so that cool breezes would accelerate evaporation and chill the contents.

However, the scientific evolution of absorption cooling did not begin until 1774 with the isolation of ammonia, oxygen, and carbon dioxide gases by English scientist Joseph Priestly. Another Englishman, Michael Faraday, used a closed "U-shaped" tube with one branch heated to increase pressure while the other was cooled. He observed that silver chloride has a peculiar propensity to absorb ammonia. Faraday demonstrated a chilling effect in the sealed tube as ammonia evaporated and then migrated back to the silver chloride powder, where it was reabsorbed.

For the next 70 years other scientists, engineers and creative individuals worked in varying degrees with absorption cooling principles and designs. In 1846, Ferdinand Carre invented the cycle and built a practical machine using the two-pressure ammonia / water principal, and he developed the first absorption machine in 1850, using water and sulfuric acid as the working fluid. By 1866, Ferdinand and his brother Edmond commercialized the application of these machines which were used primarily to make ice. And in 1860 Ferdinand received the first U.S. patent for this commercial absorption unit. This design found its way into the United States during the Civil War for the same purpose [20].

Absorption cooling technology was still relatively new with limited exposure to 
its application potential. A fresh new day for absorption was born on August 18, 1922 , when Swedish engineering students, Carl G. Munters and Baltzen Van Platen patented the single pressure ammonia / water hydrogen cycle. Another prestigious scientist, Albert Einstein, worked on an absorption refrigerator cycle design in 1927 for which he received a patent that had been assigned to Servel. Servel was founded in 1902 as the Hercules Buggy Works, and became a manufacturer of electric refrigerators (the name is short for "Serve Electrically"). In 1925, Servel purchased US rights to a new $\mathrm{AB}$ Electrolux gas heat-driven absorption refrigerator invented by Carl G. Munters and Baltzar Van Platen. The new Electrolux-Servel absorption refrigerator entered the US market in 1926. As a measure of productivity, from 1927 to 1955 , Servel was assigned over 250 patents on absorption refrigeration. These efforts brought absorption refrigerators to millions of homes until production was stopped in the 1950 s.

In 1933, water cooling of the Van Platen / Munters cycle was replaced by air cooling. The condenser was directly air-cooled while the absorber was cooled by a secondary circuit containing Methyl Chloride and its heat rejected to the air. By 1940, the absorber as well as the condenser on the refrigerator absorption cycle was directly air-cooled. In 1939, Servel introduced the water-cooled, two-pressure water/salt absorption air conditioner at the New York World's Fair.

Improvements and refinements in absorption refrigeration continued. Servel revived the two-pressure ammonia / water cycle of Carre with an air-cooled design, and commercial manufacturing began in 1964. 
In the late 1960 's, American companies manufactured $100 \%$ of $\mathrm{LiBr} / \mathrm{H}_{2} \mathrm{O}$ absorption chillers worldwide, using the standard single-effect absorption cycle. Trane Company introduced the first mass-produced steam-fired double-effect $\mathrm{LiBr} / \mathrm{H}_{2} \mathrm{O}$ absorption chiller in 1970 . Several factors have influenced absorption chiller sales since then. Natural gas prices, as well as, fuel availability concerns and governmental policies caused U.S. absorption chiller sales to decline in the mid-1970s and throughout the 1980s. But Absorption chiller use in countries like China, Korea and Japan has grown exponentially at that time [5].

Today, with the enhanced interesting in absorption refrigeration technology, some other new advanced designs have been applied or will be applied in this field. People try to use different ways to improve their COP, simplify system structure and operating process, reduce the driving temperature, and improve the system safety. As a result, some enhanced cycle designs require less heat energy to accomplish the same cooling effect. And an efficiency improvement of almost 30 percent was obtained while not drastically changing the overall size of the unit.

Absorption technology has provided business, industry and homes with refrigeration and air conditioning technology over the past 150 years. Absorption equipment was used to solve problems that could not otherwise be solved. In 1850 it was the only technology available. In 1926, the absorption refrigerator was the solution to an increasing number of consumer deaths caused by early vapor compression refrigerators (due to the toxicity of sulfur dioxide, methyl chloride, and ammonia gases used in earlier mechanical compressor home refrigerators since 1918). 
Nowadays, with the rapid technology improving, advanced absorption cooling system has become an accepted and sound alternative for cooling residential, light commercial, and industrial process application. The air-cooled, $\mathrm{NH}_{3}-\mathrm{H}_{2} \mathrm{O}$ and $\mathrm{H}_{2} \mathrm{O}$ - $\mathrm{LiBr}$ cycle continues to offer many distinct advantages to the industry. Both mixtures had some disadvantages to limit their applications either, the disadvantage of $\mathrm{H}_{2} \mathrm{O}-\mathrm{LiBr}$ system came from its negative pressure while the main disadvantage of the $\mathrm{NH}_{3}-\mathrm{H}_{2} \mathrm{O}$ system was its high water content in the vapour phase which requires an auxiliary rectifier to separate it from $\mathrm{NH}_{3}$. This also results in a high vapour pressure at elevated temperatures for the $\mathrm{NH}_{3}-\mathrm{H}_{2} \mathrm{O}$ system. Further more, the $\mathrm{NH}_{3}-\mathrm{H}_{2} \mathrm{O}$ cycle exhibits a relatively low COP. Efforts are being made to search for better refrigerant-absorbent pairs that can improve system performance.

In our recent research, a salt-mixture has been chosen as the sorbent that has been developed by DY Refrigeration and has been used in the ice-maker fishery industry [50]. The major active component of sorbent is sodium thiocyanate $\left(\mathrm{NH}_{3}-\mathrm{NaSCN}\right) . \mathrm{NH}_{3}$ is chosen as sorptive. $\mathrm{NaSCN}$ is soluble in liquid $\mathrm{NH}_{3}$. The sorption process involves vapour ammonia, sorbent-ammonia liquid solution and sodium thiocyanate $(\mathrm{NaSCN})$ crystals. When absorbing $\mathrm{NH}_{3}, \mathrm{NaSCN}$ will be partially or totally dissolved and forms a solution. It's found that the mixed solid (NaSCN) and liquid $\left(\mathrm{NH}_{3}-\mathrm{NaSCN}\right)$ together demonstrate a strong sorptive ability for $\mathrm{NH}_{3}$, with the adsorption on the flake-shaped solid surface and absorption into the solution. The effects of the two sorption mechanisms are functioning with different magnitudes at different stages of the process. This combined sorptive refrigeration system could be 
called as Double Mechanism Sorptive Refrigeration (DMSR) system. The specially-engineered DMSR process happens with a solid-liquid-vapour three-phase process, which has several advantages.

\subsection{Objectives}

This thesis work aims to develop a theoretical framework and a working prototype for a thermal-driven refrigeration system using a new sorbent-sorptive pair as working pair. The main objectives for this thesis work can be summarized as follows:

1. Conduct a survey of the existing thermal driven refrigeration system.

2. Establish laboratory facilities for new DMSR system testing procedures.

3. Develop a preliminary theoretical analysis approach to the DMSR system working solution.

4. Develop a mathematical model to simulate the DMSR system performance in different working conditions.

5. Perform tests regarding the DMSR system performance and temperature characteristics of every heat exchanger and component.

6. Compare the simulation and experiment results to verify the mathematical model and improve the DMSR system performance.

7. Summarize results and lay the foundation for future practices such as the new prototype building and mathematical model update. 


\subsection{Organization}

This thesis presents studies of modeling and experimental investigation of a new thermal-driven refrigeration system. It is organized as follows:

Chapter 1 Introduction: introduces thermal-driven refrigeration system concept and a brief development history. Provides the objectives, and presents the scope of the thesis.

Chapter 2 Thermal-driven refrigeration system summarization: presents the primary types of current thermal-driven refrigeration system, introduces the normal system structures and commonly used working solutions, provides the fundamental and the main advantages of DMSR system.

Chapter 3 Mathematical modeling and computational simulation process: establishes the mathematical model and simulation programs on the DMSR thermal-driven refrigeration system. System performance, thermal network, heat transfer capacities and other system working conditions are simulated, and the relationship among different components are discussed.

Chapter 4 Experimental investigation of DMSR thermal-driven refrigeration system characteristics: provides details of the experimental investigation including a description of the test specimens, test apparatus, and experimental procedures. The results are presented and discussed.

Chapter 5 Conclusions and recommendations: provides conclusions, points out some problems that occurred in the present work, recommends corresponding solutions, and discusses future work. 


\section{Chapter 2 \\ Thermal-driven refrigeration system fundamentals}

\subsection{Principle of operation}

Absorption refrigeration systems transform latent heat of the phase change liquid-vapor or solid-vapor between different temperature levels. Absorption systems use two working fluids, the refrigerant and the sorbent. Thus the temperature of phase transition can be manipulated not only by changing the pressure but also by changing the refrigerant concentration.

An absorption refrigeration cycle is a combination of "absorption process" and "desorption process" as shown in Fig. 2.1. In this cycle, there are four most important components: the evaporator $\mathrm{E}$ where cooling is provided, the generator $\mathrm{G}$, where the driving heat is conveyed to, the absorber $\mathrm{A}$ and condenser $\mathrm{C}$, from which the pumped heat is disposed of. In the generator vapor is desorbed from the solution due to the heat input. The vapor is condensed, throttled and evaporated as in compression systems. After evaporation the vapor is absorbed in the solution which is cooled in the absorber. The solution is pumped to the generator to be regenerated and throttled back to the absorber.

To improve efficiency without altering its basic operation, a solution heat exchanger SHX is normally placed between solution pumped to the generator and solution back to the absorber. For cooling applications, the efficiency (coefficient of 
performance, $C O P$ ) is defined as the ratio of cooling load, $\mathrm{Q}_{\mathrm{L}}$, divide to driving heat input, $Q_{\mathrm{l}}$, is obtained from:

$$
C O P=\frac{\text { cooling capacilty obtained at evaporator }}{\text { heat input for the generator }+ \text { work input for the pump }}
$$

The work input for the pump is negligible relative to the heat input at the generator; therefore, the pump work is often neglected for the purposes of analysis.

desorption process

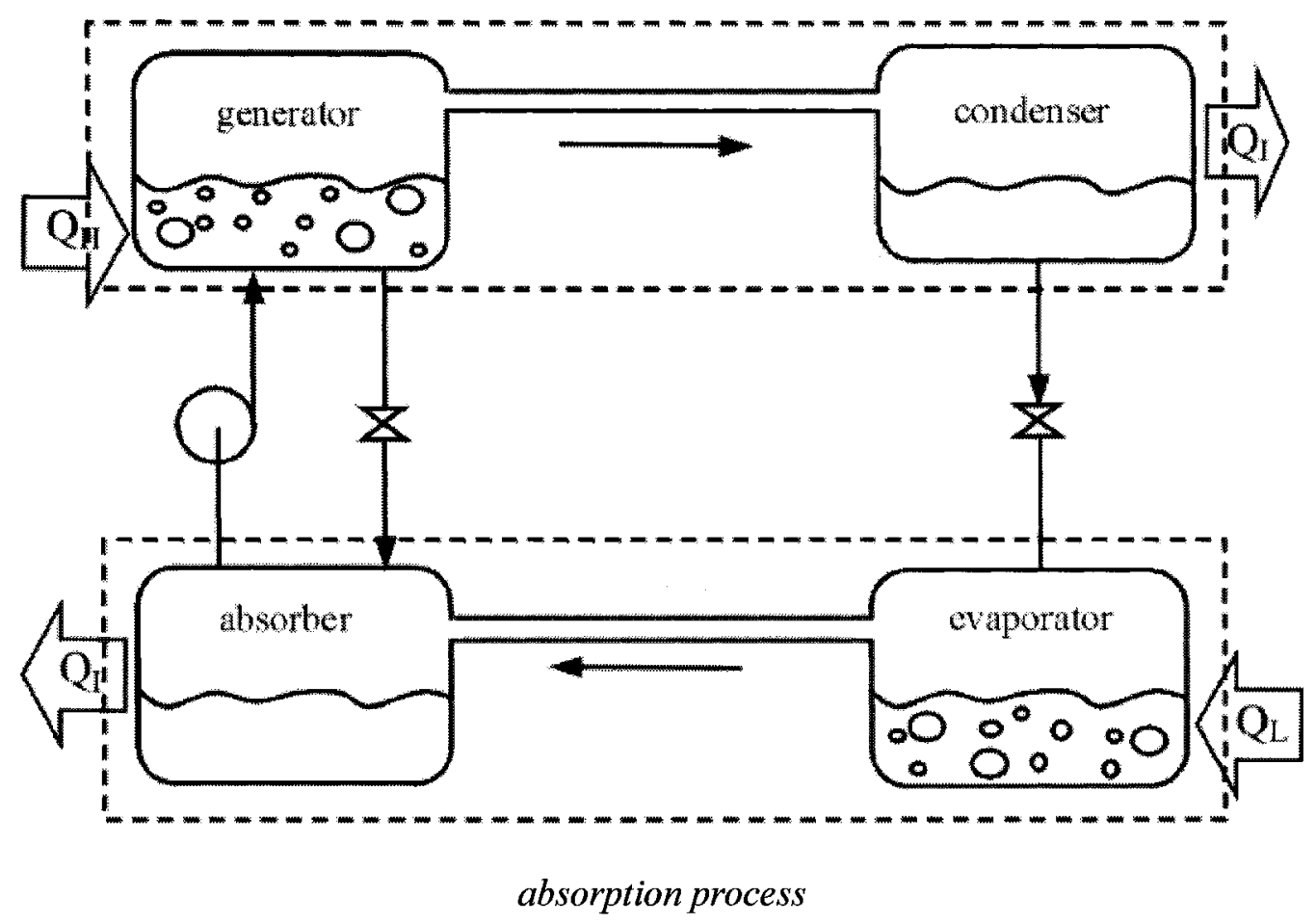

Figure 2.1 A continuous absorption refrigeration cycle

Any absorption refrigeration cycle exchanges heat with three external reservoirs: low, intermediate, and high temperature levels. When an absorption system is operated as a refrigerator or a heat pump, the driving heat is supplied from the high temperature reservoir. Refrigeration effect is produced at a low temperature level and rejects heat out at an intermediate temperature level. The difference between them is 
the duty. For a refrigerator or air conditioning system, the useful heat transfer is at a low temperature. For the heat pump, the useful heat transfer is at an intermediate temperature. Normally, the surrounding is used as a low temperature reservoir for a heat pump or as an intermediate temperature reservoir for the air conditioning system.

\subsection{Working fluid for absorption refrigeration systems}

Performance of an absorption refrigeration system is critically dependent on the chemical and thermodynamic properties of the working fluid [21]. A fundamental requirement of absorbent/refrigerant combination is that, in liquid phase, they must have a margin of miscibility within the operating temperature range of the cycle. The mixture should also be chemically stable, non-toxic, and non-explosive. In addition to these requirements, the following are desirable [22].

- The elevation of boiling point (the difference in boiling point between the pure refrigerant and the mixture at the same pressure) should be as large as possible.

- Refrigerant should have high heat of vaporization and high concentration within the absorbent in order to maintain low circulation rate between the generator and the absorber per unit of cooling capacity.

- Transport properties that influence heat and mass transfer, e.g., viscosity, thermal conductivity, and diffusion coefficient should be favorable. 
- Both refrigerant and absorbent should be non-corrosive, environmental friendly, and low-cost.

Many working fluids are suggested in literature. A survey of absorption fluids provided by Marcriss [23] suggests that, there are some 40 refrigerant compounds and 200 absorbent compounds available. However, the most common working fluids are $\mathrm{NH}_{3} / \mathrm{H}_{2} \mathrm{O}$ and $\mathrm{LiBr} / \mathrm{H}_{2} \mathrm{O}$.

The $\mathrm{NH}_{3} / \mathrm{H}_{2} \mathrm{O}$ system utilizes ammonia as the refrigerant, and water as the absorbent. Since the invention of an absorption refrigeration system, $\mathrm{NH}_{3} / \mathrm{H}_{2} \mathrm{O}$ has been widely used for both cooling and heating purposes. Both $\mathrm{NH}_{3}$ (refrigerant) and water (absorbent) are highly stable for a wide range of operating temperature and pressure. $\mathrm{NH}_{3}$ has a high latent heat of vaporization, which is necessary for efficient performance of the system. It can be used for low temperature applications, as the freezing point of $\mathrm{NH}_{3}$ is $-77^{\circ} \mathrm{C}$. However, the toxicity of ammonia is a factor that has limited its use only to well-ventilated areas. Since both $\mathrm{NH}_{3}$ and water are volatility, the cycle requires a rectifier to strip away water that normally evaporates with $\mathrm{NH}_{3}$. Without a rectifier, the water would accumulate in the evaporator and offset the system performance. There are other disadvantages such as its high pressure, corrosive reaction to copper and copper alloy, and so on. However, $\mathrm{NH}_{3} / \mathrm{H}_{2} \mathrm{O}$ is environmental friendly and cost effective. The ability to provide direct gas-fired and air-cooled air-conditioning is the primary selling point of this technology. Machines are available in capacity ranging from 3 to 25 Ton $(10$ to $90 \mathrm{~kW})$ with coefficient of performance typically around 0.5 . Thermodynamic properties of $\mathrm{NH}_{3} / \mathrm{H}_{2} \mathrm{O}$ can be 
obtained from [24-26].

The use of $\mathrm{LiBr} / \mathrm{H}_{2} \mathrm{O}$ for absorption refrigeration systems began around 1930 [27]. Two outstanding features of $\mathrm{LiBr} / \mathrm{H}_{2} \mathrm{O}$ are non-volatility absorbent of $\mathrm{LiBr}$ (the need of a rectifier is eliminated) and extremely high heat of vaporization of water (refrigerant). However, using water as a refrigerant limits the low temperature application to that above $0^{\circ} \mathrm{C}$. As water is the refrigerant, the system must be operated under vacuum conditions. At high concentrations, the solution is prone to crystallization. It is also corrosive to some metal and expensive. Absorption machines based on $\mathrm{H}_{2} \mathrm{O}-\mathrm{LiBr}$ are typically configured as water chillers for air-conditioning systems in large buildings. Machines are available in sizes ranging from 10 to 1500 Ton $(1$ Ton $=12,000 \mathrm{Btu} / \mathrm{hr}=3.517 \mathrm{~kW})$. The coefficient of performance $(\mathrm{COP})$ of these machines typically varies over the range $0.7<\mathrm{COP}<1.2$ depending on the particular cycle configuration. Thermodynamic properties of $\mathrm{LiBr} / \mathrm{H}_{2} \mathrm{O}$ can be obtained from [28-32]. Some additive may be added to $\mathrm{LiBr} / \mathrm{H}_{2} \mathrm{O}$ as a corrosion inhibitor [33, 34] or to improve heat-mass transfer performance [35-39].

Although $\mathrm{LiBr} / \mathrm{H}_{2} \mathrm{O}$ and $\mathrm{NH}_{3} / \mathrm{H}_{2} \mathrm{O}$ have been widely used for many years and their properties are well known, much extensive research has been carried out to investigate new working fluids. Fluorocarbon refrigerant-based working fluids have been studied. R22 and R21 have been widely suggested because of their favorable solubility with number of organic solvents. The two solvents, which have stood out are Dimethyl Ether of Tetraethylene Glycol (DMETEG) and Dimethyl Formamide (DMF). Research on these kinds of working fluids may be obtained from the literature 
$[40-45]$.

A binary mixture using inorganic salt absorbent such as $\mathrm{LiBr} / \mathrm{H}_{2} \mathrm{O}$ or $\mathrm{NaOH} / \mathrm{H}_{2} \mathrm{O}$ may be the most successful working fluids for an absorption refrigeration system [46]. However, at high concentration conditions or high temperature conditions, the solution is prone to crystallization. It was found that the addition of a second salt as in a ternary mixture such as $\mathrm{LiBr}+\mathrm{ZnBr}_{2} / \mathrm{H}_{2} \mathrm{O}$ can improve the solubility of the solution. Various ternary mixtures have been tested for using with an absorption system [47-49].

In our research, an uncommon used salt-mixture has been chosen as the sorbent that has been developed by DY Refrigeration and has been used in the ice-maker fishery industry [50]. The major active component of this sorbent is sodium thiocyanate $(\mathrm{NaSCN})$, ammonia is chosen as sorptive. Sodium thiocyanate is soluble in liquid ammonia. The sorption process involves vapour ammonia, sorbent-ammonia liquid solution and dispersed flake-shaped floating sodium thiocyanate. When absorbing ammonia, sodium thiocyanate will be partially or totally dissolved and forms a solution. From our previous study, it's found that the mixed solid and liquid together demonstrate a strong sorptive ability for vapor ammonia.

From literature [18], it is also predicted that the performance of the $\mathrm{NH}_{3} / \mathrm{NaSCN}$ cycle is better than those of other sorptive cycles. The advantages provided by this system over other absorption units include lower generator and evaporator temperatures, a higher coefficient of performance (COP) (about 10 percent absolute higher than the ones for the $\mathrm{NH}_{3} / \mathrm{H}_{2} \mathrm{O}$ system working at the same conditions). 
Compared to $\mathrm{NH}_{3} / \mathrm{H}_{2} \mathrm{O}$ system, the $\mathrm{NH}_{3} / \mathrm{NaSCN}$ adsorption system doesn't need a rectifier because there is only $\mathrm{NH}_{3}$ in the vapor phase and the salt (NaSCN) doesn't evaporate.

\subsection{Various designs of absorption refrigeration cycles}

Besides working solution selection, the design of system structure is critical to system performance, too. Based on the fundamental absorption refrigeration design, various modifications can be applied to improve the system performance. The most widely used system designs will be described in this section; essential parts will be adopted to optimize our system.

\subsubsection{Single-effect absorption system}

A single-effect absorption refrigeration system is the simplest and most commonly used design. There are two design configurations depending on the working fluids used. Figure 2.2 shows a single-effect system using non-volatility absorbent such as $\mathrm{LiBr} / \mathrm{H}_{2} \mathrm{O}$.

High temperature heat supplied to the generator is used to evaporate refrigerant out from the solution (this portion of heat is then rejected out to the surroundings at the condenser) and is used to heat the solution from the absorber temperature (this portion of heat is rejected out to the surroundings at the absorber). Thus, irreversibility is caused as high temperature heat at the generator is wasted at the 
absorber and the condenser. In order to reduce this irreversibility, a solution heat exchanger is introduced as show in Figure 2.2. The heat exchanger allows the solution from the absorber to be preheated before entering the generator by using the heat from the hot solution leaving the generator. Therefore, the COP is improved as the heat input at the generator is reduced. Moreover, the size of the absorber can be reduced as it has a lower temperature (absorption favorable) and less heat is rejected. Experimental studies shows that COP can be increased up to $60 \%$ when a solution heat exchanger is used.

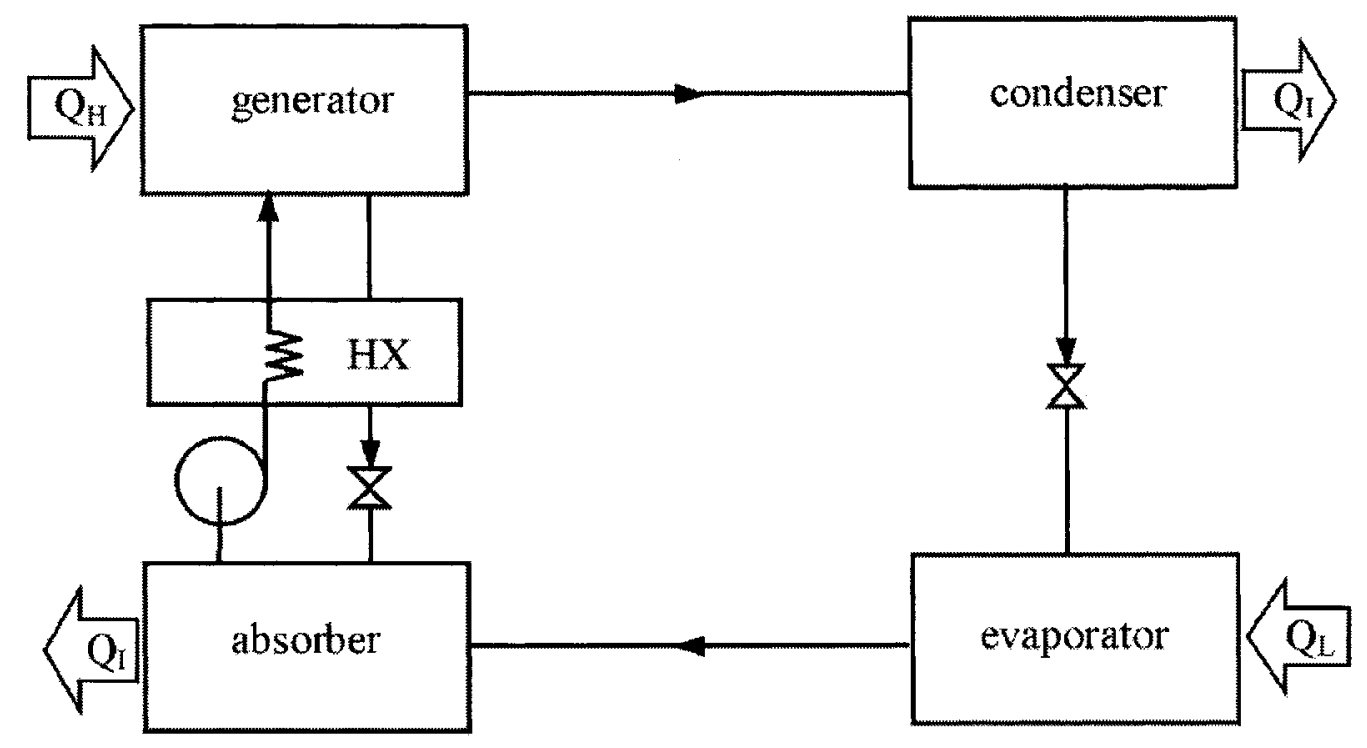

Figure 2.2 A single-effect $\mathrm{LiBr} / \mathrm{H}_{2} \mathrm{O}$ absorption refrigeration system with a solution heat exchanger $(\mathrm{HX})$ that helps decrease heat input at the generator

When volatility absorbent such as water is used, the system requires an extra component called "a rectifier", which will purify the refrigerant before entering the condenser. As the absorbent used (water) is highly volatile, it will evaporate together with ammonia (refrigerant). Without the rectifier, this water will condense and 
accumulate inside the evaporator, causing the performance to drop.

Even if the most common working fluids used are $\mathrm{LiBr} / \mathrm{H}_{2} \mathrm{O}$ and $\mathrm{NH}_{3} / \mathrm{H}_{2} \mathrm{O}$, researchers have studied the performance of single-effect absorption system using various kinds of working fluids such as $\mathrm{LiNO}_{3} / \mathrm{NH}_{3}, \quad \mathrm{NH}_{3} / \mathrm{NaSCN}$, $\mathrm{LiBr}+\mathrm{ZnBr}_{2} / \mathrm{CH}_{3} \mathrm{OH}, \mathrm{LiNO}_{3}+\mathrm{KNO}_{3}+\mathrm{NaNO}_{3} / \mathrm{H}_{2} \mathrm{O}, \mathrm{LiCl} / \mathrm{H}_{2} \mathrm{O}$, and Glycerol $/ \mathrm{H}_{2} \mathrm{O}$. The choice of working fluids is based on the system structure and working conditions.

\subsubsection{Absorption heat transformer}

Another type of absorption cycle is known as "an absorption heat transformer" or "a reverse absorption heat pump". Unlike commonly used absorption systems, this system uses heat from an intermediate temperature reservoir as the driving heat (normally from industrial waste heat). The system rejects heat out at a low temperature level (normally to the surroundings). The useful output is obtained at the highest temperature level. The use of an absorption heat transformer allows any waste heat to be upgraded to a higher temperature level without any other heat input except some work required circulating the working fluid.

Figure 2.3 shows a schematic diagram of an absorption heat transformer. This cycle has similar components as a single-effect absorption cycle. The difference is that an expansion device installed between the condenser and the evaporator is substituted by a pump. Waste heat at a relatively low temperature is supplied to the generator for refrigerant separation in the usual manner. Liquid refrigerant from the condenser is then pumped to the evaporator with elevated pressure. In the evaporator, 
it is vaporized by using the same low temperature waste heat used to drive the generator, on the other words, absorption heat transformers are usually operated so that the generator and evaporator temperatures are equal. The vapor refrigerant is then absorbed into solution in the absorber which rejects the useful heat out at a high temperature level.

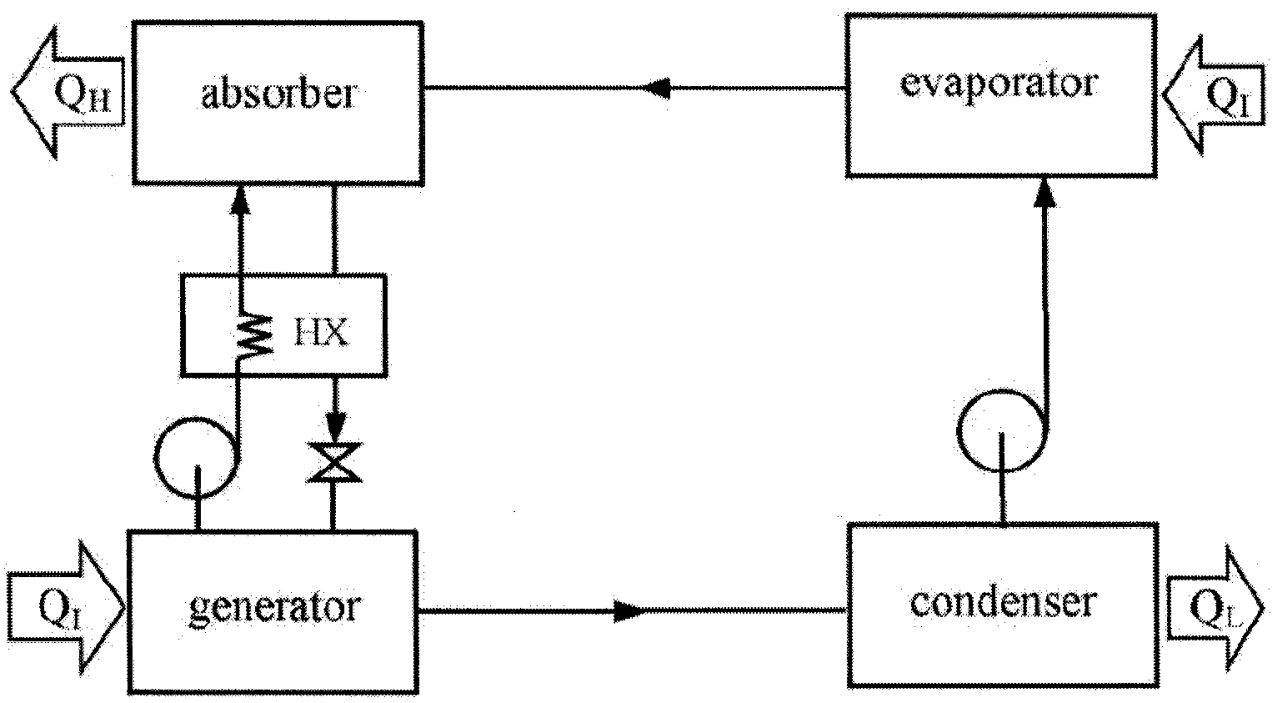

Figure 2.3 Absorption heat transformer absorbs waste heat at the generator. Liquid refrigerant is pumped to the evaporator to absorb waste heat. High temperature useful heat from the absorber is heat of absorption

Low-grade heat can be upgraded by using a heat transformer, e.g. solar energy, or industrial waste heat. Performance of an absorption heat transformer with various working fluids has been studied such as $\mathrm{LiBr} / \mathrm{H}_{2} \mathrm{O}, \mathrm{LiBr}+\mathrm{ZnBr}_{2} / \mathrm{CH}_{3} \mathrm{OH}$ [51], DMETEG/R21 and DMF/R21 [52-54].

\subsubsection{Multi-effect absorption refrigeration cycle}

The main objective of a higher effect cycle is to increase system performance when high temperature heat source is available. By the term "multi-effect", the cycle 
has to be conFigured in a way that heat rejected from a high-temperature stage is used as heat input in a low-temperature stage for generation of additional cooling effect in the low-temperature stage.

Double-effect absorption refrigeration cycle was introduced during 1956 and 1958 [55]. Figure 2.4 shows a system using $\mathrm{LiBr} / \mathrm{H}_{2} \mathrm{O}$. High temperature heat from an external source is supplied to the first-effect generator. The vapor refrigerant generated is condensed at high pressure in the second-effect generator. The heat rejected is used to produce additional refrigerant vapor from the solution coming from the first-effect generator. This system configuration is considered as a series-flow-double-effect absorption system.

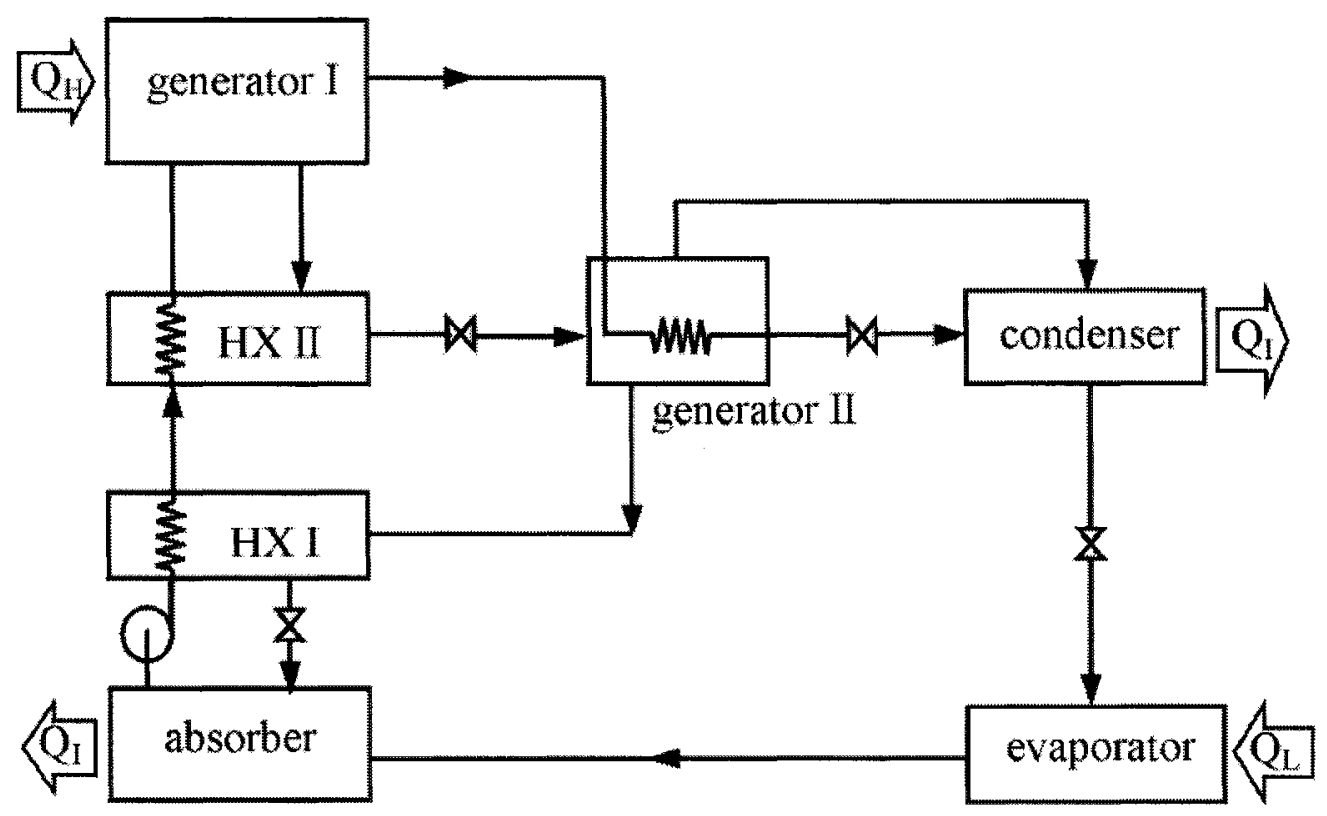

Figure 2.4 A double-effect $\mathrm{LiBr} / \mathrm{H}_{2} \mathrm{O}$ absorption cycle. Heat released from the condensation of refrigerant vapor is used as heat input in generator II. This cycle is operated with 3 pressure levels i.e. high, moderate and low pressure

A double-effect absorption system is considered as a combination of two single 
effect absorption systems whose $\mathrm{COP}$ value is $\mathrm{COP}_{\text {single }}$. For one unit of heat input from the external source, cooling effect produced from the refrigerant generated from the first-effect generator is $1 \times \mathrm{COP}_{\text {single }}$. For any single-effect absorption system, it may be assumed that the heat rejected from the condenser is approximately equal to the cooling capacity obtained. Thus the heat supply to the second generator is $1 \times \mathrm{COP}_{\text {single. }}$. The cooling effect produced from the second-effect generator is $\left(1 \times \mathrm{COP}_{\text {single }}\right) \times \mathrm{COP}_{\text {single }}$. Therefore, the $\mathrm{COP}$ of this double-effect absorption system is $\mathrm{COP}_{\text {double }}=\mathrm{COP}_{\text {single }}+\left(\mathrm{COP}_{\text {single }}\right)^{2}$. According to this analysis, a double effect absorption system has a COP of 0.96 when the corresponding single-effect system has a COP of 0.6 .

Theoretical studies of a double-effect absorption system have been provided for various working fluids such as $\mathrm{NH}_{3} / \mathrm{H}_{2} \mathrm{O}$. If $\mathrm{LiBr} / \mathrm{H}_{2} \mathrm{O}$ is replaced with $\mathrm{NH}_{3} / \mathrm{H}_{2} \mathrm{O}$, maximum pressure in the first-effect generator will be extremely high. Figure 2.5 shows a double-effect absorption system using $\mathrm{NH}_{3} / \mathrm{H}_{2} \mathrm{O}$. In contrast to the system for $\mathrm{LiBr} / \mathrm{H}_{2} \mathrm{O}$, this system can be considered as a combination of two separated single-effect cycles. The evaporators and the condensers of both cycles are integrated together as a single unit as shown. Thus, there are only two pressure levels in this system and the maximum pressure can be limited to an acceptable level. Heat from external source supplies to generator II only. As water is an absorbent, there is no crystallization problem in the absorber. Hence, absorber II can be operated at high temperature and rejects heat to the generator $\mathrm{I}$. This system configuration is considered as a parallel-flow-double-effect absorption system. 


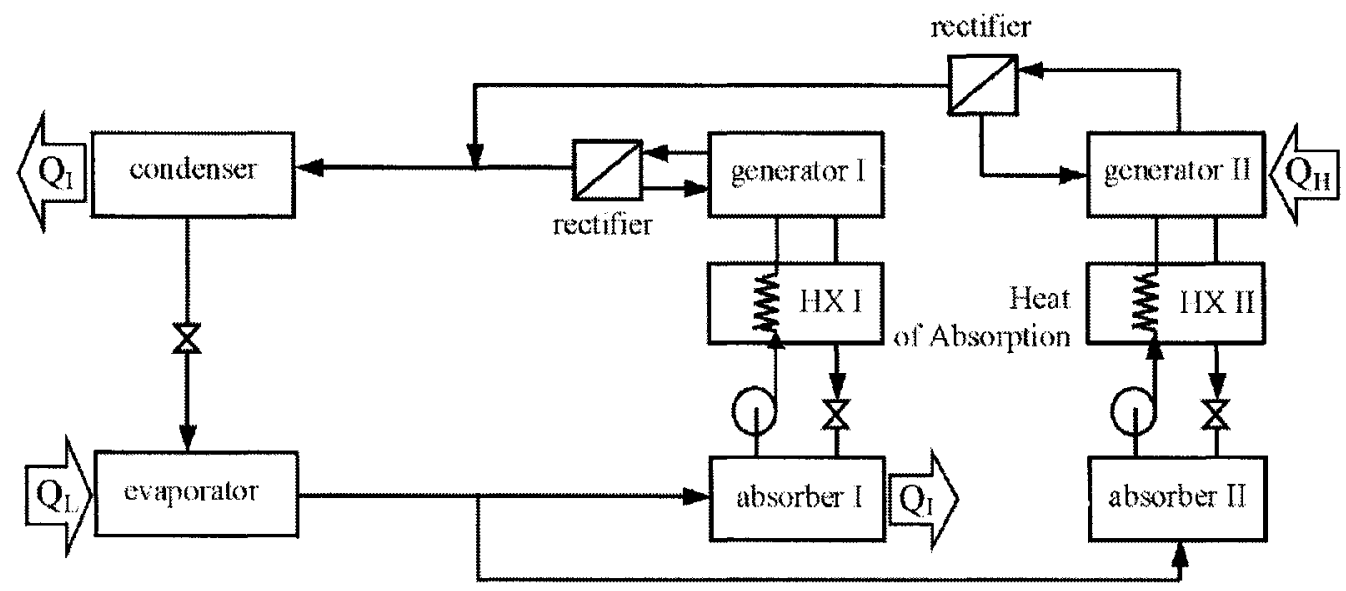

Figure 2.5 A double-effect absorption cycle operates with two pressure levels. Heat of absorption from Absorber II is supplied to the Desorber I for the refrigerant separation process

Based on the fundamental of double-effect absorption cycle, several types of multi-effect absorption cycle have been analyzed such as the triple effect absorption cycle shown in Figure 2.6 and even the quadruple-effect absorption cycle. Although the increase of effects number will increase the system COP, however, an improvement of COP is not directly linked to the increment of number of effect. It must be noted that, when the number of effects increase, COP of each effect will not be as high as that for a single-effect system. Moreover, the higher number of effect leads to more system complexity. Therefore, the double-effect cycle is the one that is most available commercially. 


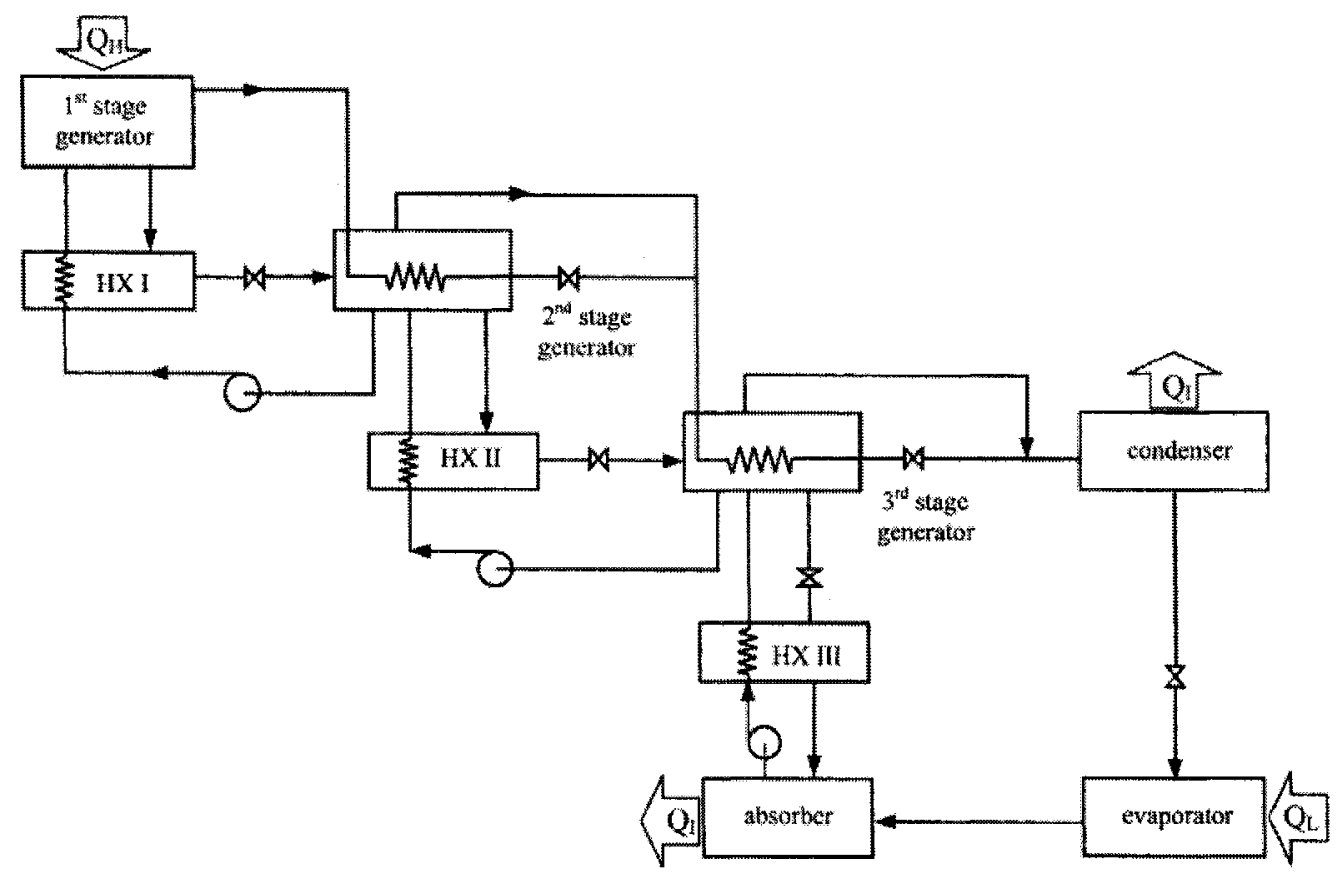

Figure 2.6 A triple-effect absorption cycle operates at 4 pressure levels. Heat of condensation from the higher-pressure stage is used for refrigerant separation in the lower-pressure stage

\subsubsection{Absorption refrigeration cycle with GAX}

GAX (Generator Absorber heat eXchange) stands for generator/absorber heat exchanger or sometimes is called DAHX which stands for desorber/absorber heat exchanger. Referring to the parallel-flow-double-effect absorption system mentioned earlier, the system consists of two single-effect cycles working in a parallel manner. The concept of GAX is to simplify this two-stage-double-effect absorption cycle but still produce the same performance. The idea of GAX was introduced in 1911 by Altenkirch and Tenckhoff [5]. The simplified configuration is shown schematically in Figure 2.7.

An absorber and a generator may be considered as a counter-flow-heat exchanger as shown in Figure 2.7. At the absorber, weak-refrigerant solution from the 
generator and vapor refrigerant from the evaporator enter at the top section. Heat produced during the absorption process must be rejected out in order to maintain ability to absorb the refrigerant vapor. At the top section, heat is rejected out at a high temperature. In the lower section, the solution further absorbs the vapor refrigerant while cooled down by rejecting heat to the surrounding. At the generator, rich-refrigerant solution from the absorber enters at the top section. In this section, the refrigerant is dried out from the solution as it is heated by using the heat rejected from the top section of the absorber. At the lower section of the generator, the solution is further dried as it is heated by the external source. Referring to Figure 2.7, there is an additional secondary-fluid, which used for transferring heat between the absorber and the generator. By using GAX, a single-effect absorption system can provide as high COP as that for the two-stage-double-effect absorption system.

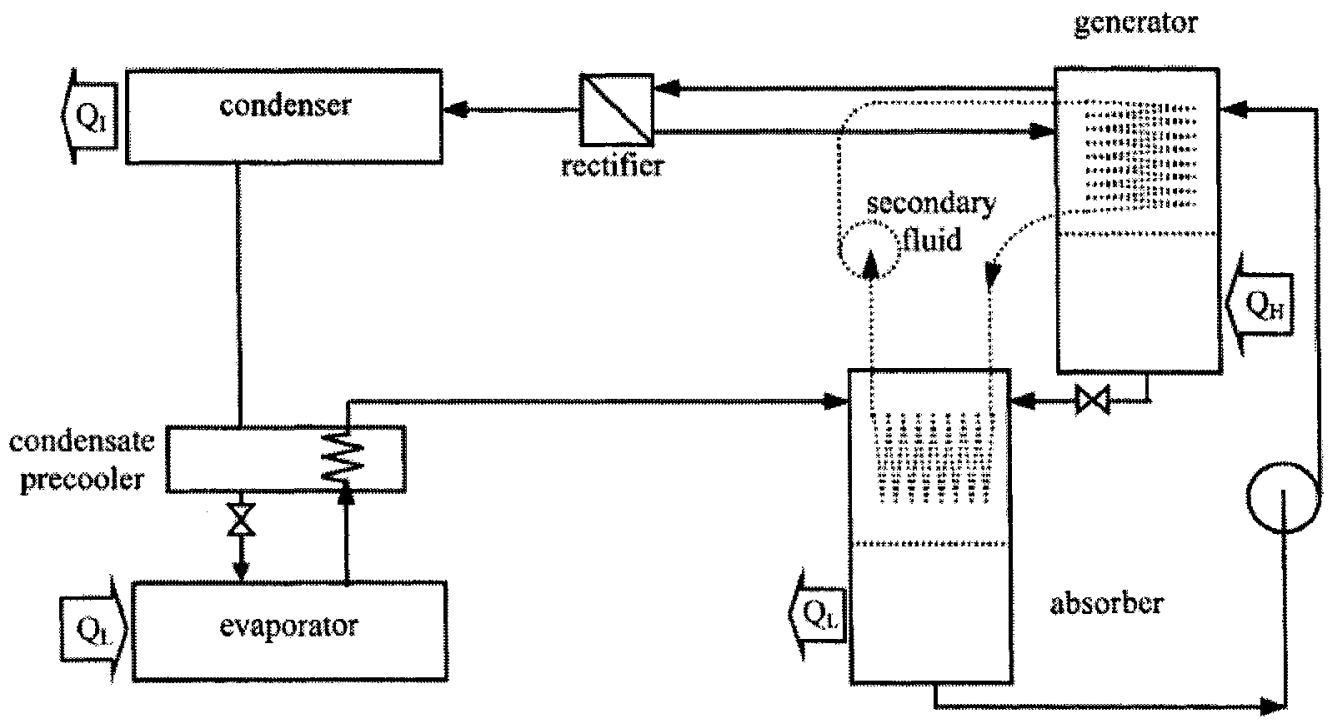

Figure 2.7 The dotted loop shows secondary fluid used for transferring heat from high temperature section in the absorber to low temperature section in the generator 


\subsubsection{Absorption refrigeration cycle with an absorber heat recovery}

It is already mentioned earlier that the use of a solution heat exchanger improves the system COP. Rich-refrigerant solution from the absorber can be preheated before entering the generator by transferring heat from hot solution coming from the generator. By introducing an absorber-heat-recovery, temperature of the rich-refrigerant solution can be further increased.

Similar to the GAX system, the absorber is divided into two sections. Heat is rejected out at different temperatures. The lower temperature section rejects heat out to the surroundings as usual. However, the higher temperature section is used to preheat rich-refrigerant solution as shown in Figure 2.8. Therefore, the heat input to the generator is reduced causing the COP to increase.

This system was studied theoretically by using various working fluids, such as $\mathrm{NH}_{3} / \mathrm{H}_{2} \mathrm{O}$ and $\mathrm{LiNO}_{3} / \mathrm{NH}_{3}[56,57]$. The cycle with an absorber-heat-recovery was found to have $10 \%$ improvement in COP. However, no machine based on this absorber design has been built yet. 


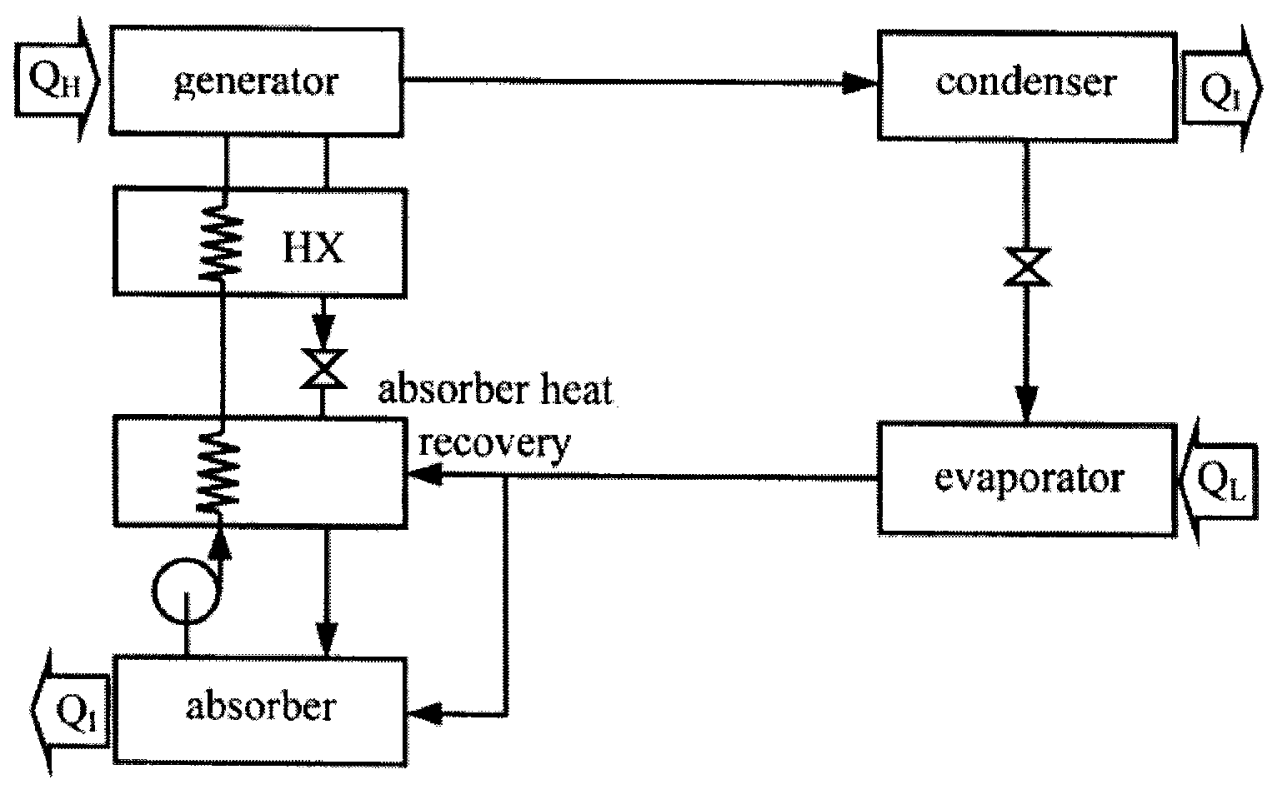

Figure 2.8 The cycle with absorber heat recovery uses heat of absorption to preheat the outgoing stream from the absorber to the generator

\subsubsection{Half-effect absorption refrigeration cycle}

It must be noted that, any absorption refrigeration system can be operated only when the solution in the absorber is richer in refrigerant than that in the generator. When the temperature increases or the pressure reduces, the fraction of refrigerant contained in the solution is reduced, and vice versa. When the generator temperature is dropped, the solution circulation rate will be increased causing the COP to drop. If it is too low, the system can be no longer operated.

The half-effect absorption system was introduced for an application with a relatively low-temperature heat source. Figure 2.9 shows a schematic diagram of a half-effect absorption refrigeration cycle. The system configuration is exactly the 
same as the double-effect absorption system using $\mathrm{NH}_{3} / \mathrm{H}_{2} \mathrm{O}$ (as shown in Figure 2.5) except the heat flow directions are different. Referring to Figure 2.9, high temperature heat from an external source transfers to both generators. Both absorbers reject heat out to the surroundings. Absorber II and generator I are operated at an intermediate pressure level. Therefore, the circulation rate between generator I and absorber I and between generator II and absorber II can be maintained at acceptable levels. It must be noted that COP of the half-effect absorption system is relatively low as it rejects about $50 \%$ more heat than a single-effect absorption cycle [58]. However, it can be operated with the relatively low temperature heat source.

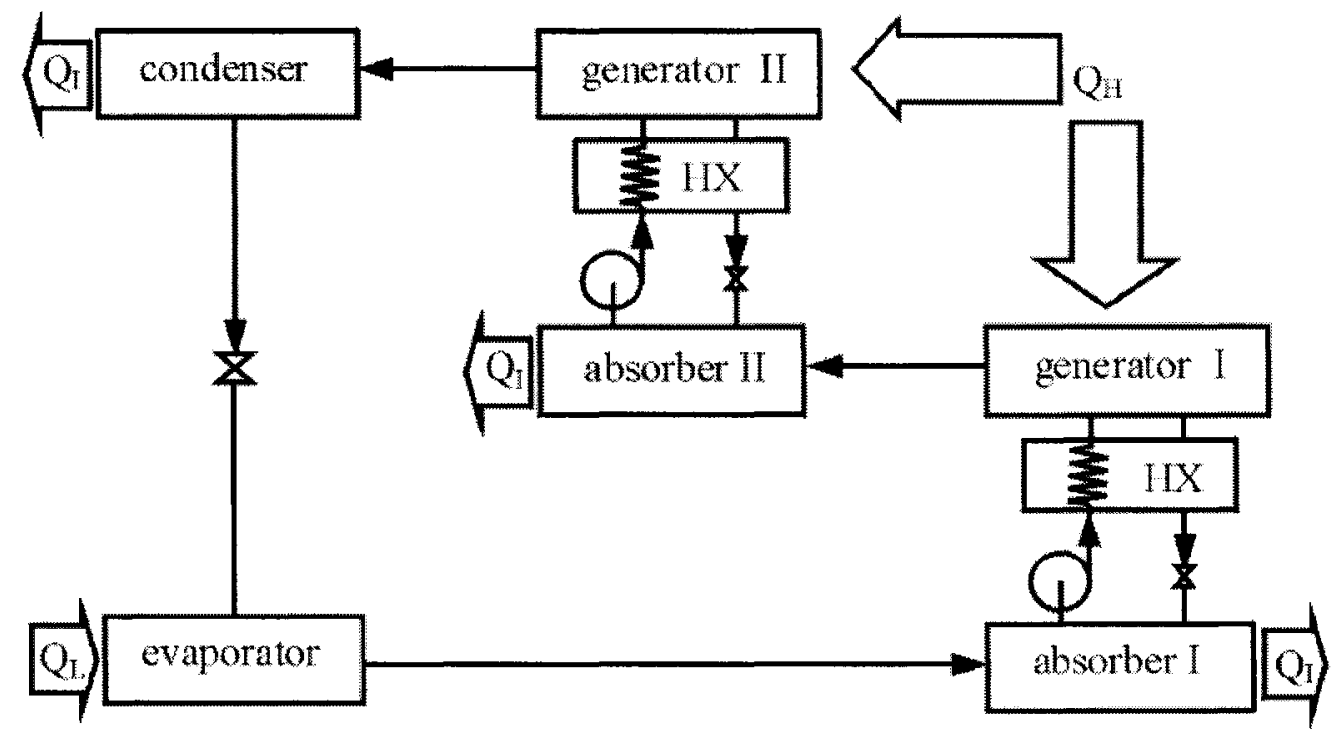

Figure 2.9 A half-effect absorption cycle is a combination of two single-effect cycles but working at different pressure levels. Letting heat source temperature be lower than the minimum temperature which is necessary for a single-effect cycle working at the same pressure level

\subsubsection{Combined vapor absorption-compression cycle}

This system is usually known as an absorption-compression system. A schematic 
diagram of a typical absorption-compression cycle is shown in Figure 2.10(a). It can be seen that, a condenser and an evaporator of a conventional vapor-compression system are replaced with a resorber (vapor absorber) and a desorber (vapor generator). For given surrounding temperature and refrigerating temperature, the pressure differential across the compressor is much lower than a conventional vapor-compression system. Thus, the COP is expected to be better than a conventional vapor-compression system. Altenkirch did the first investigation in 1950 and proposed a potential design for energy-saving [58]. The cycle can be conFigured as a heat pump cycle. Machielsen [59] developed a heat pump cycle as shown in Figure 2.10(b).

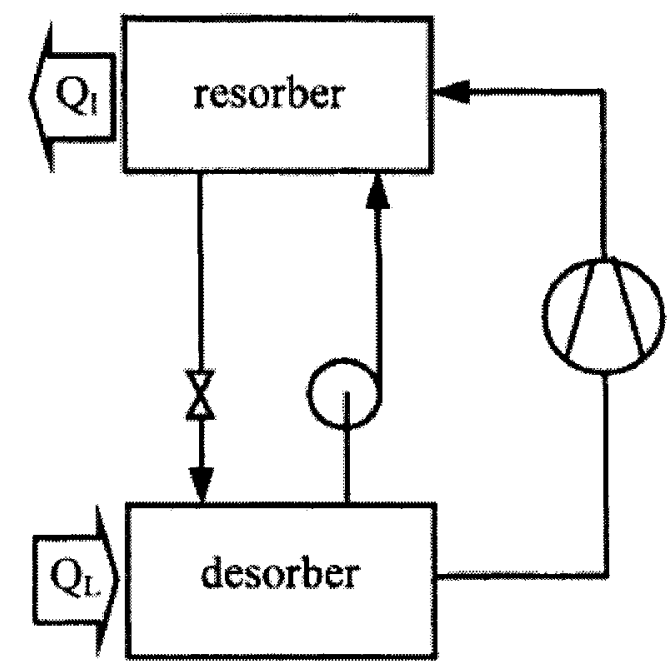

(a)

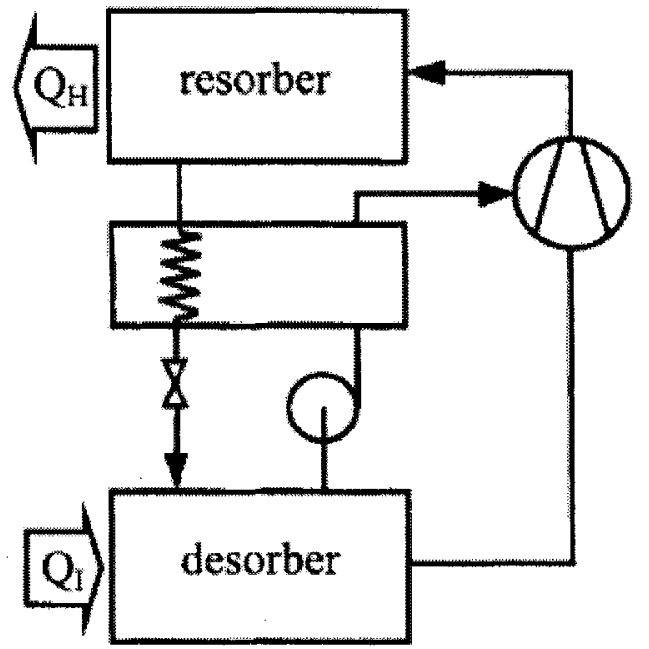

(b)

Figure 2.10 Combined vapor absorption/compression heat pump

An interesting configuration is a double-effect vapor absorption-compression cycle as shown in Figure 2.11. The rejected first-stage absorber heat is supplied to the generator of the second-stage. The transfer of heat is done internally which overcomes 
the large temperature difference at the moderate pressure ratio. This concept has been shown successfully in several studies, [59-61].

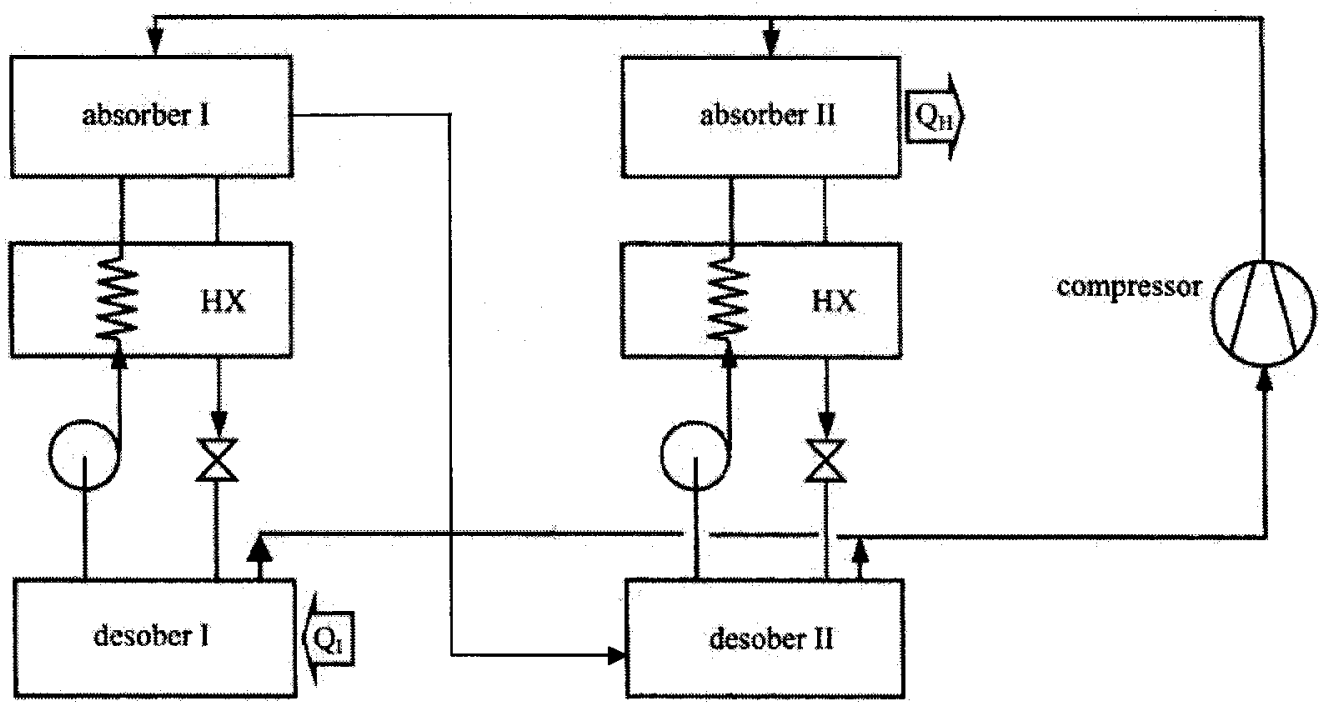

Figure 2.11 A double effect absorption-compression cycle is conFigured as a heat pump. Heat of absorption in the first stage will be supplied to the second stage for refrigerant separation

Another configuration of the vapor absorption/compression cycle, proposed by Cacciola et al. [62] is shown schematically in Figure 2.12 and employs two combinations of working fluids, $\mathrm{NH}_{3} / \mathrm{H}_{2} \mathrm{O}$ and $\mathrm{KHO} / \mathrm{H}_{2} \mathrm{O}$. This is a compromise of the $\mathrm{NH}_{3} / \mathrm{H}_{2} \mathrm{O}$ cycle and $\mathrm{KHO} / \mathrm{H}_{2} \mathrm{O}$ cycle. The highest system pressure is reduced and the rectifier of $\mathrm{NH}_{3} / \mathrm{H}_{2} \mathrm{O}$ system is abstained. This cycle can be operated with an ambient temperature lower than $0^{\circ} \mathrm{C}$ without freezing or crystallization problems. 


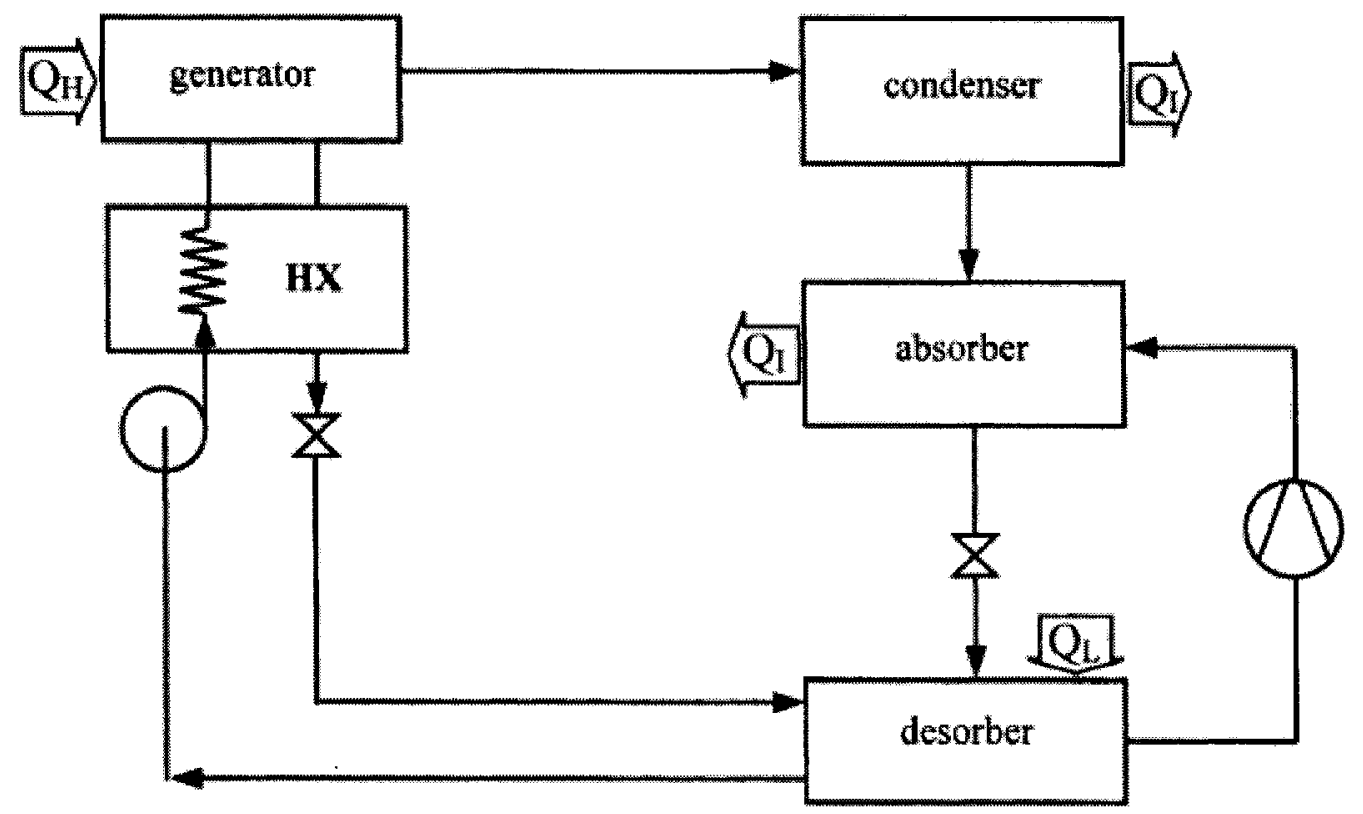

Figure 2.12 A combined cycle proposed by Caccoila et al. [86], employing combination of two working fluids i.e. $\mathrm{NH}_{3} / \mathrm{H}_{2} \mathrm{O}$ and $\mathrm{H}_{2} \mathrm{O} / \mathrm{KHO}$. The rectifier is absent and also the highest pressure is decreased

The first experimental result of an absoption/compression cycle with direct desorber/absorber heat exchanger was presented by Groll and Radermacher. This is a modified plant from a two stage-solution circuit proposed by Rane and Radermacher [60] and Rane et al. [61]. This technology is the basis for the study of GAX cycle in these days.

Various designs of combined vapor absorption/compression cycle have been introduced. They can achieve high COP. However, they are complex and the driving energy is in the form of mechanical work. Thus, they can not be considered as a heat-operated system. 


\subsubsection{Sorption-resorption cycle}

Altenkirch introduced the idea of a sorption-resorption cycle in 1913. The cycle employs two solution circuits instead of only one. The condenser and evaporator section of a conventional single-effect absorption system is replaced with a resorber and a desorber respectively as shown in Figure 2.13 [63]. This provides more flexibility in the cycle design and operations. The solution loops concentrations can be varied allowing adjustment of the component temperatures and pressures to the application requirement.

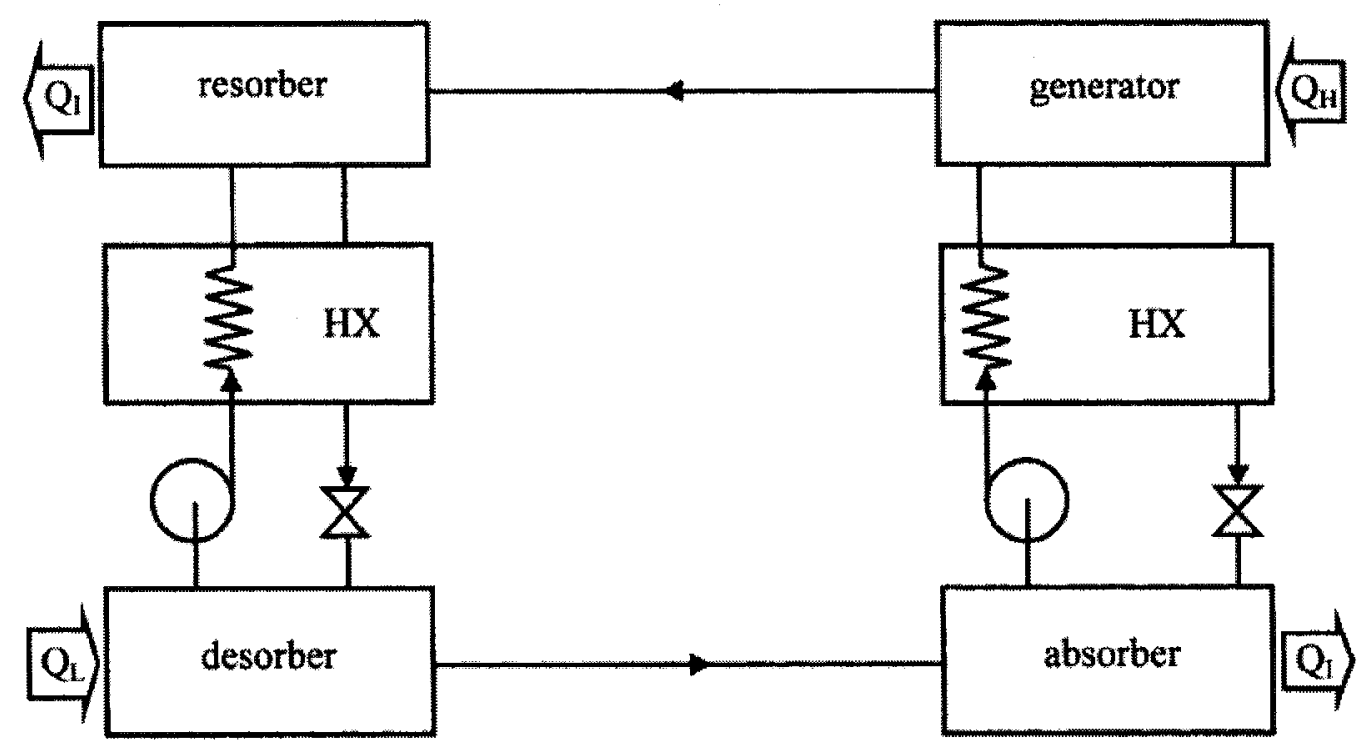

Figure 2.13 A resorption cycle proposed by Altenkirch uses two solution circuits

\subsubsection{Dual-cycle absorption refrigeration}

The concept of a dual-cycle absorption system is similar to a parallel-double-effect absorption system. However, this system consists of two 
completely separated cycles using different kinds of working fluid. Hanna et al. invented a dual-cycle absorption refrigeration and heat pump as shown in Figure 2.14. This system consists of two single-effect absorption cycles using $\mathrm{NH}_{3} / \mathrm{H}_{2} \mathrm{O}$ and $\mathrm{LiBr} / \mathrm{H}_{2} \mathrm{O}$. The $\mathrm{NH}_{3}$ system is driven by heat obtained from an external heat source. The heat reject from its absorber and condenser is used as a driving heat for the $\mathrm{LiBr} / \mathrm{H}_{2} \mathrm{O}$ system. The $\mathrm{LiBr} / \mathrm{H}_{2} \mathrm{O}$ system rejects heat to the surrounding at the condenser and the absorber as usual. The cooling effect can be obtained from both evaporators.

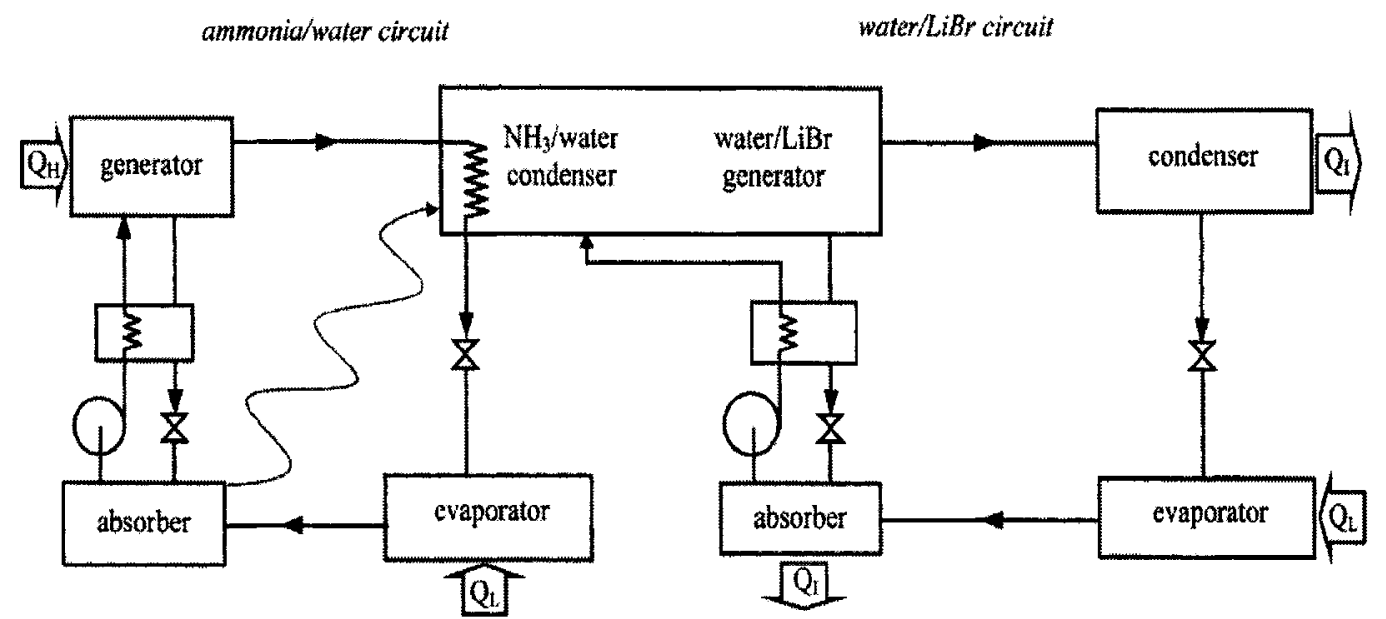

Figure 2.14 Solar driven dual cycle absorption employs two different working fluids i.e. $\mathrm{NH}_{3} / \mathrm{H}_{2} \mathrm{O}$ and $\mathrm{H}_{2} \mathrm{O} / \mathrm{LiBr}$. Heat of absorption and condensation from $\mathrm{NH}_{3} /$ water cycle are supplied to the generator of $\mathrm{H}_{2} \mathrm{O} / \mathrm{LiBr}$ cycle

\subsubsection{Combined ejector-absorption refrigeration cycle}

An ejector can be used to improve performance of an absorption refrigeration system. One notable approach devised by Kuhlenschmidt [64] is shown in Figure 2.15. The aim is to develop an absorption system using working fluid based on salt 
absorbent, capable of operating at low evaporator temperatures and employing an air-cooled absorber. This system employs two-stage generators similar to that used in a double effect absorption system. However, in contrast to a conventional double-effect absorption system, the low-pressure vapor refrigerant from the second-effect generator is used as a motive fluid for the ejector that entrains vapor refrigerant from the evaporator. The ejector exhaust is discharged to the absorber, causing the absorber pressure to be at a level higher than that in the evaporator. Therefore, the concentration of solution within the absorber can be kept from crystallization when the system is needed to operate with low evaporator temperature or with high absorber temperature (such as an air-cooled unit). It can be noted that there is no condenser in this system, as the high-pressure vapor refrigerant is condensed in the second effect generator and the low-pressure vapor refrigerant is used as the motive fluid for the ejector. Neither theoretical nor experimental results of this system are available yet. However, one can expect that the COP of this system will not be higher than that of a single-effect absorption system. As some of the vapor refrigerant generated is discharged directly to the absorber (as the motive fluid) without producing any cooling effect. Moreover, the absorber used needs to have a far greater absorption capacity than any other absorption system with the same cooling capacity. 


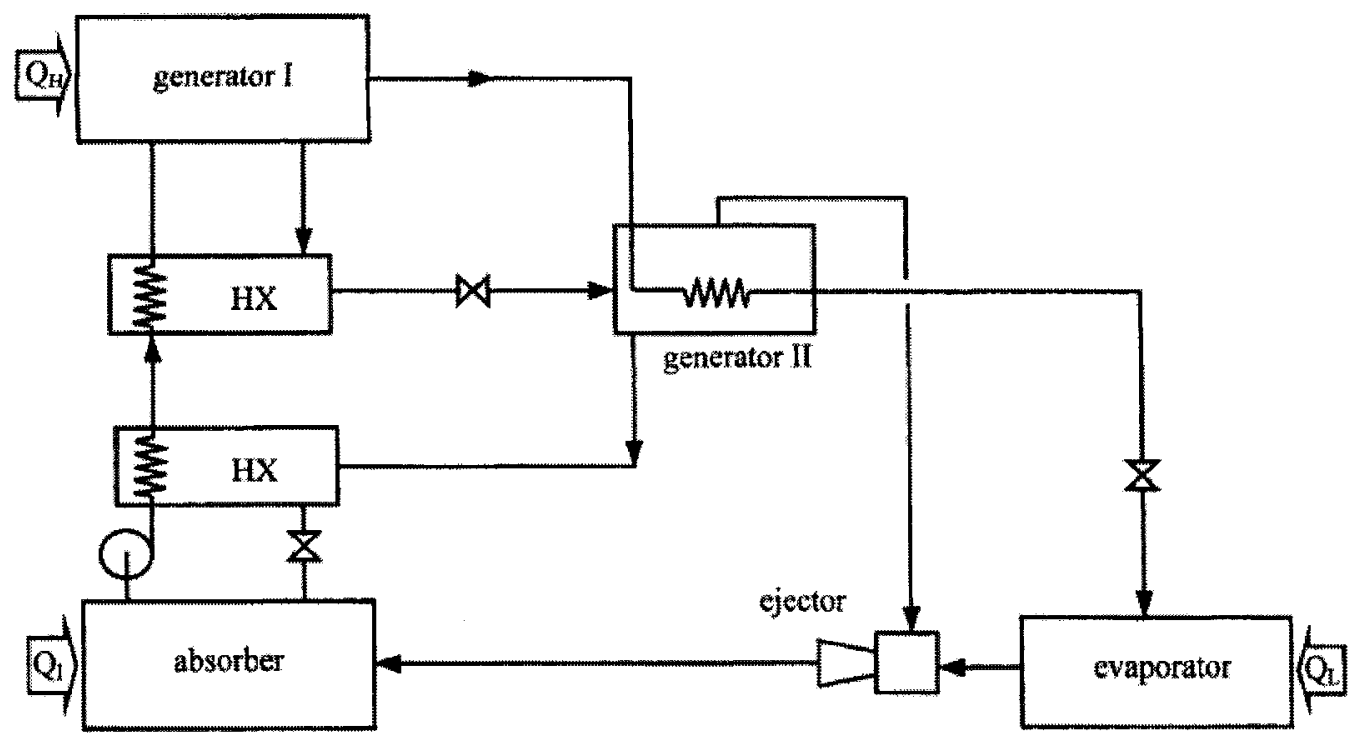

Figure 2.15 A modified double-effect combined ejector-absorption refrigeration cycle where there is no condenser included

Another approach of using ejector with an absorption system was introduced by Chung et al. [65] and Chen [66], as shown in Figure 2.16. Similar to Kuhlenschmidt, an ejector is used to maintain an absorber pressure at a level higher than that in the evaporator. In contrast to the previous system, the ejector's motive fluid is the high pressure liquid solution from the generator. Therefore, high-pressure and high-density refrigerant can be used only. This is because a liquid-driven ejector is not suitable to operate with low-density vapor such water, as in the case for systems using $\mathrm{LiBr} / \mathrm{H}_{2} \mathrm{O}$. Experimental investigation showed that, by using DMETEG/R22 and DMETEG/R21 as working fluids, the pressure ratio between the absorber and the evaporator of 1.2 were found. The increase in absorber pressure results in the circulation of the solution being lower than that for a conventional system operated at the same condition. Thus, an improvement in the COP can be expected. 


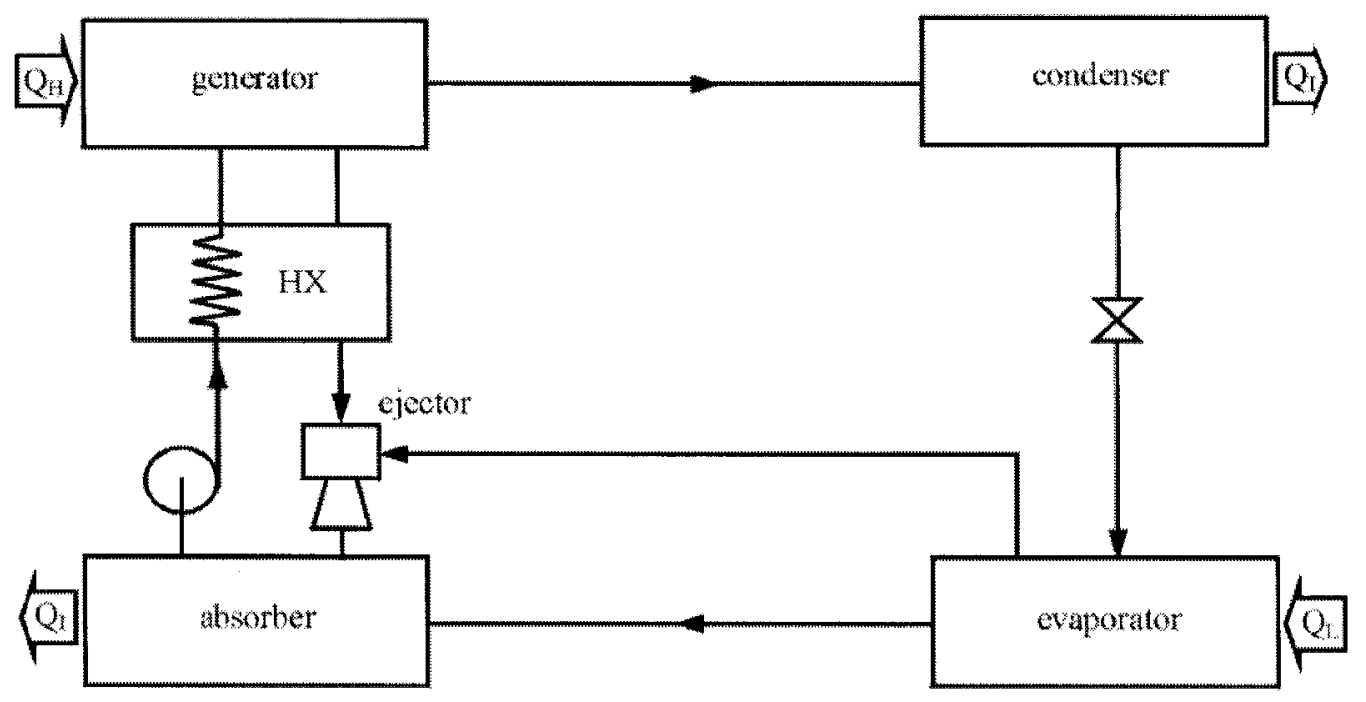

Figure 2.16 A combined ejector/absorption system using DMETEG/R22 and DMETEG/R21 as working fluids. The strong solution in the returning leg from generator serves as primary fluid and refrigerant vapor from evaporator as second fluid

Another approach proposed by Aphornratana and Eames [67] is shown in Figure 2.17. An ejector is placed between a generator and a condenser of a single-effect absorption system. $\mathrm{LiBr} / \mathrm{H}_{2} \mathrm{O}$ is used as the working fluid. The ejector uses high-pressure water vapor from the generator as the motive fluid. Thus, the generator is operated at a pressure higher than the condenser. This allows the temperature of the solution to be increased without the danger of crystallization. If the temperature and pressure are simultaneously increased, the solution concentration is maintained constant and the heat input to the generator is only slightly increased. The ejector entrains vapor refrigerant from the evaporator; hence, more cooling effect is produced. COP is significantly increased over a conventional single-effect absorption system. Experimental investigation showed that COP as high as 0.86 to 1.04 was found. However, this system must be operated with a high temperature heat source $\left(190^{\circ} \mathrm{C}\right.$ to 
$210^{\circ} \mathrm{C}$ ) and acceptable surrounding temperature. As the generator temperature is high, the corrosion of construction material may be problematic.

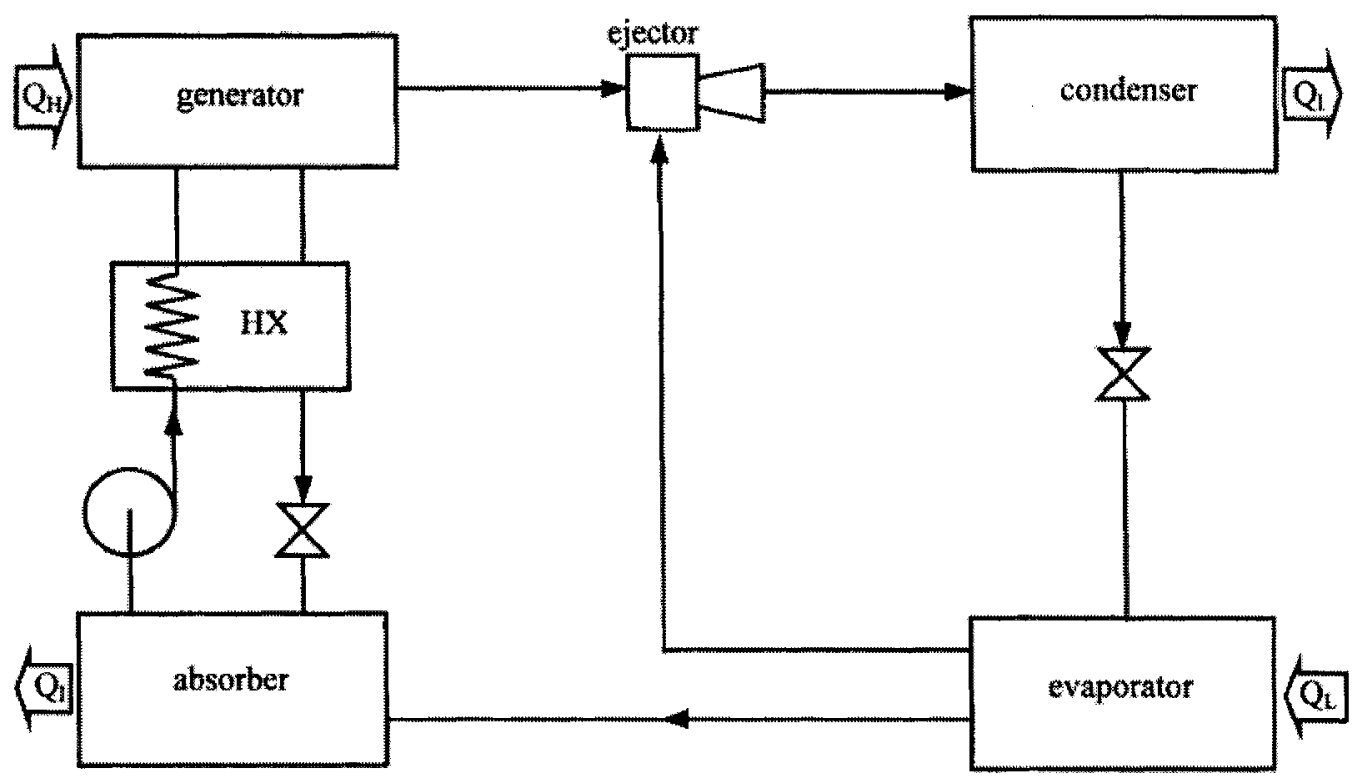

Figure 2.17 A combined ejector/absorption proposed by Aphornratana and Eames [92], was invented. High pressure refrigerant vapor from the generator enters the ejector as motive fluid to carry the refrigerant vapor from the evaporator

The approach proposed by Eames and $\mathrm{Wu}[68,69]$ is shown in Figure 2.18. This cycle is a combined cycle between a steam jet heat pump and a single-effect absorption cycle. In this system, a steam jet system is used as an internal heat pump, which was used to recover rejected heat during the condensation of the refrigerant vapor from a single-effect absorption cycle. The heat pump supplies heat to the generator of an absorption system. The refrigerant vapor generated from the generator is entrained by the steam ejector and is liquefied together with the ejector's motive steam by rejecting heat to the solution in the generator. In this system the corrosion problem is eliminated as the solution maximum temperature is maintained at $80^{\circ} \mathrm{C}$. 
The driving heat (from an external source) is supplied to the steam boiler only at temperatures around $200^{\circ} \mathrm{C}$. The experimental COP of this system was found to be 1.03 .

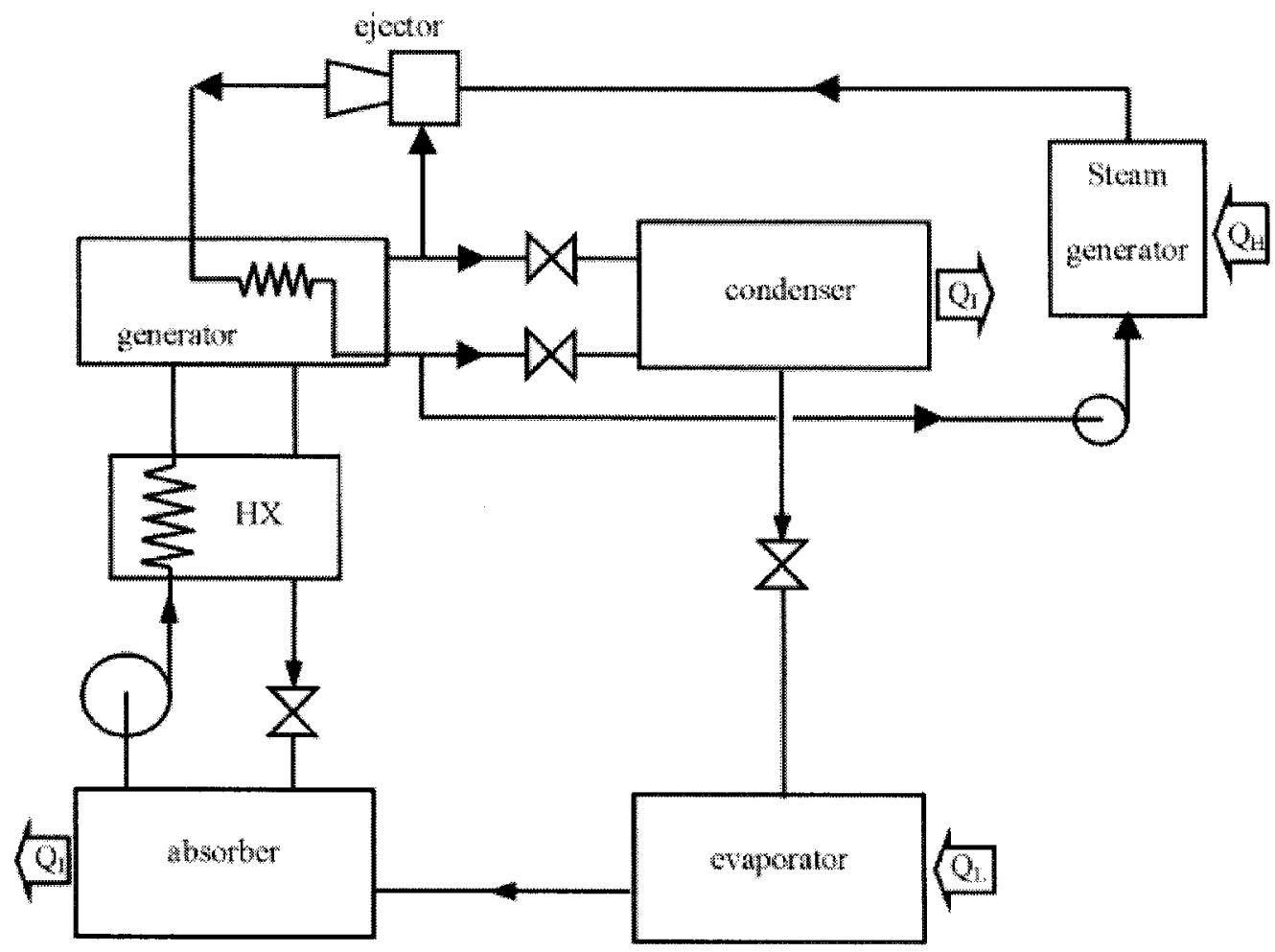

Figure 2.18 A combined cycle proposed by Eames and Wu [68]. The highest solution circuit temperature is maintained at about $80^{\circ} \mathrm{C}$. So the corrosion problem is alleviated

\subsubsection{Osmotic-membrane absorption cycle}

This system, as shown in Figure 2.19, was proposed by Zerweck [70]. The system consists of a condenser and an evaporator as usual. Rich-refrigerant solution in the absorber and weak-refrigerant solution in the generator are separated from each other by using an osmotic membrane. The osmotic membrane allows only the refrigerant to pass. Thus, the refrigerant from the absorber can be transferred to the 
generator by an osmotic diffusion effect through the membrane without any mechanical pump.

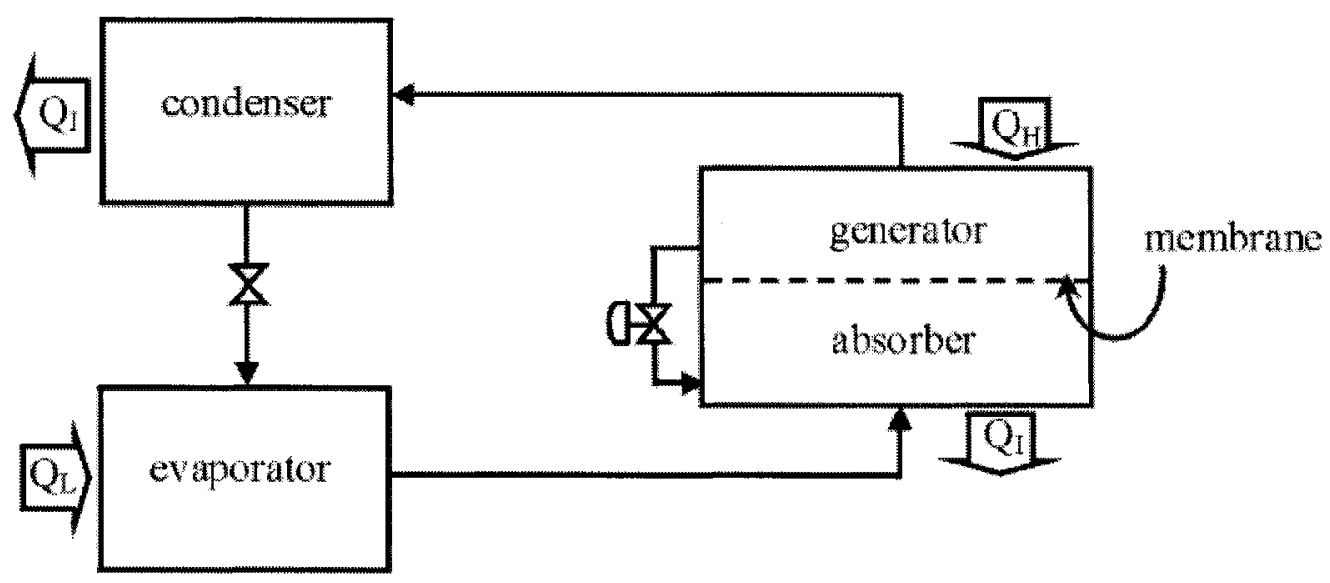

Figure 2.19 An osmotic membrane absorption cycle employs heat for refrigerant separation and producing pressure difference within the system

The pressure difference within the generator and the absorber is also dependent on the type of the membrane used. Normally, the membrane is not perfect; the absorbent from the absorber may be diffused together with the refrigerant to the generator. Moreover, a bleed valve may be needed to re-strengthen the solution in the absorber if the membrane is imperfect. In practice, the membrane must be able to withstand all the operating conditions; pressure, temperature, and high aggressive working fluid. The membrane should also minimize heat transfer between the generator and the absorber. Thus, a bleed valve is needed to re-strengthen the solution in the absorber. 


\subsubsection{Self-circulation absorption system using $\mathrm{LiBr} / \mathrm{H}_{2} \mathrm{O}$}

Even if the prime energy for an absorption refrigeration system is in the form of heat, some electricity still required to drive a circulation pump. There are some absorption refrigeration systems that do not require any circulation pump. In such a system, working fluid is circulated naturally by a thermosyphon effect known as a bubble pump.

Yazaki Inc. of Japan introduced a self-circulate absorption refrigeration system based on a single-effect system using $\mathrm{LiBr} / \mathrm{H}_{2} \mathrm{O}$. Using water as a refrigerant, differential pressure between the condenser and the evaporator is very low and can be maintained by using the principle of hydrostatic-head. The solution from the absorber can be circulated to the generator by a bubble pump. The weak-refrigerant solution returns gravitationally back to absorber. A schematic diagram of this system is shown in Figure 2.20. With the effect of the bubble pump, the solution is boiled and pumped at the same time. 


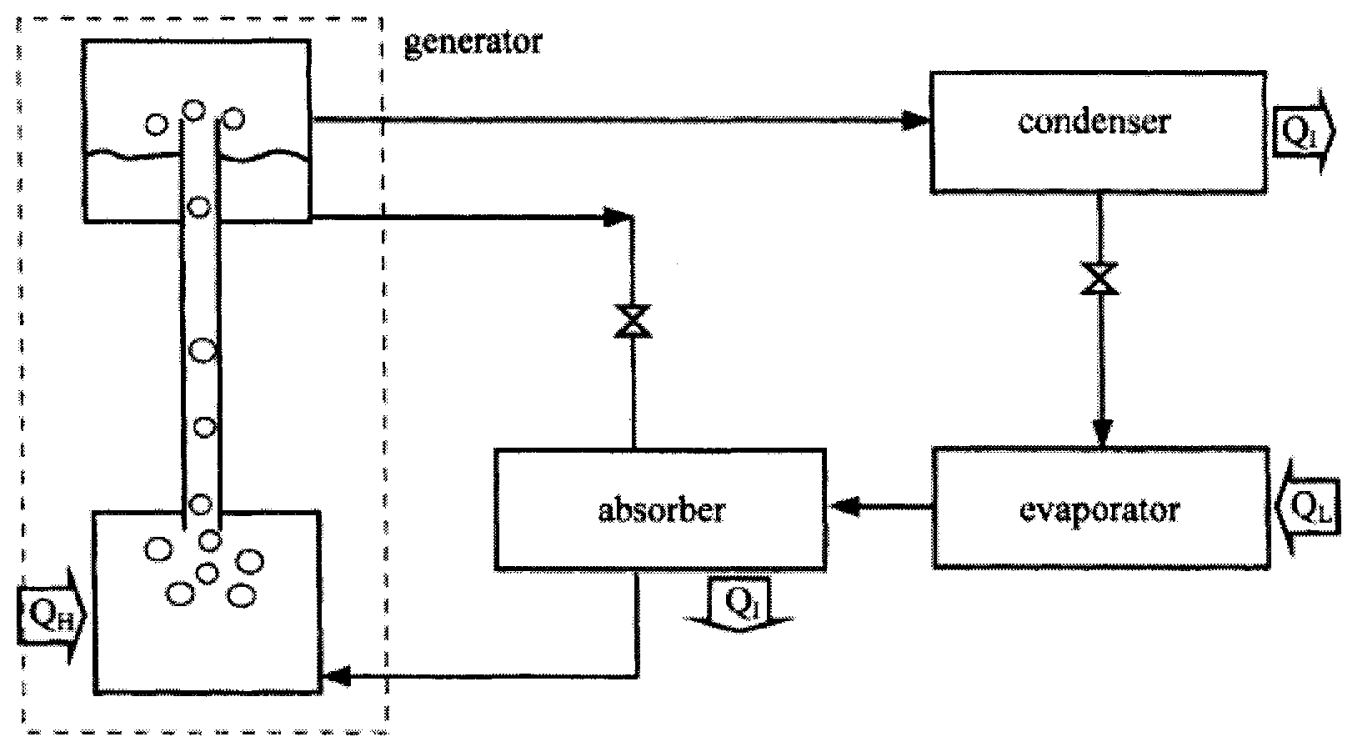

Fig. 2.20 The diagram shows a bubble pump in a generator module. Heat input to the generator is used for both circulation of working fluid and evaporation of refrigerant

Eriksson and Jernqvist [71], developed a $10 \mathrm{~kW}$ self-circulation absorption heat transformer using $\mathrm{NaOH} /$ water. Due to the high temperature and pressure differential between the condenser and the evaporator, the absorber and evaporator are located at 7 and $10 \mathrm{~m}$ below the condenser and generator, respectively. The lowest and highest point of this machine is $14 \mathrm{~m}$. which is equivalent to a pressure difference of about 1 bar inside the system.

\subsubsection{Diffusion absorption refrigeration system (DAR)}

DAR is another type of self-circulate absorption system using $\mathrm{NH}_{3} / \mathrm{H}_{2} \mathrm{O}$. The concept of these kind of system was proposed by Platen and Munters [72], students at the Royal Institute of Technology, Stockholm. Figure 2.21 shows a schematic 
diagram of this system. As $\mathrm{NH}_{3}$ is the working fluid, differential pressure between the condenser and the evaporator is too large to be overcome by a bubble-pump. An auxiliary gas is charged to the evaporator and the absorber. Therefore, no pressure differential in this system and the bubble-pump can be used. The cooling effect is obtained based on the principle of partial pressure. Because the auxiliary gas is charged into the evaporator and the absorber, the partial pressure of ammonia in both evaporator and absorber is kept low enough to correspond with the temperature required inside the evaporator. The auxiliary gas should be non-condensable such as hydrogen or helium.

An outstanding feature of this system is that it can be operated in places where no electricity is available. It has been used for a long time in domestic refrigerators. It contains no moving part, which means it is free of maintenance and produces less noise during the operation. However, in the traditional models, its cooling capacity is very small, less than $50 \mathrm{~W}$. With this cooling capacity, it is only suitable to be used as a refrigerator in a hotel room or recreation vehicle and it is not enough for air conditioning applications [73]. 


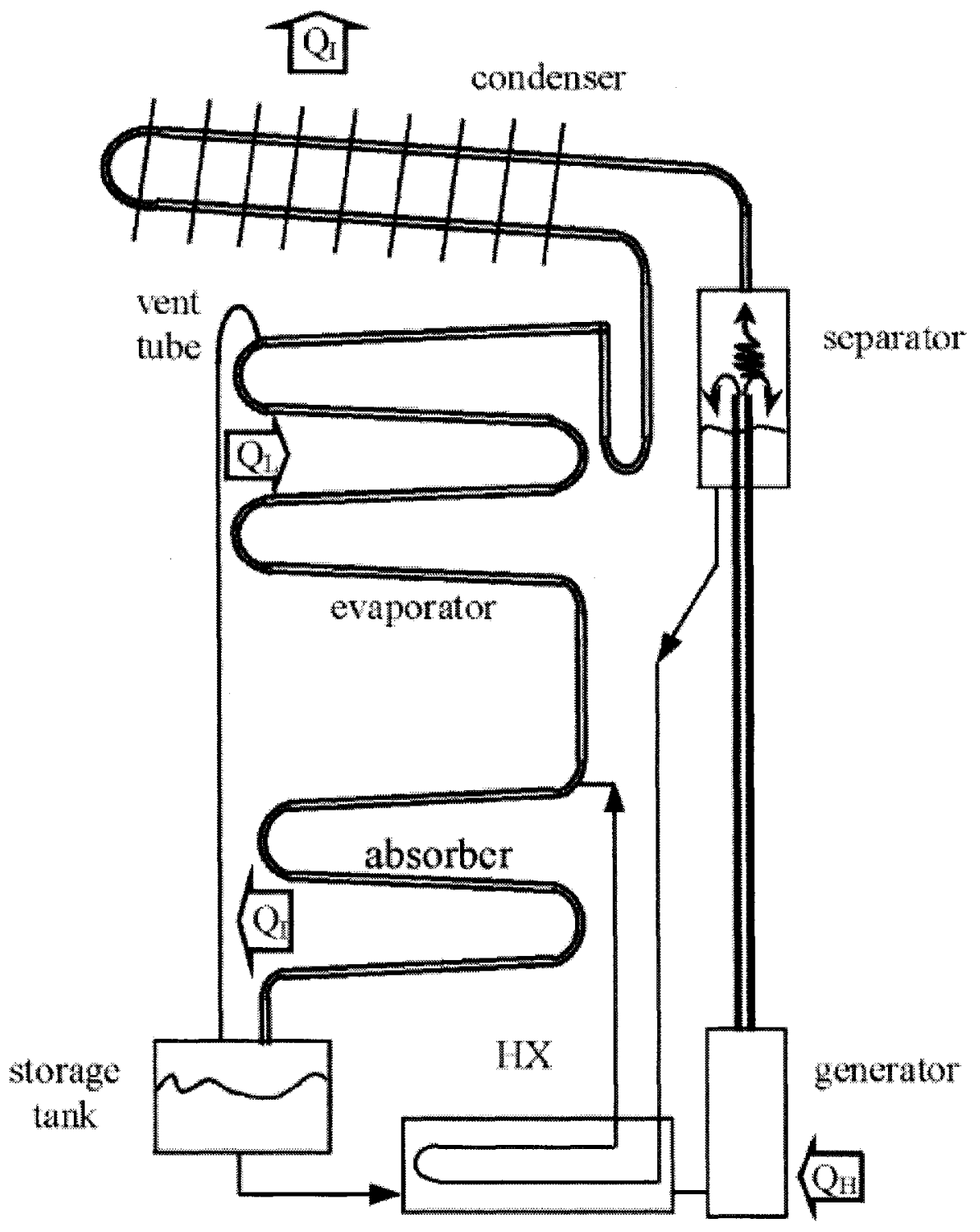

Figure 2.21 A diffusion absorption refrigerator (DAR). This system was once widely used as a domestic refrigerator as no electricity is required in its operation. $\mathrm{NH}_{3} / \mathrm{H}_{2} \mathrm{O}$ /auxiliary gas is charged in the machine as the working fluid

Modifications of the traditional model machines have been made; for example enhancement of boiler performance [74], by altering the auxiliary gas to helium [75]. The original DAR uses hydrogen as the auxiliary gas. It is known that hydrogen can cause danger if it leaks. Helium is an alternative auxiliary gas that was introduced to replace hydrogen. The comparisons of hydrogen and helium as auxiliary gas have 
been investigated [75-77].

Various types of absorption refrigeration systems, many type absorption cycles have been developed. The system performance has been increased steadily. However, the system complexities were increased over conventional single-effect absorption system simultaneity, this greatly affects the new system. The Double Mechanism Sorptive Refrigeration (DMSR) system design from this research has the potential high performance and commercial possibility. The details of this system will be investigated in next section. Based on our literature research and experimental work, it can be determined that this system can provide COP as high as a double-effect system with little increase in system complexity. This system can be widely used as a domestic refrigerator, air conditioning and other systems. More efforts are being made to improve its performance.

\subsection{Fundamental of the novel DMSR system}

As mentioned in previous sections, there are several mature absorption technologies in practice for a long time. $\mathrm{NH}_{3}-\mathrm{H}_{2} \mathrm{O}$ and $\mathrm{H}_{2} \mathrm{O}-\mathrm{LiBr}$ have been well-known as working pairs to be applied in the most common absorption systems. Both mixtures had some disadvantages to limit their applications. The disadvantage of $\mathrm{H}_{2} \mathrm{O}-\mathrm{LiBr}$ system came from its negative pressure while the main disadvantage of the $\mathrm{NH}_{3}-\mathrm{H}_{2} \mathrm{O}$ system was its high water content in the vapour phase which requires an auxiliary rectifier to separate it from $\mathrm{NH}_{3}$. This also results in a high vapour pressure 
at elevated temperatures for the $\mathrm{NH}_{3}-\mathrm{H}_{2} \mathrm{O}$ system. Further more, the $\mathrm{NH}_{3}-\mathrm{H}_{2} \mathrm{O}$ cycle exhibits a relatively low COP. Efforts are being made to search for better refrigerant-absorbent pairs that can improve system performance.

In our recent research, a salt-mixture has been chosen as the sorbent that has been developed by DY Refrigeration and has been used in the ice-maker fishery industry [50]. The major active component of sorbent is sodium thiocyanate ( $\mathrm{NaSCN}$ ). $\mathrm{NH}_{3}$ is chosen as sorptive. NaSCN is soluble in liquid $\mathrm{NH}_{3}$. The sorption process involves vapour ammonia, sorbent-ammonia liquid solution and sodium thiocyanate (NaSCN) crystals. When absorbing $\mathrm{NH}_{3}, \mathrm{NaSCN}$ will be partially or totally dissolved and forms a solution. It's found that the mixed solid (NaSCN) and liquid $\left(\mathrm{NH}_{3}-\mathrm{NaSCN}\right)$ together demonstrate a strong sorptive ability for $\mathrm{NH}_{3}$, with the adsorption on the solid surface and absorption into the solution. The effects of the two sorption mechanisms are functioning with different magnitudes at different stages of the process. This combined sorptive refrigeration system could be called as Double Mechanism Sorptive Refrigeration (DMSR) system. The specially-engineered DMSR process happens with a solid-liquid-vapour three-phase process, which has several advantages.

\subsubsection{The working fluid}

Choosing a better refrigeration-absorbent working pair is critical to the performance of absorption refrigeration system. The disadvantages of $\mathrm{NH}_{3}-\mathrm{H}_{2} \mathrm{O}$ and 
$\mathrm{H}_{2} \mathrm{O}$ - $\mathrm{LiBr}$ discussed in previous sections make people try to find a better working pair. In the DMSR system, a salt-mixture has been chosen as the sorbent. The major active component of this sorbent is sodium thiocyanate $(\mathrm{NaSCN})$. And because of its low evaporating temperature, $\mathrm{NH}_{3}$ is chosen as sorptive. Some researchers have performed the comparisons of the performance of several different working pairs, and the results show that ammonia-sodium thiocyanate cycles are suitable alternatives to ammonia-water absorption systems and the performance of the ammonia-sodium thiocyanate cycle is better than that of the other absorption cycle over a wide range, such as $\mathrm{NH}_{3}-\mathrm{H}_{2} \mathrm{O}$ and $\mathrm{NH}_{3}-\mathrm{LiNO}_{3}[6,18]$.

Figure 2.22 shows the comparison of COP values vs. generator temperatures for $\mathrm{NH}_{3}-\mathrm{H}_{2} \mathrm{O}, \mathrm{NH}_{3}-\mathrm{LiNO}_{3}$ and $\mathrm{NH}_{3}-\mathrm{NaSCN}$ absorption cycles in the cycle operating at $T_{c}=25^{\circ} \mathrm{C}, T_{a}=25^{\circ} \mathrm{C}, T_{e}=-5^{\circ} \mathrm{C}$ and the cycle include a solution heat exchanger with the effectiveness of $80 \%$ from a simulation result of Da-wen Sun [9]. It is shown that the COP values for these three cycles increase with generator temperatures. And there exists a low generator temperature limit for each cycle. A cycle cannot be operated at generator temperatures lower than its limit, and the suitable generator temperature for all these three cycle should above $65^{\circ} \mathrm{C}$. It is shown that, for generator temperatures higher than $75^{\circ} \mathrm{C}$, the $\mathrm{NH}_{3}-\mathrm{NaSCN}$ cycle gives the best performance, and the $\mathrm{NH}_{3}-\mathrm{H}_{2} \mathrm{O}$ cycle has the lowest COP. This is important for utilizing waste heat and solar energy since the fluid temperature for these cases are generally about $80^{\circ} \mathrm{C}-$ $200^{\circ} \mathrm{C}$ 


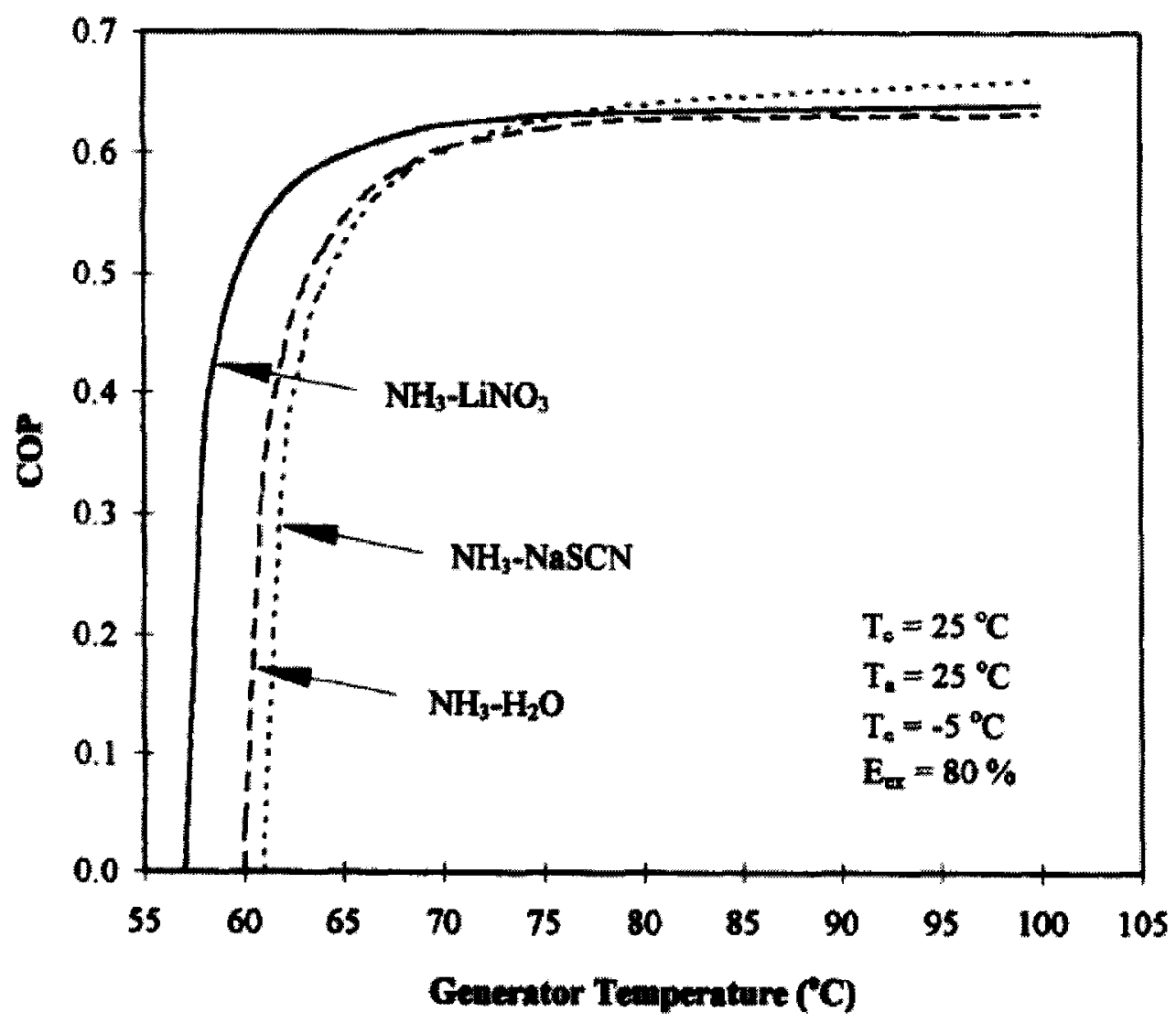

Figure 2.22 Comparison of the effect of COP values on generator temperatures [6]

Figure 2.23 gives the comparison of COP values vs. evaporator temperatures for $\mathrm{NH}_{3}-\mathrm{H}_{2} \mathrm{O}, \mathrm{NH}_{3}-\mathrm{LiNO}_{3}$ and $\mathrm{NH}_{3}-\mathrm{NaSCN}$ absorption cycles in the cycle operating at $T_{c}=25^{\circ} \mathrm{C}, T_{a}=25^{\circ} \mathrm{C}, T_{g}=90^{\circ} \mathrm{C}$ and the cycle include a solution heat exchanger with the effectiveness of $80 \%$. With the increase in evaporator temperature, the COP values for each cycle increase. For evaporator temperatures lower than zero, which is the temperature range for refrigeration, the $\mathrm{NH}_{3}-\mathrm{NaSCN}$ cycle still gives the best performance, and the $\mathrm{NH}_{3}-\mathrm{H}_{2} \mathrm{O}$ cycle has the lowest COP values. Only for high evaporator temperature, such as above $7^{\circ} \mathrm{C}$, the performance of the $\mathrm{NH}_{3}-\mathrm{H}_{2} \mathrm{O}$ cycle is better than that of the $\mathrm{NH}_{3}-\mathrm{NaSCN}$ cycle. 


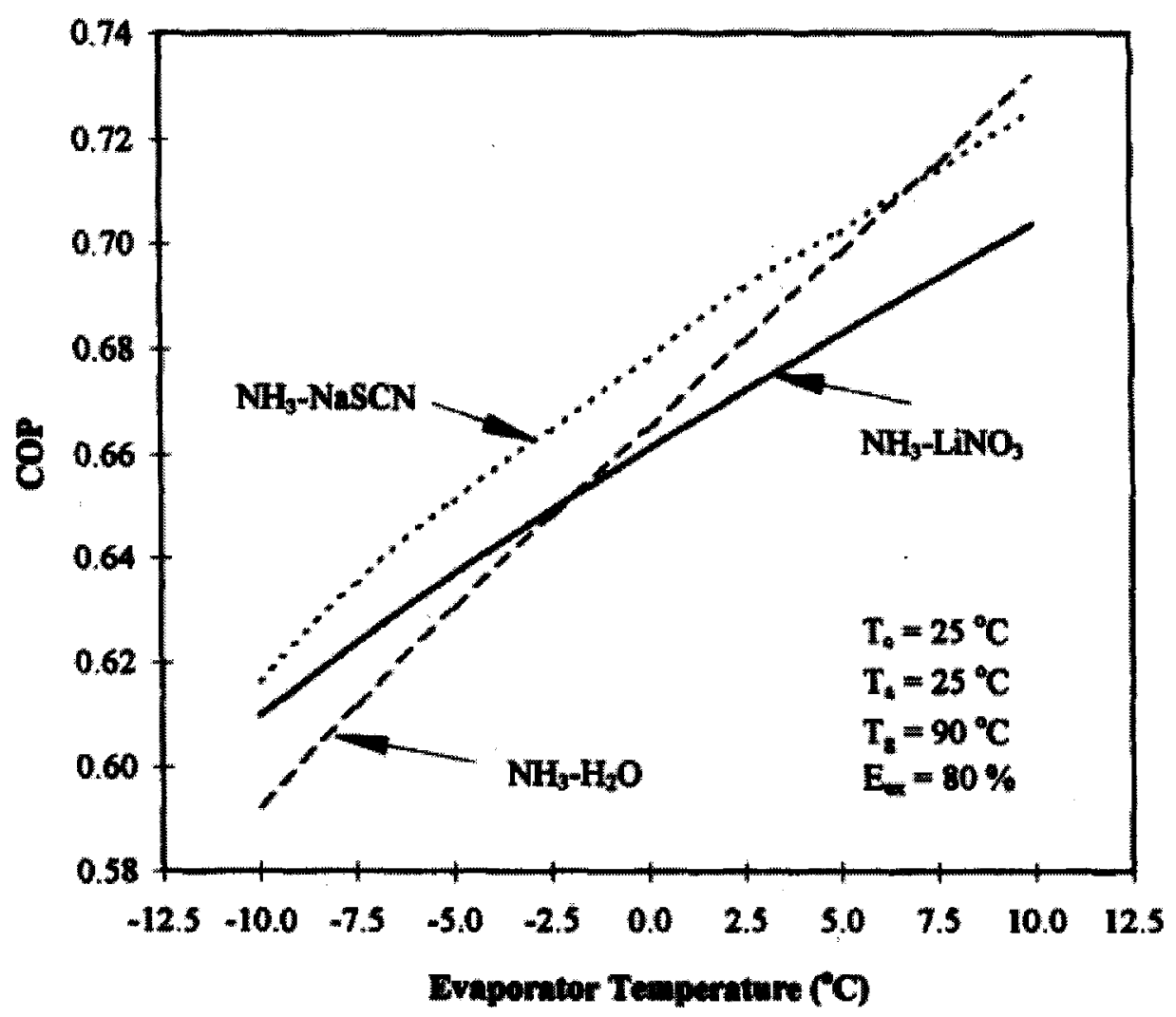

Figure 2.23 Comparison of the effect of COP values on evaporator temperatures [6]

Figure 2.24 illustrates the comparison of COP values vs. condenser temperatures for $\mathrm{HN}_{3}-\mathrm{H}_{2} \mathrm{O}, \mathrm{NH}_{3}-\mathrm{LiNO}_{3}$ and $\mathrm{NH}_{3}-\mathrm{NaSCN}$ absorption cycles in the cycle operating at $T_{a}=25^{\circ} \mathrm{C}, T_{c}=-5^{\circ} \mathrm{C}, T_{g}=90^{\circ} \mathrm{C}$ and the cycle include a solution heat exchanger with the effectiveness of $\mathbf{8 0 \%}$. Increasing condenser temperatures cause a decrease in system performance for each cycle. It is shown that for low condenser temperatures, for temperatures below $30^{\circ} \mathrm{C}$, both the $\mathrm{NH}_{3}-\mathrm{NaSCN}$ and $\mathrm{NH}_{3}-\mathrm{LiNO}_{3}$ cycles show better performance than the $\mathrm{NH}_{3}-\mathrm{H}_{2} \mathrm{O}$ cycle, and the COP values for the $\mathrm{NH}_{3}-\mathrm{NaSCN}$ cycle are the highest. 


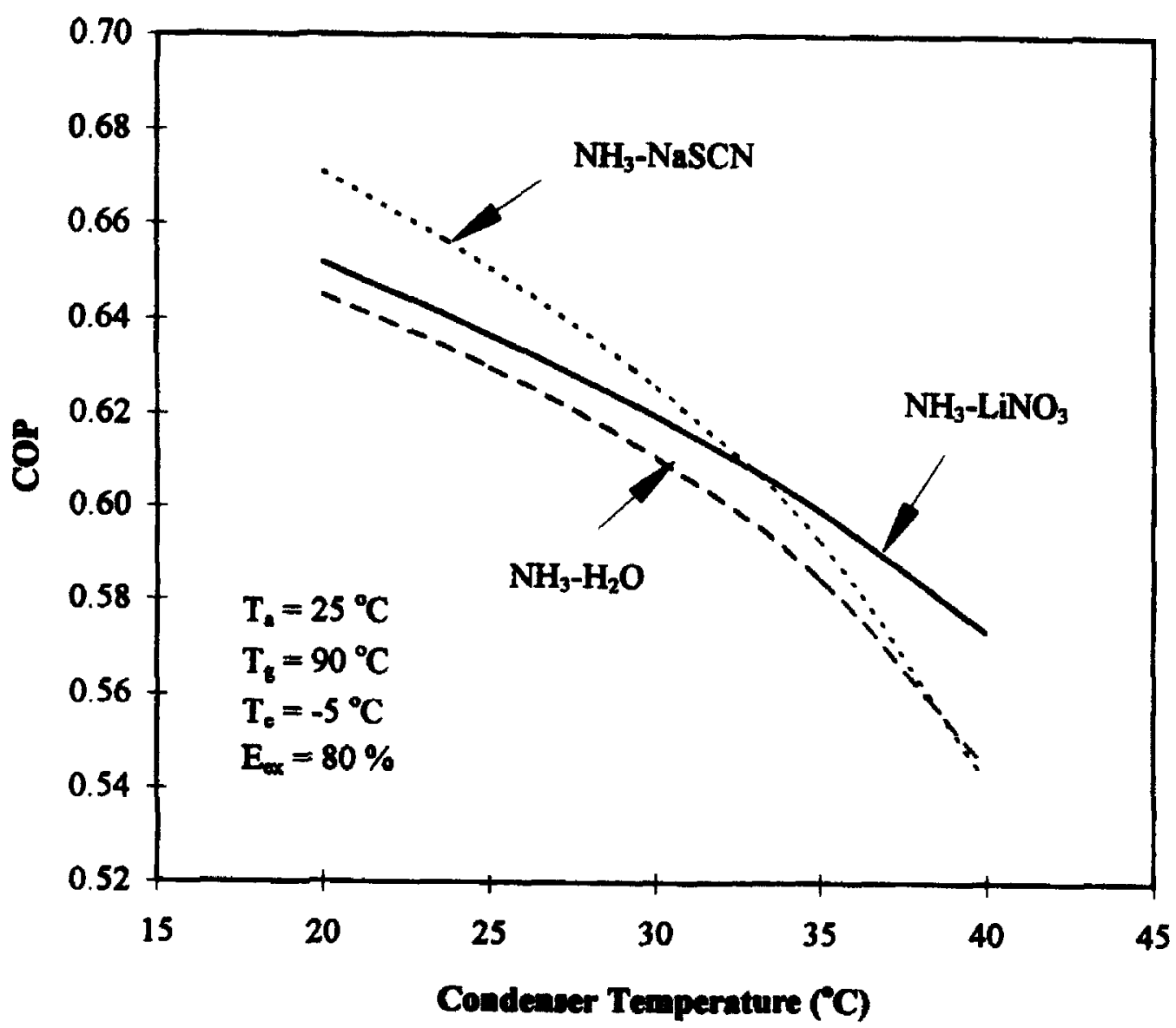

Figure 2.24 Comparison of the effect of COP values on condenser temperatures [6]

The comparison of COP values vs. absorber temperatures for $\mathrm{NH}_{3}-\mathrm{H}_{2} \mathrm{O}$, $\mathrm{NH}_{3}-\mathrm{LiNO}_{3}$ and $\mathrm{NH}_{3}-\mathrm{NaSCN}$ absorption cycles is shown in Figure 2.25. The effect of absorber temperature is similar to that of condenser temperature. Generally speaking, the condenser and absorber temperatures should be at a similar level.

The results of Figure 2.22 to Figure 2.25 predicted that the performance of the $\mathrm{NH}_{3}-\mathrm{NaSCN}$ cycle is better than those of other sorptive cycles. The advantages provided by this system over other absorption units include lower generator and evaporator temperatures, a higher coefficient of performance (COP), (about $5 \sim 10$ 
percent absolute higher than the ones for the $\mathrm{NH}_{3}-\mathrm{H}_{2} \mathrm{O}$ system working at the same operating conditions). Compared with $\mathrm{NH}_{3}-\mathrm{H}_{2} \mathrm{O}$ system, the $\mathrm{NH}_{3}-\mathrm{NaSCN}$ adsorption system doesn't need the rectifier because there are only $\mathrm{NH}_{3}$ in the vapour phase and the salt $(\mathrm{NaSCN})$ doesn't evaporate at all, that makes the system simpler and cheaper $[6]$.

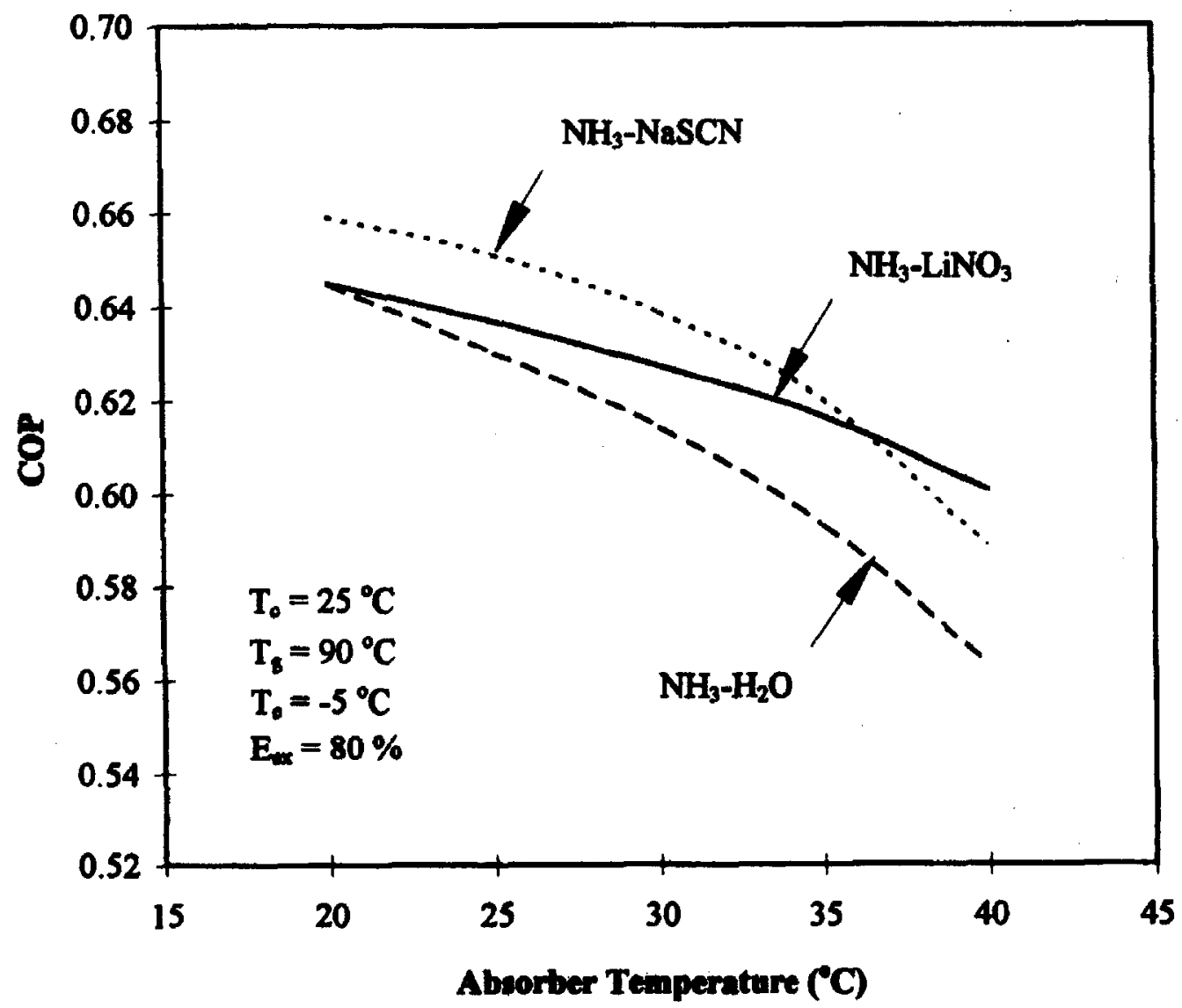

Figure 2.25 Comparison of the effect of COP values on absorber temperatures [6]

\subsubsection{Circulating loops in DMSR system}

For traditional absorption refrigeration system, the pressure deference between the condenser and the evaporator is so large that a supercharging pump has to be used 
to circulate the working fluid. In the new DSMR system, hydrogen is used as an expansion gas to balance the system pressure, based on Dalton's Law. The pressure of the system is constant, so that a magnetic pump can be used to delivery the solution with minimal power consumption. The cooling effect is obtained based on the principle of partial pressure. Because the expansion gas is charged into the evaporator and the absorber, the partial pressure of ammonia in both evaporator and absorber is kept low enough to correspond with the temperature required inside the evaporator.

This new design bases on the original diffusion absorption refrigeration (DAR) system, while the $\mathrm{NH}_{3}-\mathrm{H}_{2}-\mathrm{H}_{2} \mathrm{O}$ working fluid is changed to $\mathrm{NH}_{3}-\mathrm{H}_{2}-\mathrm{NaSCN}$. For original $\mathrm{NH}_{3}-\mathrm{H}_{2}-\mathrm{H}_{2} \mathrm{O}$ diffusion absorption refrigeration system, the refrigerant (ammonia) serves as a transporting medium to carry energy from a low temperature source to a high temperature sink. The absorbent (water) absorbs the refrigerant at low temperature and low partial pressure and releases it at high temperature against high partial pressure. And the auxiliary gas (hydrogen) provides pressure equalization for the working fluid between the condenser and evaporator, and it enables the use of magnetic pump or bubble pump driven by heat to deliver the solution. At the same time, it suppresses the evaporation of refrigerant because of mass transfer resistance to ammonia vapor, caused the inert hydrogen gas. The expansion gas also produces a mass transfer resistance during sorption process. In the absorber there is ammonia-hydrogen (water as well) mixture in the gas phase, ammonia-water solution in the liquid phase. These factors result in the original DAR system always perform a relatively low COP and often the huge evaporator and absorber volumes to improve 
the evaporation and absorption process.

To overcome the disadvantages of original DAR system, the DSMR system use sodium thiocyanate as the absorbent to replace water, from this change, the system COP can reach an acceptable level. At the same time, other advantages of the diffusion absorption refrigeration system, such as, using magnetic pump to replace supercharging pump used in traditional absorption refrigeration system to decrease the mechanical work input, no need of throttling, noise free during operation, are preserved.

Compared with current $\mathrm{H}_{2} \mathrm{O}-\mathrm{LiBr}, \mathrm{NH}_{3}-\mathrm{H}_{2}-\mathrm{H}_{2} \mathrm{O}$ and $\mathrm{NH}_{3}-\mathrm{H}_{2} \mathrm{O}$ systems, there are only $\mathrm{NH}_{3}$ in the vapor phase. The salt-mixture (active component - NaSCN) doesn't evaporate at all, so this new sorptive system doesn't need a rectifier. This makes the system simpler. In order to avoid other additives entrained to condenser, a simple droplet separator is designed and applied to outlet of the generator.

\subsubsection{Simple and optimum structure}

The DSMR system consists of a series of components, a generator, an evaporator, a condenser, a DMSR absorber, a solution heat exchanger, two cooling heat exchangers, and two circulation pumps and fan(s), the use of $\mathrm{MH}_{3}-\mathrm{H}_{2}-\mathrm{NaSCN}$ solution make this system simpler and has a higher COP compared to current $\mathrm{H}_{2} \mathrm{O}-\mathrm{LiBr}, \mathrm{NH}_{3}-\mathrm{H}_{2}-\mathrm{H}_{2} \mathrm{O}$ and $\mathrm{NH}_{3}-\mathrm{H}_{2} \mathrm{O}$ systems. A diagram of its structure is shown in Figure 2.26. 


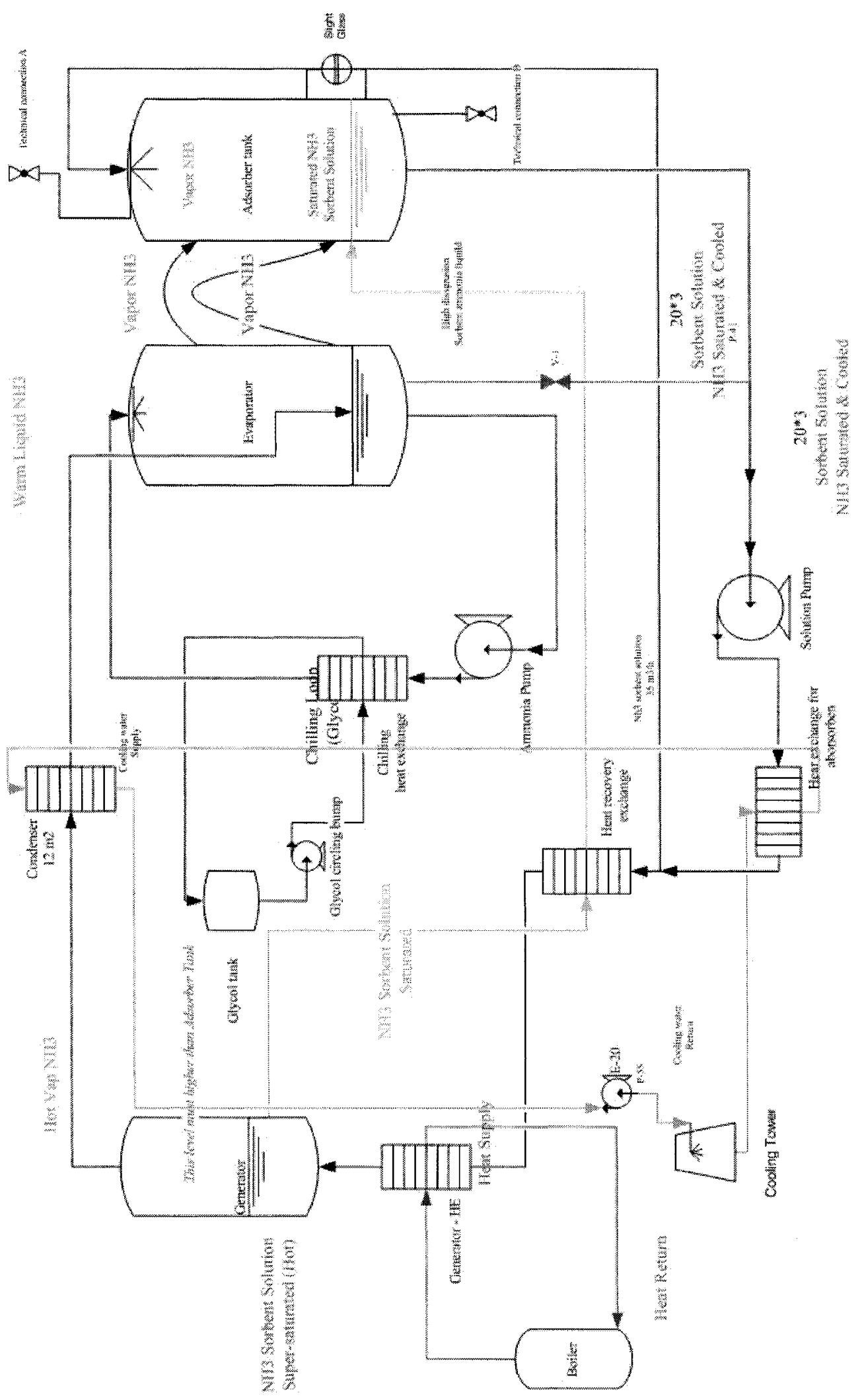

Figure 2.26 Double Mechanism Sorptive Refrigeration (DMSR) system 
In order to realize high efficiency of the DMSR system, and further improve the system performance, a series of theoretical model and experimental work are performed. The experimental data are first used to validate individual components under working conditions in an expected operation range. The system model, then, is validated with the whole system performance, such as COP and cooling capacity, etc.

\section{a) DMSR absorber and evaporator}

The combined DMSR absorber and evaporator is a unique design. There are four tubes to connect the absorber tank and evaporator tank, which allow the circulation of the gas phase.

\section{b) Generator}

When the ammonia is vaporized from the solution inside the generator, entrainments carried by ammonia vapor may deposit and contaminate the system. As mentioned, the solution contains $\mathrm{NaSCN}$ and some other additives, which are easily condensed in the vapor lines and condensers. A droplet separator is recently designed and applied to outlets of the generators.

c) Off-the-shelf components

Off-the-shelf components include circulation pumps, heat exchangers, automation system, safety system, and encapsulation protection. The selection of these components is important to system performance either, for example, the flow rate of the circulation pump will decide the solution circulation ratio; the efficiencies of heat exchangers will greatly influence the whole system efficiency, and the automation system and safety system will ensure a stable operation. 
Because of these characteristics discussed before, the DMSR system includes such significant advantages compared with other existing system as below:

- The DMSR system is expected to achieve a cooling temperature as low as $-30^{\circ} \mathrm{C}$, which is not possible with current $\mathrm{H}_{2} \mathrm{O}-\mathrm{LiBr}, \mathrm{NH}_{3}-\mathrm{H}_{2}-\mathrm{H}_{2} \mathrm{O}$ and $\mathrm{NH}_{3}-\mathrm{H}_{2} \mathrm{O}$ systems.

- This new sorptive system doesn't need the rectifier because there is only $\mathrm{NH}_{3}$ in the vapor phase. The salt-mixture (active component - NaSCN) doesn't evaporate at all. This makes the system simpler.

- Hydrogen is filled into the system as an expansion gas to balance the system pressure. A minimal power is required to drive the liquid circulation. Thus, magnetic pumps can be used to delivery the solution instead of the supercharged pump used in other absorption systems.

- Low grade heat sources can be used to drive the system, typically $90 \sim 120^{\circ} \mathrm{C}$, with which the evaporating (refrigerating) temperature can reach $-30^{\circ} \mathrm{C}$.

- A high COP value up to 0.7 can be achieved.

- This system can work in moving environment, thus, there are potential applications for automotive, fishery, etc.

\subsection{Chapter closure}

This chapter mainly introduces the primary types of current thermal driven refrigeration system, introduces their normal structures and commonly used working solutions. And provides the basic structure and main advantages of DMSR system. 
The detailed introduction to the thermodynamic and structure properties of DMSR system will be covered in Chapter 3 . 


\section{Chapter 3}

\section{Thermodynamics properties of working fluid and mathematical modeling}

In this chapter, the basic thermal properties of the working pair will be collected, compared and formulated, which include enthalpy, viscosity, density, thermal conductivity, diffusivity and the crystallization line. The relationship between the solution crystallization temperature and solution concentration need to be investigated.

Furthermore, based on the parameters, such as the ambient temperature, heater temperature and the concentration of solution, a steady state computer simulation model should be built to predict the operation of the system. This model is based on detailed mass and energy balance and heat and mess transfer relationships for the cycle components. The model should be able to determine: the equations for the maximum and minimum concentration of the solution; and the temperature, flow rate and enthalpy of the solutions at the inlet and outlet of the heat exchangers. Then a computer program will be developed to simulate the effect of various operating conditions on the performance of the individual components of the DMSR system. These include an absorber, a generator, a condenser, an evaporator and a solution heat exchanger. In this computer program, simultaneous heat and mass transfer has been considered instead of only heat transfer as in previous works. The performance of absorber, generator, condenser and evaporator were simulated independently, the 
whole system was then simulated as a working absorption cycle under various operating conditions. And then the present simulation results were compared quantitatively with the experimental results.

\subsection{Thermodynamic properties of the working fluid}

The performance and efficiency of reversible cycles are independent of the properties of the working fluids in use. However, the performance and efficiency of a real machine are determined to a large degree by the properties of the working fluids. Both the equipment cost and the operating cost of an absorption refrigeration system are strongly dependent on the working fluid properties.

Thermodynamic property relation for mixtures is a subject that has been well-known in chemical thermodynamics for many years go back to Gibbs (1876). More recent general treatments of chemical thermodynamics were performed by Lewis and Randall (1961) and Rowlinson and Swinton (1982). In recent years, mixtures have become commonly used in energy conversion cycle. The emphasis is focus on thermodynamic properties and, specifically, on the relationships between the thermodynamic properties of a mixture. These relationships allow the derivation of thermodynamic properties from measured experimental data, to check the consistency of data and to apply the laws of thermodynamics to an engineering system [5].

A lot of working fluids have been considered for absorption machines. These 
include water/ammonia, water/sodium hydroxide, water/sulfuric acid, ammonia/lithium nitrate, ammonia/sodium thiocyanate and hundreds of other mixture. The literature contains numerous studies on properties of various working fluids. Some of these fluids are widely used in current absorption refrigeration machines, such as water/ammonia, some of these are for specialized applications such as high temperature, while others are proposed as possessing improved properties over the conventional fluids.

In the new Double Mechanism Sorptive Refrigeration (DMSR) system, ammonia/ sodium thiocyanate was chosen as working fluid because of its great advantages mentioned above. For this mixture, the thermodynamic properties have been studied by C. A. Infante Ferreira [18], and the detailed graphical treatments and mathematic equations have been recommended.

To evaluate an absorption refrigeration cycle, equilibrium data are required as are data on crystallization boundaries, saturation pressure, viscosities of solution, heat of solution, densities, heat capacities, thermal conductivities and enthalpies. In this section equations will be provided for the evaluation of the different properties of the ammonia/ sodium thiocyanate solution.

\subsubsection{Crystallization line}

In the absorption refrigeration system history, some absorption chillers are notorious for "freezing up" or crystallizing. The basic mechanism of failure is simple 
enough - working fluid solution becomes so concentrated that crystals of absorbent form and plug the machine (usually the heat exchanger section). In the DMSR system, a small quantity of solid sodium thiocyanate should be crystallized from solution and be pumped to absorber tank to absorb the vapor ammonia directly, this will greatly increase the system absorptivity. To avoid plugging the machine, a high power circulation pump is utilized. For this reason, the crystallization information is a very important part for the absorption refrigeration system design. In order to minimize the possibility of crystallization, the relationship between the solution crystallization temperature and solution concentration need to be investigated. For our DMSR system, the concentration of weak solution has to be high enough at the inlet of the absorber after the heat lost when solution through solution heat exchanger.

Blytas and Daniels present an experimental phase diagram for ammonia/ sodium thiocyanate solution system. The crystallization line presented by these authors has been divided into five different concentration ranges by C. A. Infante Ferreira and can be estimate from [18]:

$$
\begin{aligned}
& 0.000<X<0.360 \\
& X C R I S=0.360107-0.00012865 T-0.0000030158 T^{2} \\
& +0.00000001058 T^{3}-0.000000000039364 T^{4} \\
& 0.360<X<0.565 \\
& X C R I S=0.4924+0.0124 T+0.0003 T^{2} \\
& 0.430<X<0.565 \\
& X C R I S=0.386+0.0094 T-0.0001 T^{2} \\
& 0.565<X<0.735 \\
& X C R I S=0.2198-0.006444 T
\end{aligned}
$$


$0.735<X<1.000$

$X C R I S=7.2395+0.080303 T$

For our system, only the crystallization temperature from $0^{\circ} \mathrm{C}$ to $150^{\circ} \mathrm{C}$ is concerned. The relationship between the solution crystallization temperature and solution concentration are shown in Figure 3.1, where " $\mathrm{x}$ " in this Figure is the solution crystallization point in different concentrations $(0.32<\mathrm{X}<0.45)$

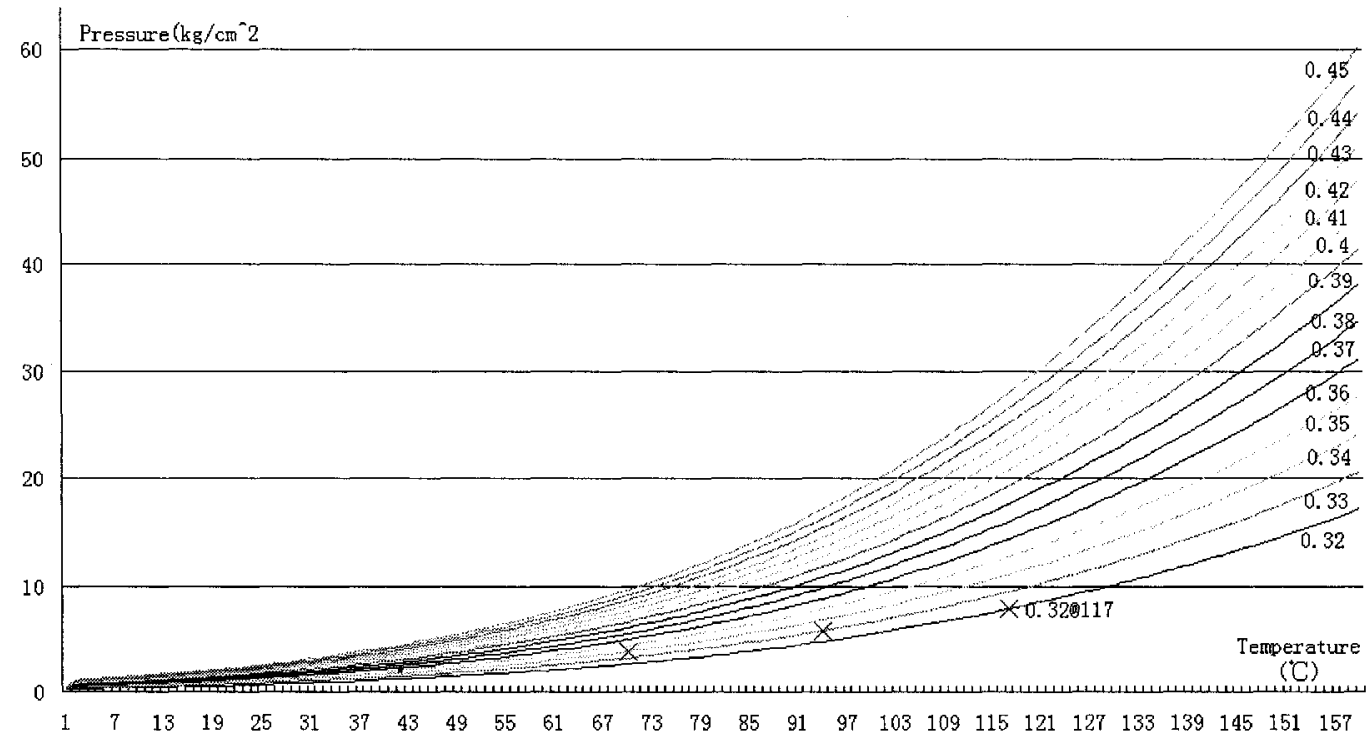

Figure 3.1 The relationship among the $\mathrm{NH}_{3}-\mathrm{NaSCN}$ solution crystallization temperature, equilibrium pressure and solution concentration

\subsubsection{Equilibrium pressure}

Equilibrium pressure is another important property for the absorption refrigeration system. A partial ammonia pressure differential between condenser and evaporator is essential to our absorption refrigeration system as it causes the liquid ammonia with high partial pressure from condenser to greatly decrease its boiling point in evaporator with a lower partial pressure. Without this change in pressures, the 
refrigeration system would not be performed and the system would simply act as an ammonia container.

The experimental equilibrium pressure data have been presented by Blytas and Daniels in the range $0.343<\mathrm{X}<0.730$ and Roberson et, al. [18]. In the range $0.343<\mathrm{X}<0.529$. The relation between saturation equilibrium pressure and temperature of ammonia/ sodium thiocyanate mixture is given as [9]:

$$
\ln P=A+\frac{B}{T}
$$

Where

$$
\begin{aligned}
& A=15.7266-0.298628 X \\
& B=-2548.65-2621.92(1-X)^{3}
\end{aligned}
$$

And Figure 3.2 shows detailed graphical diagram of the relation between saturation equilibrium pressure and temperature and concentration of ammonia/ sodium thiocyanate solution. It is shown that the solution saturation pressure will increase together with the temperature and solution concentration. 


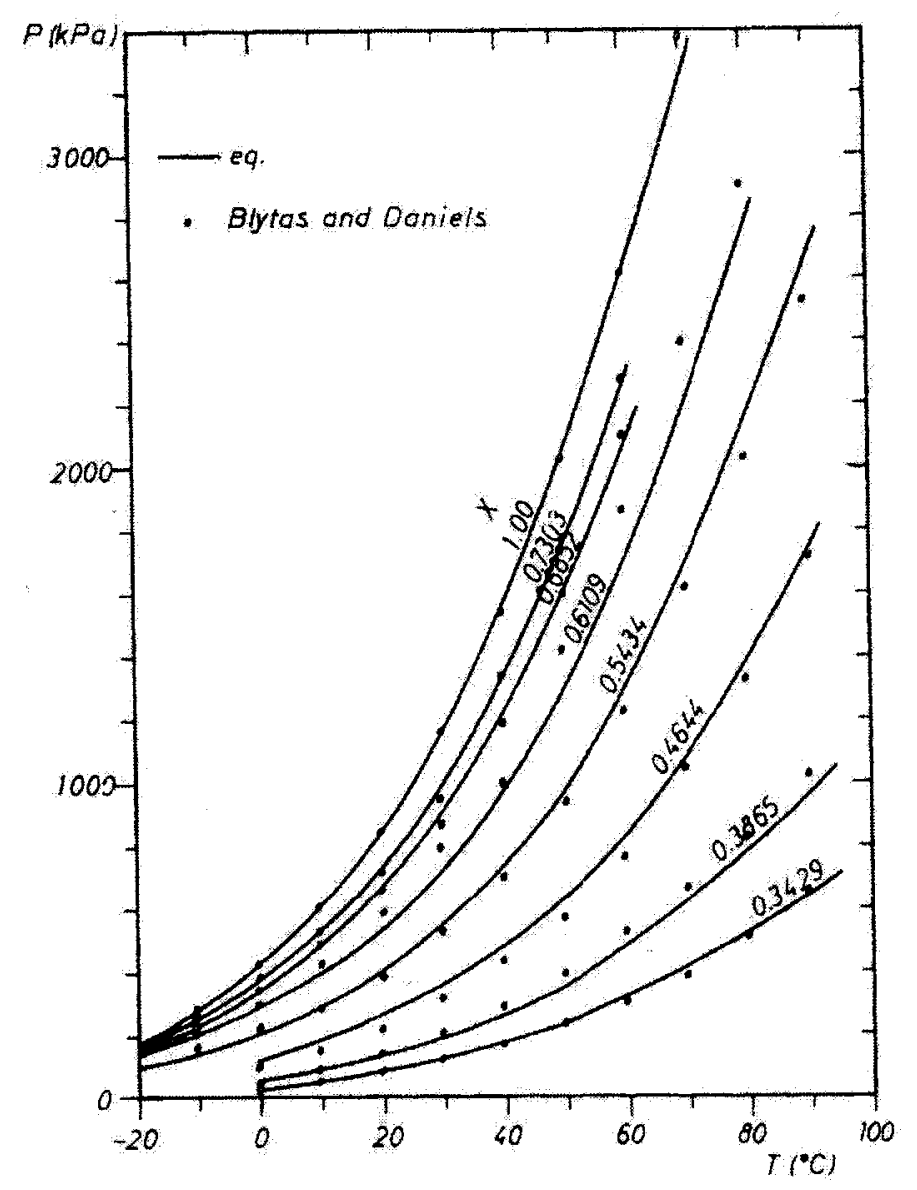

Figure 3.2 The relationship among the $\mathrm{NH}_{3}-\mathrm{NaSCN}$ solution saturation equilibrium pressure, temperature and solution concentration (comparison between experimental data and equation 3.6) [18]

\subsubsection{Density}

It's well known that density is a measure of mass per unit of volume. Hence, the higher an object's density is, the higher it's mass per unit volume will be. Blytas and Daniels reported density values for solutions of sodium thiocyanate in liquid ammonia. These values together with the pure liquid ammonia data presented in other papers have been correlated to be given by [18]:

$$
\rho=A+B(T-273.15)+C(T-273.15)^{2}
$$


Where

$$
\begin{aligned}
& A=1707.519-2400.4348 X+2256.5083 X^{2}-930.0637 X^{3} \\
& B=-3.6341 X+5.4552 X^{2}-3.1674 X^{3} \\
& C=10^{-3}\left(5.1 X-3.6 X^{2}-5.4 X^{3}\right)
\end{aligned}
$$

\subsubsection{Viscosity}

A liquid's resistance to flowing is called its viscosity. Viscosity is an important property in our design. The more viscous the fluid, the more difficult it can be carried to other place. It means a small pump is enough to circulate the low viscosity solution. And it is what we expected.

The viscosity of most liquids is affected by temperature. For our solutions of sodium thiocyanate in liquid ammonia, it is affected by temperature and solution concentration. The relation between them is described as the following equation [18]:

$$
\eta=10^{-6}\left(A(1-X)^{3.9365}+B\right)
$$

Where

$$
\begin{aligned}
& A=-0.5289(T-273.15)+29.695 \\
& B=2.19 \times 10^{-11}(393.15-T)^{4.636}+0.1
\end{aligned}
$$

Figure 3.3 shows a comparison between Blytas and Daniels' experimental data and the calculated viscosities by above equation. 


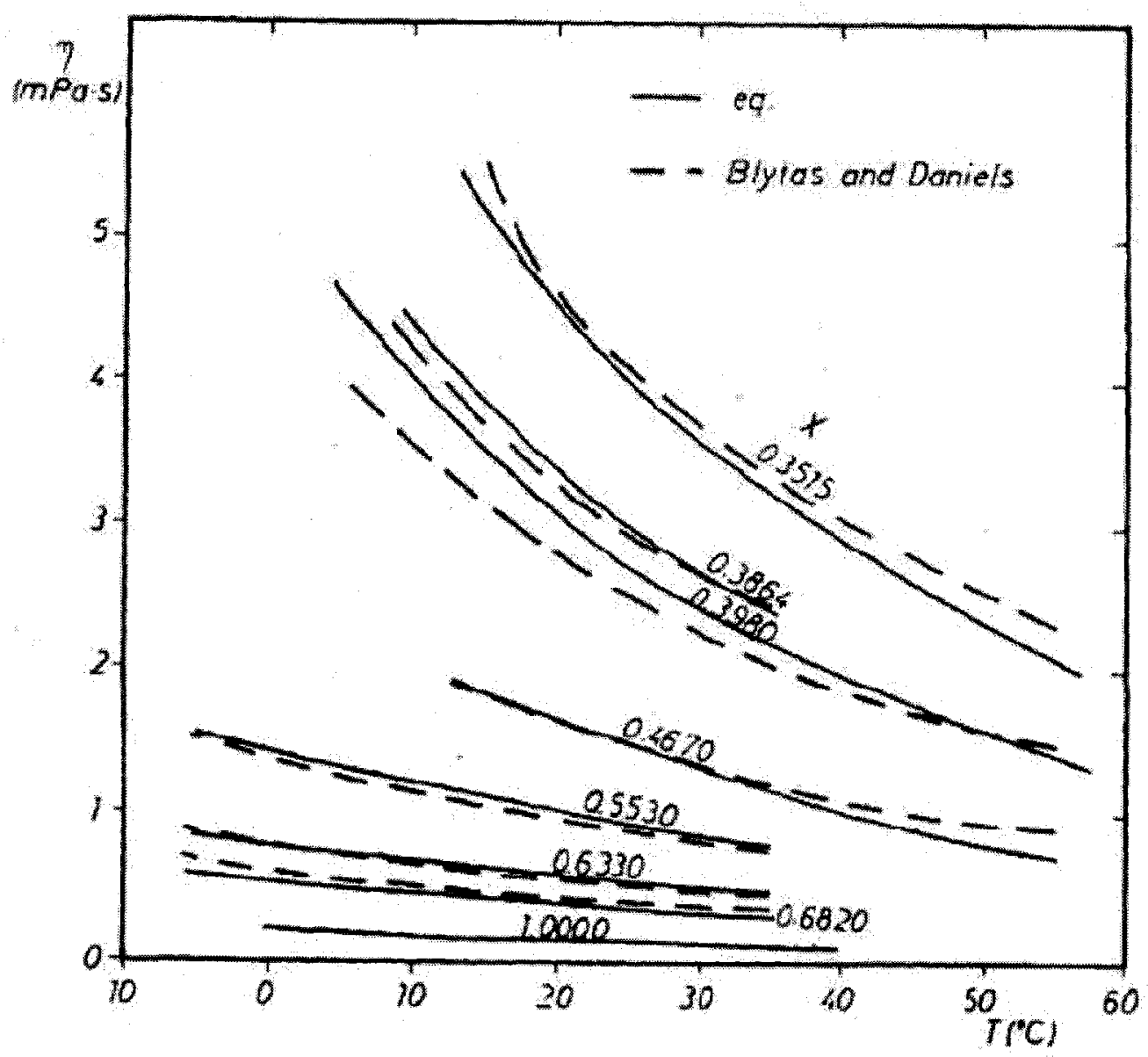

Figure 3.3 The relationship among the $\mathrm{NH}_{3}-\mathrm{NaSCN}$ solution viscosity, temperature and solution concentration (comparison between experimental data and equation 3.12) [18]

\subsubsection{Thermal conductivity}

Thermal conductivity, an intrinsic material property for which the values depend on the chemical composition, porosity, density, structure, and fabric of the material, is clearly another important parameter for our research, because the rate of heat transfer on the solution side in our system depends on not only the temperature gradient, but also the thermal conductivity of the solution.

The experimental thermal conductivity data of Blytas and Daniels have been 
correlated to given [18]:

$$
\lambda=A(1-X)^{B}+C
$$

Where

$$
\begin{aligned}
& A=10^{-3}\left(1.05 \times 10^{-2}(T-273.15)+7.655\right) \\
& B=7.5 \times 10^{-3}(T-273.15)+0.305 \\
& C=10^{-4}\left(6.93 \times 10^{-7}(T-323.15)^{3}+5.47\right)
\end{aligned}
$$

\subsubsection{Specific heat}

The specific heat capacity of a solid or liquid is defined as the heat required raising unit mass of substance by one degree of temperature. And it is obviously an important part of energy calculations since it tells us how much energy is needed to heat up one gram of the substance one degree temperature.

Blytas and Daniel and Sargent and Beckman present specific heat data for solutions of sodium thiocyanate in liquid ammonia. These values, together with the pure liquid ammonia data have been correlated to give [18]:

$$
C p=A+B(T-273.15)+C(T-273.15)^{2}
$$

Where

$$
\begin{aligned}
& A=0.24081-0.22814 X+0.79291 X^{2}-0.35137 X^{3} \\
& B=10^{-1}\left(0.251 X-0.8 X^{2}+0.612 X^{3}\right) \\
& C=10^{-3}\left(-0.1 X+0.3 X^{2}-0.1 X^{3}\right)
\end{aligned}
$$

Figure 3.3 shows a comparison between Blytas and Daniels' experimental data 
and the calculated specific heat by above equations.

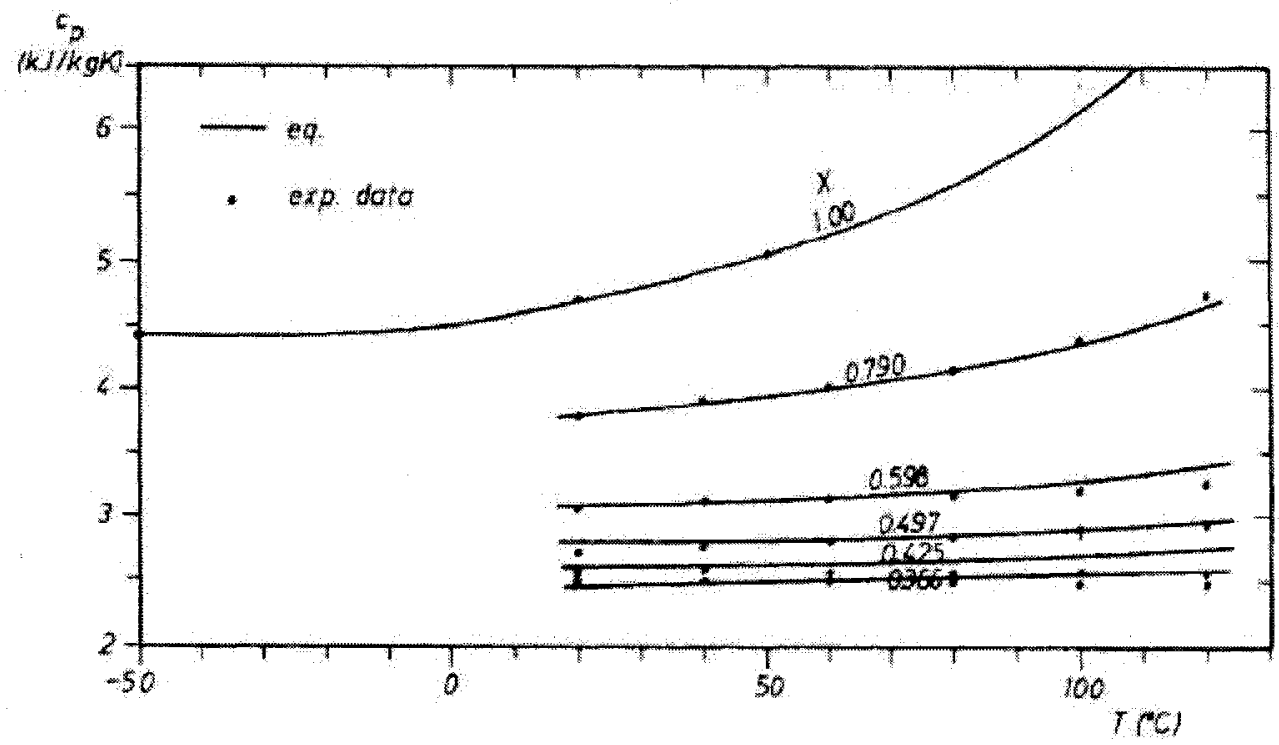

Figure 3.4 The relationship among the $\mathrm{NH}_{3}-\mathrm{NaSCN}$ solution specific heat, temperature and solution concentration (comparison between experimental data and equation 3.19) [18]

\subsubsection{Liquid enthalpy}

Enthalpy is the sum of the internal energy of matter and the product of its volume and pressure. And this thermodynamic property is useful particularly for nearly-constant pressure processes, where any energy input to the system must go into internal energy and the mechanical work of expanding the system. For systems at constant pressure, the change in enthalpy is the heat received or released by the system plus the non-mechanical work that has been done. Therefore, for a simple system, with a constant number of particles, the difference in enthalpy is the maximum amount of thermal energy derivable from a thermodynamic process in which the pressure is held constant. 
For the DMSR absorption refrigeration system, the liquid solution enthalpy is no doubt the most important thermodynamic property. Because the system pressure is constant, and there is no mechanical energy input to be considered. In generator and absorber part, the only way to drive the system to exchange energy with heat source and surrounding is by the solution enthalpy change.

The exact relation among liquid enthalpy, temperature and solution concentration is given by C. A. Infante Ferreira. The reference state of zero enthalpy was chosen as $0^{\circ} \mathrm{C}$ for the saturated ammonia and $0^{\circ} \mathrm{C}$ for solid sodium thiocyanate. The integral heat of solution curve at $0^{\circ} \mathrm{C}$ was obtained from the differential heat of solution as proposed by Bonauguri and Polononi. The integral heat of solution curve was used to obtain an enthalpy-concentration curve at $0^{\circ} \mathrm{C}$. The heat capacity is used to extend this curve to higher and lower temperatures. The result equation for liquid enthalpy is:

$$
\hbar=A(1-X) / 81.08+\int_{273.15}^{7} C p d T
$$

Where

$$
A=\left(6464-80450.38 X+23972.57 X^{2}\right)
$$

For our system, the working temperature range is about from $20^{\circ} \mathrm{C}$ to $110^{\circ} \mathrm{C}$, and in this range above equation can be written as [9]:

$$
h=A+B(T-273.15)+C(T-273.15)^{2}+D(T-273.15)^{3}
$$

Where

$$
\begin{aligned}
& A=79.72-1072 X+1287.9 X^{2}-295.67 X^{3} \\
& B=2.4081-2.2814 X+7.9291 X^{2}-3.5137 X^{3} \\
& C=10^{-2}\left(1.255 X-4 X^{2}+3.06 X^{3}\right)
\end{aligned}
$$




$$
D=10^{-5}\left(-3.33 X+10 X^{2}-3.33 X^{3}\right)
$$

These equations are presented by Da-wen Sun [9], and are in agreement with the equation proposed by C. A. Infante Ferreira in our working conditions, compared to the equations presented by C. A. Infante Ferreira [18], they are easier to be used, so in our simulating process, these equations are adapted as the solution liquid enthalpy equations. The result enthalpy-concentration diagram is shown in Figure 3.5.

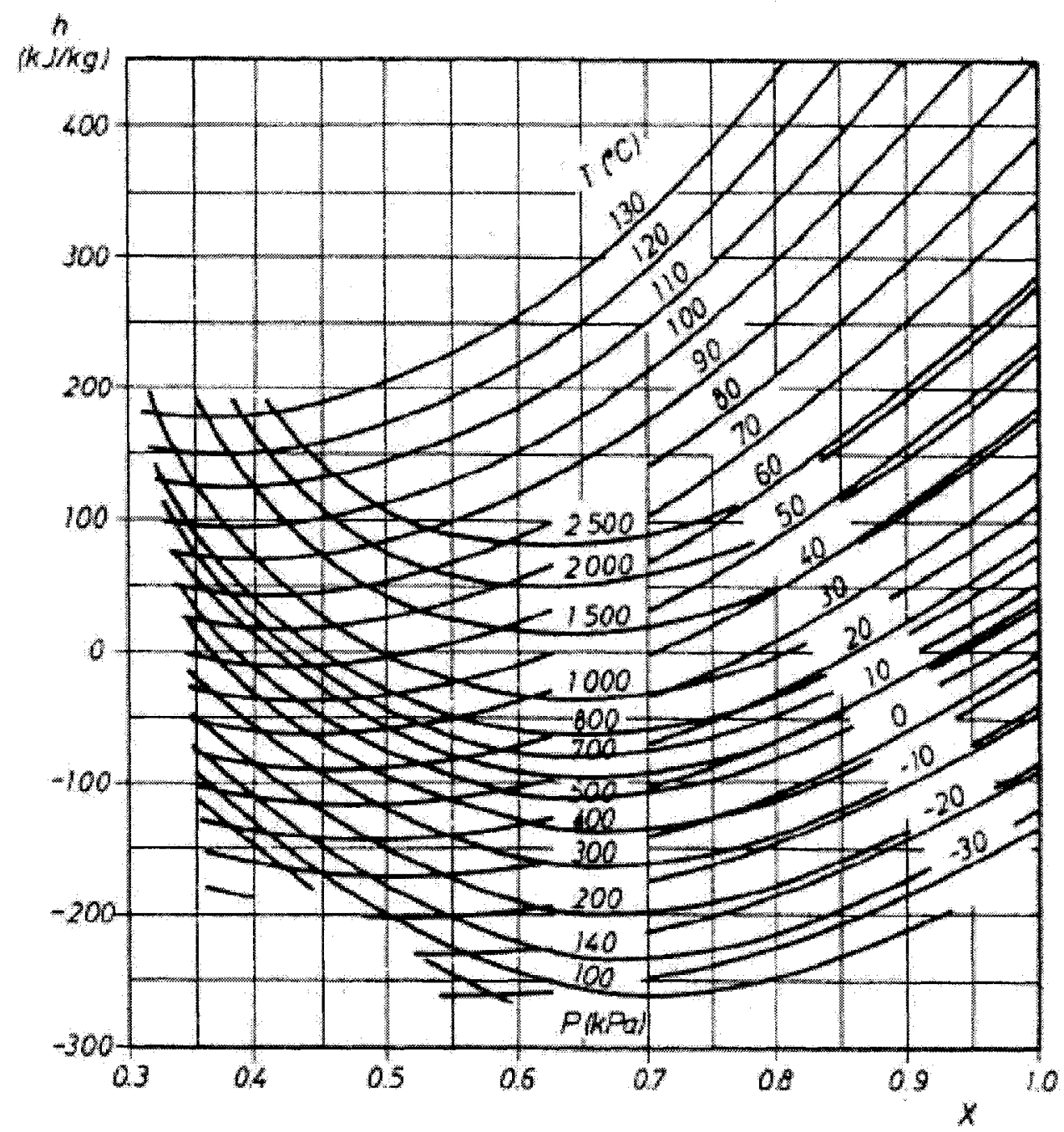

Figure 3.5 The relationship among the $\mathrm{NH}_{3}-\mathrm{NaSCN}$ solution liquid enthalpy, temperature and solution concentration (comparison between experimental data and equation 3.12) [18] 


\subsubsection{Thermodynamic properties of liquid and vapor ammonia}

To evaluate the DMSR absorption refrigeration cycle, except for thermodynamic properties of ammonia-sodium thiocyanate solution, the liquid and vapor ammonia properties are required. Because in condenser and evaporator parts, except hydrogen gas, only liquid and vapor ammonia exist. And it means the properties of ammonia will mainly determine the evaporator temperature.

In the usual ranges of pressure and temperature concerning refrigeration applications, the two phase equilibrium pressure and temperature of the refrigerant ammonia are linked by the relation [9]:

$$
P=10^{3} \sum_{i=0}^{6} a_{i}(T-273.15)^{i}
$$

The specific enthalpies of saturated liquid and vapor ammonia are expressed in terms of temperature as follows:

$$
\begin{aligned}
& h_{l}=\sum_{i=0}^{6} b_{i}(T-273.15)^{i} \\
& h_{v}=\sum_{i=0}^{6} c_{i}(T-273.15)^{i}
\end{aligned}
$$

The above three equations are fitted by Dawen Sun (1996) [9] with source data taken from ASHRAE handbook. Their coefficients are listed in table 3.1. 
Table 3.1 Coefficients of equations 3.30, 3.31 and 3.32

\begin{tabular}{lccc}
\hline$i$ & $a_{i}$ equation & $b_{i}$ equation 3.31 & $c_{i}$ equation 3.32 \\
\hline 0 & $3.2871 \times 10^{-1}$ & $1.9879 \times 10^{2}$ & $1.4633 \times 10^{3}$ \\
1 & $1.6001 \times 10^{-2}$ & $4.4644 \times 10^{0}$ & $1.2839 \times 10^{0}$ \\
2 & $2.3652 \times 10^{-4}$ & $6.2790 \times 10^{-3}$ & $-1.1501 \times 10^{-2}$ \\
3 & $1.6132 \times 10^{-6}$ & $1.4591 \times 10^{-4}$ & $-2.1523 \times 10^{-4}$ \\
4 & $2.4303 \times 10^{-9}$ & $-1.5262 \times 10^{-6}$ & $1.9055 \times 10^{-6}$ \\
5 & $-1.2494 \times 10^{-11}$ & $-1.8069 \times 10^{-8}$ & $2.5608 \times 10^{-8}$ \\
6 & $1.2741 \times 10^{-13}$ & $1.9054 \times 10^{-10}$ & $-2.5964 \times 10^{-10}$ \\
Standard error & $1.6 \times 10^{-3}$ & $8.5626 \times 10^{0}$ & $1.059 \times 10^{1}$ \\
Mean deviation & $1.252 \times 10^{-2}$ & $5.566 \times 10^{-3}$ & $3.679 \times 10^{-3}$ \\
\hline
\end{tabular}

The above equations are valid for saturated liquid and vapor ammonia, in our system, at the outlet of generator, the ammonia vapor is superheated. The above equation is not valid for this situation. Unfortunately, people always use saturated situation equations to simulate the whole cycle, it makes the simulation result not good enough to describe the real situation. In order to decrease the error in our simulation process, superheated vapor ammonia thermodynamic properties, especially specific heat and enthalpy should be used. The following equations are fitted by the author with source data taken from the properties of R-717 (ANHYDROUS AMMONIA) handbook presented by Industrial Refrigeration Consortium of University of Wisconsin [78]: 


$$
C p(T)=A T^{6}+B T^{5}+C T^{4}+D T^{3}+E T^{2}+F T+G
$$

Where

$$
\begin{aligned}
& A=1.753904 \times 10^{-11} \\
& B=-3.3202467 \times 10^{-8} \\
& C=2.6213545 \times 10^{-5} \\
& D=-1.1044825 \times 10^{-2} \\
& E=2.6188861 \times 10^{0} \\
& F=-3.3128843 \times 10^{2} \\
& G=1.7466553 \times 10^{4}
\end{aligned}
$$

The relation between temperature and specific enthalpies of superheated vapor ammonia is given as:

$$
h_{\text {sup erheated }}\left(T_{2}\right)=h_{\text {saturated }}\left(T_{1}\right)+\int_{T_{1}}^{T_{2}} C p d T
$$

Where $T_{1}$ is the saturate temperature for this kind of superheated vapor ammonia, and $h_{\text {saturated }}\left(T_{1}\right)$ is the corresponding enthalpy, $T_{2}$ is temperature of the super-heated vapor ammonia, $h_{\text {superheated }}\left(T_{2}\right)$ is the corresponding enthalpy.

\subsection{DMSR system mathematical model}

The simulation procedure involves the development of the mathematical models for each component making up the $\mathrm{NH}_{3}-\mathrm{H}_{3}-\mathrm{NaSCN}$ absorption refrigeration system. The overall system performance may then be evaluated by combining these models together in a sequence of system operation. All heat exchangers were shell and tube of 
the counter flow type.

Figure 3.6 illustrates the main components of the DMSR system. High partial pressure ammonia (2) from the condenser passes into the evaporator where the partial pressure of ammonia is reduced to the expected low value because of hydrogen gas in evaporator. The liquid ammonia vaporizes in the evaporator by absorbing heat from the material being cooled and resulting low partial pressure vapor (3) passes to the absorber, where it is absorbed by the strong solution (8) coming from the generator through an solution heat exchanger, and form the weak solution (4). The weak solution is pumped to the solution heat exchanger and then the generator, and the solution is boiled in the generator. The remaining solution (7) flows back to the absorber and the superheated vapor ammonia passes into the condenser and liquefied to high pressure liquid ammonia by release heat to the cooling material and, thus, completes the cycle. Weak solution (strong solution) means that the ability of the solution to absorb the refrigerant vapor is weak (strong), according to the ASHRAE definition. And the function of solution heat exchanger is to improve system performance.

The system performance is measured by the coefficient of performance (COP):

$$
C O P=\frac{Q_{e}}{Q_{g}+W_{p u m p}}
$$




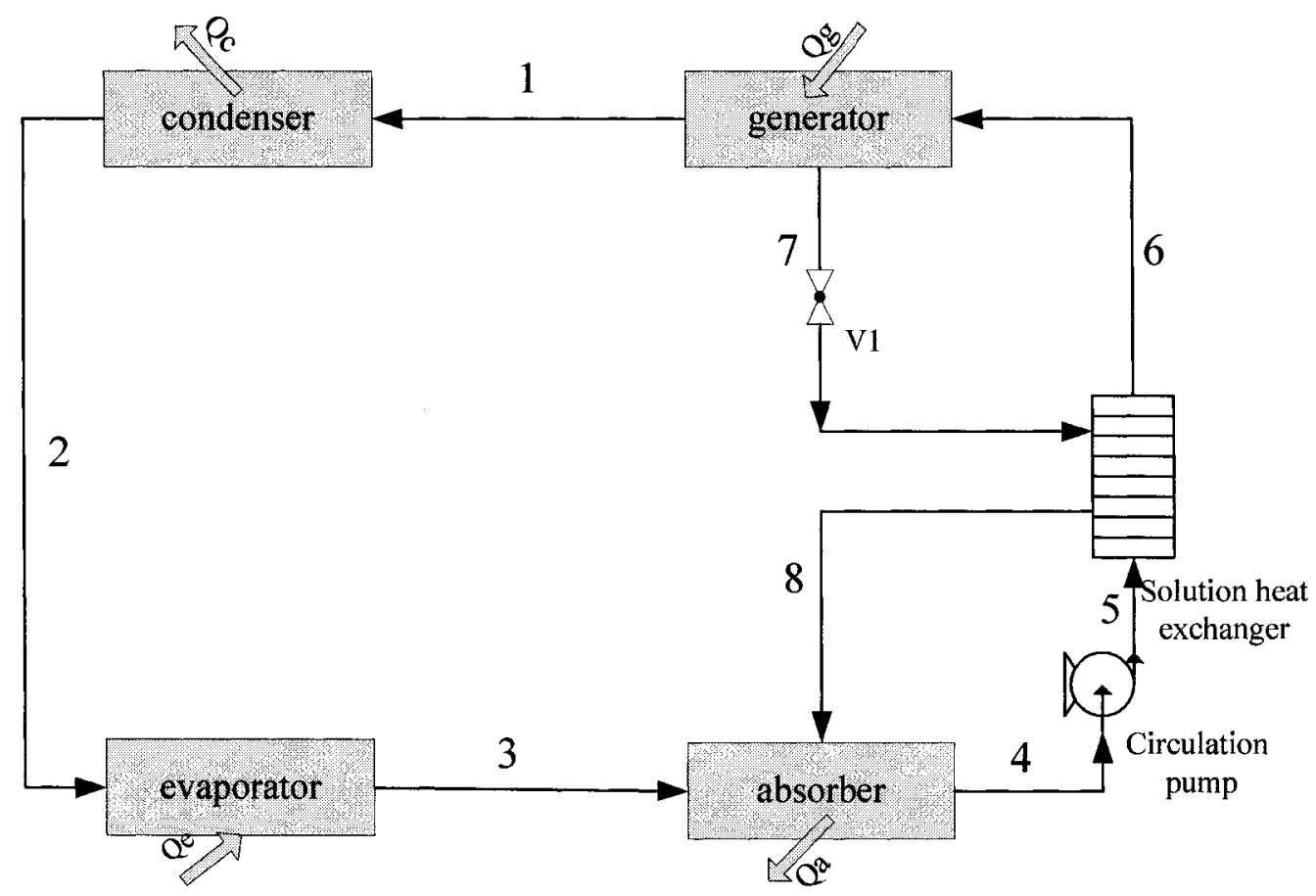

Figure 3.6 The schematic of the absorption refrigeration cycle

In order to simplify analysis without ignoring the basic physical situation, several conditions and assumptions were incorporated in the model as follows:

1. The system is simulated under steady state conditions. That is, the mass

flow rate of ammonia vapor generated in the generator is exactly the same as the flow rate of ammonia vapor being absorbed in the absorber.

2. The system pressure is constant within the whole device; the pressure drop in the pipes and vessels is negligible.

3. The heat losses from the generator to the surroundings and the heat gains to the evaporator from the surroundings are negligible. 


\section{2.1. Absorber}

In the absorber, the $\mathrm{NH}_{3}-\mathrm{NaSCN}$ solution circulates through a heat exchanger cooled by water flowing inside and is sprayed in a vertical tank. It absorbs the ammonia vapor coming from the evaporator continuously. Then it is collected at the bottom of the absorber, some of this solution is circulated and sprayed from the top of the absorber tank, the rest is transferred to the generator. To release the heat, a compact "multi-plate type" heat exchanger is used. In order to reach optimum heat transfer rate, the $\mathrm{NH}_{3}-\mathrm{NaSCN}$ solution and cooling water are in counter flow type, the heat of absorption is released from the solution to the cooling water at the interface of the plate wall. The absorber model started with the following assumptions:

1. The liquid is Newtonian and has constant physical properties. The values of the properties are based on the liquid entry conditions.

2. Momentum effects and shear stress at the interface are negligible.

3. The liquid is a binary mixture and only ammonia and hydrogen are present in the vapor phase.

4. There is no heat transfer from the liquid to the vapor phase and no heat transfer because of radiation, viscous dissipation, pressure gradients, concentration gradients or chemical reactions.

Under the above assumptions, the equations of mass and energy conservation are determined to describe the heat and mass transfer in the absorber. They are given in final forms as follows:

Mass conservation equation: 


$$
\begin{aligned}
& \dot{m}_{3}+\dot{m}_{8}=\dot{m}_{4} \quad \text { (Total mass balance) } \\
& \dot{m}_{3}+\dot{m}_{8} X_{8}=\dot{m}_{4} X_{4} \quad \text { (Ammonia mass balance) }
\end{aligned}
$$

Where $\dot{m}_{3}$ is the mass flow rate of the ammonia vapor coming from the evaporator, $\dot{m}_{8}$ is the mass flow rate of strong $\mathrm{NH}_{3}-\mathrm{NaSCN}$ solution coming from generator, and $\dot{m}_{4}$ is the mass flow rate of weak solution after absorbing process, $X_{8}$ is the ammonia mass fraction in strong solution, and for the same, $X_{4}$ is the ammonia mass fraction in weak solution at the outlet of the absorber.

Energy conservation equation:

$$
Q_{a}=\dot{m}_{3} h_{3}+\dot{m}_{8} h_{8}-\dot{m}_{4} h_{4}
$$

Where $h_{3}$ is the specific enthalpy of saturated vapor ammonia, $h_{8}$ is the liquid enthalpy of strong solution, $h_{4}$ is the liquid enthalpy of weak solution at the outlet of the absorber, and $Q_{a}$ is the released energy in absorbing process, which is totally absorbed by the cooling water, for simplification purpose, we assumed the overall heat transfer coefficient $U_{a}$ as a constant. Because the heat exchanger area is constant, $Q_{a}$ can be determined as follows,

$$
Q_{a}=K_{a}\left(T_{\text {hoa }}-T_{\text {cia }}\right)
$$

Where

$$
K_{a}=U_{a} A_{\text {exa }}
$$

$T_{h o a}$ is the weak solution output temperature, $T_{\text {cia }}$ is the cooling water input temperature, and $A_{\text {exa }}$ is the absorber heat exchange area. The temperature difference used in this equation means the flow pattern of this heat exchanger is counter flow. From the above equations, we can clearly define the thermodynamic 
states for every input and output condition of the absorber.

\section{2.2. Solution heat exchanger}

The solution heat exchanger is used between the generator and absorber to improve system performance. Low temperature is favorable to absorption process and high temperature is favorable to generator process. And it is obvious that the temperature of strong solution at the liquid outlet of the generator is higher than the temperature of weak solution at the outlet of the absorber, so heat can be transferred from strong solution to weak solution to improve the system performance without adding external energy. For this reason, a solution heat exchanger is used.

The DMSR refrigeration system uses the same kind of heat exchangers in different locations. The solution heat exchanger is a "multi-plate type" heat exchanger, the same as the absorber cooling device. For simplification, we assume the effectiveness of the solution heat exchanger is $80 \%$, it means, the temperature difference between the inlet and outlet temperature of the strong solution divided the temperature difference between inlet temperature of the strong solution and inlet temperature of the weak solution is $\mathbf{8 0 \%}$. The relationship of temperatures is given as:

$$
T_{8}=E_{e x} T_{5}+\left(1-E_{e x}\right) T_{7}
$$

In this equation, $T_{7}$ and $T_{8}$ is the inlet and outlet temperature of the strong solution, $T_{5}$ is the inlet temperature of weak solution, and $E_{e x}$ is the effectiveness of the solution heat exchanger. Under this assumption, the equations of energy 
conservation are given as:

$$
\dot{m}_{6} h_{6}-\dot{m}_{5} h_{5}=\dot{m}_{7} h_{7}-\dot{m}_{8} h_{8}
$$

Where $h_{7}$ and $h_{8}$ is the inlet and outlet enthalpy of the strong solution, and $h_{5}$ and $h_{6}$ is the inlet and outlet enthalpy of the weak solution. Because both the mass flow rate of the strong solution and the weak solution remain constant at the inlet and outlet of solution heat exchanger, it means:

$$
\dot{m}_{5}=\dot{m}_{6}
$$

And

$$
\dot{m}_{7}=\dot{m}_{8}
$$

Equation 3.49 can be written as:

$$
h_{6}=h_{5}+\frac{\dot{m}_{7}}{\dot{m}_{6}}\left(h_{7}-h_{8}\right)
$$

Thus we can solve for the thermodynamic state of weak solution at the inlet of generator, such as the temperature, enthalpy and mass flow rate.

\section{2.3. Generator}

Generator is the centre piece of the DMSR absorption system, in this part, external heat with temperature ranging from $80^{\circ} \mathrm{C}$ to $120^{\circ} \mathrm{C}$ is used as system driven source. Because the internal energy increases, superheated vapor ammonia is released from weak $\mathrm{NH}_{3}-\mathrm{NaSCN}$ solution, at the same time, with the decrease of the ammonia content, the solution changes to high temperature strong solution and is fed back to absorber. The relationship among superheated vapor ammonia, high temperature strong $\mathrm{NH}_{3}-\mathrm{NaSCN}$ solution, low temperature weak solution and the external heat 
input should be determined.

The same as in other system components, the mass and energy conservation can be determined in the generator. We assumed the system is under steady state condition and energy is transferred only between the generator and an external heat source, such as an electrical heater. No heat gain or loss to the environment. Under these assumptions, the mass and energy balances yield:

Mass conservation equation:

$$
\begin{array}{ll}
\dot{m}_{1}+\dot{m}_{7}=\dot{m}_{6} \quad \text { (Total mass balance) } \\
\dot{m}_{1}+\dot{m}_{7} X_{7}=\dot{m}_{6} X_{6} \quad \text { (Ammonia mass balance) }
\end{array}
$$

Energy conservation equation:

$$
Q_{g}=\dot{m}_{1} h_{1}+\dot{m}_{7} h_{7}-\dot{m}_{6} h_{6}
$$

Where $\dot{m}_{1}$ is the mass flow rate of the superheated vapor ammonia, $h_{1}$ is the specific enthalpy of superheated vapor ammonia, $X_{7}$ is the ammonia mass fraction in strong solution, and $X_{6}$ is the ammonia mass fraction in weak solution at the inlet of the generator. $h_{6}$ is the liquid enthalpy of weak solution, and $Q_{g}$ is the external energy input in generating process, which is totally absorbed by the circulating solution, for the same reason as the absorber, we assumed the overall heat transfer coefficient $\mathrm{U}_{\mathrm{g}}$ as a constant. Because the heat exchanger area is constant, $Q_{g}$ can be determined as follow,

$$
Q_{g}=K_{g}\left(T_{h o g}-T_{c i g}\right)
$$

Where

$$
K_{g}=U_{g} A_{\text {exg }}
$$


$T_{\text {hog }}$ is the external heat source output temperature, $T_{\text {cig }}$ is the weak solution input temperature, and $A_{\text {exg }}$ is the generator heat exchange area. In order to reach the best heat exchanger effectiveness, just like the absorber heat exchanger, the flow pattern of generator heat exchanger is counter-flow. From the above equations, we can clearly define the thermodynamic states for every input and output of the absorber.

From equations 3.53 and 3.54 , the flow rates of the strong and weak solutions can be determined:

$$
\begin{aligned}
& \dot{m}_{7}=\frac{1-X_{6}}{X_{6}-X_{7}} \dot{m}_{1} \\
& \dot{m}_{6}=\frac{1-X_{7}}{X_{6}-X_{7}} \dot{m}_{1}
\end{aligned}
$$

From equation 3.59 , the circulation ratio of the system can be derived as

$$
f=\frac{\dot{m}_{6}}{\dot{m}_{1}}
$$

\section{2.4. Condenser}

The function of condenser is the same as condenser in common mechanical vapour compression systems, superheated vapour ammonia is cooled down to the saturated vapour first, and then condenses into liquid phase. In order to simplify the simulation process, we assume the system in its optimum state. It means the output liquid ammonia from the condenser is in saturated state. So the thermodynamic states for the condenser input and output can be determined as follow: 
Mass conservation equation:

$$
\dot{m}_{1}=\dot{m}_{2} \quad \text { (Ammonia mass balance) }
$$

Energy conservation equation:

$$
Q_{c}=\dot{m}_{1} h_{1}-\dot{m}_{2} h_{2}
$$

Where $\dot{m}_{2}$ is the mass flow rate of saturated liquid ammonia, $h_{2}$ is the specific enthalpy of saturated liquid ammonia, and $Q_{c}$ is the released energy in condensing process, which is totally absorbed by the cooling water, and we ignored the effect of phase change and assumed the overall heat transfer coefficient $U_{c}$ as a constant. Because the heat exchanger area is constant, $Q_{c}$ can be determined as follow,

$$
Q_{c}=K_{c}\left(T_{h o c}-T_{c i c}\right)
$$

Where

$$
K_{c}=U_{c} A_{e x c}
$$

$T_{\text {hoc }}$ is the saturated liquid ammonia output temperature, $T_{c i c}$ is the cooling water input temperature, and $A_{e x c}$ is the condenser heat exchange area. In order to reach the best heat exchanger effectiveness, just like the absorber heat exchanger, the flow pattern of condenser heat exchanger is counter flow.

\section{2.5. Evaporator}

The evaporator is the place where liquid ammonia changes its phase to vapor ammonia. Because the specific enthalpy of vapor ammonia is greatly higher than that of liquid ammonia, as a result, external energy should be supplied in this process, this 
is the "working part" of an absorption system as chilled water or cool air is produced.

As a character of our system, the system pressure is always consistent, in order to reduce the partial pressure of ammonia in evaporator, hydrogen is filled into the system as an expansion gas. Based on Dalton's Law, The total pressure in a container is the sum of the partial pressures of all the gases in the container, in our DMSR system,

$$
P_{s y s}=P_{\mathrm{NH}_{3}}+P_{\mathrm{H}_{2}}
$$

Where $\mathrm{P}_{\text {sys }}$ is the whole system pressure, which equal to the pressure in other parts; $P_{\mathrm{NH}_{3}}$ is the partial pressure of vapor ammonia in evaporator, and $P_{\mathrm{H}_{2}}$ is the partial pressure of expansion gas hydrogen, to simplify the simulation process, and based on the properties and charged quality of vapor hydrogen, we assumed that:

$$
P_{H_{2}}=3.032 T_{3}
$$

Where $T_{3}$ is the evaporator temperature. Under this assumption, for the evaporator, the mass and energy balances yield:

Mass conservation equation:

$$
\dot{m}_{2}=\dot{m}_{3} \quad \text { (Ammonia mass balance) }
$$

Energy conservation equation:

$$
Q_{e}=\dot{m}_{2} h_{2}-\dot{m}_{3} h_{3}
$$

From the above equations, the relationships of mass and energy for $\mathrm{NH}_{3}-\mathrm{NaSCN}$ solution and ammonia are developed, if the generator, condenser, absorber and evaporator temperatures and the refrigerant mass flow rate or the required refrigerating load are given, combined with the thermodynamic properties of 
$\mathrm{NH}_{3}-\mathrm{NaSCN}$ solution and liquid and vapor ammonia, the above equations can be solved simultaneously to give the system performance.

\subsection{DMSR system computational model}

The simulation of any absorption system means the representation of the actual behavior of the system mathematically. This process was done by developing mathematical models for each component making up the absorption refrigeration system. These components are an absorber, a generator, a solution heat exchanger, a condenser and an evaporator. These models are then combined and solved to give the required information about the temperature, concentration and flow rate at each state point of the system and the heat transfer at each component as well as the performance of the system. For the state points shown in Fig. 3.6, the flowchart of our computational simulation program is shown in Fig. 3.7. 


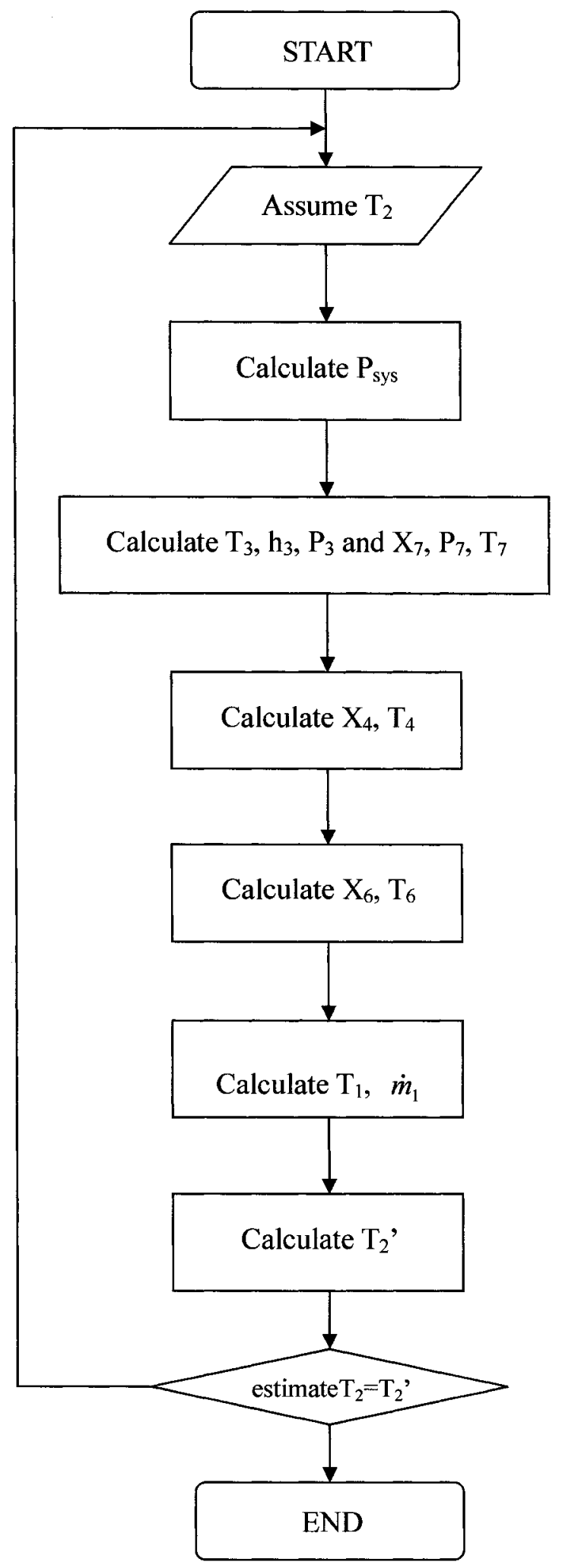

Figure 3.7 The flowchart of computational simulation program 
The purpose of present study is to analyze the characteristics of the DMSR absorption refrigeration system, which include the thermodynamic properties of $\mathrm{NH}_{3}-\mathrm{NaSCN}$ solution and liquid or vapor ammonia, the influence of the expansion gas hydrogen, and the influence of each components making up the refrigeration system, and then try to find a way to optimize the system performance. So the computational simulation for each component is just as important as the simulation of the whole system.

In the present work, firstly, a simulation program is built to simulate the effect of each component in various operating conditions on the performance of the absorption refrigeration system. It means, by changing one component's condition and keeping other system parameters constant, the changes of system performance, circulation ratio and cooling capacity are analyzed; and then, in the second simulation program, these components are combined to the whole system, and the whole system performance was studied at different operating conditions.

In the first program, in order to compare the effect of different components, the component condition, such as temperature, was changed directly, which is impossible in real operating conditions but very useful in system optimizing process. And for the purpose of understanding and analyzing the real working situation, the second program was built to simulate the whole system based on the input conditions of the components.

As a reference point for evaluation of the effect of different parameters, a design condition is selected which corresponds to the design point for the system. For the 
first program, the design condition is described in Table 3.2. And for the second program, the whole system program, the design condition is described in Table 3.3. The table lists the following input parameters:

1. Heat transfer coefficient of the heat source (external heat source) and its inlet temperature, heat transfer coefficients of the cooling water and their inlet temperatures for condenser and absorber and heat transfer coefficient of the antifreeze and its inlet temperature.

2. Mass flow rate of weak solution leaving the solution pump from the absorber and the effectiveness of the solution heat exchanger.

Next, the following calculated quantities are shown in Table 3.4:

1. The temperature, mass flow rate and concentration at all the state points corresponding to Fig. 3.6. The concentration is the ammonia concentration, percent by weight, in the solution.

2. The heat transfered in the evaporator, condenser, absorber and generator.

3. The COP.

After the design point was selected, similar calculations were made for other selected sets of operating conditions. The performance characteristics of the individual components of the system are discussed over a wide range of operating conditions, and then, the performance of the entire system is discussed. 
Table 3.2 The design condition for the single components simulation program

\begin{tabular}{lcc}
\hline \multicolumn{1}{c}{ Unit } & Description & Value \\
\hline $\begin{array}{l}\text { Input parameters } \\
\text { Absorber }\end{array}$ & Temperature & $15^{\circ} \mathrm{C}$ \\
Condenser & Temperature & $15^{\circ} \mathrm{C}$ \\
Generator & Temperature & $85^{\circ} \mathrm{C}$ \\
Evaporator & Outlet chilled liquid temperature & $-20^{\circ} \mathrm{C}$ \\
$\begin{array}{l}\text { Solution pump } \\
\text { Solution heat } \\
\text { exchanger }\end{array}$ & Mass flow rate of the weak solution & $0.03 \mathrm{~kg} / \mathrm{s}$ \\
\hline
\end{tabular}

Table 3.3 The design condition for the whole system simulation program

\begin{tabular}{lcc}
\hline \multicolumn{1}{c}{ Unit } & \multicolumn{1}{c}{ Description } & Value \\
\hline $\begin{array}{l}\text { Input parameters } \\
\text { Absorber }\end{array}$ & Heat transfer coefficient & $3 \mathrm{~kW} /{ }^{\circ} \mathrm{C}$ \\
& Inlet cooling water temperature & $15^{\circ} \mathrm{C}$ \\
Condenser & Heat transfer coefficient & $3 \mathrm{~kW} /{ }^{\circ} \mathrm{C}$ \\
& Inlet cooling water temperature & $15^{\circ} \mathrm{C}$ \\
& Heat transfer coefficient & $3 \mathrm{~kW} /{ }^{\circ} \mathrm{C}$ \\
Generator & Inlet heat source temperature & $95^{\circ} \mathrm{C}$ \\
& Mass flow rate of the weak solution & $0.03 \mathrm{~kg} / \mathrm{s}$ \\
Solution pump & Effectiveness of the heat exchanger & $80 \%$ \\
$\begin{array}{l}\text { Solution heat } \\
\text { exchanger }\end{array}$ & Outlet chilled liquid temperature & $-10^{\circ} \mathrm{C}$ \\
\hline \begin{tabular}{l} 
Evaporator \\
\hline
\end{tabular} & &
\end{tabular}




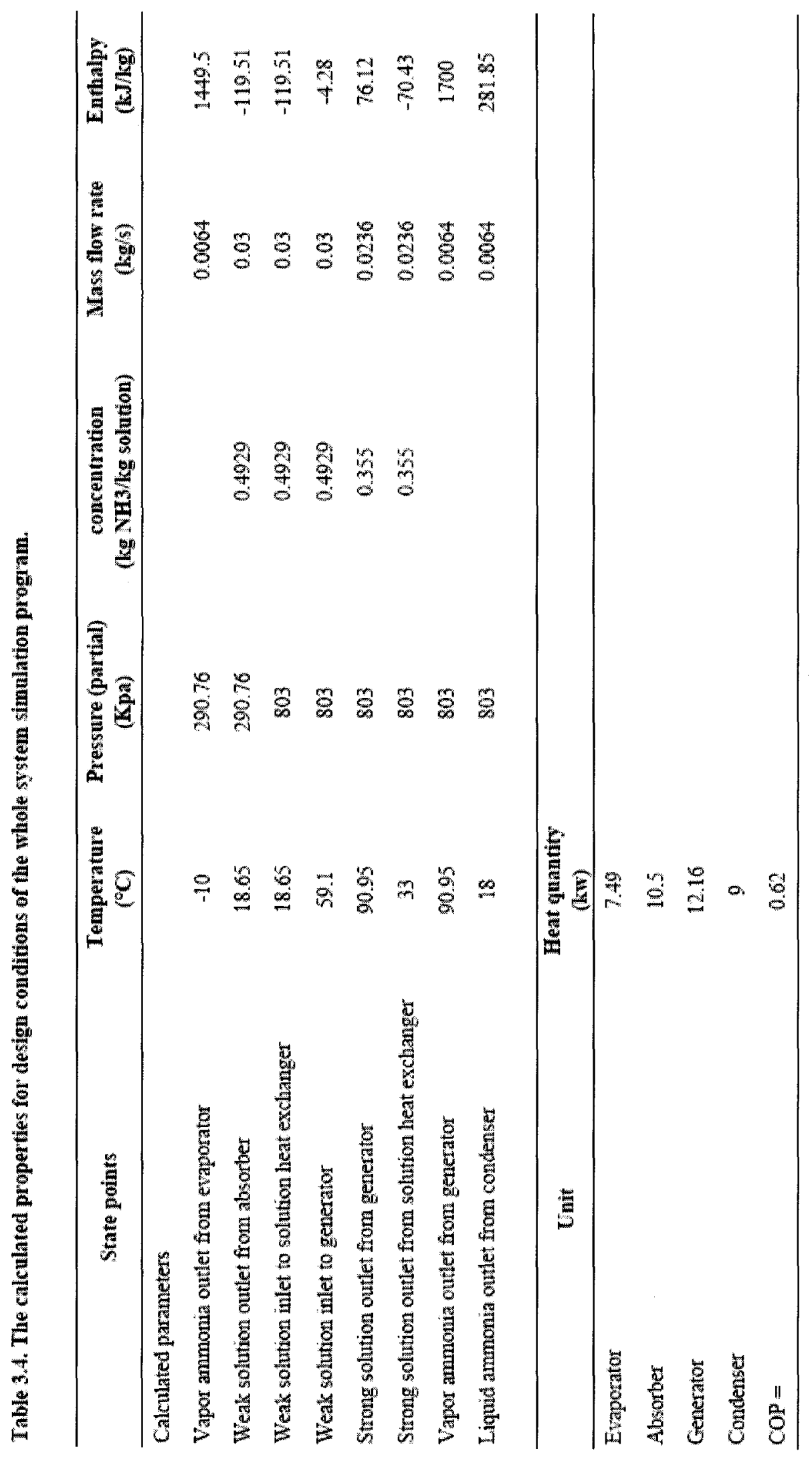

91 


\subsection{Result and discussion}

From the computational simulation programs described above, results were collected and organized. Discussion of the results is provided below in the following topics.

\section{4.1. Individual component performance}

For the purpose of improving the system performance, except the thermodynamic properties of the solution, the characteristics of each component is the most important part and was simulated separately in our program. The computer program was shown in Appendix I.

As described above, the system components include a generator, a condenser, an evaporator, an absorber and a solution heat exchanger. The effect of different component on the system performance was simulated and the results were discussed in the following part. It means, one of the components' value, such as the generator temperature or solution exchanger efficiency changes while keeping the other variables constant. The following processes are simulated separately:

1. Change the generator temperature while keeping other components value constant. Compare the changes of system COP, heating load from the energy input equipment, cooling capacity output from the evaporator, and the system circulation ration which is defined as the mass flow rate of weak solution at the inlet of generator divided by the mass flow rate of ammonia separated 
from the desorption process.

2. Change the condenser temperature while keeping other components values constant. Compare the changes of system COP, heating load from the energy input equipment, cooling capacity output from the evaporator, and the system circulation ration.

3. Change the evaporator temperature while keeping other components values constant. Compare the changes of system COP, heating load from the energy input equipment, cooling capacity output from the evaporator, and the system circulation ration.

4. Change the absorber temperature while keeping other components values constant. Compare the changes of system COP, heating load from the energy input equipment, cooling capacity output from the evaporator, and the system circulation ration.

5. Change the solution heat exchanger effectiveness while keeping other components values constant. Compare the changes of system COP, heating load from the energy input equipment, and the heat rejected from the absorber.

\subsubsection{Influence of generator temperature}

Figure 3.8 shows the comparison of $\mathrm{COP}$ values vs. generator temperature for DMSR system. For the system optimizing purpose, the system is supposed to operate 
at constant condenser, absorber and evaporator temperature condition. Based on the "design point" described before, the condenser, absorber and evaporator temperature were chosen as $T_{c}=15^{\circ} \mathrm{C}, T_{a}=15^{\circ} \mathrm{C}$, and $T_{e}=-20^{\circ} \mathrm{C}$, and the efficiency of solution heat exchanger is chosen as $\mathbf{8 0 \%}$.

Figure 3.8 shows that the system COP value increases with generator temperature. And there exists a low generator temperature limit for the system able to work. It means for our system at the selected operating condition, if the generator temperature is below $58^{\circ} \mathrm{C}$, the system COP will be close to zero, the system does not work at all. And from $58^{\circ} \mathrm{C}$ to $75^{\circ} \mathrm{C}$, the $\mathrm{COP}$ increase rapidly, after 80 generator temperature, the COP will increase in very slow pace. This is an important point for utilizing industry or civil waste heat and solar energy since fluid temperatures for a lot of this kind of heat source are generally about $90^{\circ} \mathrm{C}$.

Based on the discussion above, the DMSR system can be operated in the low generator temperature and high condenser and absorber temperature condition to reach a very low evaporator temperature with an acceptable system $\mathrm{COP}$, this is the main advantage of this new refrigeration system. 


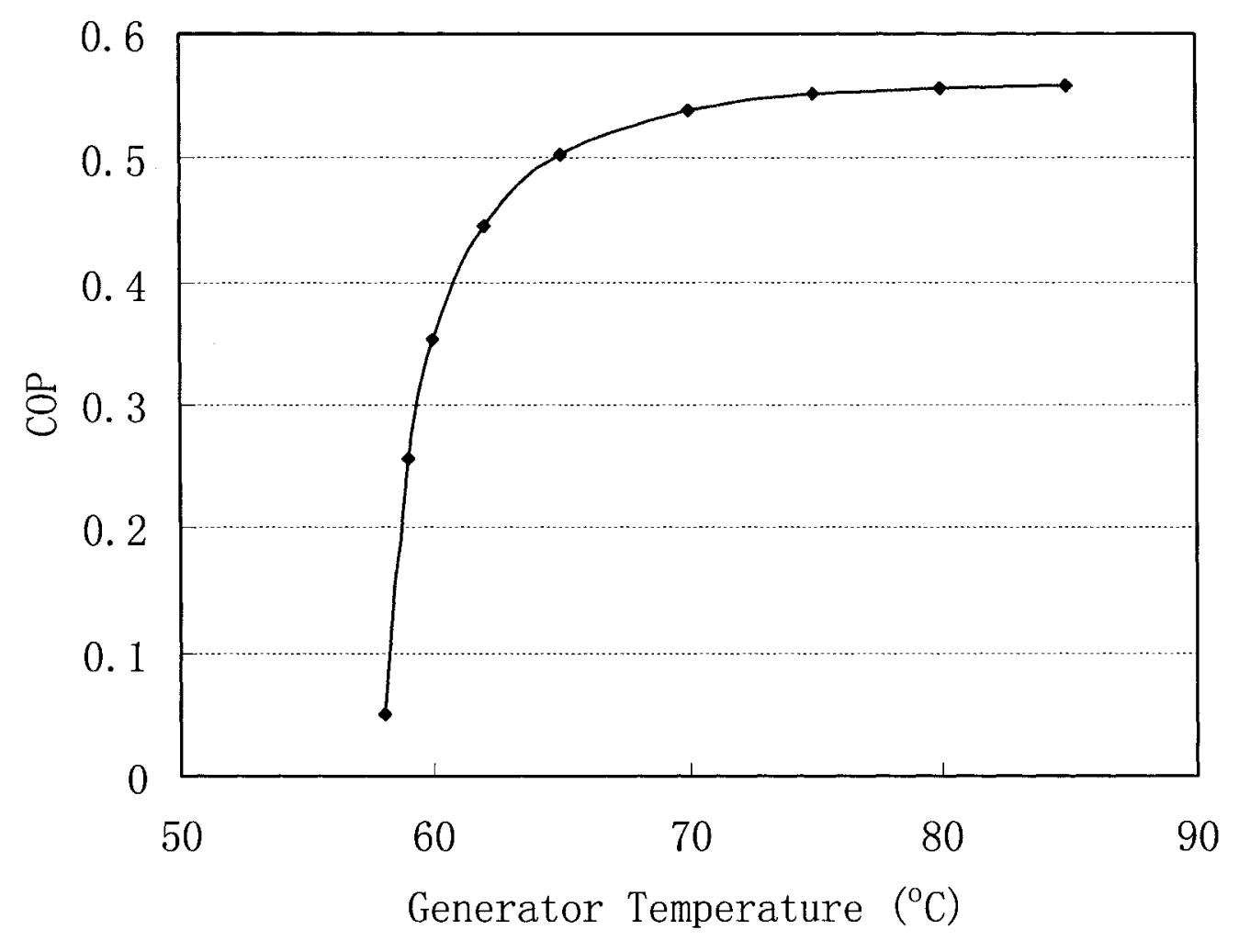

Figure 3.8 The effect of generator temperature on COP value

Figure 3.9 shows the corresponding comparison of system circulation ratio vs. generator temperature. As described above, circulation ratio is the mass flow rate of weak $\mathrm{NH}_{3}-\mathrm{NaSCN}$ solution input to the generator divided by the mass flow rate of vapor ammonia leave the generator. In the DMSR system, the mass flow rate of weak solution is only determined by the circulation pump and will not change in different operating conditions. It means that the lower the circulation ratio, the more vapor ammonia will release from the weak solution and the higher the concentration difference of the weak and strong solution.

Figure 3.9 shows that for the same refrigeration effect, the system circulation ratio will decrease if the generator temperature increases. Another characteristic also 
can be observed that, if the generator temperature approaches its low temperature limit, $58^{\circ} \mathrm{C}$ in this case, the circulation ratio should increase dramatically. Therefore, it is highly impractical to operate a cycle at a generator temperature too low, although it is still operable theoretically as shown in Figures 3.8 and 3.9.

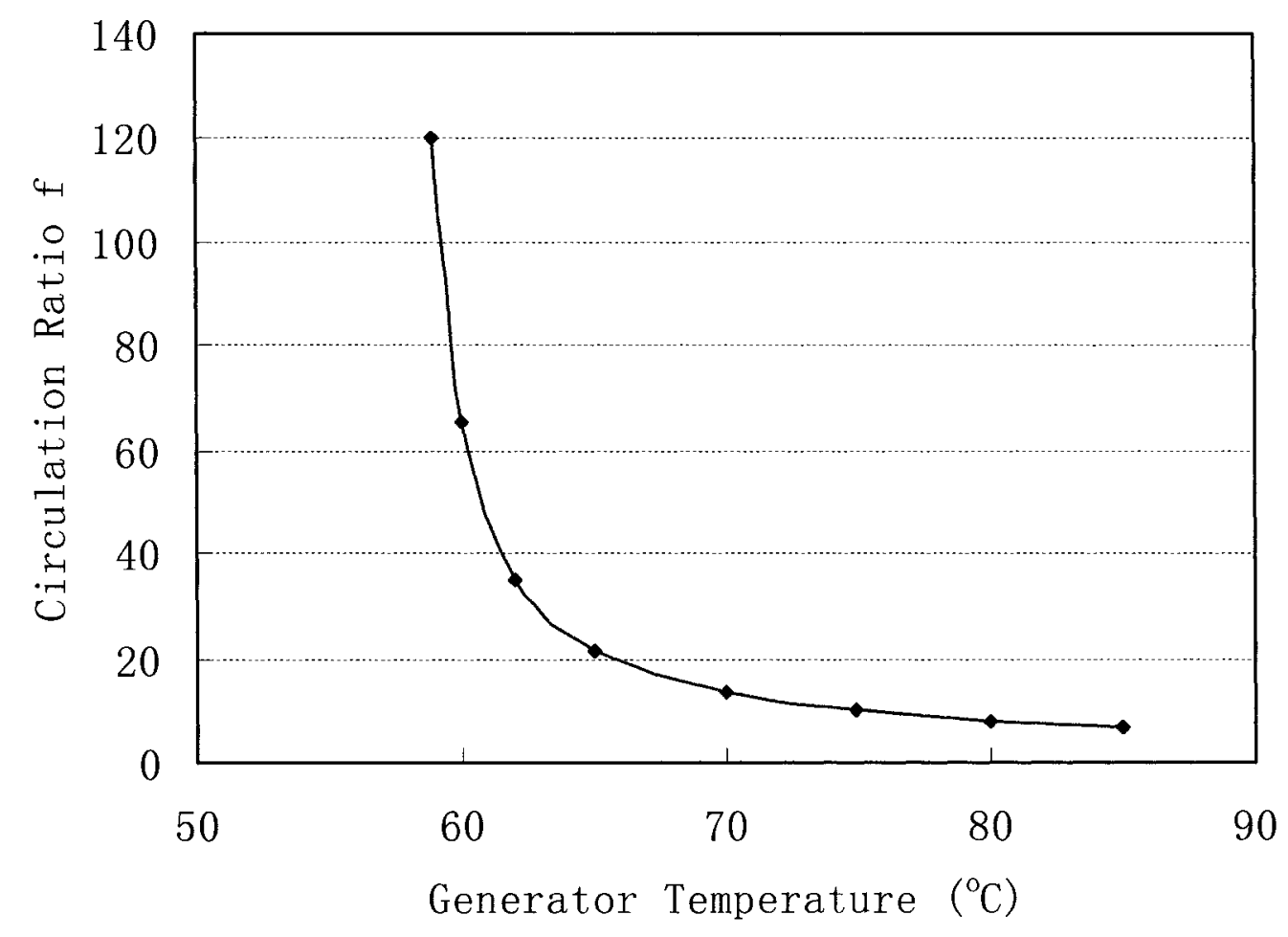

Figure 3.9 The relation between generator temperature and circulation ratio

Figure 3.10 shows the variation of system cooling capacity as a function of the generator temperature at the design operating conditions for the evaporator temperature keeping at $-20^{\circ} \mathrm{C}$ and the absorber and condenser temperature constantly maintaining at $15^{\circ} \mathrm{C}$. The cooling capacity is higher value at higher generator temperature. At the low temperature limit, the cooling capacity is almost closed to zero. 


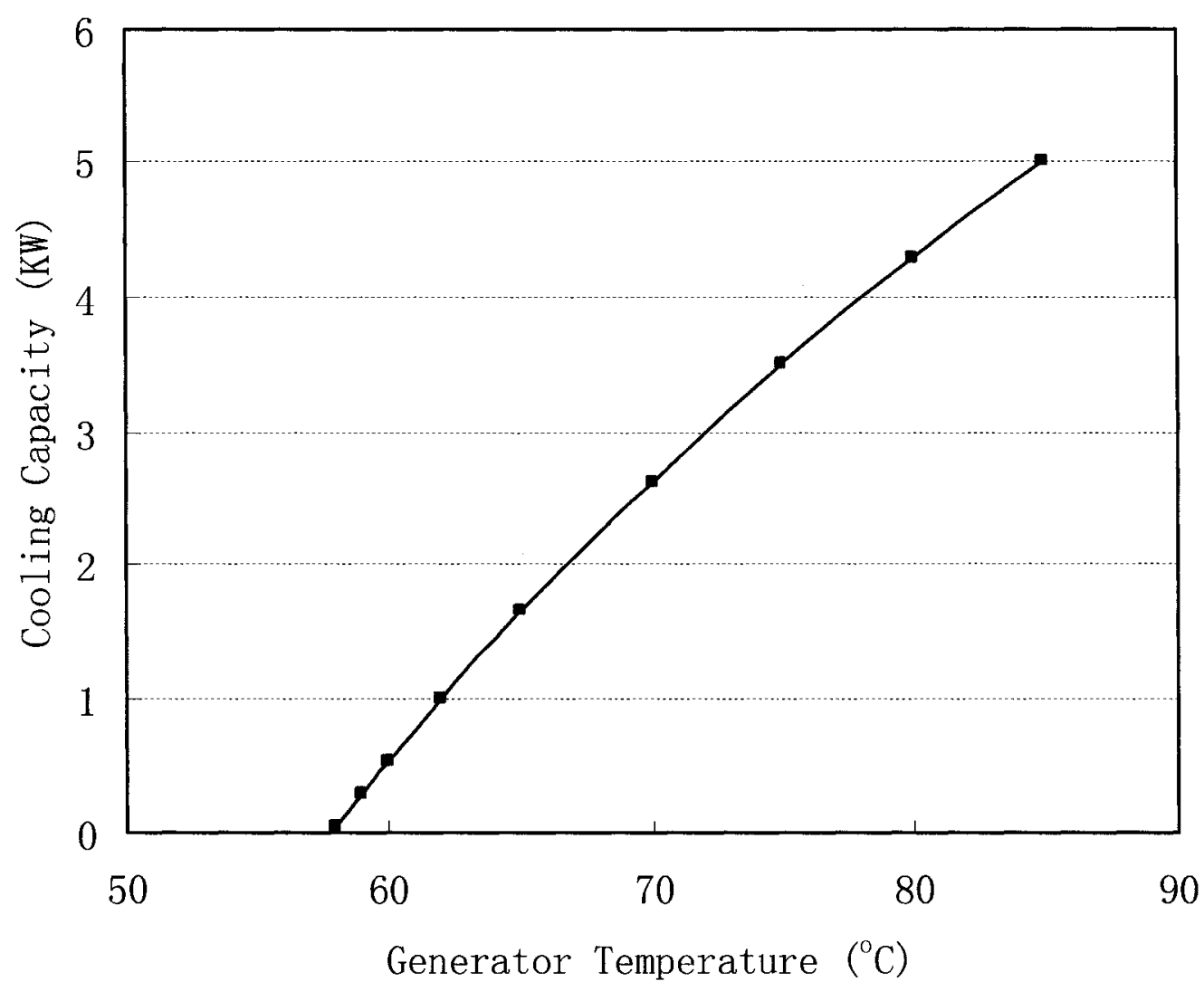

Figure 3.10 The relation between generator temperature and cooling capacity

It is easily understood that, just like the effect of cooling capacity on generator temperature, the heating load to generator should increase with the generator temperature increase. Figure 3.11 shows the variation of heating load to generator as a function of the generator temperature at the design operating conditions. As described above, because the weak solution temperature at the inlet to the generator is almost constant with the generator temperature increase, only output vapor ammonia and strong solution temperature increased. Based on the thermodynamic properties of vapor ammonia and $\mathrm{NH}_{3}-\mathrm{NaSCN}$ solution, the enthalpy of ammonia and solution will increase with the temperature increase. Especially for vapor ammonia, desorption 
from liquid solution will increase its enthalpy dramatically, thus more heat is absorbed from the heat supply equipment. And another result of the generator temperature increase is that, the solution concentration, especially strong solution concentration, will decrease simultaneously, and if the generator temperature is high enough, the crystallization problem should be detected.

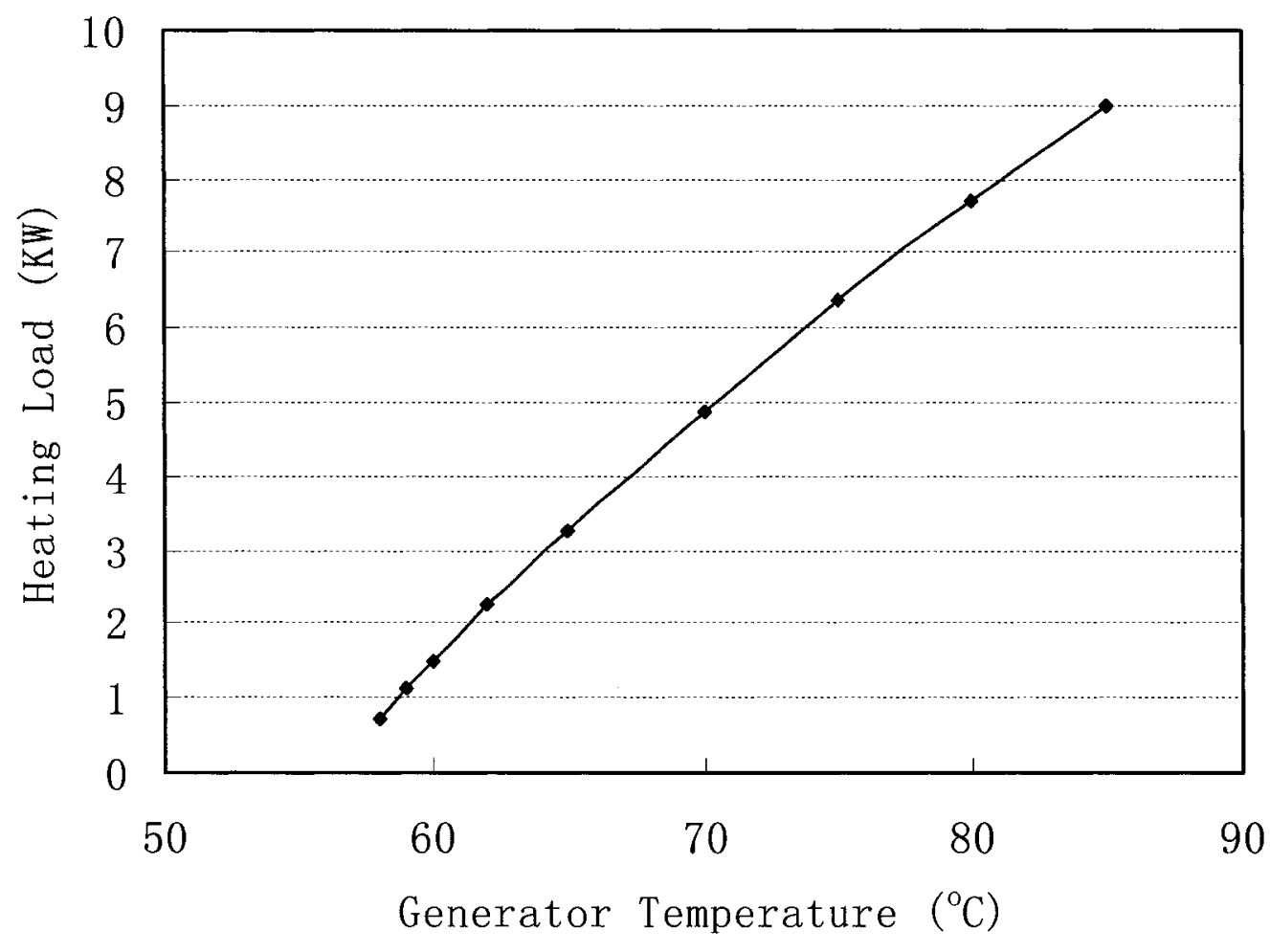

Figure 3.11 The relation between generator temperature and heating load

\subsubsection{Influence of condenser temperature}

Condenser is another important component in absorption refrigeration system, where superheated vapour ammonia from generator is cooled down to the saturated vapour, and then change to liquid phase, while large amount of heat is rejected to the 
cooling medium (water). Figure 3.12 shows the variation of system COP as a function of the condenser temperature. The system is assumed to operate at constant generator, absorber and evaporator temperature. Based on the "design point" described above, the generator, absorber and evaporator temperature are chosen as $T_{g}=85^{\circ} \mathrm{C}, T_{a}=15^{\circ} \mathrm{C}$, and $T_{e}=-20^{\circ} \mathrm{C}$, and the efficiency of solution heat exchanger is chosen as $80 \%$.

Figure 3.12 shows that the system COP decreases with the condenser temperature increase. It can be explained that, when the condenser temperature increase, less energy is rejected from the ammonia, and the enthalpy of liquid ammonia from condenser is higher than that of lower condenser temperature, even not all vapor ammonia can condense to liquid ammonia. When the ammonia absorbs energy and evaporates to low temperature vapor ammonia in the evaporator, with the same mass flow rate and evaporator temperature. Because the liquid ammonia has a higher enthalpy, based on the conversion of energy, less energy is absorbed. As a result, the system COP is lower than that of lower condenser temperature condition. And if the condenser temperature reaches the high temperature limit in this operating condition, the superheated vapor ammonia can not be cooled down to liquid phase, the enthalpy difference for the inlet and outlet ammonia of the evaporator is close to zero, the system COP will close to zero either, the system can not provide cooling in this condition. 


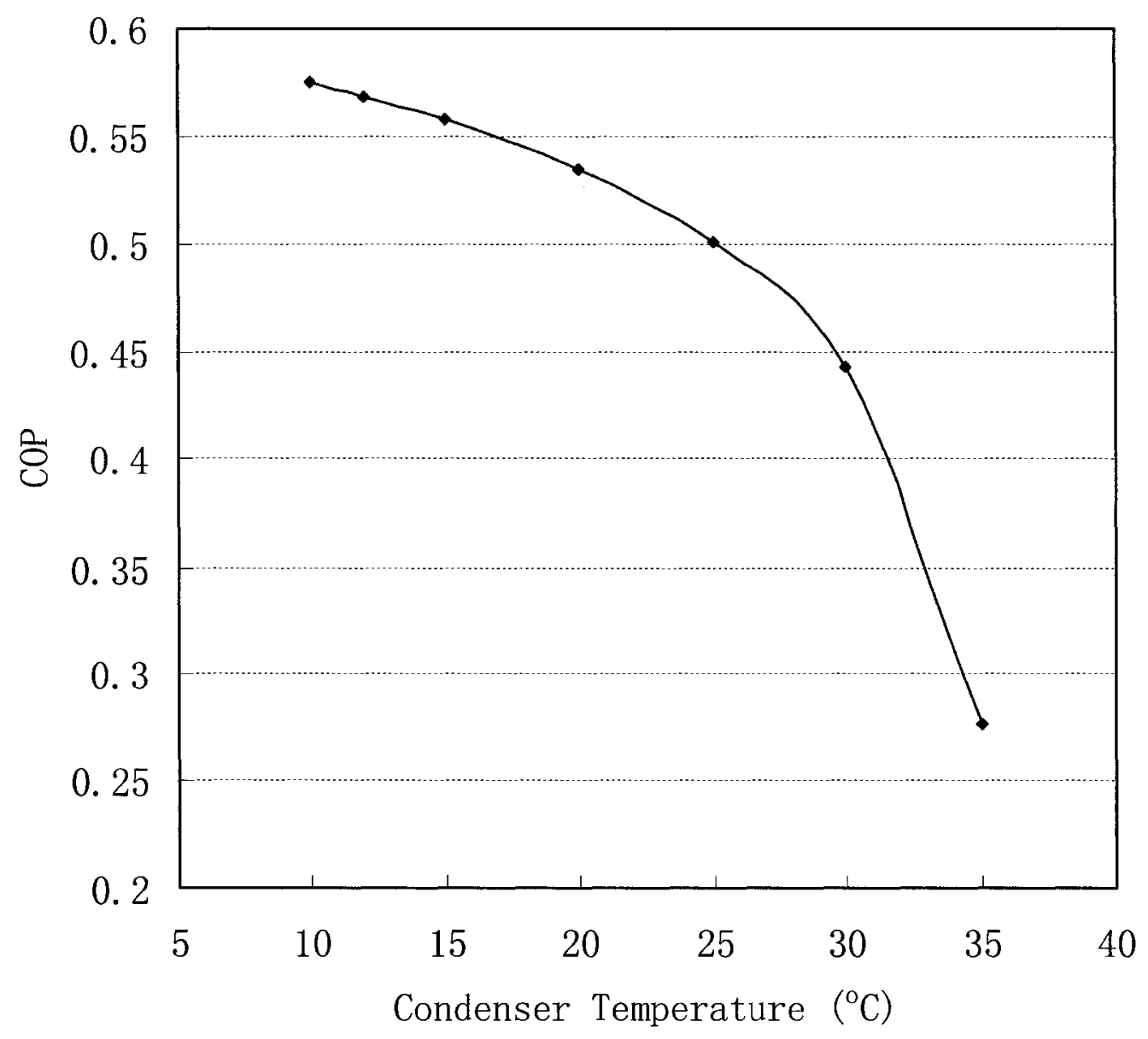

Figure 3.12 The relation between condenser temperature and COP

Figure 3.13 shows the relation between the condenser temperature and the circulation ratio. It can be observed that the circulation ratio increase with the condenser temperature increase, if the condenser temperature is higher than $30^{\circ} \mathrm{C}$, the circulation ratio would increase dramatically. On the other hand, because of the thermodynamic properties of solution, the circulation ratio for $\mathrm{NH}_{3}-\mathrm{NaSCN}$ absorption refrigeration system is higher than that for $\mathrm{NH}_{3}-\mathrm{H}_{2} \mathrm{O}$ or $\mathrm{NH}_{3}-\mathrm{LiNO}_{3}$ system, at the same operation condition. This means that either the solution pump needs to run faster or a bigger pump is required for the $\mathrm{NH}_{3}-\mathrm{NaSCN}$ absorption refrigeration system [9]. 


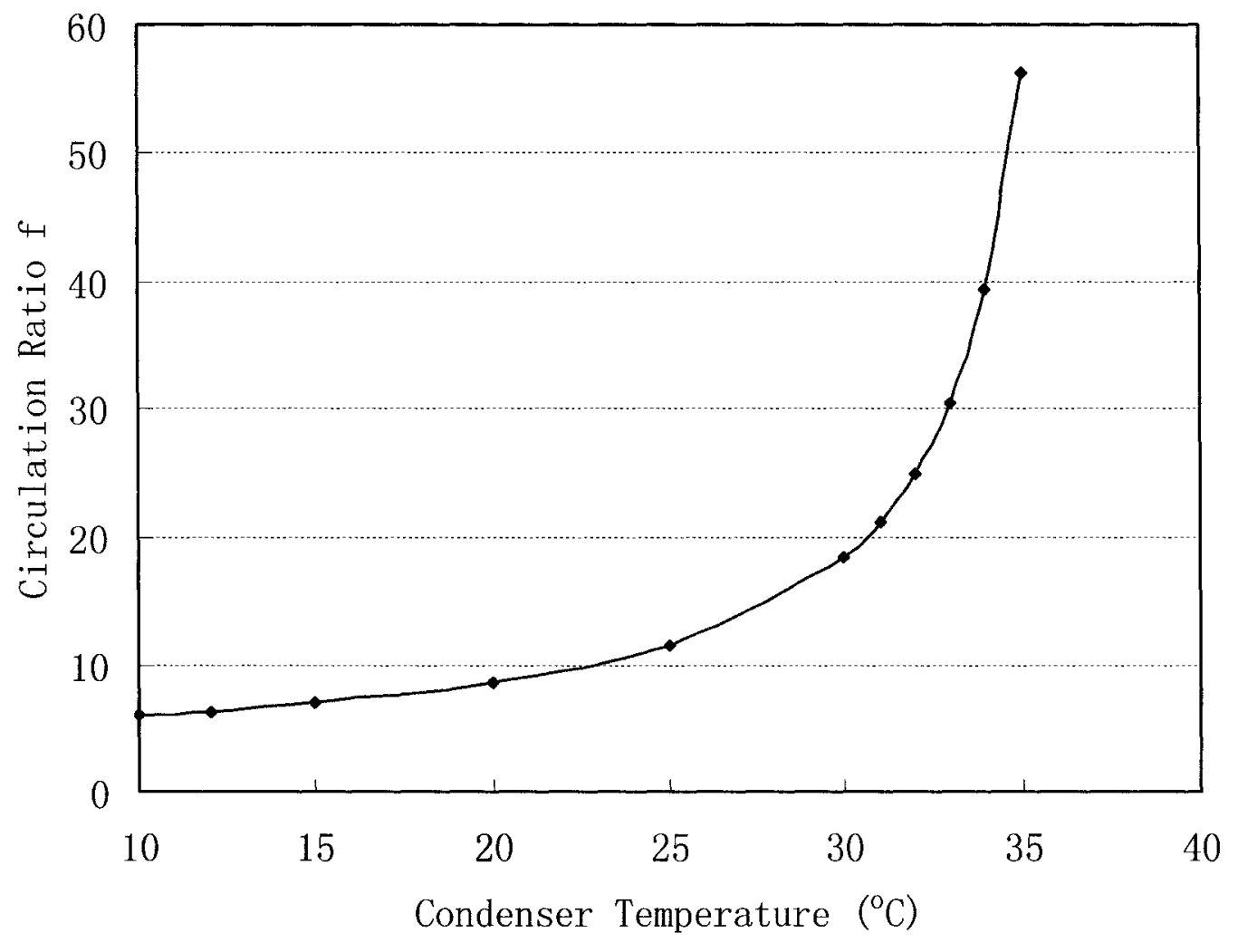

Figure 3.13 The relation between condenser temperature and circulation ratio

Figure 3.14 shows the variation of cooling capacity as a function of the condenser temperature. The cooling capacity decreases with condenser temperature increase. At the condenser temperature $10^{\circ} \mathrm{C}$, the cooling capacity is almost $6 \mathrm{~kW}$, and when the condenser temperature increases to $35^{\circ} \mathrm{C}$, the cooling capacity decrease to less than $1 \mathrm{~kW}$. If the condenser temperature increase to the high temperature limit for the operation conditions, the system cooling capacity will close to zero. For this reason, if high cooling capacity is needed, low cooling water temperature should be applied to the condenser; if the system is used as the heat pump, it means high cooling water outlet temperature is needed, the system COP might be lower. 


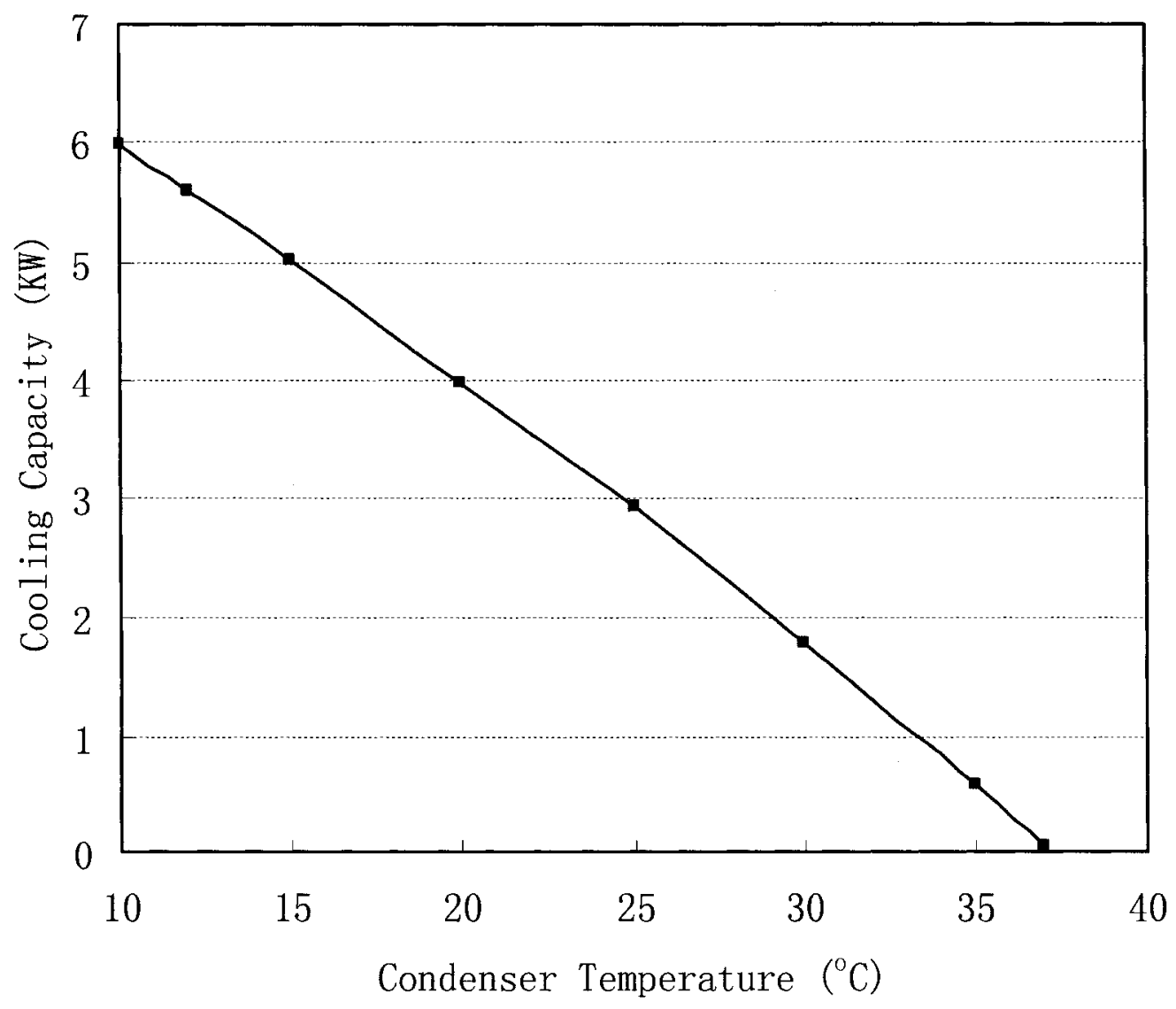

Figure 3.14 The relation between condenser temperature and cooling capacity

The effect of condenser temperature on heating load are shown in Figure 3.15, it can be observed that the heating load to generator decrease with the condenser temperature increase. When the condenser temperature increases from $10^{\circ} \mathrm{C}$ to $35^{\circ} \mathrm{C}$, the heating load decreases from a value above $10 \mathrm{~kW}$ to about $2 \mathrm{~kW}$. Just like the system cooling capacity, if the condenser temperature reaches the high temperature limit, the heating load will close to zero. In order to increase heating load (or to increase system COP) in high condenser temperature operating condition, other components conditions should be changed, for example, to increase the generator 
temperature.

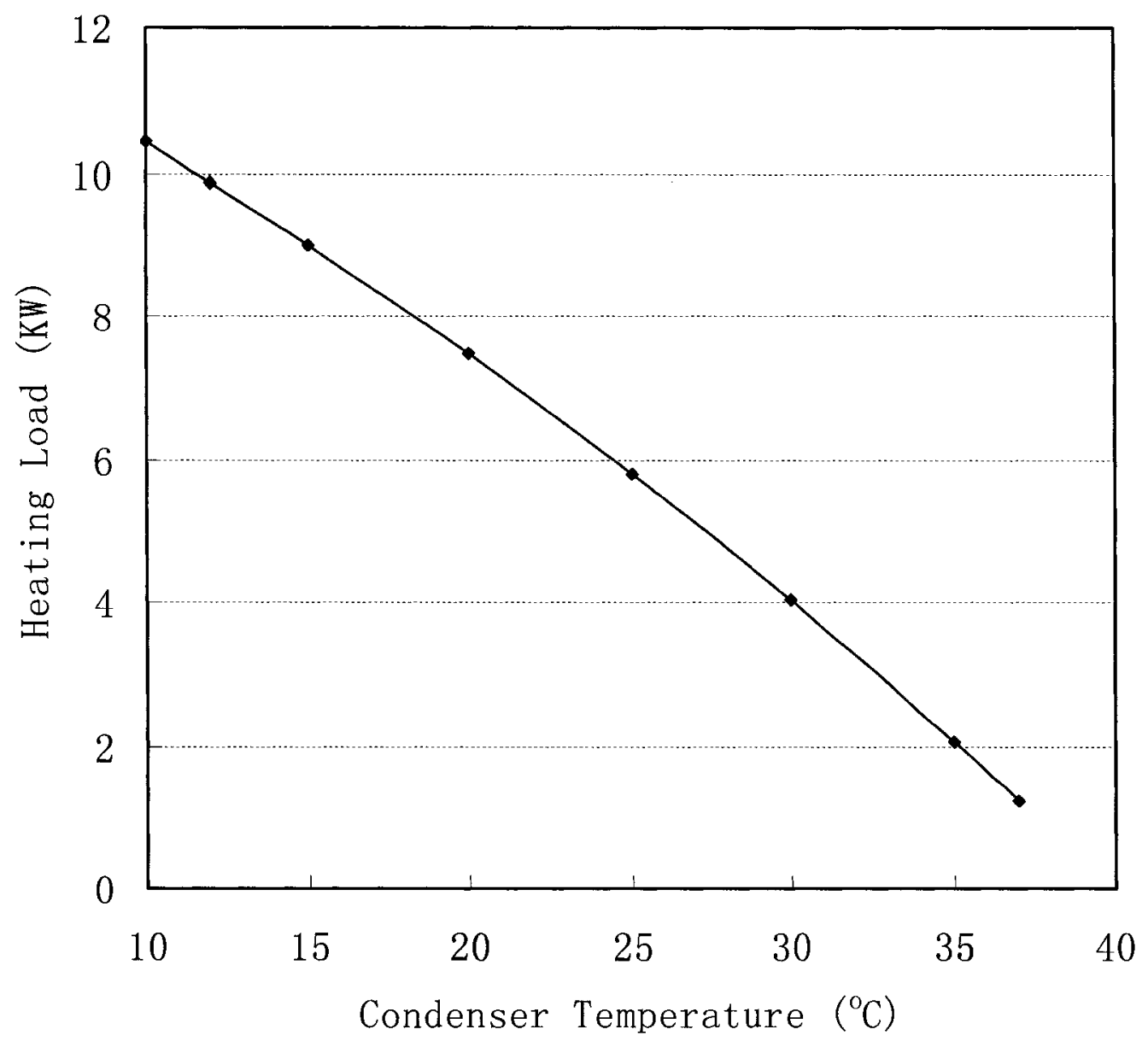

Figure 3.15 The relation between condenser temperature and heating load

\subsubsection{Influence of evaporator temperature}

Evaporator is the component where the refrigeration system exchanges energy with outside environment. High partial pressure liquid ammonia from condenser changes to low partial pressure vapor ammonia, resulting to dramatically decrease in temperature. Based on the principle of evaporator described above, the evaporator temperature can be changed by changing the ammonia partial pressure. In original 
absorption refrigeration system, the expansion valve was used to control the ammonia vapor pressure in evaporator, but in the $\mathrm{NH}_{3}-\mathrm{H}_{2}-\mathrm{NaSCN}$ DMSR system, hydrogen gas is charged to replace the expansion valve. The evaporator temperature can be changed by change the partial pressure of hydrogen. Based on Dalton's Law, if the total pressure is constant, a higher hydrogen partial pressure yields a lower partial pressure of vapor ammonia and lower evaporator temperature. However, the total system pressure should be remained at certain level related to condenser and generator pressure where hydrogen partial pressure should be zero.

For simulation purpose, the system is supposed to operate at constant generator, condenser, and absorber temperature, based on the "design point" described above, the generator, condenser and absorber temperature were chosen as $T_{g}=85^{\circ} \mathrm{C}, T_{c}=15^{\circ} \mathrm{C}$, and $T_{a}=15^{\circ} \mathrm{C}$, and the efficiency of solution heat exchanger is chosen as $80 \%$.

Figure 3.16 shows the variation of system $\mathrm{COP}$ as a function of the evaporator temperature. Based on the simulation result, the system COP will increase with the evaporator temperature increase. If the evaporator temperature below $-30^{\circ} \mathrm{C}$, the system COP will reduce to a value below 0.45 , which means the system need a bigger circulation pump or a higher generator temperature to reach the same cooling capacity compared with the operating condition in which the evaporator temperature is above $-10^{\circ} \mathrm{C}$.

Figure 3.17 shows the relationship between the system circulation ratio and the evaporator temperature. It can be observed that if the circulation ratio decreases, the evaporator temperature will increase. If the evaporator temperature decreases down to 
$-30^{\circ} \mathrm{C}$, the circulation ratio will increase dramatically. It means when evaporator temperature is below $-30^{\circ} \mathrm{C}$, limited vapor ammonia will released from the working solution, as a result, the heating release from the condenser and the absorber, the system cooling capacity, the heating load from the generator, and the concentration difference of the weak and strong solution will decrease to an extremely low level. As shown in Figure 3.18 and Figure 3.19, the system cooling capacity and heating load decrease with the evaporator temperature decrease, if the evaporator temperature below $-30^{\circ} \mathrm{C}$, the cooling capacity will less than $2 \mathrm{~kW}$, at the same time, the heating load will less than $5 \mathrm{~kW}$, compared with over $12 \mathrm{~kW}$ cooling capacity and almost 20 $\mathrm{kW}$ heating load when evaporator temperature is $0^{\circ} \mathrm{C}$. The super-low evaporator temperature working condition is unpractical.

Although the low evaporator temperature working condition is very difficult to operate for the DMSR system, because of the low COP and cooling capacity, it still has some advantages over other working solutions, such as $\mathrm{NH}_{3}-\mathrm{H}_{2} \mathrm{O}$ and $\mathrm{NH}_{3}-\mathrm{LiNO}_{3}$. 


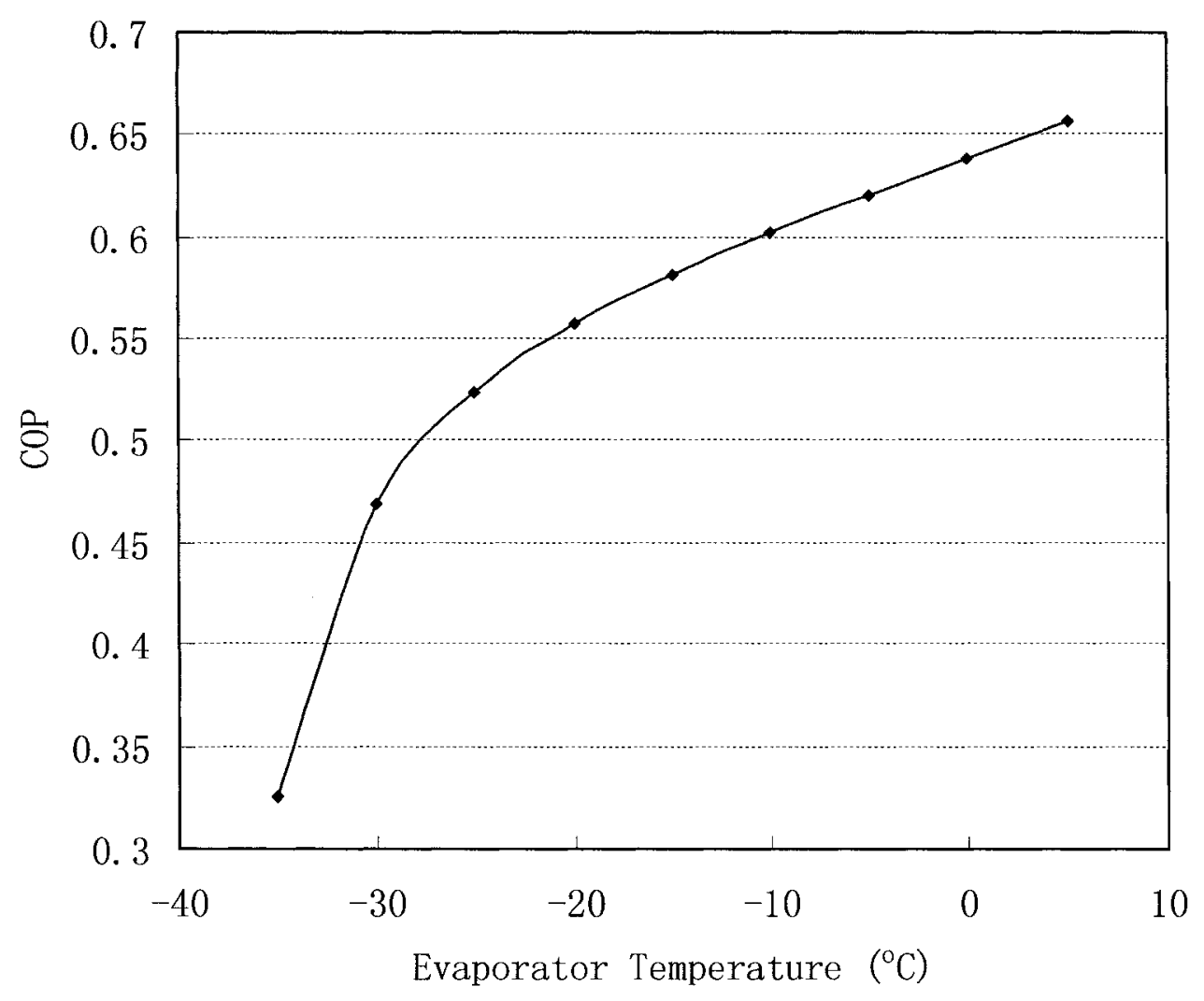

Figure 3.16 The relation between evaporator temperature and COP

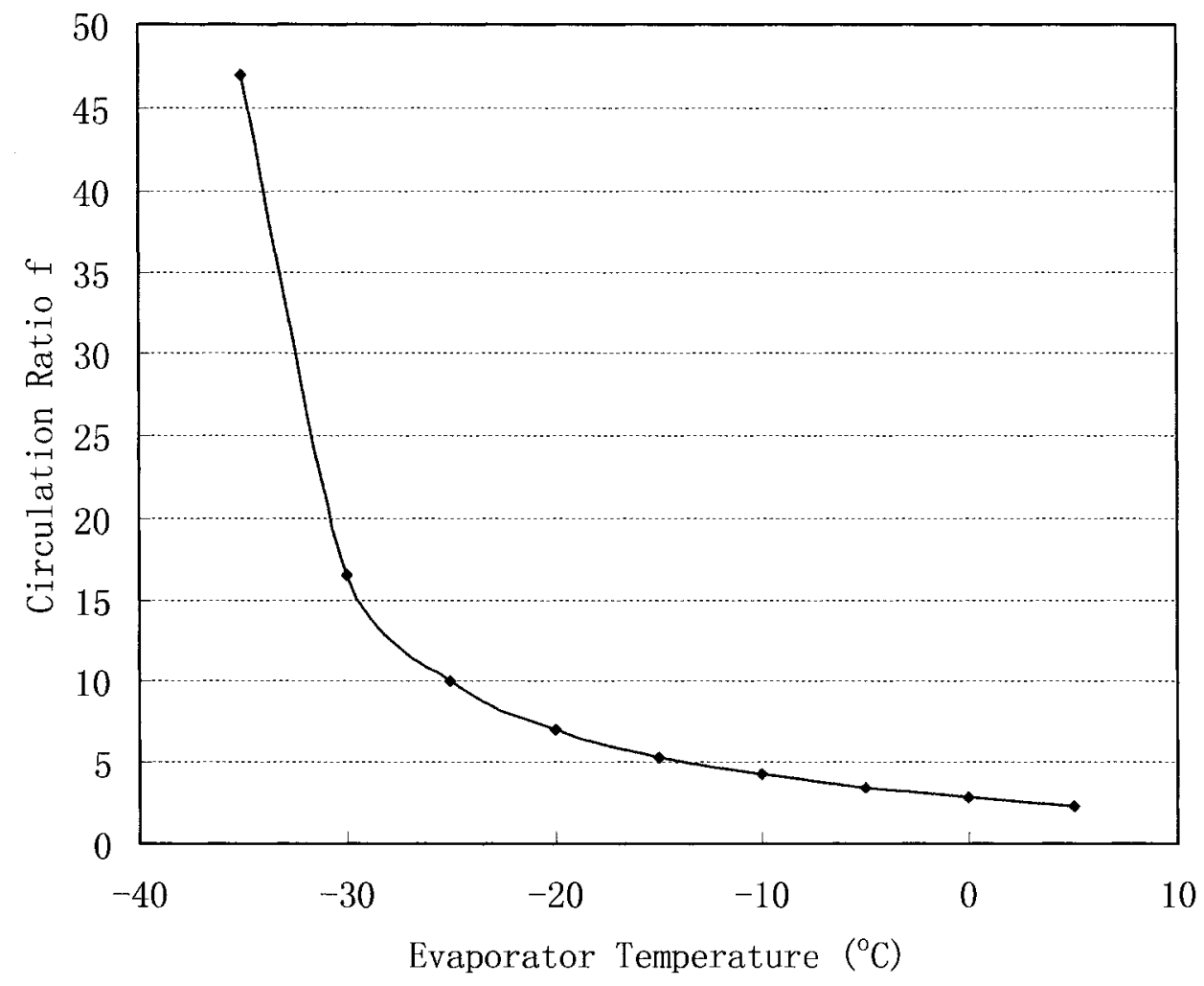

Figure 3.17 The relation between evaporator temperature and circulation ratio 


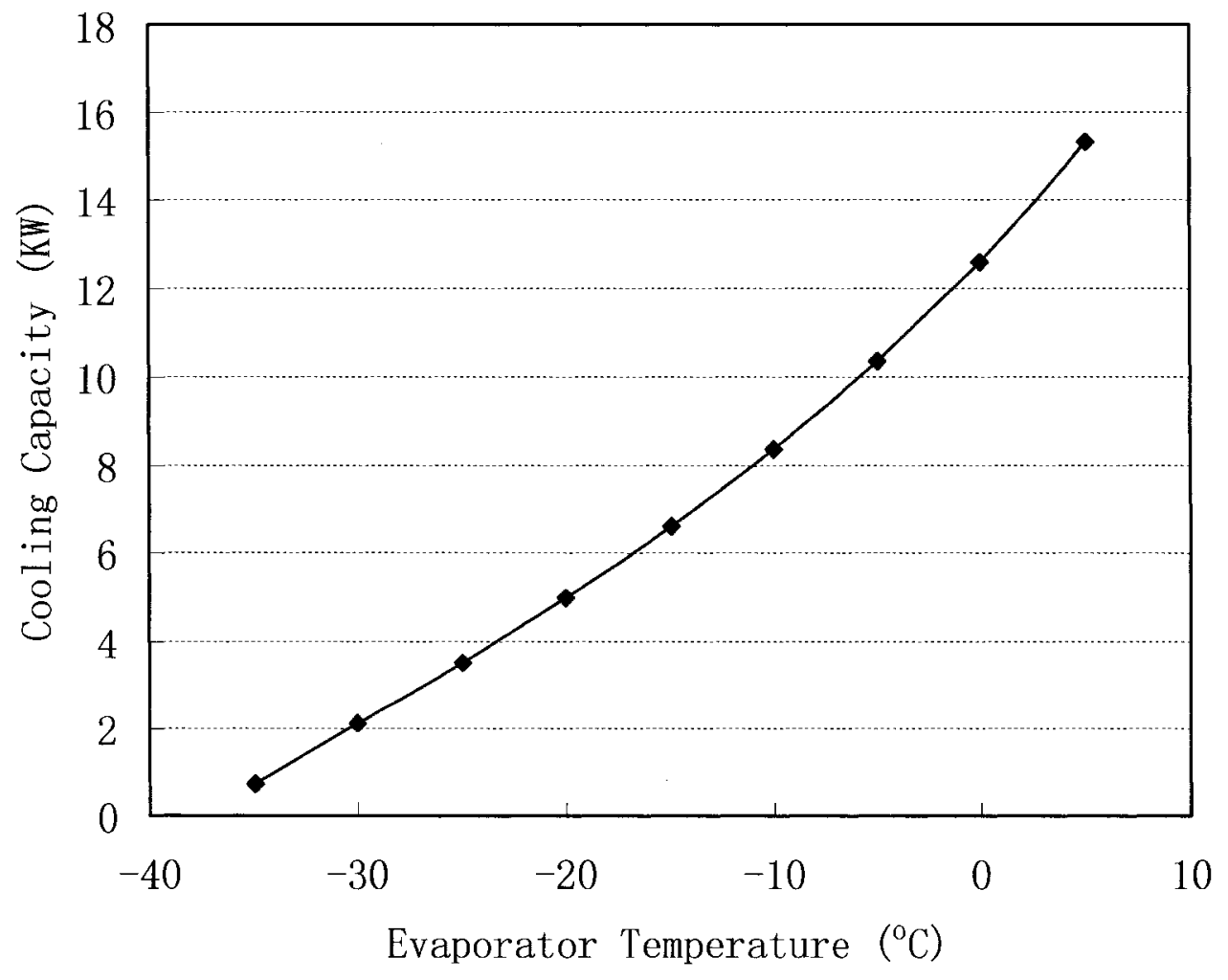

Figure 3.18 The relation between evaporator temperature and cooling capacity

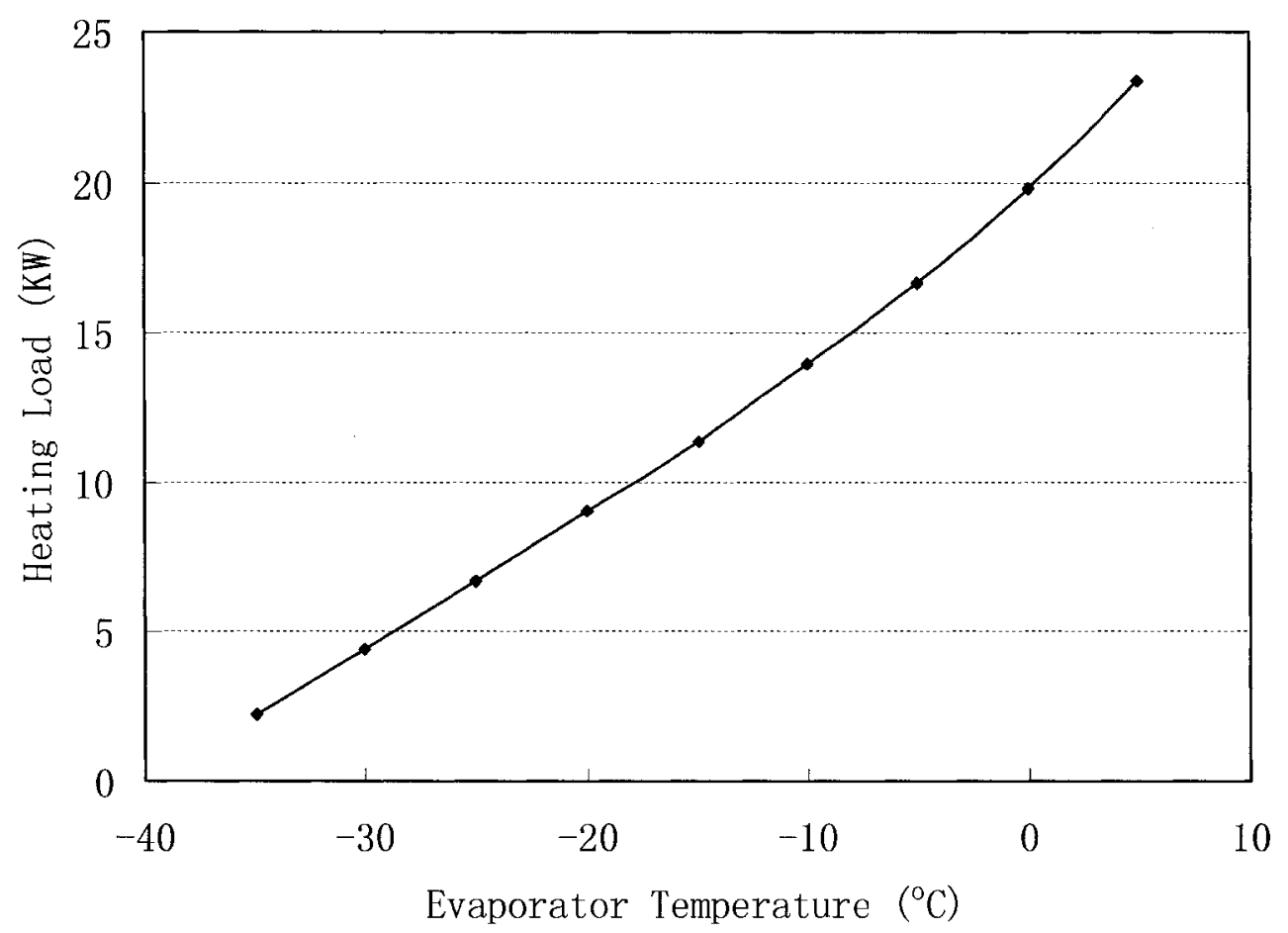

Figure 3.19 The relation between evaporator temperature and heating load 


\subsubsection{Influence of absorber temperature}

Absorber is a component where vapor ammonia is absorbed by strong solution that is transferred to generator. In the absorber, the $\mathrm{NH}_{3}-\mathrm{NaSCN}$ solution circulates through a heat exchanger cooled by water flowing inside and is sprayed in a vertical tank. It absorbs the ammonia vapor coming from the evaporator continuously. Then it is collected at the bottom of the absorber, part of this solution is circulated and sprayed from the top of the absorber tank, the rest is transferred to the generator.

For the simulation purpose, the system is supposed to operate at constant generator, condenser, and evaporator temperature condition. Based on the "design point" described above, the generator, condenser and evaporator temperature are chosen as $T_{g}=85^{\circ} \mathrm{C}, T_{c}=15^{\circ} \mathrm{C}$, and $T_{e}=-20^{\circ} \mathrm{C}$, and the efficiency of solution heat exchanger is chosen as $80 \%$.

Based on the simulation results, Figure 3.20 to Figure 3.23 show the variation of system COP, circulation ratio, cooling capacity and heating load as functions of the absorber temperature. It is shown that the increasing absorber temperatures cause an increase in circulation ratio and decrease in system performance, cooling capacity and heating load. Similarly as the influence of condenser temperature, if the system is used as refrigeration equipment, low absorber temperature, on the other word, low cooling water temperature for absorber should be applied; if the system is designed for heat pump mode, a high temperature of cooling water output is needed, however, a low system COP will be observed. If the absorber temperature reaches the high temperature limit in this operating condition, the vapor ammonia can not be absorbed 
by liquid solution, thus the system COP, cooling capacity and heating load will be close to zero, and the system can not be operated in this condition.

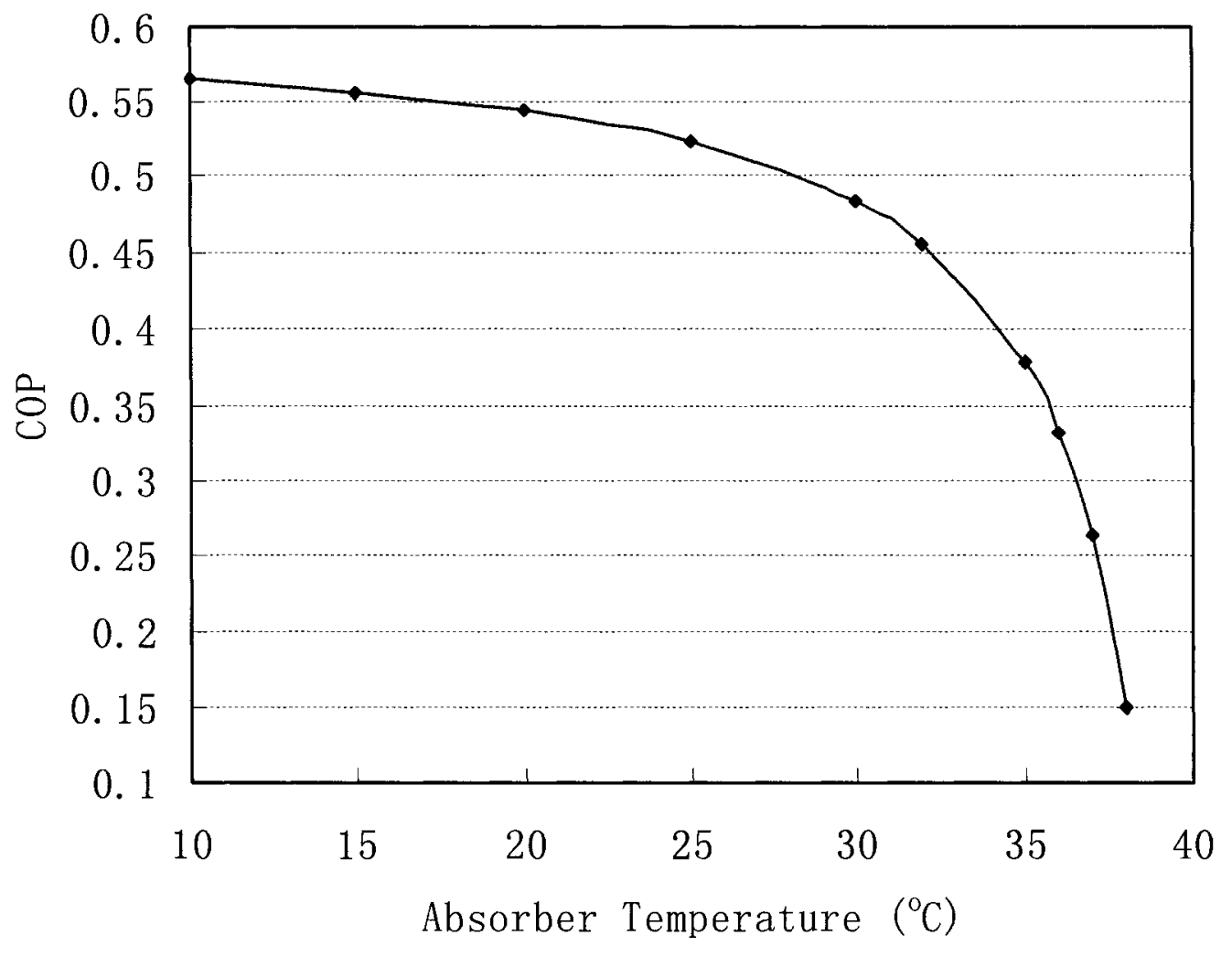

Figure 3.20 The relation between absorber temperature and COP 


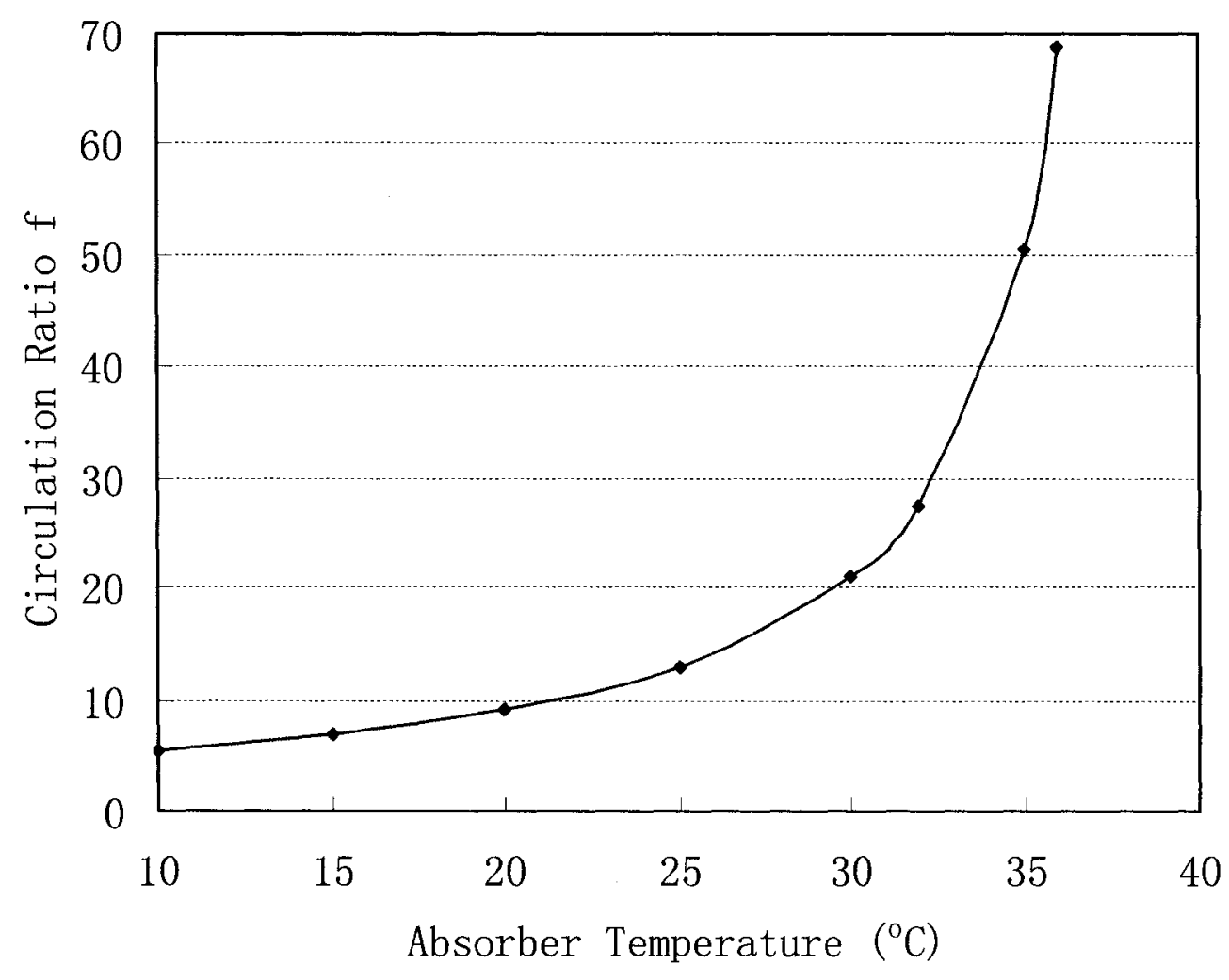

Figure 3.21 The relation between absorber temperature and circulation ratio

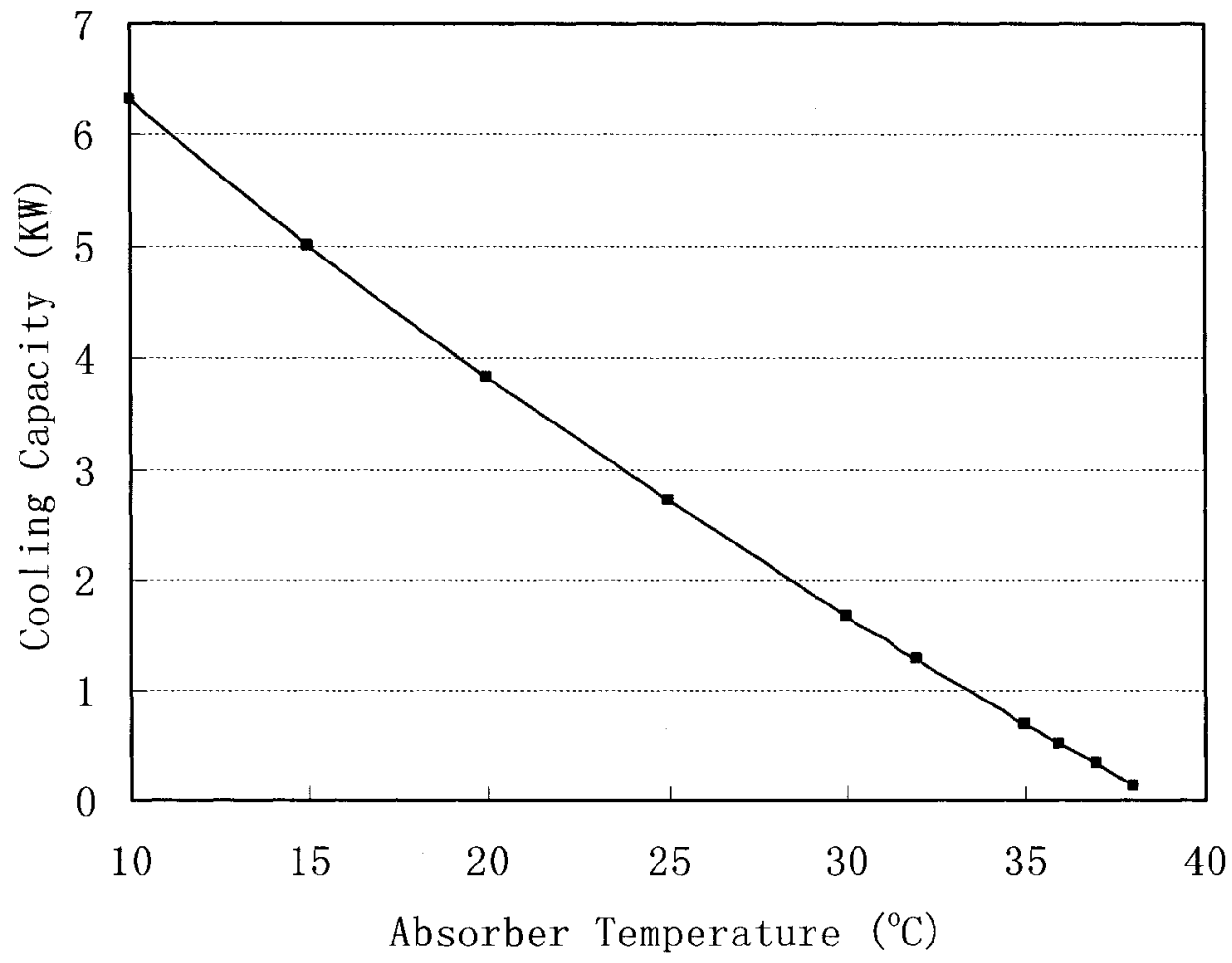

Figure 3.22 The relation between absorber temperature and cooling capacity 


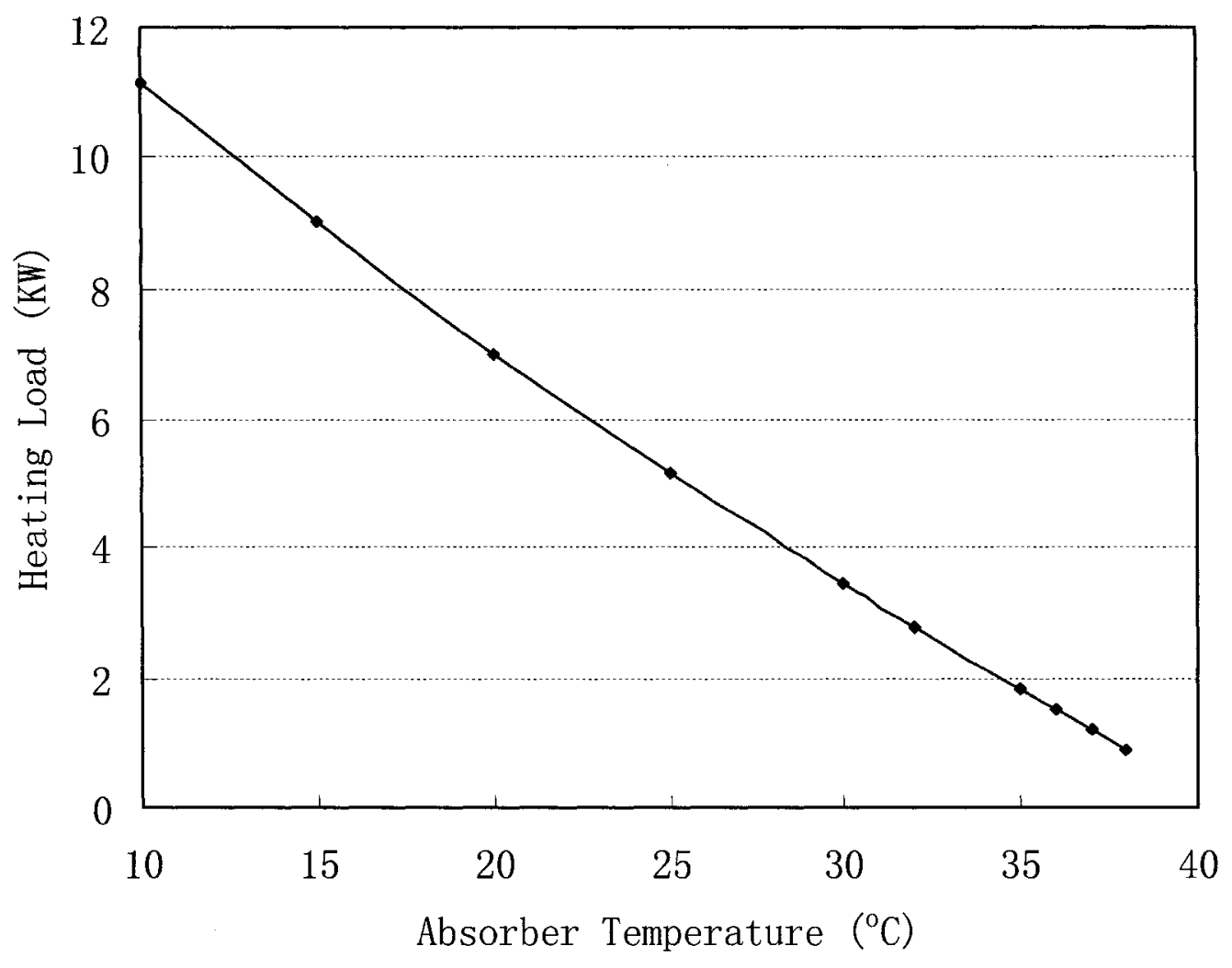

Figure 3.23 The relation between absorber temperature and heating load

\subsubsection{Influence of solution heat exchanger effectiveness}

The solution heat exchanger is used between the generator and absorber to improve system performance. For the absorbing process, the absorbency of low temperature strong solution is better than high temperature solution. For the generating process, however, the higher the temperature, the easier the ammonia vapor is generated from the solution in generator. And it is obvious that the temperature of strong solution at outlet of the generator is higher than the temperature of weak solution at the outlet of the absorber, so we can transfer some heat from the strong solution to the weak solution to improve the system performance without 
consuming extra energy. For this purpose, a solution heat exchanger is used.

The heat transfer efficiency of the heat exchanger is determined by the heat exchange size and the material of heat exchanger, the thermodynamic properties of solutions, the flow velocities and the flow arrangement. Even for the same heat exchanger device, with different solution inlet temperature, flow velocity or solution concentration conditions, the heat exchanger effectiveness will be different. For simplification, we define a new value to measure the heat exchange ability: the effectiveness of solution heat exchanger, $E_{\text {ex }}$, just like shown in equation 3.48 , and assume it is a constant over the operating range.

In this section, different heat exchanger efficiencies will be applied to the DMSR system and simulated to describe the influence on system performance. For this purpose, the system is assumed to operate at constant generator, condenser, evaporator, and absorber temperature. Based on the "design point" described above, the generator, condenser, evaporator, absorber temperature are chosen as $T_{g}=85^{\circ} \mathrm{C}$, $T_{c}=15^{\circ} \mathrm{C}, T_{e}=-20^{\circ} \mathrm{C}$, and $T_{a}=15^{\circ} \mathrm{C}$, and the solution heat exchanger effectiveness is changed from 0 to 1.0 , the influence on system COP, heating load to the generator and heat rejection from the absorber is obtained and described in Figure 3.24 to Figure 3.26 .

Figure 3.24 shows the relationship between the system COP and the solution heat exchanger effectiveness, it can be observed that the system performance increase with the solution heat exchanger effectiveness, if the efficiency value is zero, it means no solution heat exchanger is included in the DSMR system, the high temperature 
strong solution from generator and the low temperature weak solution from the absorber are transferred to the absorber and generator directly, there is no heat exchange between them. In this condition, the system COP value is only 0.39 . With the solution heat exchanger effectiveness increase, the system COP will increase gradually. In generally, the heat exchanger effectiveness value 0.8 is commonly chosen to simulate the system performance in order to get reasonable simulation results. It can be observed that in our simulation process, if 0.8 is chosen as the efficiency value, the system COP is about 0.56 , which is $43.6 \%$ higher than that without solution heat exchanger process, so the effect of solution heat exchanger is significant.

Figure 3.25 shows the variation of heating load to the generator as a function of solution heat exchanger effectiveness. It can be observed that the heat absorbed by the weak solution to drive the whole system working decreases with the solution heat exchanger increase, it means if a high efficiency solution heat exchanger is applied in absorption refrigeration system, to obtain the needed evaporator temperature and cooling capacity, the required driven energy will be reduced. Correspondingly adding the internal heat exchanger device to the system or increasing the internal heat exchanger effectiveness is one of the most effective methods to improve the system performance and, indeed, this measure is applied in almost all kinds of absorption refrigeration system optimizing process.

Figure 3.26 shows the effect of solution heat exchanger effectiveness on heat rejection from absorber. Similarly as the influence on heating load, the heat rejection 
from absorber will decrease with the increase of heat exchanger effectiveness. It can be well understood, because of the effect of the solution heat exchanger, the temperature of strong solution from the generator decreases, and part of the internal energy is transferred to low temperature weak solution, as a result, the energy rejected from absorbing process will decrease. On the other hand, because the strong solution temperature is reduced as a reason of the internal heat exchange, the solution absorbing ability will increase, that is another reason why the higher solution exchanger efficiency is corresponding to a higher system COP.

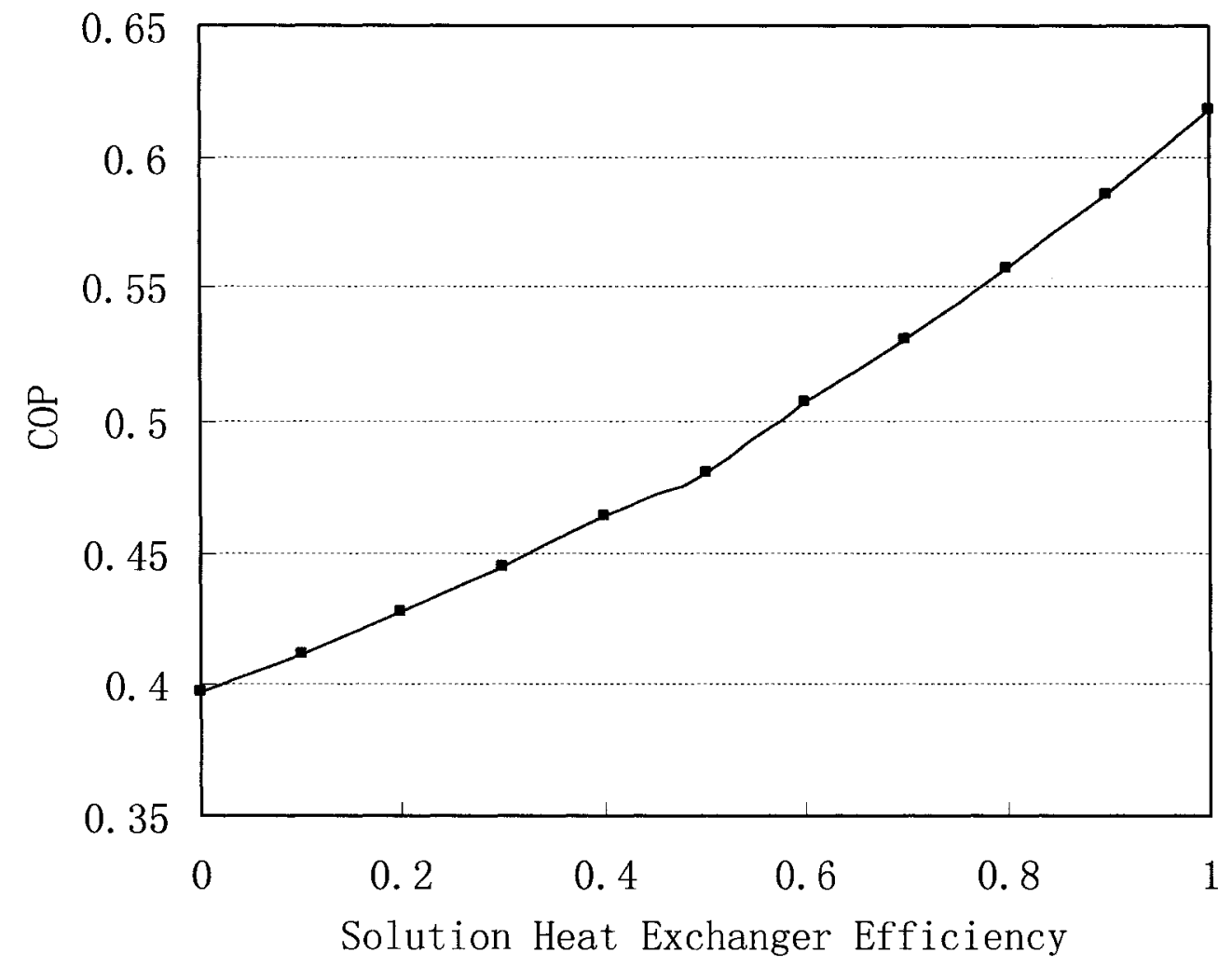

Figure 3.24 The relation between solution heat exchanger effectiveness and COP 


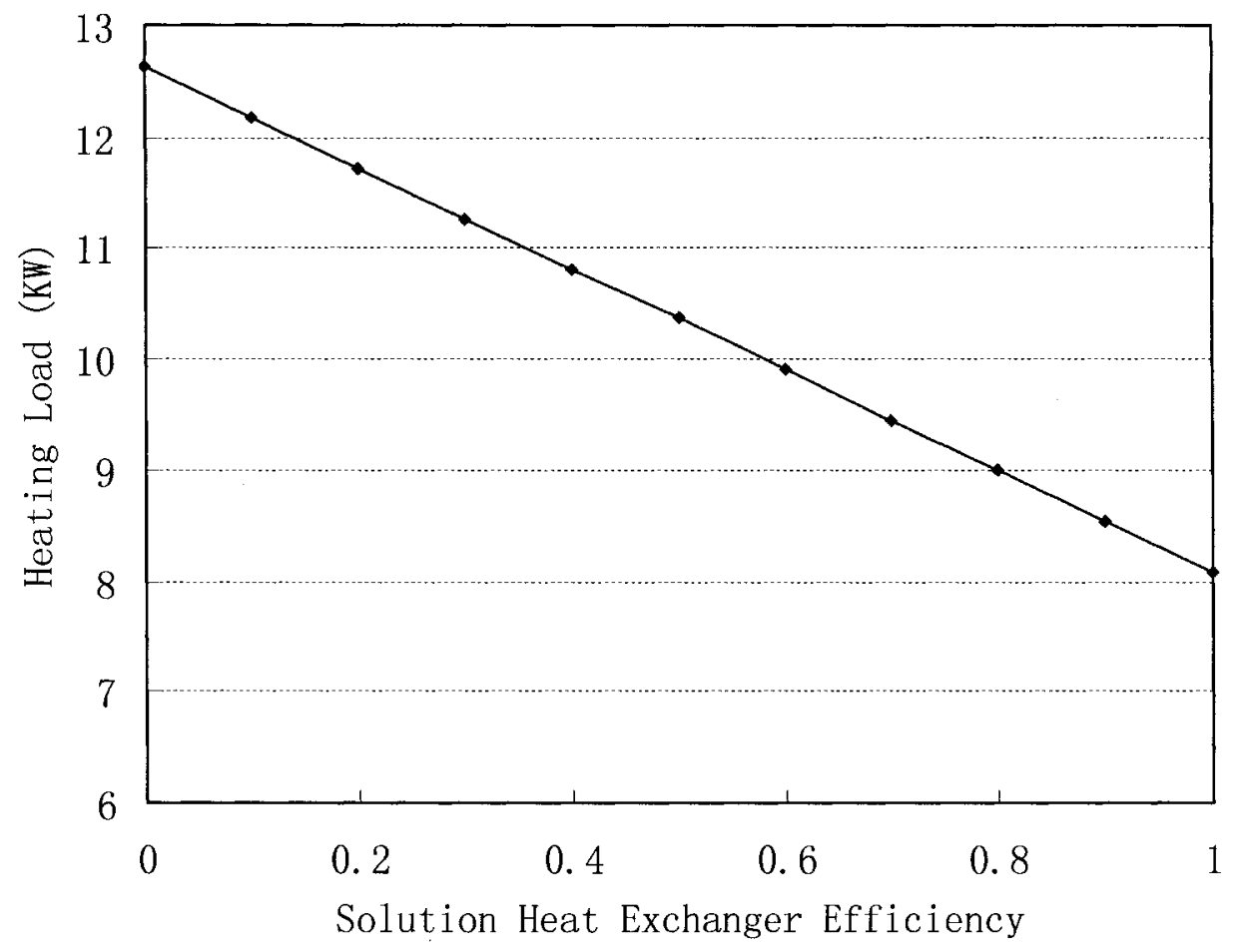

Figure 3.25 The relation between solution heat exchanger effectiveness and heating load

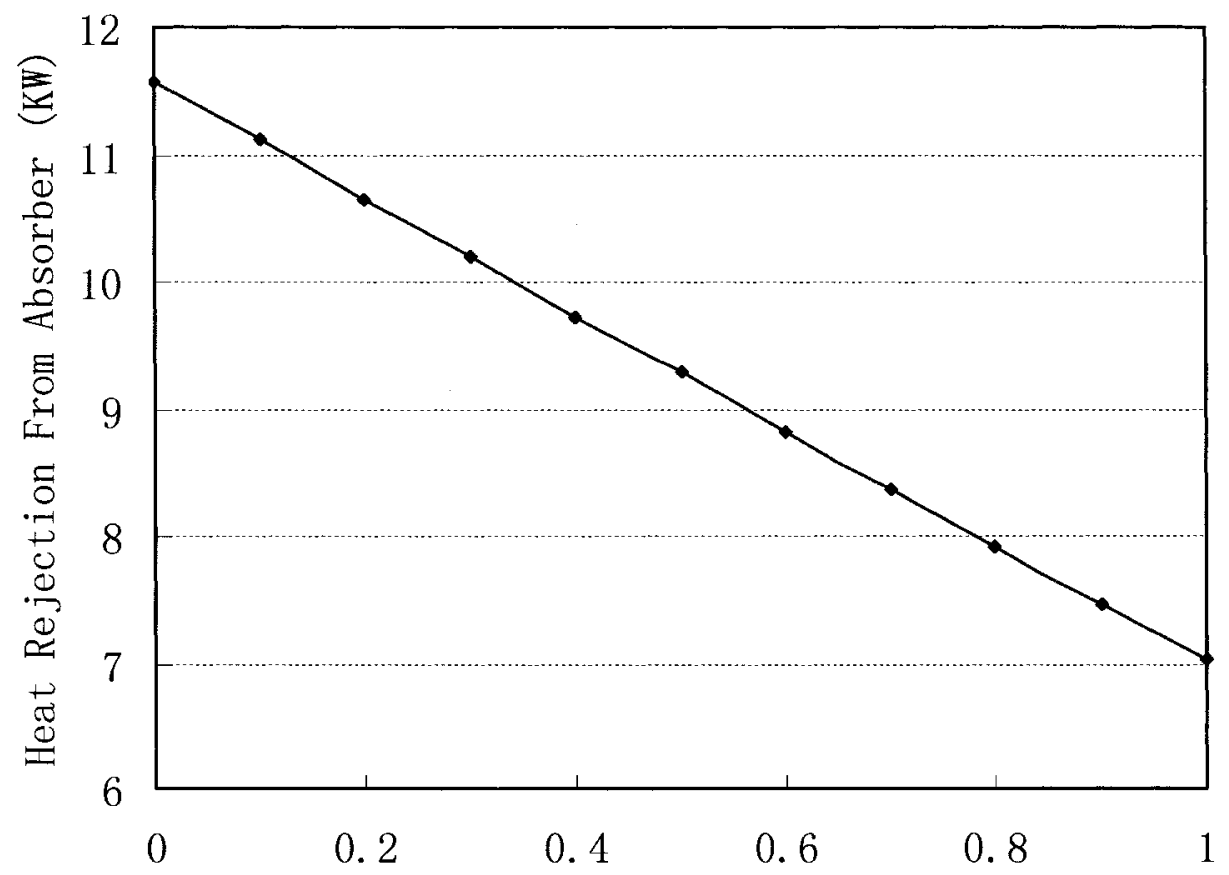

Solution Heat Exchanger Efficiency

Figure 3.26 The relation between solution heat exchanger effectiveness and heating rejection from absorber 


\section{4.2. Over all system performance}

When operating an absorption machine, a change in any input variables will cause changes in all the other dependent variables. When an input changes, the entire cycle reacts to this change and reaches a new equilibrium operating conditions. The dynamic nature of the whole equilibrium process must be taken into account when interpreting the operating data. The first computer model presented in last section does not exhibit this type of jointed behavior, but the second whole system model presented in this section will reflect the actual cycle behavior.

In order to compare the system performance in different operating conditions, based on the above design point, the effect of varying one of the input conditions, such as inlet heat source temperature from the generator, inlet cooling water temperature to the absorber, on the performance while keeping the other variables constant is simulated in this study. The following processes are simulated respectively:

1. Change the heat source temperature to generator while keeping other input variables constant. Compare the system heating load, cooling capacity, and solution concentration changes.

2. Change the partial pressure of hydrogen to obtain different evaporator temperature while keeping other input variables constant. Compare the system COP, cooling capacity changes and the solution concentration.

3. Change the cooling water inlet temperature to the condenser while 
keeping other input variables constant. Compare the system COP, cooling capacity, heat rejection from condenser, and solution concentration changes.

4. Change the cooling water inlet temperature to the absorber while keeping other input variables constant. Compare the system circulation ratio, heat rejection from absorber, and solution concentration changes.

\subsubsection{Influence of the heat source temperature}

A simple example of the interdependence of all operating variables can be obtained by varying the generator stream inlet temperature while holding other inputs constant at the design point defined in table 3.3 , the cycle performance under these conditions are summarized in Figure 3.27 to Figure 3.30 where heating load, cooling capacity, and solution concentrations are plotted versus the heat source temperature (inlet to the generator).

For system simulating purpose, the system is supposed to operate in constant condenser and absorber cooling water inlet temperatures and constant evaporator outlet temperature condition. Based on the "design point" described above, the condenser and absorber cooling water inlet temperatures were chosen as $T_{c}=15^{\circ} \mathrm{C}$, $T_{a}=15^{\circ} \mathrm{C}$, the efficiency of solution heat exchanger is chosen as $80 \%$, and three different evaporator outlet temperature $T_{e}=-30^{\circ} \mathrm{C}, T_{e}=-20^{\circ} \mathrm{C}$ and $T_{e}=-10^{\circ} \mathrm{C}$ are chosen to simulated different operating conditions for compare purpose.

Figure 3.27 shows the heating load values at the heat source temperature range 
from $65^{\circ} \mathrm{C}$ to $115^{\circ} \mathrm{C}$, which is the most commonly used temperature range for low grade or waste heat sources, the heating load varies from a low value of $1.33 \mathrm{~kW}$ to a maximum of $16.34 \mathrm{~kW}$, and the values show approximately linearly increasing with the increase of heat source temperature. On the other hand, the heating load for high evaporator outlet temperature is bigger than that for low evaporator outlet temperature condition, and for the evaporator outlet temperature value of $-30^{\circ} \mathrm{C}$, if the heat source temperature value less than $75^{\circ} \mathrm{C}$, the heating load value almost close to zero, it means no energy will be absorbed by weak solution, and obviously no vapor ammonia will released to circulate in the cycle. The system doesn't operate in this condition.

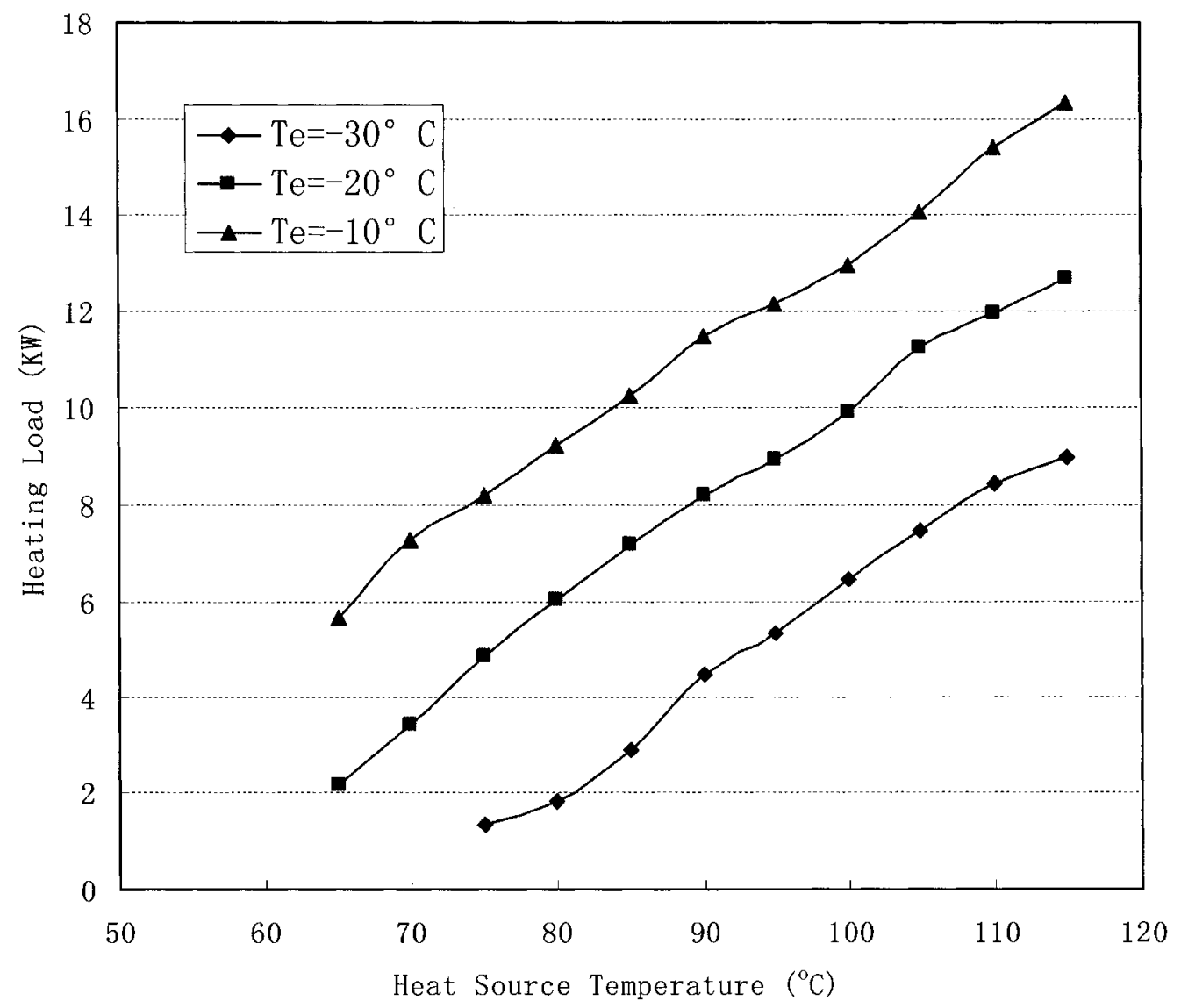

Figure 3.27 The relation between heat source temperature and heating load 
Similar to the characteristic of heating load, the system cooling capacity will increase with the increase of heat source temperature, too. As shown in Figure 3.28, the cooling capacity varies approximately linearly starting from a low value of 0.31 $\mathrm{kW}$ to a high value up to $9.07 \mathrm{~kW}$, again, high evaporator outlet temperature leads to high cooling capacity value. For the evaporator outlet temperature value of $-30^{\circ} \mathrm{C}$, if the heat source temperature value is less than $75^{\circ} \mathrm{C}$, the cooling capacity value close to zero either. Because the change of cooling capacity and heating load are almost in the same way, the system COP curve is relatively flat in ordinary working conditions with the increase of heat source temperature.

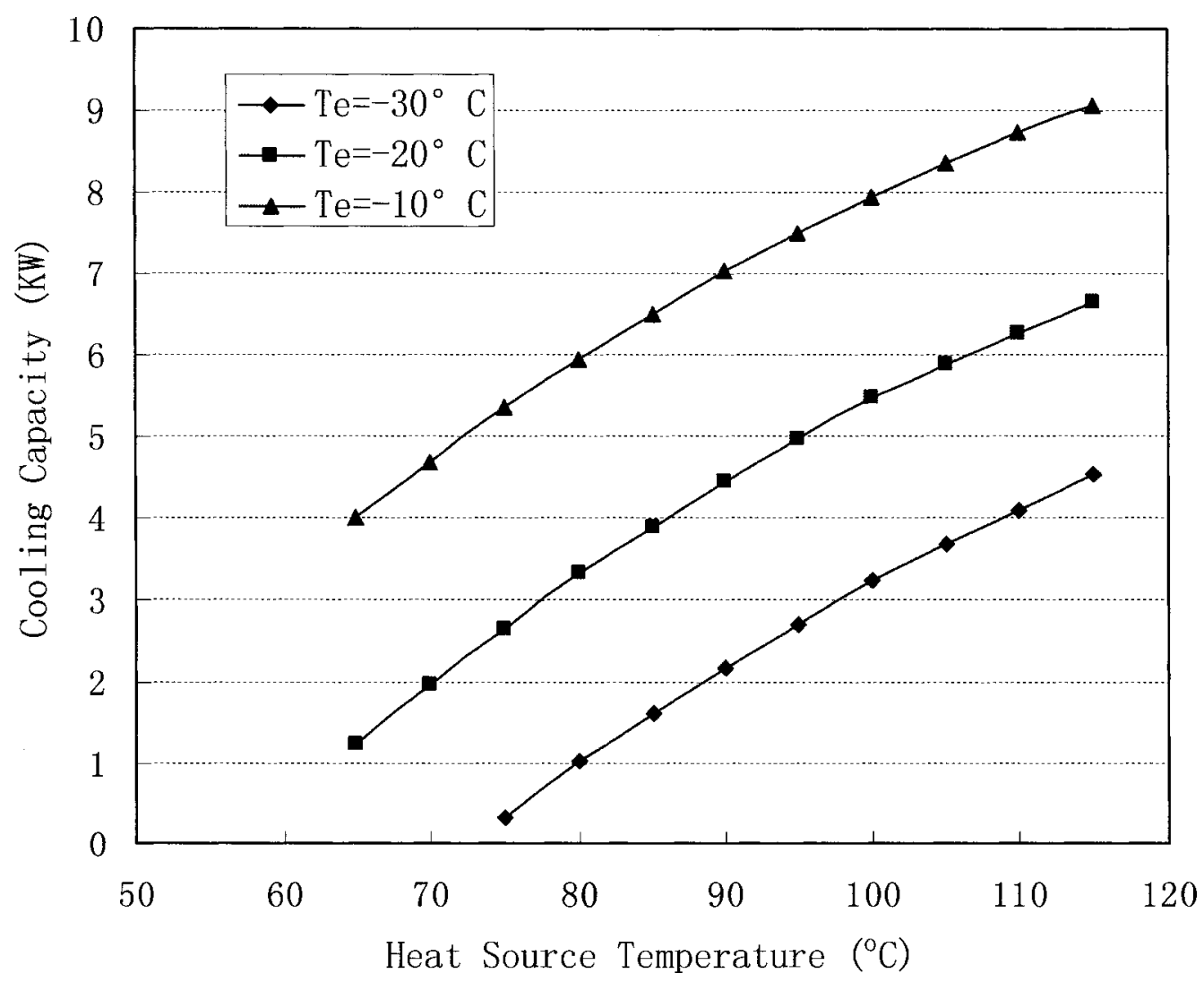

Figure 3.28 The relation between heat source temperature and cooling capacity 
The concentration of weak solution input to generator varies form 0.39 to 0.5 , while the concentration of strong solution output from generator varies from 0.3 to 0.44 ; the solution concentration is defined as the ammonia mass fraction in solution. Shown in Figure 3.29 and Figure 3.30, with the increase of heat source temperature value, both the weak solution concentration and the strong solution concentration decrease simultaneously, and the variation of the strong solution concentration is bigger than that of the weak solution. At the same time, the influence of evaporator temperature difference on the weak solution concentration is bigger than that on the strong solution. When evaporator outlet temperature increases from $-30^{\circ} \mathrm{C}$ to $-10^{\circ} \mathrm{C}$, the weak solution concentration value increases by about 0.1 , while the strong solution concentration value increases only about 0.02 .

An interesting point is that with the increase of heat source temperature, the concentration difference between the weak solution and the strong solution will increase. With the heat source temperature range from $65^{\circ} \mathrm{C}$ to $115^{\circ} \mathrm{C}$, the concentration difference increase from 0.05 to 0.18 . The reason is that with the increase of heat source temperature, more energy will be absorbed by solution in generator, which means more vapor ammonia will be released from weak solution. If the solution circulation velocity doesn't change, the weak solution will lose more ammonia and then it will change to a stronger solution, so the solution concentration difference will be higher than that of low heat source temperature conditions.

Another important reason should be noticed about solution concentration is that, the low solution concentration will cause crystallization problem. For $\mathrm{NH}_{3}-\mathrm{NaSCN}$ 
solution, if the solution concentration is lower than 0.32 in ordinary operating conditions, crystallization of $\mathrm{NaSCN}$ will occur in generator, for ordinary system, it will greatly decrease the system performance even prevent the system from working. Based on the simulation result, it can be observed that the high heat source temperature may cause a low solution concentration value. If the heat source temperature increases to $110^{\circ} \mathrm{C}$, crystallization will occur in real condition; this condition can not be operated for ordinary system.

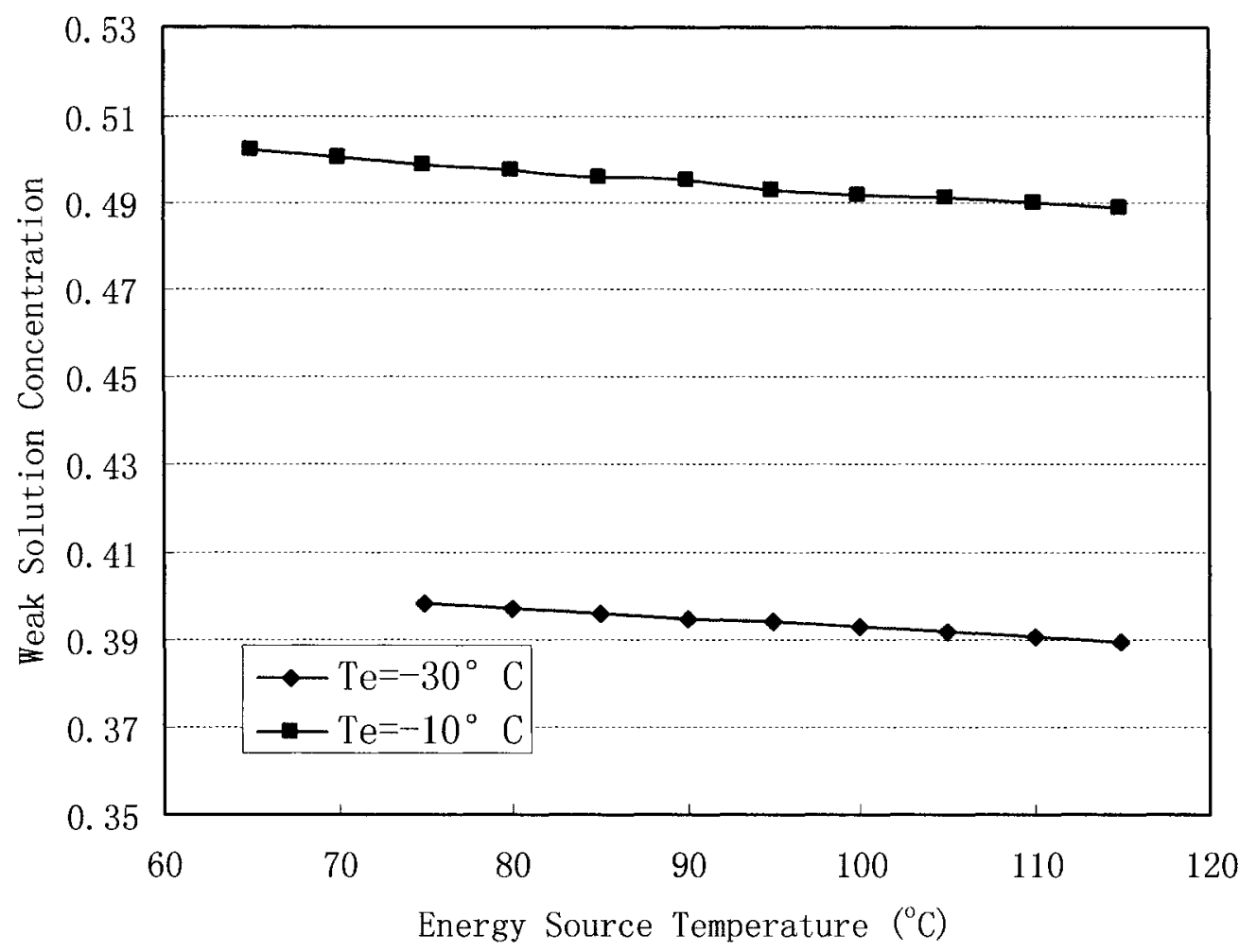

Figure 3.29 The relation between heat source temperature and weak solution concentration 


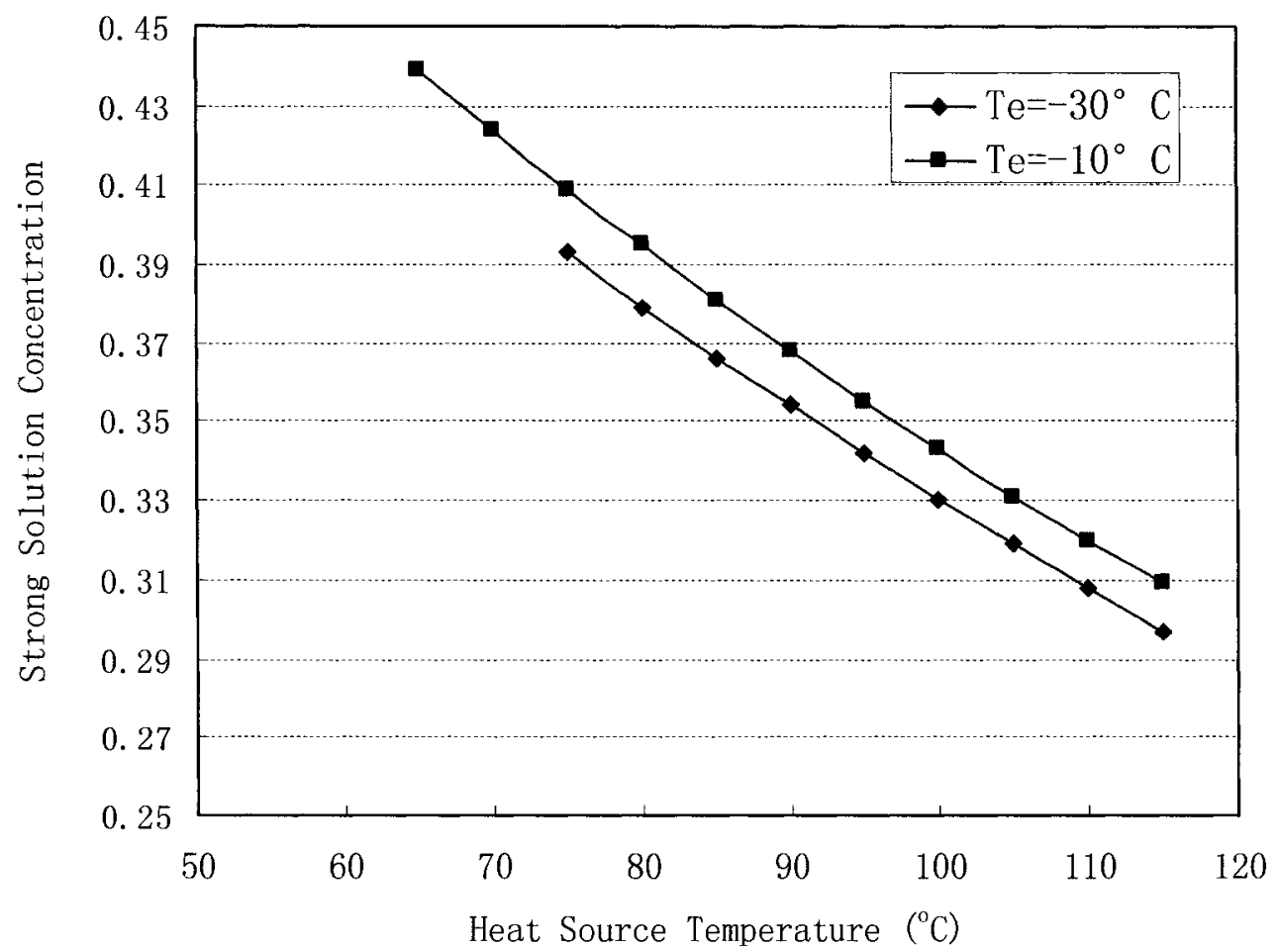

Figure 3.30 The relation between heat source temperature and strong solution concentration

\subsubsection{Influence of the partial pressure of hydrogen}

One of the characteristic of the DMSR system is that hydrogen which is charged in the evaporator and the absorber part to replace the expansion valve. The advantage of this system is: the system pressure is constant in every part, the system is simple. But the disadvantage of this system is that, the system evaporate pressure is subject to the partial pressure of expansion gas hydrogen, because the partial pressure of hydrogen is different in different evaporator temperature, and the evaporator temperature needs to be controlled in test process. In the simulation process, different hydrogen partial pressures are applied to the system directly in order to receive 
expected evaporator outlet temperature.

Figure 3.31 shows the relationship between system COP and the chilled liquid outlet temperature. The system is assumed to operate in constant condenser and absorber cooling water inlet temperatures and constant heat source temperature conditions, and based on the "design point" described above, the condenser and absorber cooling water inlet temperatures were chosen as $T_{c}=20^{\circ} \mathrm{C}, T_{a}=15^{\circ} \mathrm{C}$, the heat source temperature value is $T_{g}=95^{\circ} \mathrm{C}$, and the efficiency of solution heat exchanger was chosen as $80 \%$.

It is clear that the system COP will increase with the increase of chilled liquid outlet temperature, ranging from a low value of 0.46 to a high value of 0.625 with the chilled liquid outlet temperature rising from $-30^{\circ} \mathrm{C}$ to $5^{\circ} \mathrm{C}$. It means higher evaporator outlet temperature result in higher system performance, and super-low temperature application fields will go with a low system performance, this is the same with all kinds of refrigeration system, not only absorption or adsorption systems but also mechanical vapor compression systems.

Another point should be observed is that, when the evaporator outlet temperature changes from $-30^{\circ} \mathrm{C}$ to $-5^{\circ} \mathrm{C}$, the system $\mathrm{COP}$ increases rapidly, and if the chilled liquid outlet temperature value higher than $-5^{\circ} \mathrm{C}$, the system COP will increase in a very slow pace. An absorption machine is fundamentally a three-temperature device. The performance of such a device can be largely determined by examining how the three temperature levels change [5]. For these simulation conditions, the rejection temperature in the condenser stays approximately constant, and if the evaporator 
outlet temperature increases up to a limit point, the system performance will be affected.

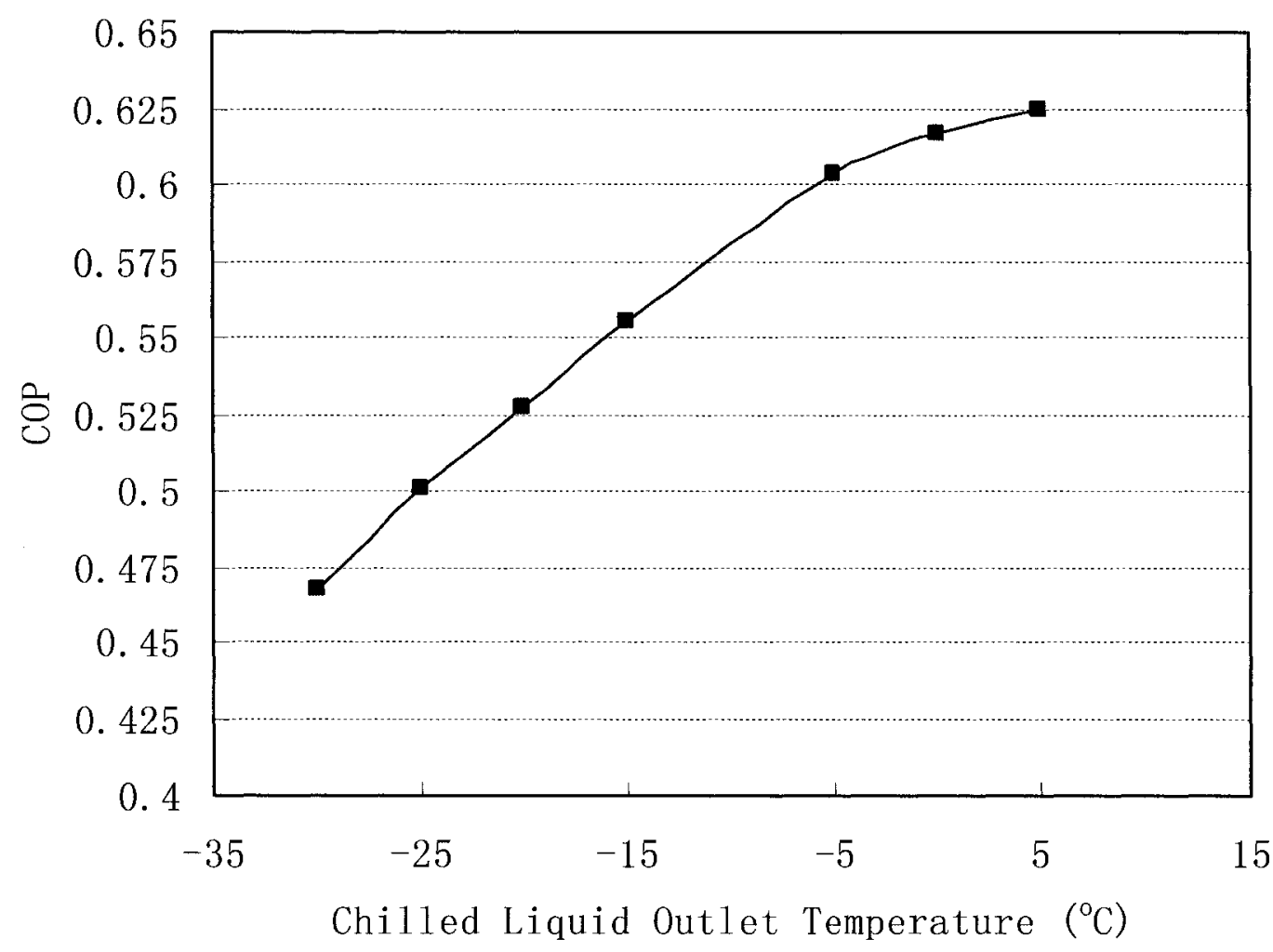

Figure 3.31 The relation between chilled liquid outlet temperature and system COP

Figure 3.32 shows the variation of cooling capacity as a function of chilled liquid outlet temperature at the design point described above and three different condenser cooling water inlet temperatures. It can be seen from this Figure that when chilled liquid outlet temperature increase from $-30^{\circ} \mathrm{C}$ to $5^{\circ} \mathrm{C}$, the system cooling capacity increase approximately linearly from $2 \mathrm{~kW}$ to a high value $13 \mathrm{~kW}$. And with the decrease of condenser cooling water temperature, the system cooling capacity will increase. 


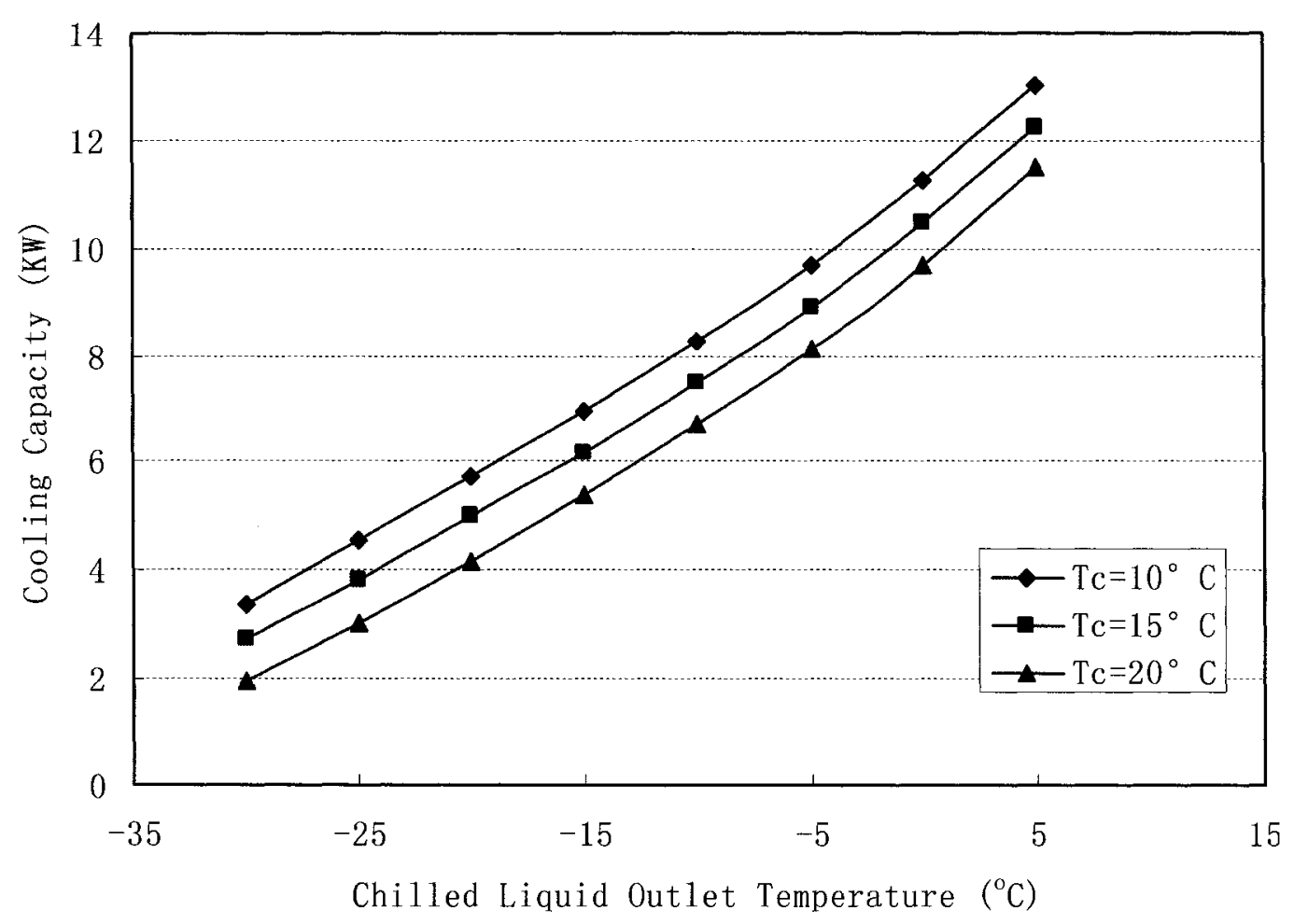

Figure 3.32 The relation between chilled liquid outlet temperature and cooling capacity

The effects of chilled liquid outlet temperature on weak and strong solution concentrations are plotted in Figure 3.33 and Figure 3.34. The weak and strong solution concentrations are both increase with the increase of evaporator outlet temperature. In the evaporator outlet temperatures range from $-30^{\circ} \mathrm{C}$ to $5^{\circ} \mathrm{C}$, the weak solution concentration increase from 0.4 to 0.6 , while the strong solution concentration rise from 0.36 to almost 0.39 , which shows the influence on the weak solution concentration is greater than that on the strong solution concentration.

On the other words, with the increase of evaporator outlet temperature, the concentration difference between weak solution and strong solution will increase. With the evaporator outlet temperature range from $-30^{\circ} \mathrm{C}$ to $5^{\circ} \mathrm{C}$, the concentration 
difference increase from 0.04 to 0.21 . The reason for this is the higher evaporator outlet temperature brings on higher cooling capacity, and more vapor ammonia need to be released from weak solution, and because the solution circulating in the DMSR system is fundamentally driven by a circulation pump, which is always working in a constant velocity, so the velocity of the weak solution flow into the generator is almost constant, it means more vapor ammonia will released from the same quantity of the weak solution compared to that at lower evaporator outlet temperature conditions, and it causes the solution concentration difference is higher.

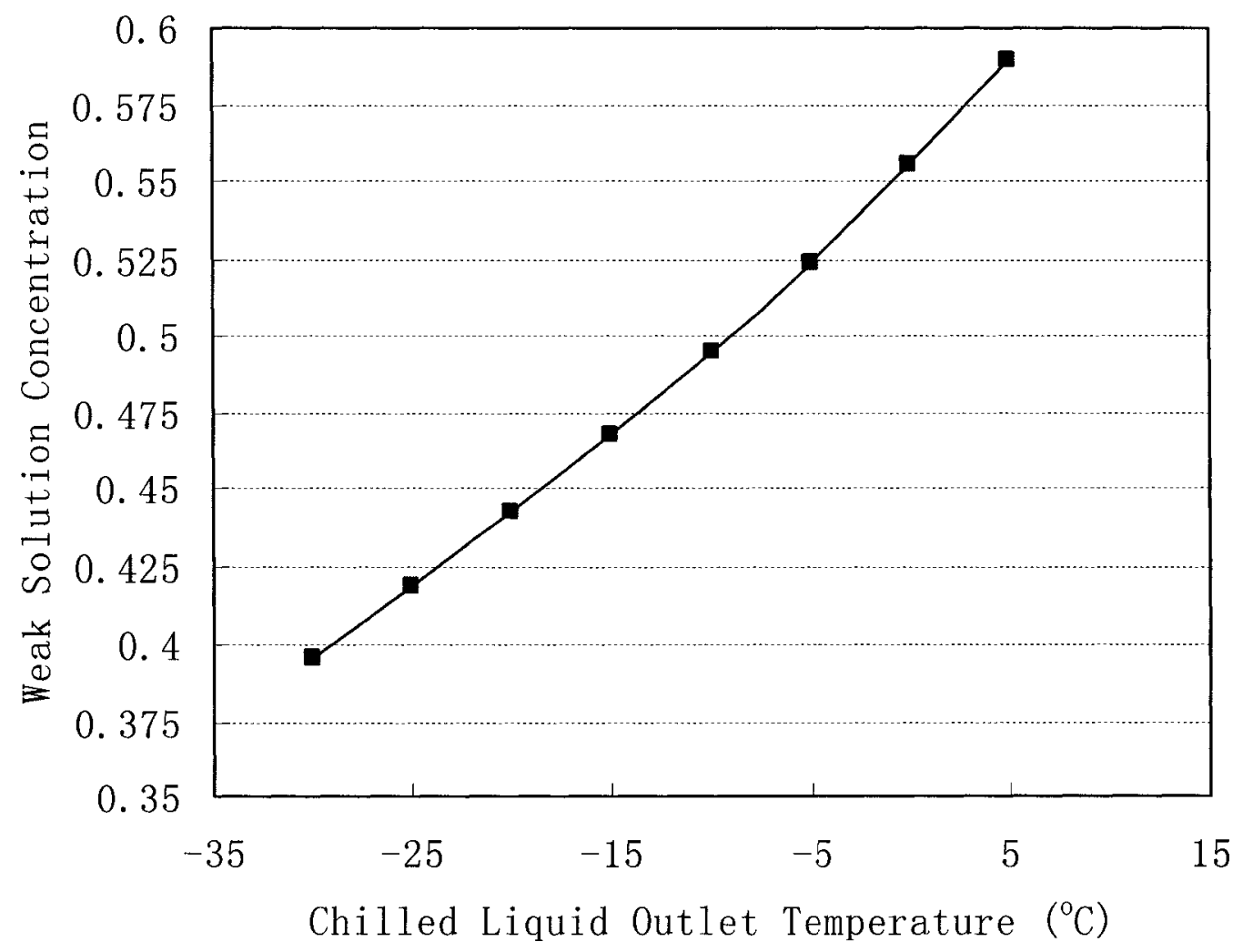

Figure 3.33 The relation between chilled liquid outlet temperature and weak solution concentration 


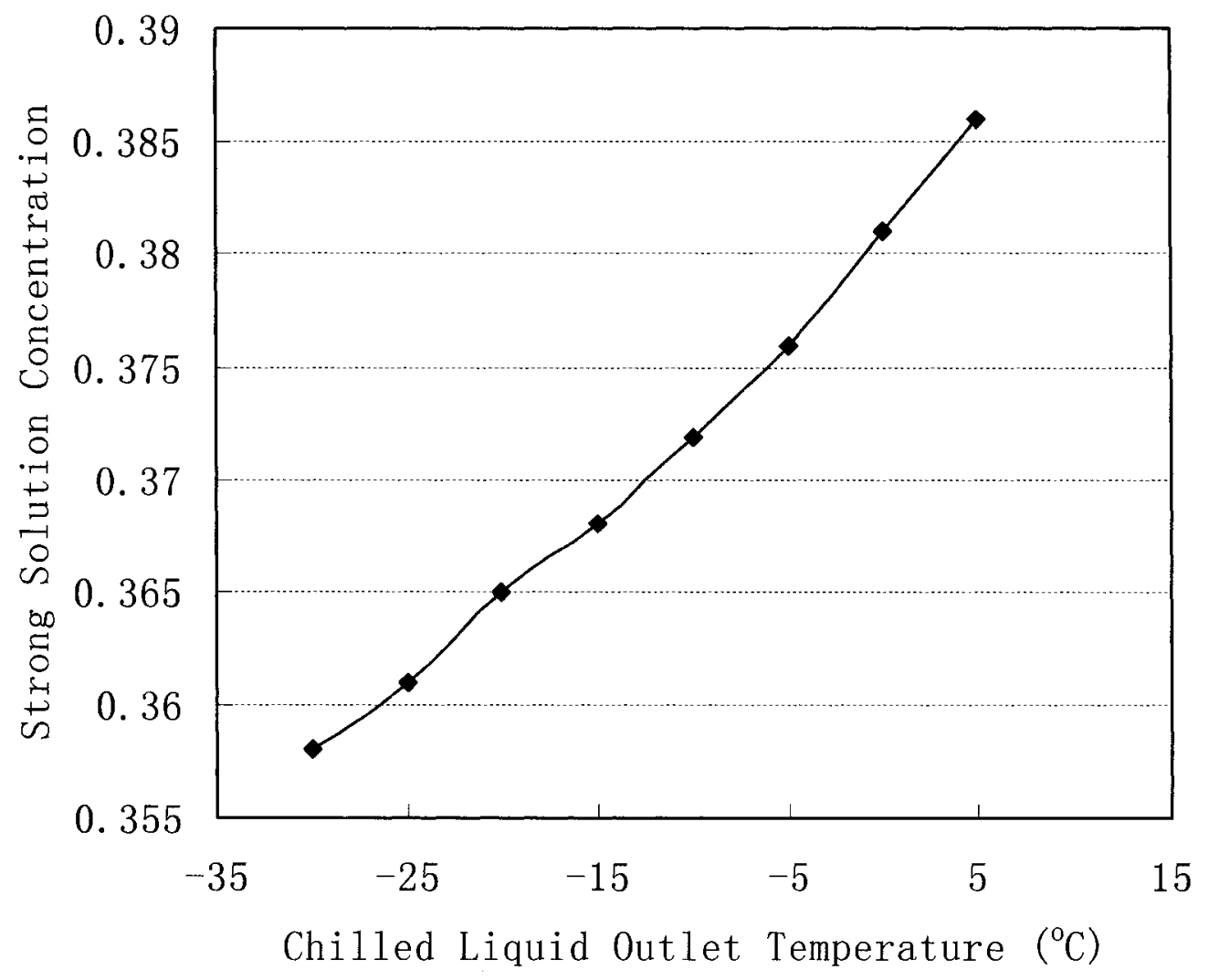

Figure 3.34 The relation between chilled liquid outlet temperature and strong solution concentration

\subsubsection{Influence of cooling water inlet temperature to the condenser}

Just like the function of condenser in common mechanical vapour compression systems, superheated vapour ammonia comes from generator is cooled down to a saturated situation, and then change to liquid phase. In fact, the condenser is heat exchanger device where large amount of heat will be delivered by cooling water.

Figure 3.35 to Figure 3.39 show the influence of condenser cooling water inlet temperature on system performance. The system is supposed to operate in constant 
absorber cooling water inlet temperatures, constant evaporator outlet temperature and constant heat source temperature conditions, and based on the "design point" described above, the absorber cooling water inlet temperatures was chosen as $T_{a}=15^{\circ} \mathrm{C}$, the evaporator outlet temperature was chosen as $T_{e}=-30^{\circ} \mathrm{C}$, the heat source temperature value is $T_{g}=95^{\circ} \mathrm{C}$, and the efficiency of solution heat exchanger was chosen as $80 \%$.

Figure 3.35 shows that the system COP decreases constantly with the condenser cooling water inlet temperature increase. It can be explained that, when the condenser cooling water inlet temperature increase, because the temperature difference between two fluid decreases, less energy will be transferred, so the enthalpy of liquid ammonia output from the condenser is higher than that at lower condenser cooling water inlet temperature condition, and if the temperature higher than a limit temperature, even not all vapor ammonia can be condensed liquid ammonia. When this ammonia absorbs less energy in the evaporator, with the same mass flow rate and evaporator temperature which means the system cooling capacity will decrease. As a result, the system COP is lower than that at a lower condenser temperature condition. And if the condenser temperature reaches the high temperature limit in this operating condition, the superheated vapor ammonia can not be cooled down to liquid phase, the enthalpy difference for the inlet and outlet ammonia in the evaporator is close to zero, the system COP will be close to zero and the system can not be operated in this condition. 


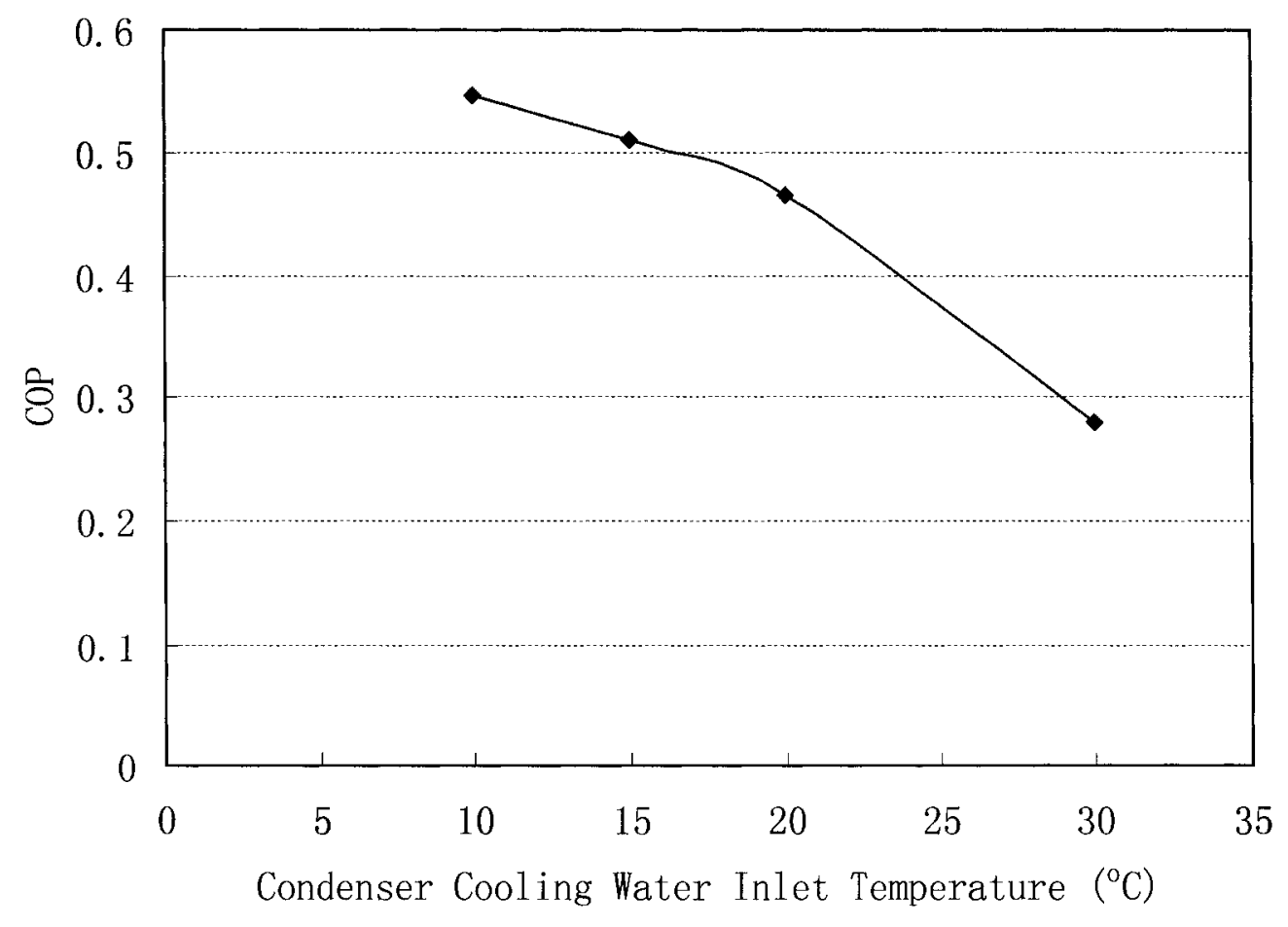

Figure 3.35 The relation between condenser cooling water inlet temperature and system COP

The influence of condenser cooling water inlet temperature on system cooling capacity is summarized in Figure 3.36, three groups of cooling capacities are plotted in different evaporator outlet temperatures. Based on the above description, the system cooling capacity will decrease with the condenser cooling water inlet temperature increase. If this temperature higher than a temperature limit, which is influenced by other operating conditions, the cooling capacity will almost close to zero. For example, in our simulation conditions, if the evaporator outlet temperature equal to $-30^{\circ} \mathrm{C}$, the corresponding temperature limit is about $30^{\circ} \mathrm{C}$, while the temperature limit for the evaporator outlet temperature value of $-20^{\circ} \mathrm{C}$ operating conditions is about $45^{\circ} \mathrm{C}$. The high evaporator outlet temperature cause high cooling 
capacity.

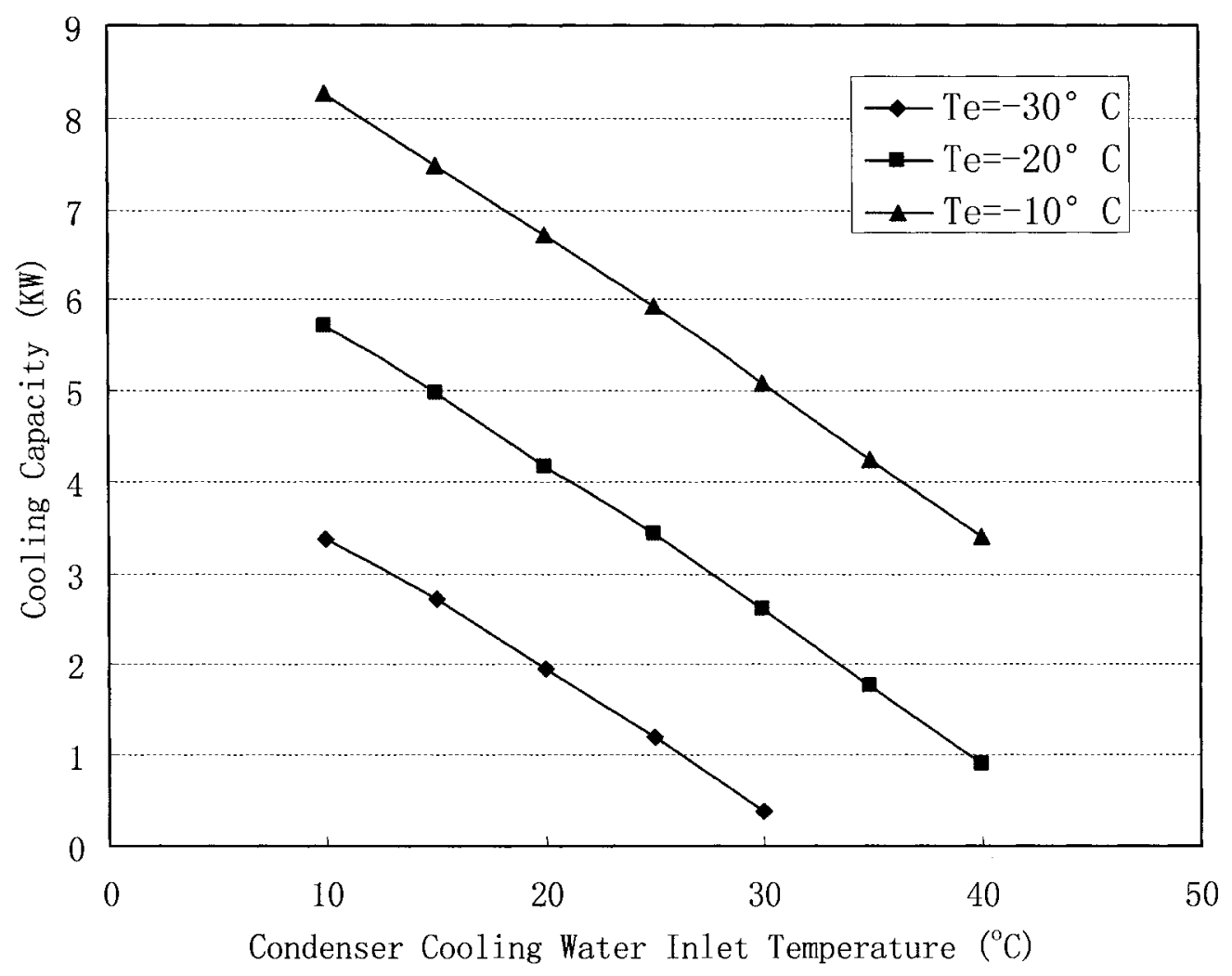

Figure 3.36 The relation between condenser cooling water inlet temperature and cooling capacity

The same as the cooling capacity, the heat rejection from condenser will decrease with the increase of condenser cooling water inlet temperature, as shown in Figure 3.37. It is very easy to understand, high cooling water inlet temperature causes low temperature difference between cooling water and input vapor ammonia, and then cause low heat exchange efficiency and less energy rejection from condenser. On the other hand, the condenser heat exchange ability on high evaporator outlet temperature working condition is higher than that at lower evaporator outlet temperature working condition. 


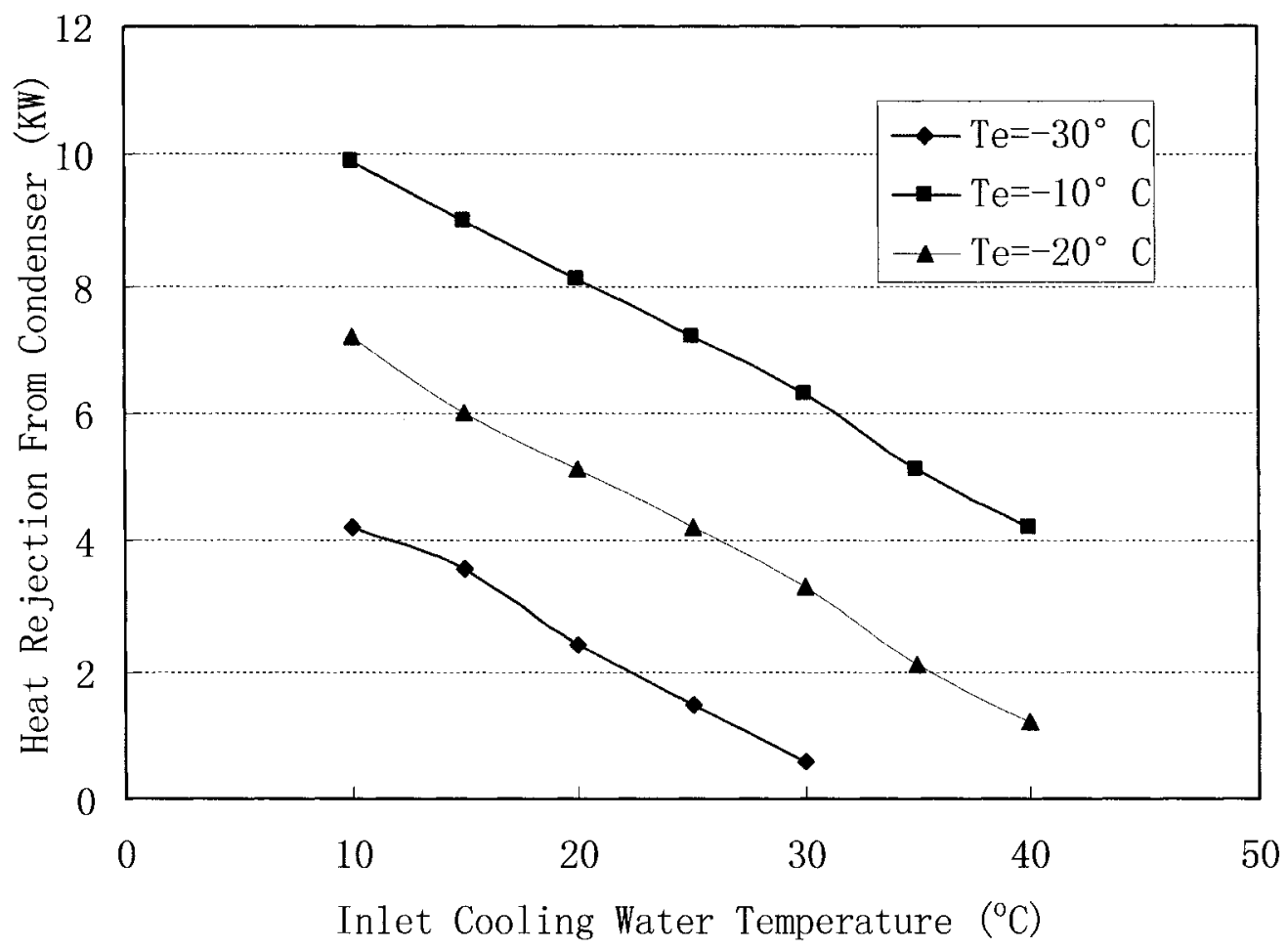

Figure 3.37 The relation between condenser cooling water inlet temperature and heat rejection from condenser

The effect of condenser cooling water inlet temperature on weak and strong solution concentrations are shown in Figure 3.38 and Figure 3.39. The concentration of weak solution at the inlet to generator changes in very small ranges with the increase of cooling water temperature. While the condenser cooling water inlet temperature increase from $10^{\circ} \mathrm{C}$ to $40^{\circ} \mathrm{C}$, the weak solution concentration increase form 0.492 to 0.502 for evaporator outlet temperature $-10^{\circ} \mathrm{C}$ working conditions, the concentration difference is only 0.01 . Compared to the influence on weak solution concentration, the increase of strong solution concentration with the rise of condenser cooling water inlet temperature is significant. When the inlet temperature values increase from $10^{\circ} \mathrm{C}$ to $40^{\circ} \mathrm{C}$, the strong solution concentration increase from 0.34 to 
0.44 , and the concentration difference between weak solution and strong solution decrease from 0.15 to 0.06 , the circulation ratio increase continuously.

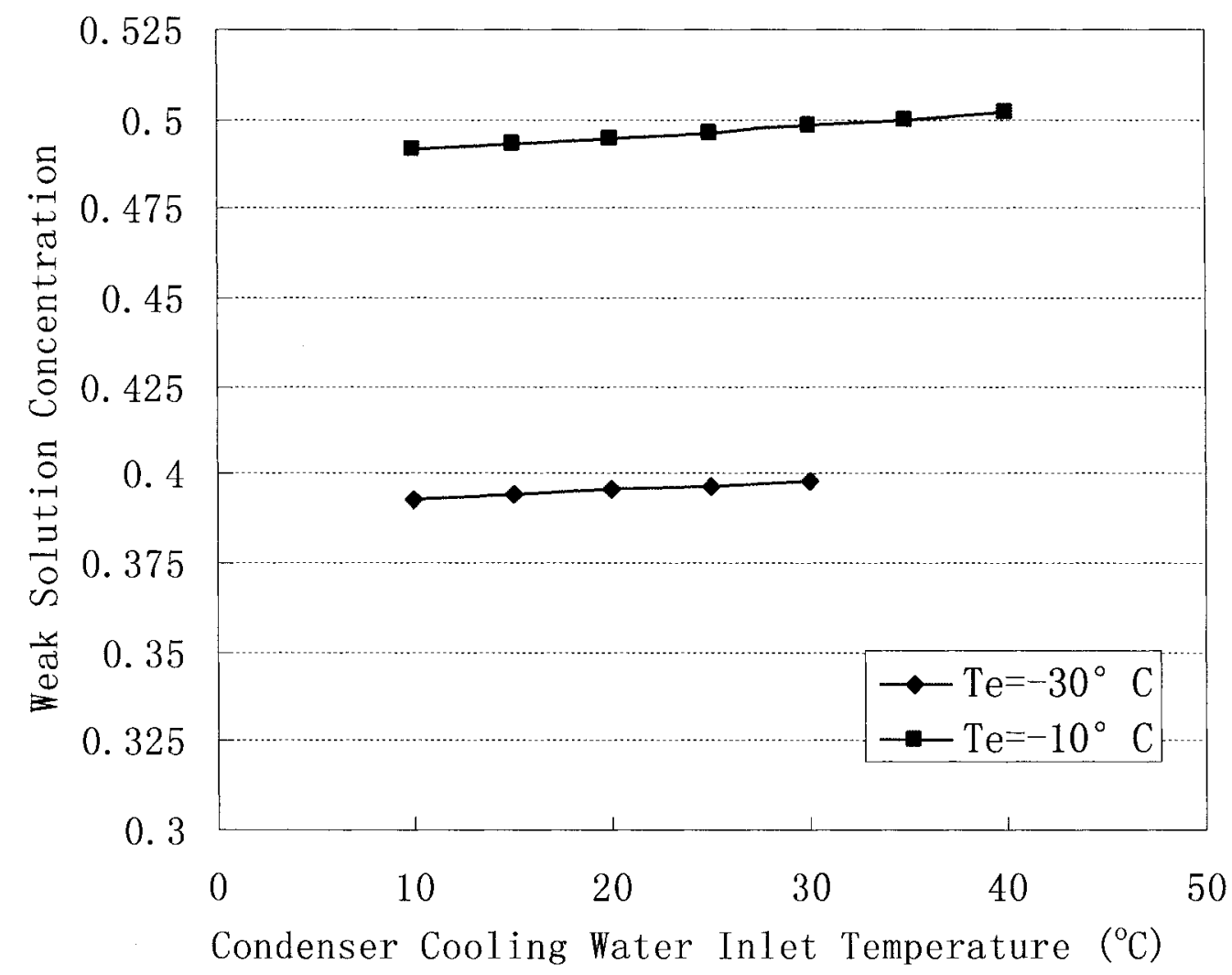

Figure 3.38 The relation between condenser cooling water inlet temperature and weak solution concentration 


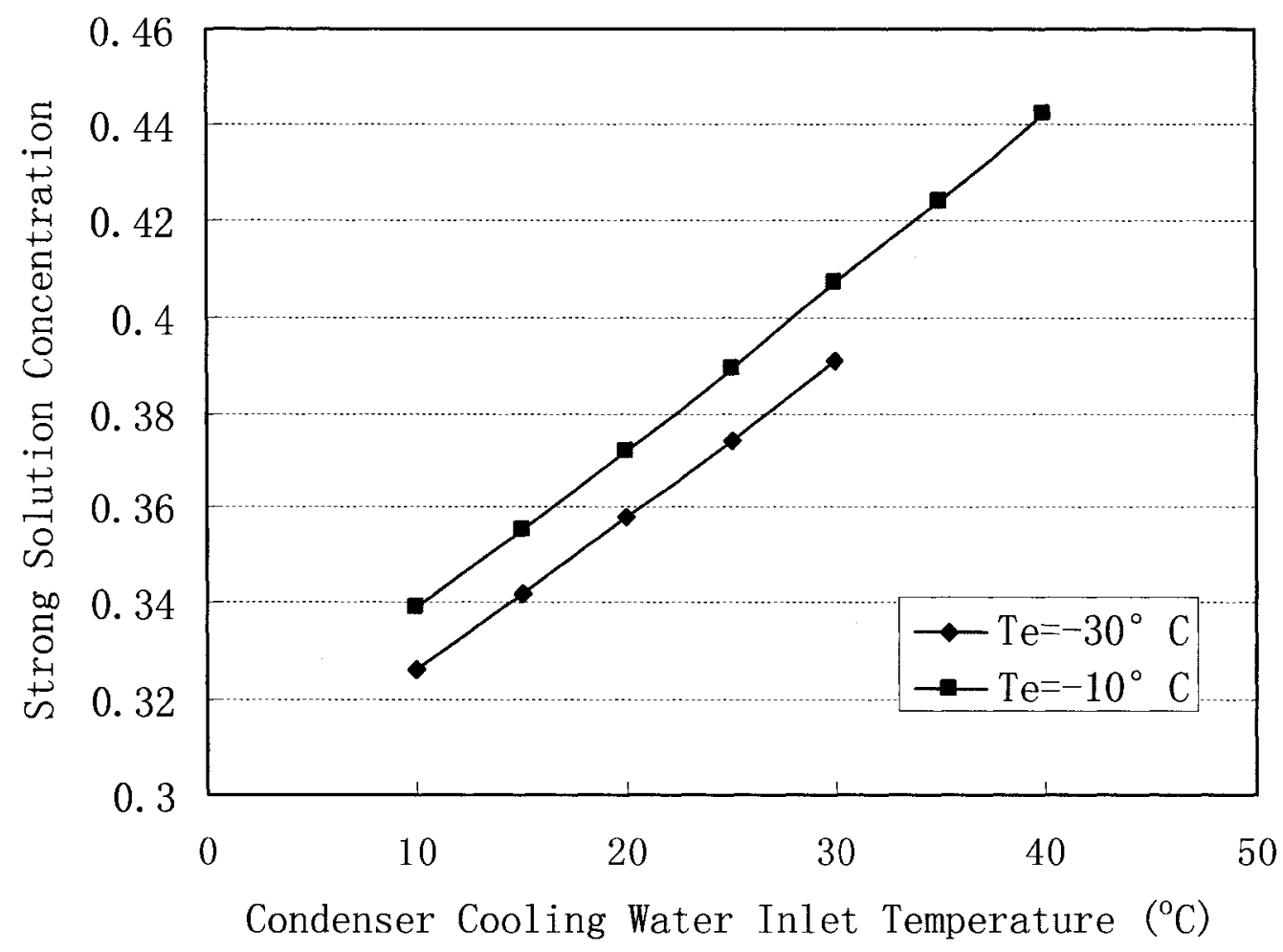

Figure 3.39 The relation between condenser cooling water inlet temperature and strong solution concentration

\subsubsection{Influence of the cooling water inlet temperature to absorber}

The influence of absorber cooling water inlet temperature is similar as that of condenser cooling water inlet temperature. Because the absorbing process is an exothermic process, the purpose of absorber cooling water is to decrease solution temperature and improve absorptivity.

Figure 3.40 shows the relationship between circulation ratio and the absorber cooling water inlet temperature, the system is assumed to operate in constant condenser cooling water inlet temperatures, constant evaporator outlet temperature 
and constant heat source temperature conditions. Based on the "design point" described above, the condenser cooling water inlet temperatures was chosen as $T_{c}=15^{\circ} \mathrm{C}$, the heat source temperature value is $T_{g}=95^{\circ} \mathrm{C}$, and the efficiency of solution heat exchanger was chosen as $80 \%$, and three different evaporator outlet temperature $T_{e}=-30^{\circ} \mathrm{C}, T_{e}=-20^{\circ} \mathrm{C}$ and $T_{e}=-10^{\circ} \mathrm{C}$ are chosen to simulated different operating conditions for comparison purpose. It can be observed that the circulation ratio increases with the absorber cooling water inlet temperature increase. For $T_{e}=-30^{\circ} \mathrm{C}$ operating conditions, if the cooling water inlet temperature increases greater than $25^{\circ} \mathrm{C}$, the circulation ratio will increase dramatically, and for high evaporator outlet temperature conditions, this temperature limit will be higher.

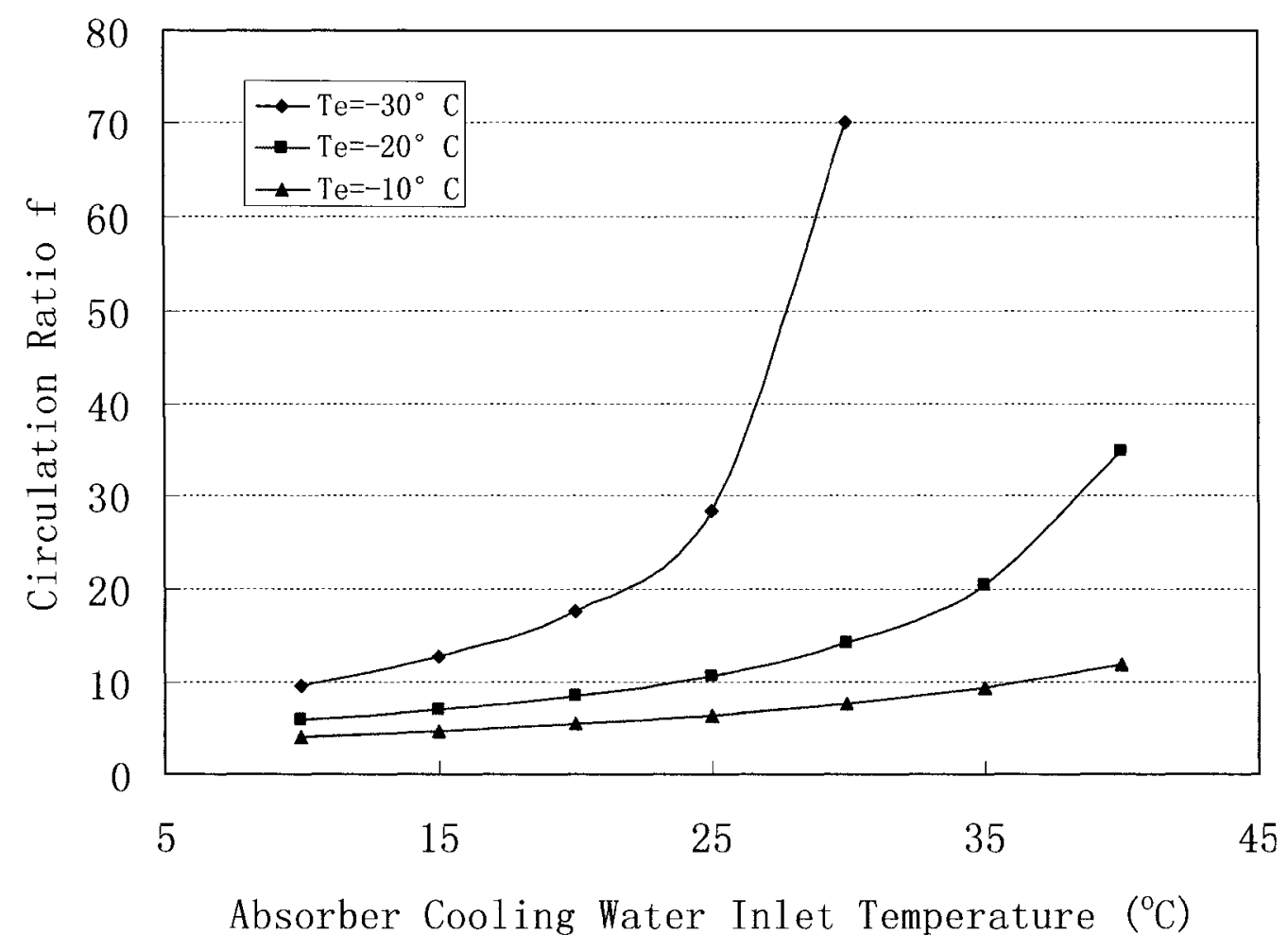

Figure 3.40 The relation between absorber cooling water inlet temperature and circulation ratio 
Another obvious phenomena can be observed is the influence on heat rejection from absorber. It can be seen from Figure 3.41 that higher absorber cooling water inlet temperature will cause less heat rejected from absorber. With the increase of evaporator outlet temperature, the heat rejection from absorber will increase. This data is useful for the heat pump operating mode. It can be described that, the heat pump performance is higher in higher ambient temperature and low heat pump output temperature operating conditions.

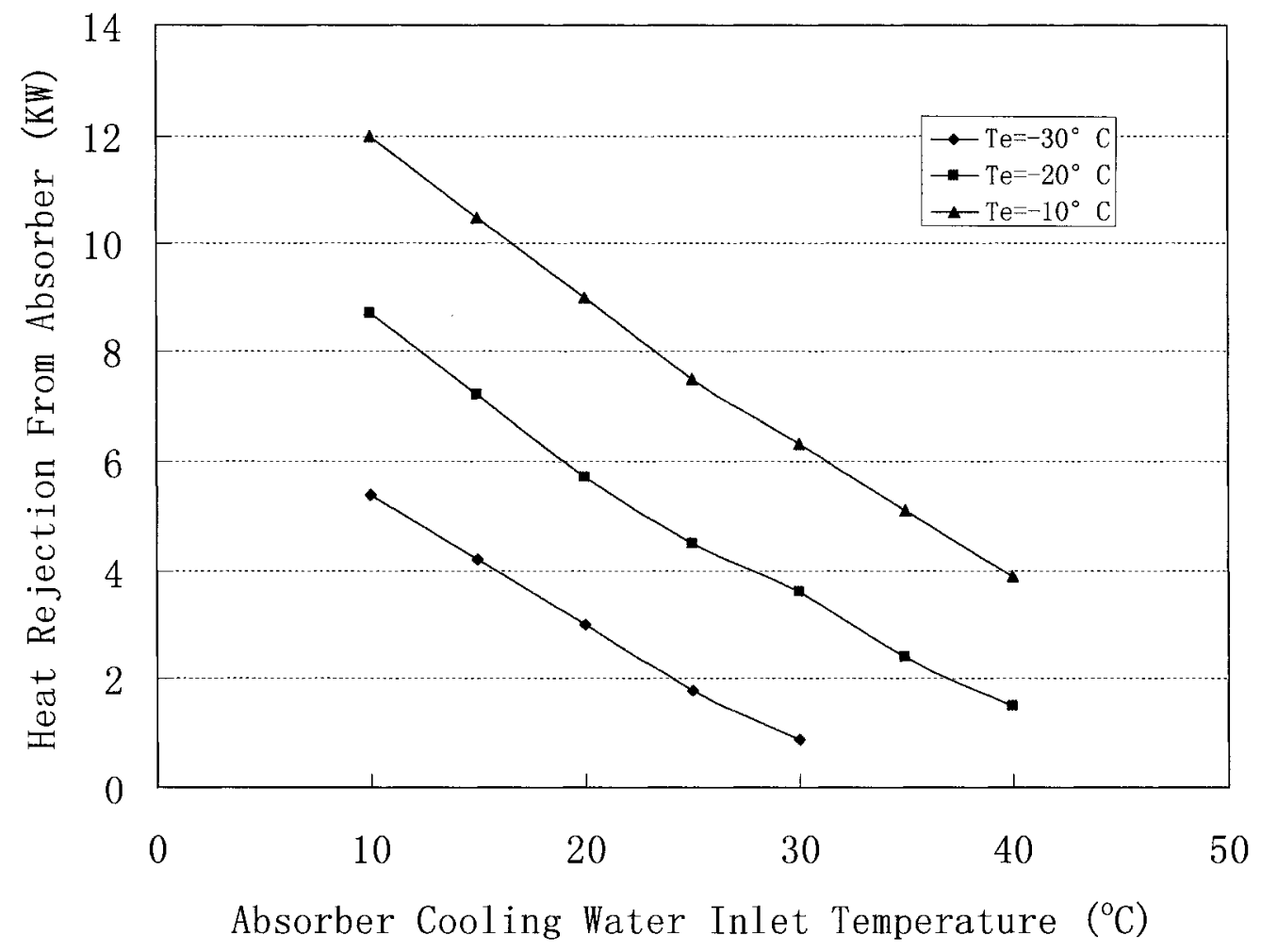

Figure 3.41 The relation between absorber cooling water inlet temperature and heat rejection from absorber

The effect of weak and strong solution concentrations on absorber cooling water inlet temperature are shown in Figure 3.42 and Figure 3.43. Unlike the influence of 
condenser cooling water, the solution concentration will decrease with the increase of absorber cooling water inlet temperature. Compared with the influence on the strong solution concentration, the decrease of the weak solution concentration with the rise of the condenser cooling water inlet temperature is more quickly, and the concentration difference between the weak solution and the strong solution decreases in this process. This character is the same as the influence of the condenser cooling water temperature. And a conclusion can be obtained: high concentration difference caused high system performance.

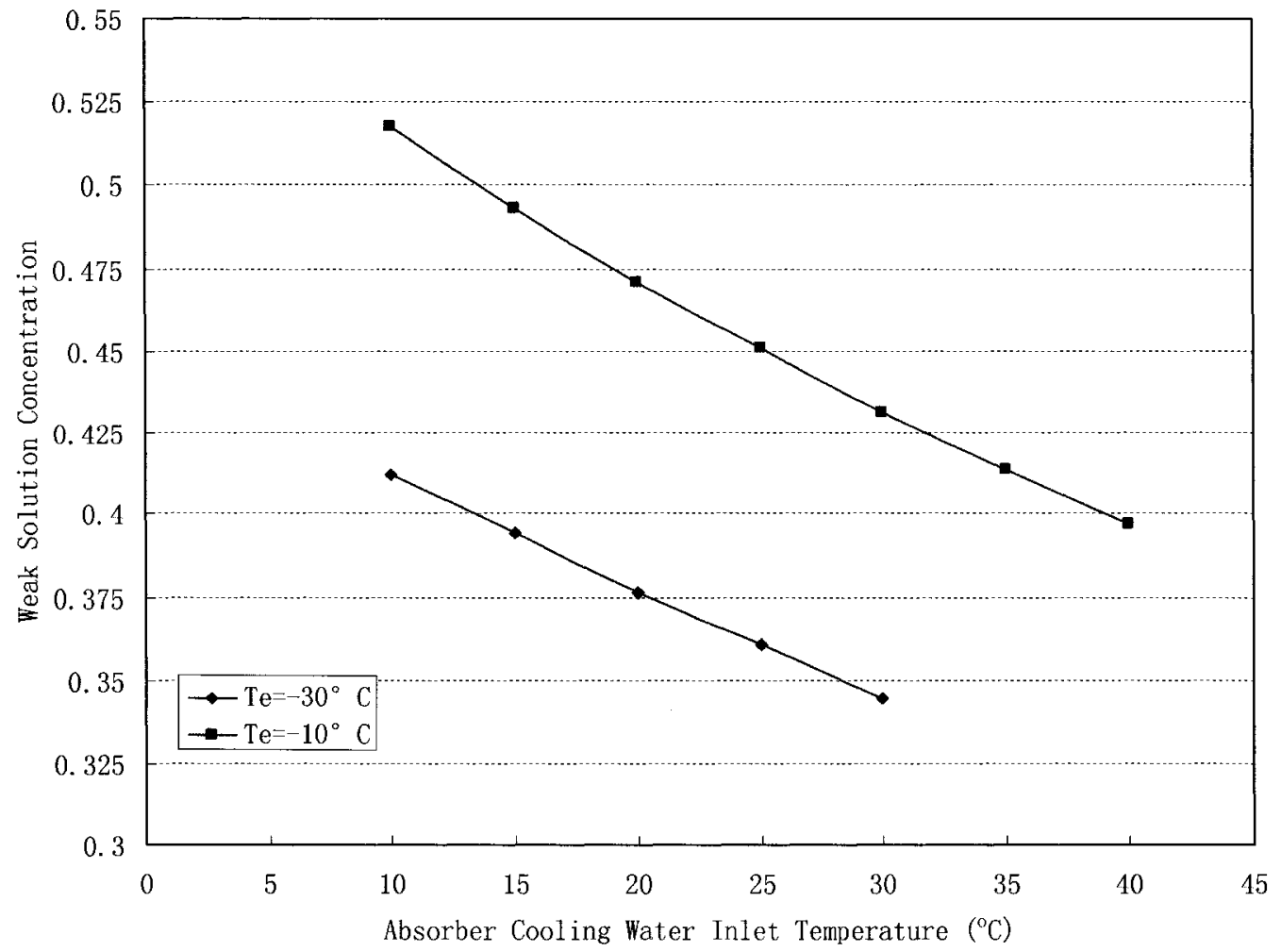

Figure 3.42 The relation between absorber cooling water inlet temperature and weak solution concentration 


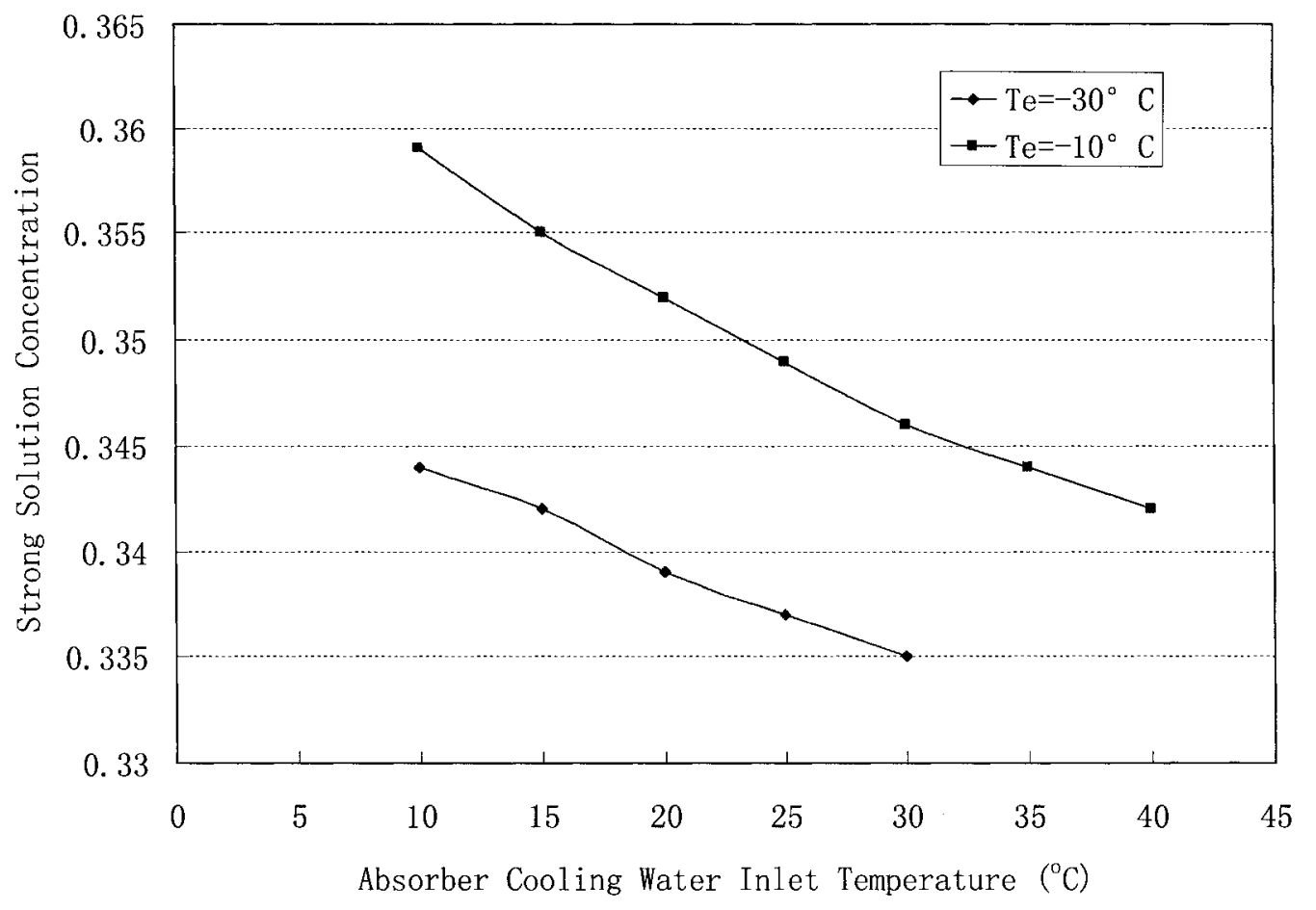

Figure 3.43 The relation between absorber cooling water inlet temperature and strong solution concentration

\subsection{Chapter closure}

In this chapter mathematical model and computational simulation programs are established to model the DMSR system operation. The relationship among different components and system performance, thermal network, heat transfer capacities and other system working conditions are discussed. The simulation results will be used to verify the experimental results obtained in chapter 4 , and will be used as the theory fundamentals for system optimization purposes. 


\section{Chapter 4}

\section{Experimental investigation of DMSR system characteristics}

The purposes of DMSR system testing are to test and evaluate the theoretical models, to collect and analyze pivotal theoretic data for system optimization purpose. The test program mainly focuses on the DMSR system performance investigation and analyses. This chapter introduces detailed DMSR system testing process, and discusses some phenomena observed in the experiments.

\subsection{Introduction to DMSR system testing}

As a refrigeration device, DMSR system performance is evaluated in terms of cooling load and COP. A typical absorption refrigeration system test involves laying a heat source upon the generator, and applying cooling sources on its condenser and absorber, and investigating the system temperature characteristics. The directly measurable factors are the temperatures. Other factors such as heat flux, pressure and solution concentration can be obtained through temperature analyses combining thermal physical and thermodynamic correlations. From this point of view, the DMSR system testing is temperature based. There is evidence that, to a great extent, temperature-based analyses are very practical and reliable. This will be further discussed in later sections. 
The DMSR system testing discussed in this chapter is essential to the DMSR system performance verification. This test acts as a working simulation of DMSR system testing, providing heat and cooling sources on the generator, absorber and condenser respectively, to verify the system performance.

Temperature analysis is a major approach to DMSR system performance evaluation and experimental investigation. Selection of temperature measurement methods and tools is the first concern for the DMSR system experimental investigation. The following sections will introduce the experimental apparatus used in our work.

\section{1.1 Introduction to experimental apparatus}

The elements for the DMSR system performance testing include a data acquisition and processing system, a heating source, a cooling source, a power supply and control system, temperature sensors, and of course, a Double Mechanism Sorptive Refrigeration (DMSR) machine first prototype built with DY engineers. These will be introduced respectively in the following sections. Figures 4.1 presents the picture of the experimental apparatus. 


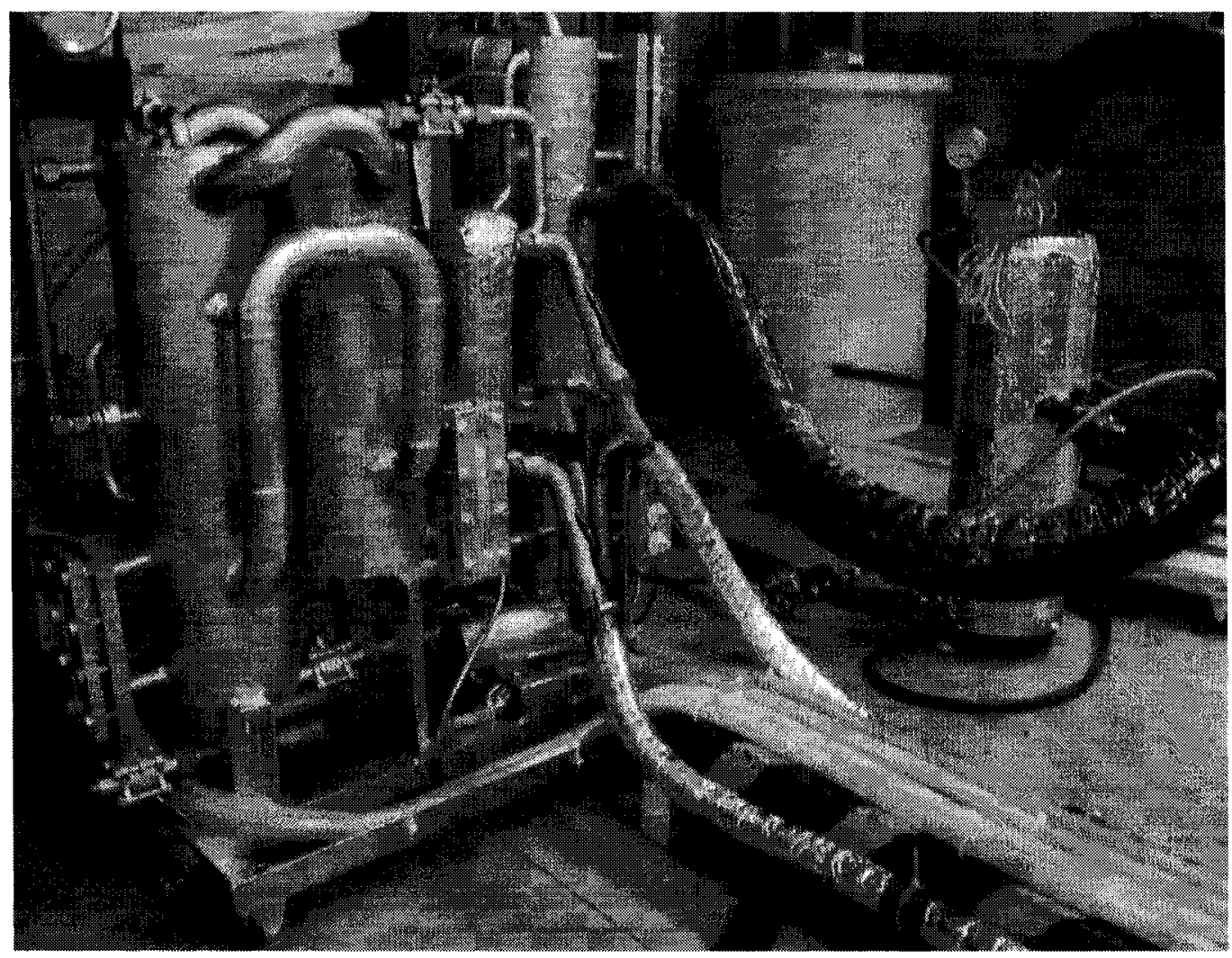

Figure 4.1 The Double Mechanism Sorptive Refrigeration (DMSR) system testing apparatus

\subsubsection{Double Mechanism Sorptive Refrigeration (DMSR) system}

The DMSR testing device used in this thesis work is the first generation prototype established by DY Refrigeration Inc. Based on the structure and function, the system components can be divided into three segments:

a) DMSR absorber and evaporator

The combined DMSR sorber and evaporator is a unique design. There are four tubes to connect the absorber and evaporator, which allow the circulation of the gas phase, the first two of the tubes is design for the circulation of hydrogen, while the 
other two for vapor ammonia circulation. To increase the gas circulation velocity, in-line fans will be integrated in at least two of the tubes in the next prototype design. The circulation speed will be measured and controlled, so that it is able to analyze influence of circulation on the performance of the system. Results are expected to lead to modification of the DMSR sorber and evaporator.

b) Generator

Generator is a cylinder tank stands at the right hand of absorber-evaporator combination shown in Figure 4.1 and connected with the hot water heater with a flexible hose. When the ammonia is vaporized from the solution inside the generator, entrainments carried by ammonia vapour may deposit and contaminate the system. As mentioned, the solution contains NaSCN and some other additives, which are easily condensed in the vapour lines and condensers. A droplet separator shown in Figure 4.2 is recently designed and placed to outlets of the generators.

c) Off-the-shelf components

Off-the-shelf components will include two circulation pumps, four heat exchangers, automation system, safety system, and encapsulation protection. As the only electrically powered components, circulation pumps are used to circulate the solution, while the heat exchangers are functioned as condenser, absorber, solution heat exchanger and cooling output device. 


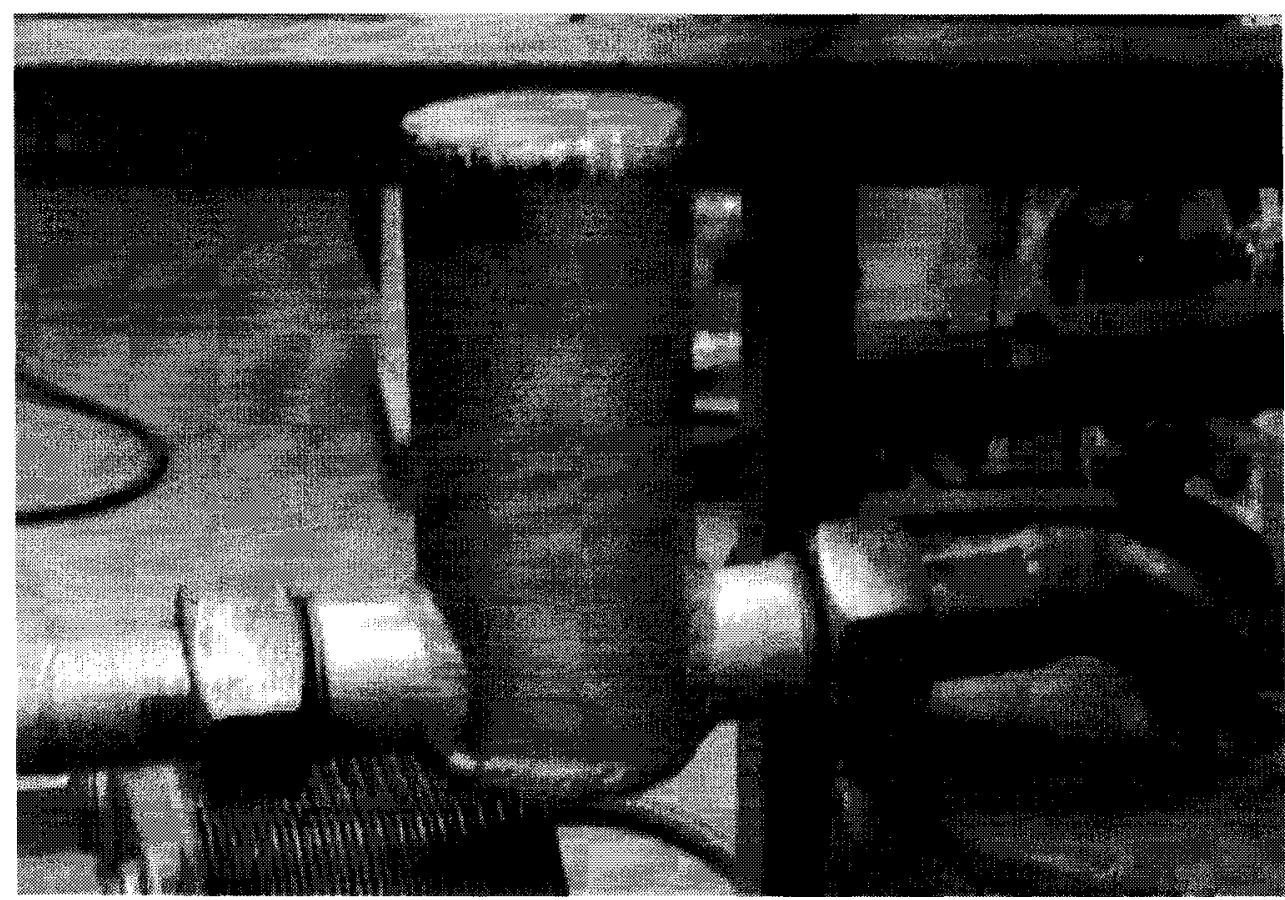

Figure 4.2 Droplet separator designed for condensing NaSCN entrainment in vapor ammonia

\subsubsection{Heat source assembly}

The heat source provides heat power input to the generator of the DMSR system.

Figure 4.3 illustrates the aspect of heat source assembly for DMSR system testing. This is a special design for this testing. Water will be heated to desired temperature by three electrical heaters and will change to vapor phase, this heat source is circulated through the generator by thermosyphon and transfer energy to the DMSR system and then return to the heater to absorb energy again. 


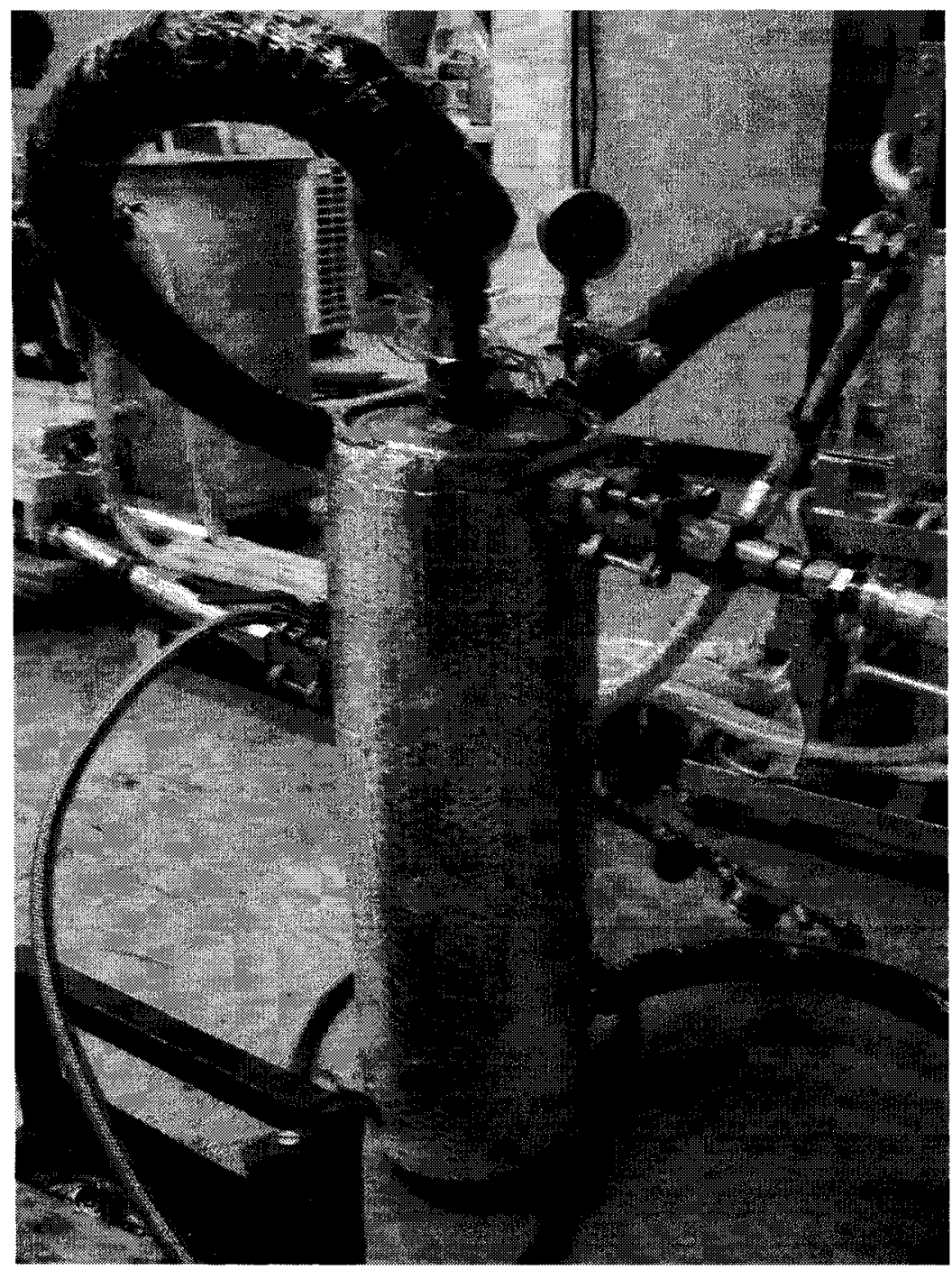

Figure 4.3 Heat source assembly for DMSR system testing

\subsubsection{Cooling collecting device}

Shown as Figure 4.4, the white tank is the cooling collecting device for DMSR system experiments. It is a double layer tank, adiabatic material is added to the interlayer for heat insulation purpose; antifreeze fluid $\left(-40^{\circ} \mathrm{C}\right)$ is filled in the inner tank and circulates to the evaporator driven by a circulation pump. An electrical heater of $1.5 \mathrm{~kW}$ is placed in the liquid antifreeze fluid to supply energy to balance the cooling capacity and simulate the loads. 


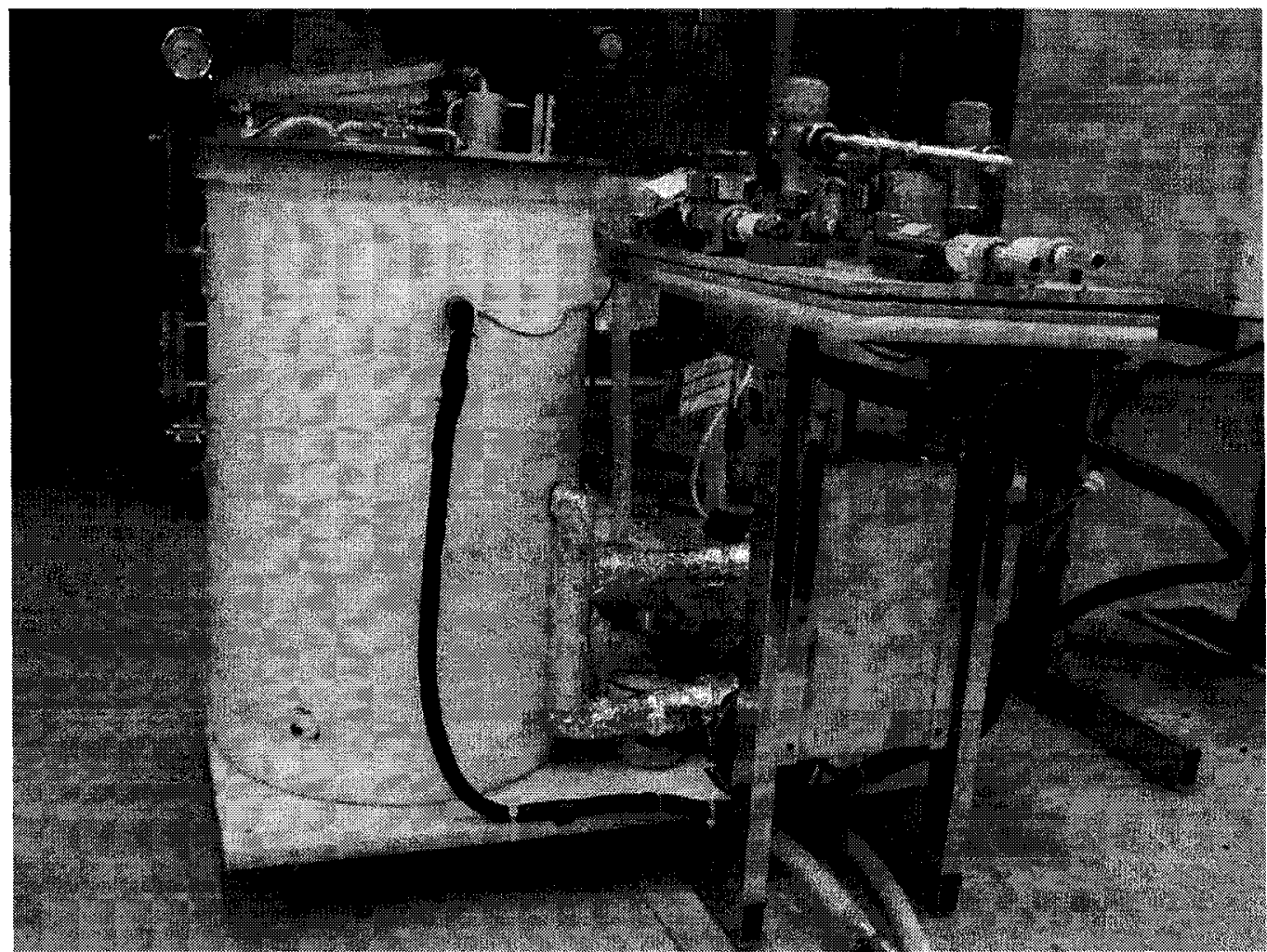

Figure 4.4 Cooling collecting device and cooling water control and detect device

\subsubsection{Data acquisition system}

The data acquisition and processing system plays a critical role in these DMSR system performance tests. It implements temperature measurements during the process of the testing, transiently recording the values of each measurement, and saving these values as data in the form of a file. The file can then be transferred to the data process section, e.g., computer systems through I/O connection.

In this research, the data acquisition system is the MCGS-51 simulation configuration system (Beijing Kunlun Tongtai Automation Software Technology Ltd., Co.), a $6 \frac{1}{2}$-digit high-performance multi-channel/data acquisition system. It is 
commonly used to measure temperature and pressure. The system hardware component and testing interface are shown in Figure 4.5 and Figure 4.6 respectively.

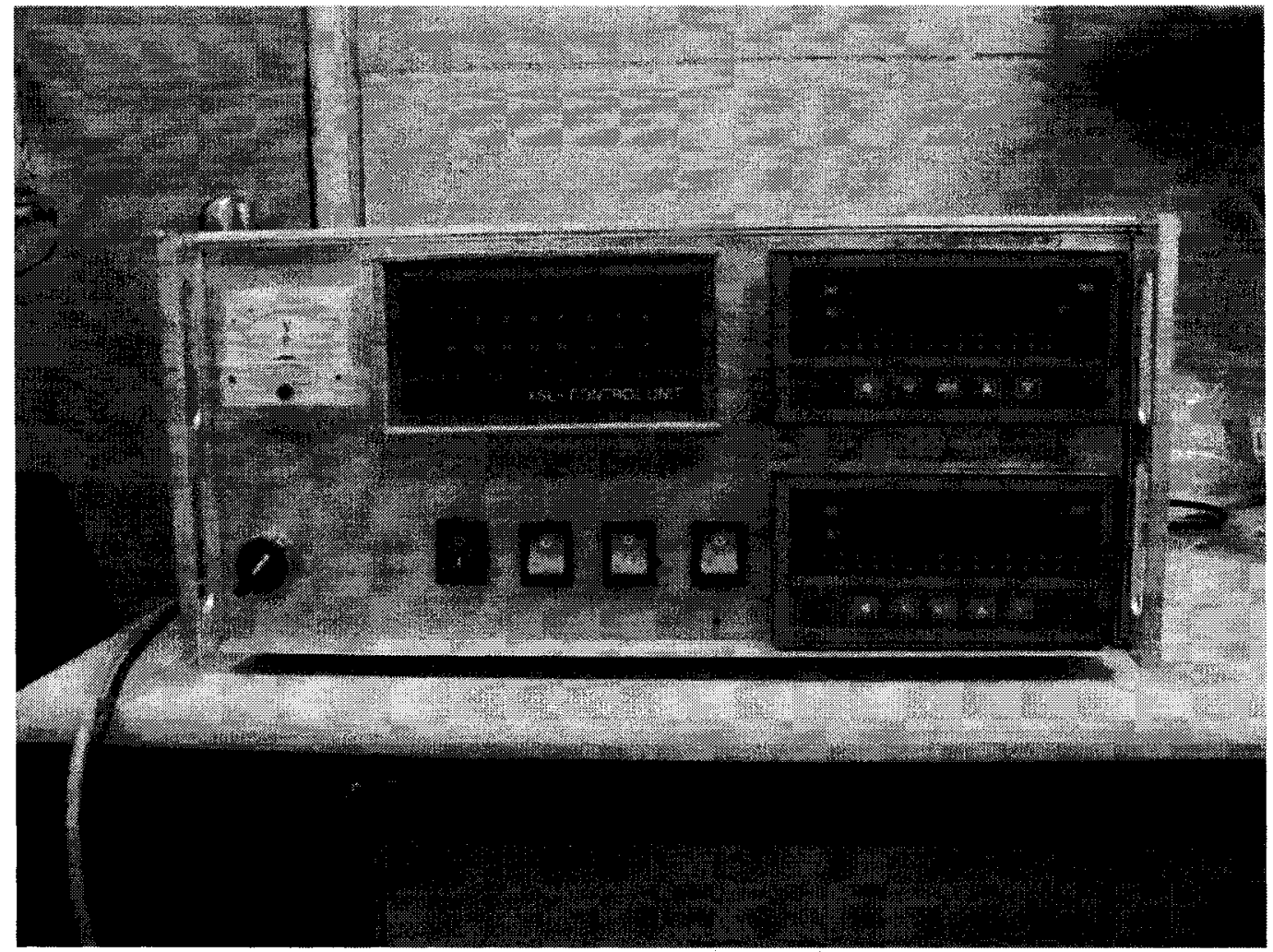

Figure 4.5 Data acquisition system hardware for DMSR system testing 


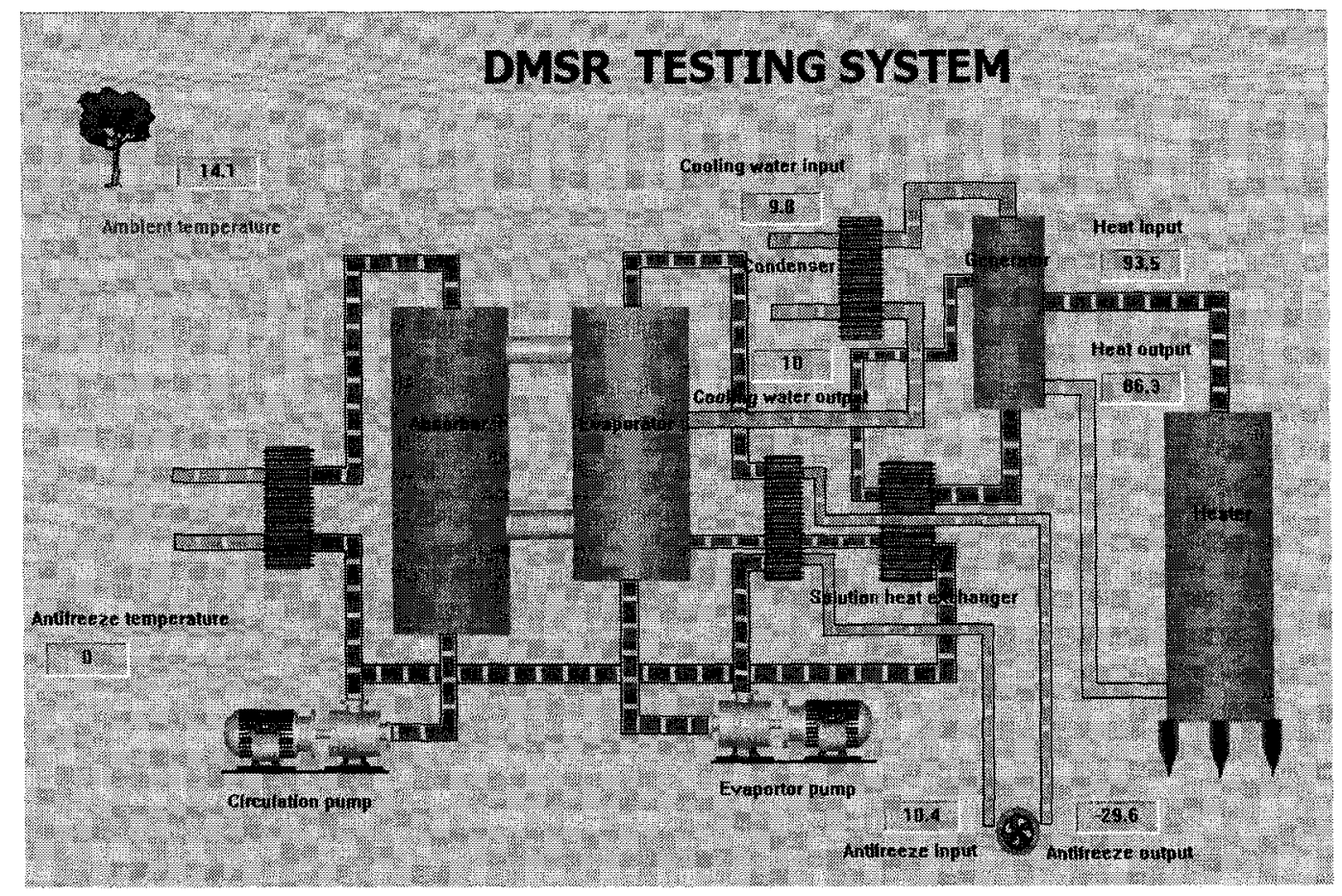

Figure 4.6 Data acquisition system interface for DMSR system testing

\subsubsection{Temperature sensors}

In our work, resistance temperature detector (RTD) sensors were employed as temperature sensors. RTDs offer high precision and an operating range of $-200^{\circ} \mathrm{C}$ to $+850^{\circ} \mathrm{C}$. They also have an electrical output that is easily transmitted, switched, displayed, recorded, and processed using suitable data-processing equipment. Because RTD resistance is proportional to temperature, applying a known current through the resistance produces an output voltage that increases with temperature. Knowledge of the exact relationship between resistance and temperature allows calculation of a given temperature. The sensors we used in this test are platinum RTDs type: PT100, Platinum's long-term stability, repeatability, fast response time, and wide temperature range make it a useful choice in many applications. As a result, platinum RTDs are 
recognized as the most reliable standard for temperature measurement.

Aluminum adhesive tape was employed to fix the sensers to the solid surface of the testing elements. This aluminum tape has an $80^{\circ} \mathrm{C}$ nominal working temperature, but in actual practice, it can work at higher temperature of up to $120^{\circ} \mathrm{C}$ with some special measures.

The aluminum adhesive tape has a very thin glue film on one side, it would have minimal effect on the thermal contact conductance between the platinum probe and the solid surface that will be measured. Thus the contact thermal resistance between the temperature measurement interfaces can be ignored in this case. Furthermore, calibration will also compensate the accuracy of the measurement.

\subsubsection{Other control and assistant assemblies}

\section{Cooling water supply and control assembly}

The cooling water supplied to the condenser and the absorber are provided and controlled by the assembly shown in Figure 4.7 , the left two tubes is supply cooling water with constant temperature to the condenser and the absorber separately, and the

two tubes on right side is the hot and cold water sources. The water temperature and flow rate are controlled separately by the temperature valves and switches. Water flow rate can be detected form the two flow meters. 


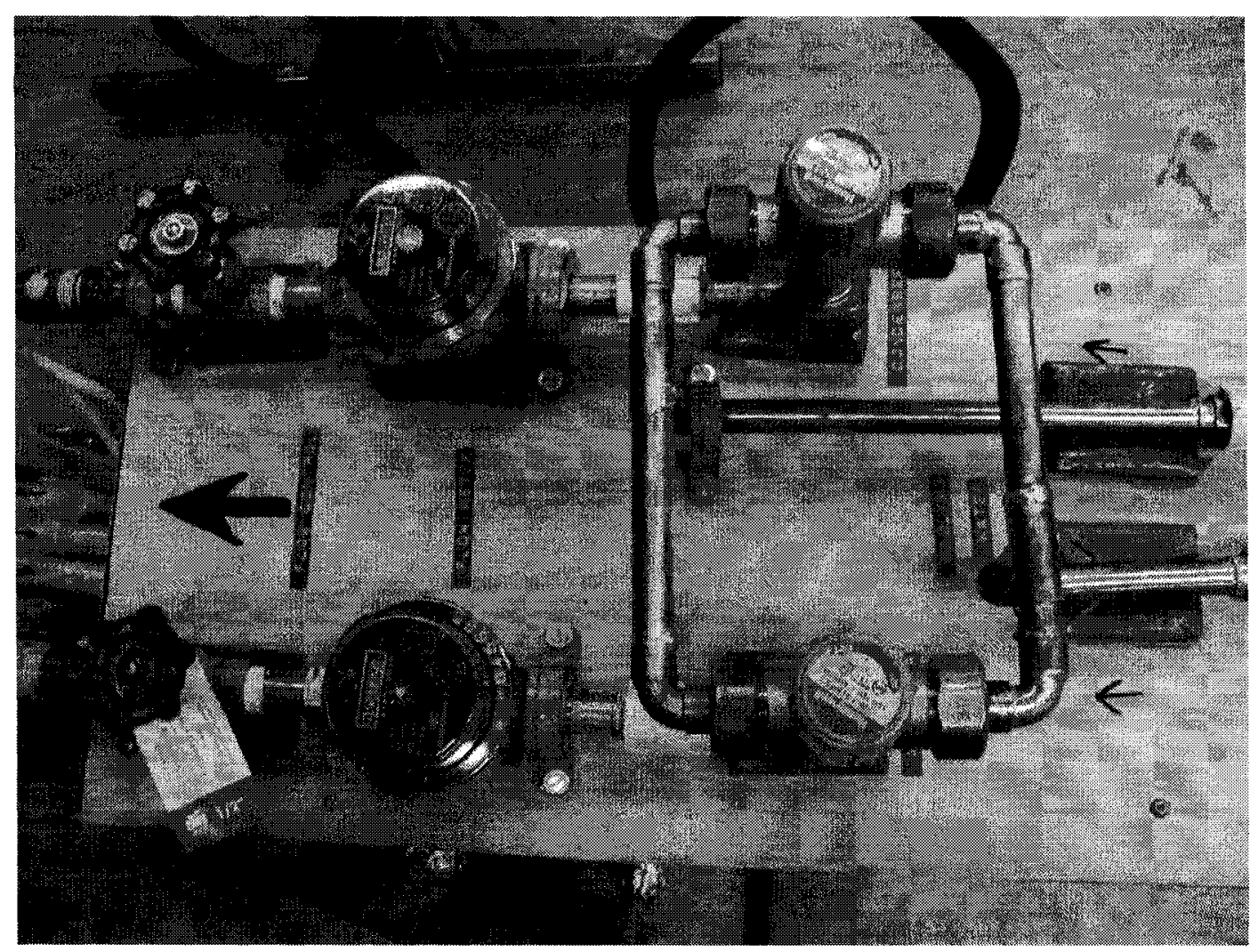

Figure 4.7 Cooling water supply and control assembly for DMSR system testing

\section{Electrical control and detecting assembly}

All electrical supply to the test devices is controlled by the electrical control and detecting assembly shown in Figure 4.8, for system safety and operating convenience. The temperature value of the cooling collecting tank has a display and control led by the electrical supply to the heater in the cooling tank. 


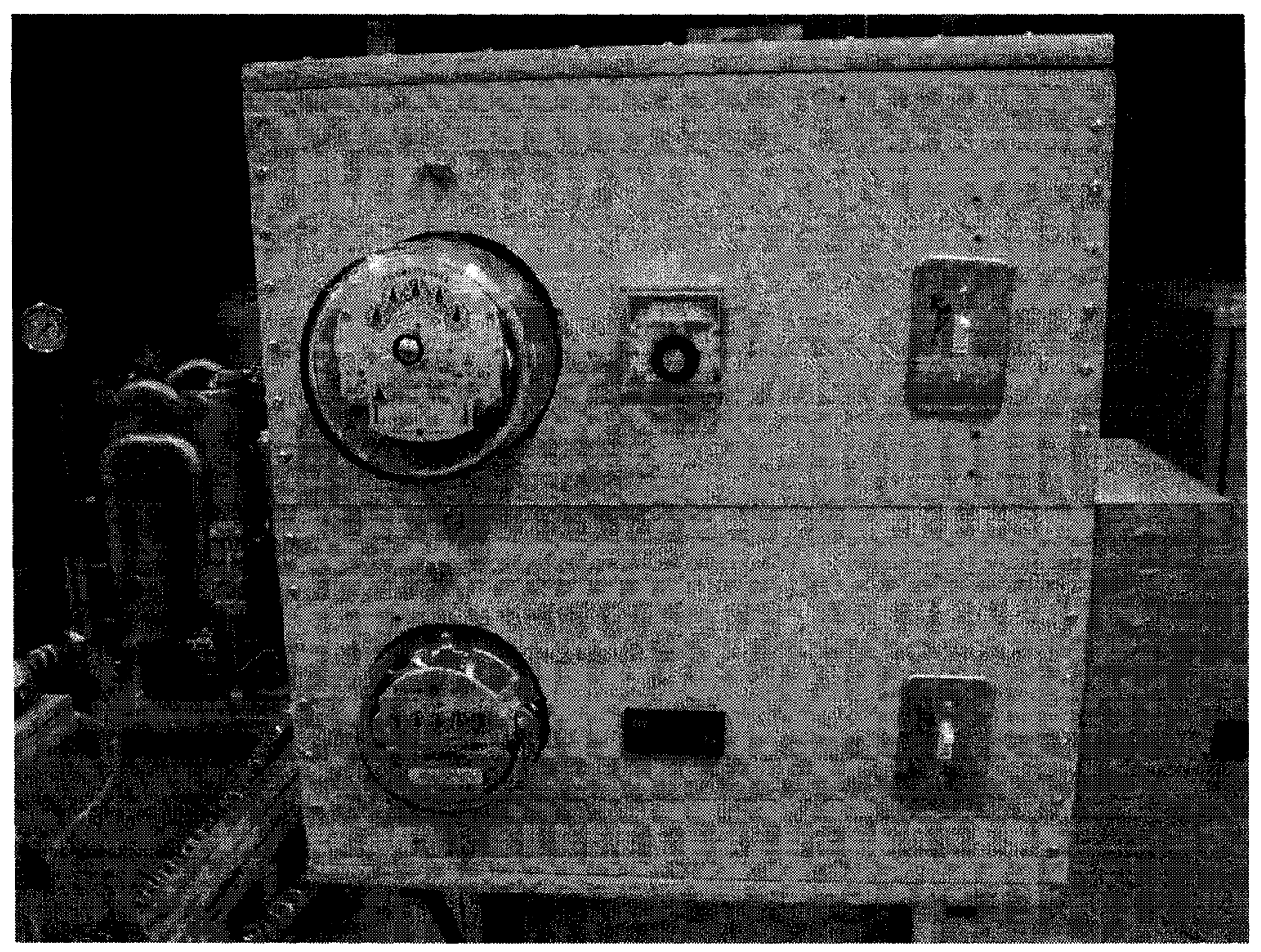

Figure 4.8 Electrical control and detecting assembly for DMSR system testing

\subsection{DMSR system testing}

\section{2.1 Experimental 1}

Typical refrigeration working conditions are set for the first prototype, the condenser and absorber cooling water temperature is about $15^{\circ} \mathrm{C}$, the heat input temperature is set to a range of $80^{\circ} \mathrm{C}$ to $100^{\circ} \mathrm{C}$, and charge the expansion gas hydrogen to control the evaporator temperature in normal refrigeration working conditions, the system performance will be observed, measured, and data are collected and analyzed in steady states. The data collected in this experiment will be used to 
check, evaluate and optimize the existing prototype.

\subsubsection{Experimental objectives}

The objectives of this experiment are summarized as follows:

1. Measuring the solution temperature, flow rates and concentration at various locations, especially at the inlet and outlet of every heat exchanger, components.

2. Monitoring system pressures at several locations;

3. Experimentally establishing the relationships among the generation temperature, flow rate, system performance and cooling load;

4. Experimentally establishing the relationships among cooling water temperature, flow rate, system performance and cooling load.

\subsubsection{Experimental principle and setup}

The experimental principle is based on the DMSR system characteristics described in the previous chapters. The condenser and absorber cooling water come from the common water pipeline and are supplied to the absorber and the condenser separately. The heat source temperature is controlled by a hot water temperature controller.

\subsubsection{Experimental procedure}

1. Connect the cooling water and antifreeze to the DMSR prototype; 
2. set hot water heater temperature (initial values);

3. Set the serial number for every sensor and install them to the correct place, check the scanner program and make sure the scanner and all sensors are not damaged and work in good conditions;

4. Insulate the DMSR prototype from loss of heat with prepared insulating materials;

5. Prepare solution in the mixing tank and charge the solution from the bottom of the absorber, and charge the expansion gas hydrogen from the top of absorber to the required partial pressure;

6. Turn on the cooling water circulation pump, solution circulation pump and antifreeze circulation pump;

7. Tune on power supply of the hot water heater and adjust the heat source temperature to required value;

8. Allow a few minutes, when the liquid ammonia is observed from the liquid level visualizer on evaporator, switch on the liquid ammonia circulation pump;

9. Waite for several minutes and let the system reach steady state.

10. Continually increase the heat source temperature, observe the change of other output value, temperatures and pressures, especially the change of evaporator outlet temperature. 


\subsubsection{Experimental results and analyses}

The experimental results about the relationship among heat source temperature, system performance, and temperature at various locations, especially at the outlet of every heat exchanger for normal refrigeration working conditions are presented in Appendix II.1.

Figure 4.9 to Figure 4.11 illustrate the record for the normal working condition tests. It can be seen that the evaporator outlet temperature will decrease with the increase of heat source temperature value. With the increase of heat source temperature, the heat load to generator will increase and then cause the increase of cooling capacity, and the flow rate of liquid antifreeze is constant in this test, the only way to increase the cooling capacity is increase the inlet and outlet temperature difference of the liquid antifreeze, this is the reason that evaporator outlet temperature decreases.

From Figure 4.10 and Figure 4.11, it can be seen that the condenser and absorber cooling water outlet temperature will increase with the increase of heat source temperature. With the same cooling water input condition, the absorber cooling water outlet temperature is higher than condenser cooling water outlet temperature. In the last chapter, the simulation results have already displayed the relationship among cooling capacity, absorber and condenser cooling water outlet temperature and heat source temperature. Comparison between these experimental results and the simulation data showed good agreement. 


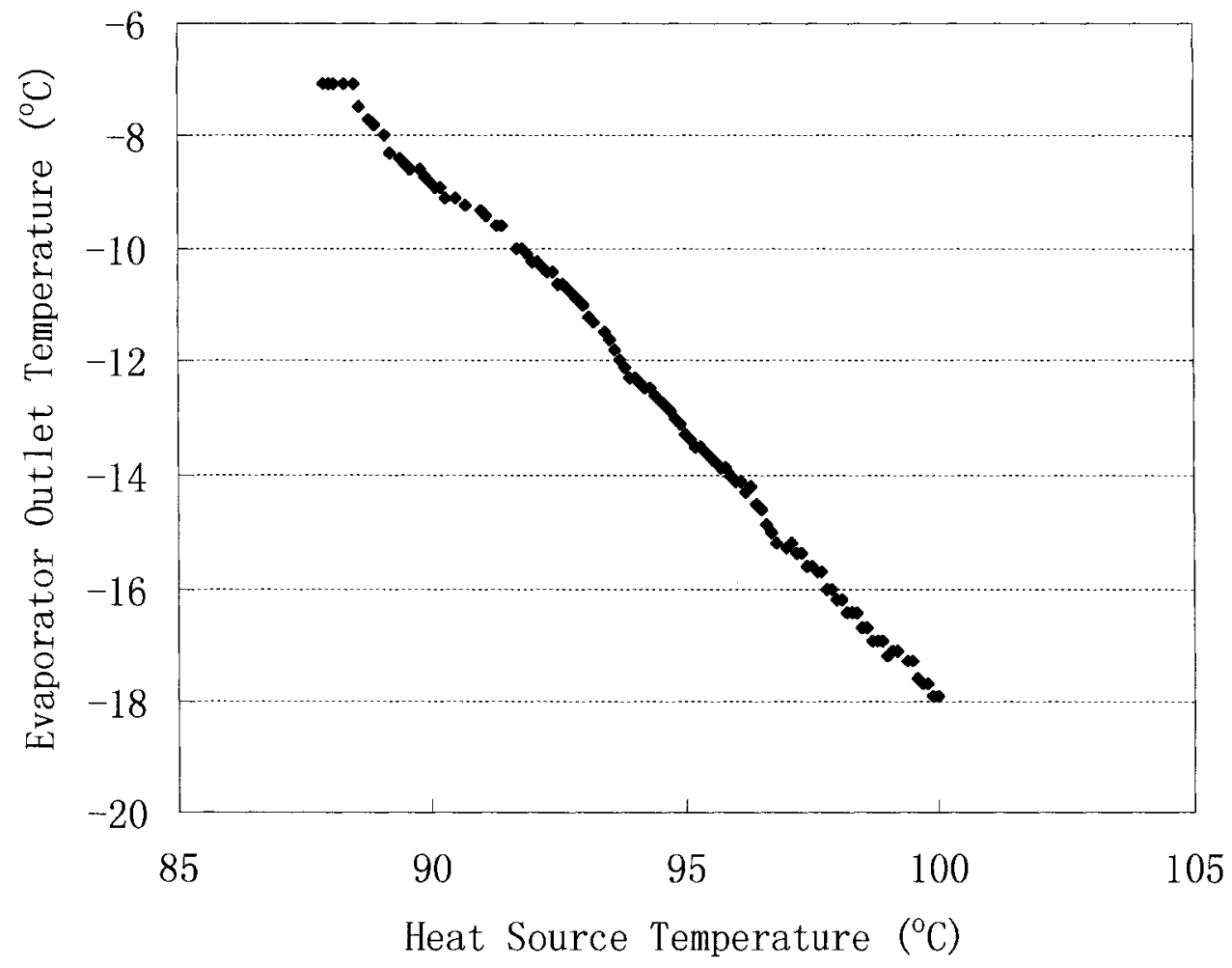

Figure 4.9 The relation between evaporator outlet temperature and heat source temperature (Normal working conditions)

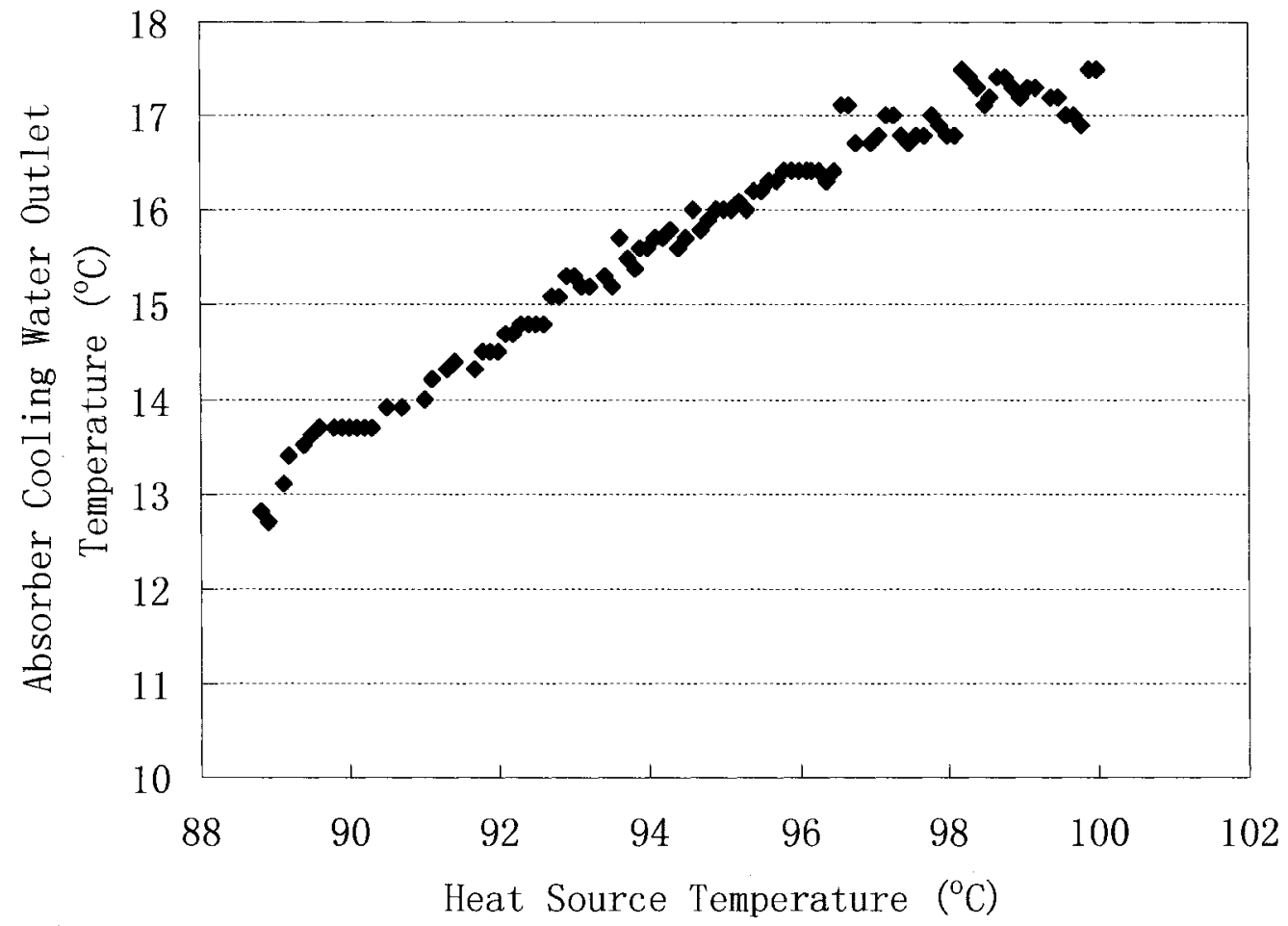

Figure 4.10 The relation between absorber cooling water outlet temperature and heat source temperature (Normal working conditions) 


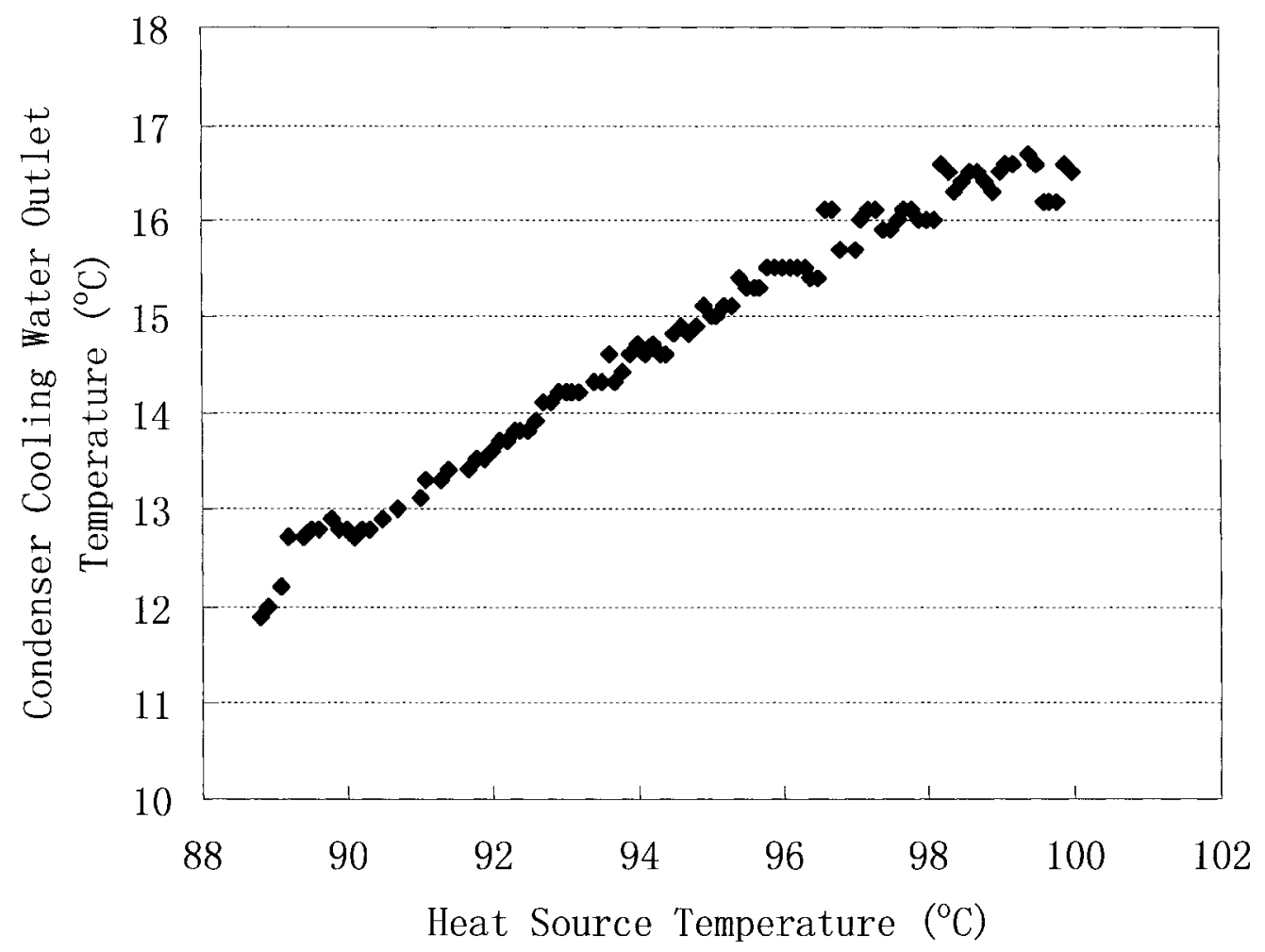

Figure 4.11 The relation between condenser cooling water outlet temperature and heat source temperature (Normal working conditions)

\section{2.2 Experimental 2}

Compared with other absorption refrigeration systems, one of the most important advantages is that the evaporating temperature of the DMSR system can reach almost $-30^{\circ} \mathrm{C}$, the function of this test is try to explore the system performance when the DMSR system working in super-cooling operating conditions, detect the possible problems, collect pivotal data to optimizing the current prototype. 


\subsubsection{Experimental objectives}

The objectives of this experiment are summarized as follows:

1. Measuring the solution temperature, flow rates and concentration at various locations, especially at the inlet and outlet of every heat exchanger and component.

2. Monitoring system pressures at some locations;

3. Detecting possible problems, collect experimental data and relationships for the purpose of modifications of the DMSR system and individual components.

\subsubsection{Experimental principle and setup}

The experimental principle is the same as last test. Based on the DMSR system characteristics described in the above chapters. The condenser and absorber cooling water come from the common water pipeline and supplied to the absorber and condenser separately. Because the evaporator output temperature value is very low, it can be speculated that the system COP will be lower than normal high evaporating temperature working conditions, so that high heat source temperature is needed. At the same time, in order to reach low evaporating temperature, more hydrogen should be charged to the system to improve the partial pressure.

\subsubsection{Experimental procedure}

The experimental procedure is exactly the same as last test; the only changes are 
shown below:

1. Charge more hydrogen to the system;

2. Increase the heat source temperature to above $100^{\circ} \mathrm{C}$, the exact value decided by the evaporating temperature value;

3. Choose correct antifreeze fluid and increase the power of heater in antifreeze tank to avoid icing.

\subsubsection{Experimental results and analyses}

The experimental results about the relationship among heat source temperature, system performance, and temperature at various locations, especially at the outlet of every heat exchanger for super-cooling refrigeration working conditions are presented in Appendix II.2.

In this experiment, with the increase of heat source temperature, the lowest evaporating temperature can reach $-30^{\circ} \mathrm{C}$. In this working condition, the cooling capacity will lower than that at normal high evaporating temperature working condition, and the system COP is less than 0.4 , this value is lower than the COP value got from simulation process. The reason is in the experimental process, in order to decrease the evaporating temperature, large amount of hydrogen is charged to the evaporator and absorber, it suppresses the evaporation of refrigerant because of mass transfer resistance to ammonia vapor, caused the inert hydrogen gas. The expansion gas also produces a mass transfer resistance during sorption process. In the simulation process, for the simplification purpose, the mass transfer resistance of expansion gas 
is neglected. It caused the achieved system COP values are higher than real experimental values. The mass transfer resistance of expansion gas will be calculated in the simulation process in the future work.

The same as the last test, the evaporating temperature will decrease with the increase of heat source temperature, when the heat source temperature increases to about $110^{\circ} \mathrm{C}$, with other exact input values used in this test, the evaporator outlet temperature value can reach $-25^{\circ} \mathrm{C}$, and if the evaporator outlet temperature value of $-30^{\circ} \mathrm{C}$ is needed, the heat source temperature should above $130^{\circ} \mathrm{C}$, at the same time, the cooling water temperature, especially the condenser cooling water inlet temperature should be decreased, too. Shown in Figure 4.13, the evaporating temperature will increase with the increase of cooling water inlet temperature.

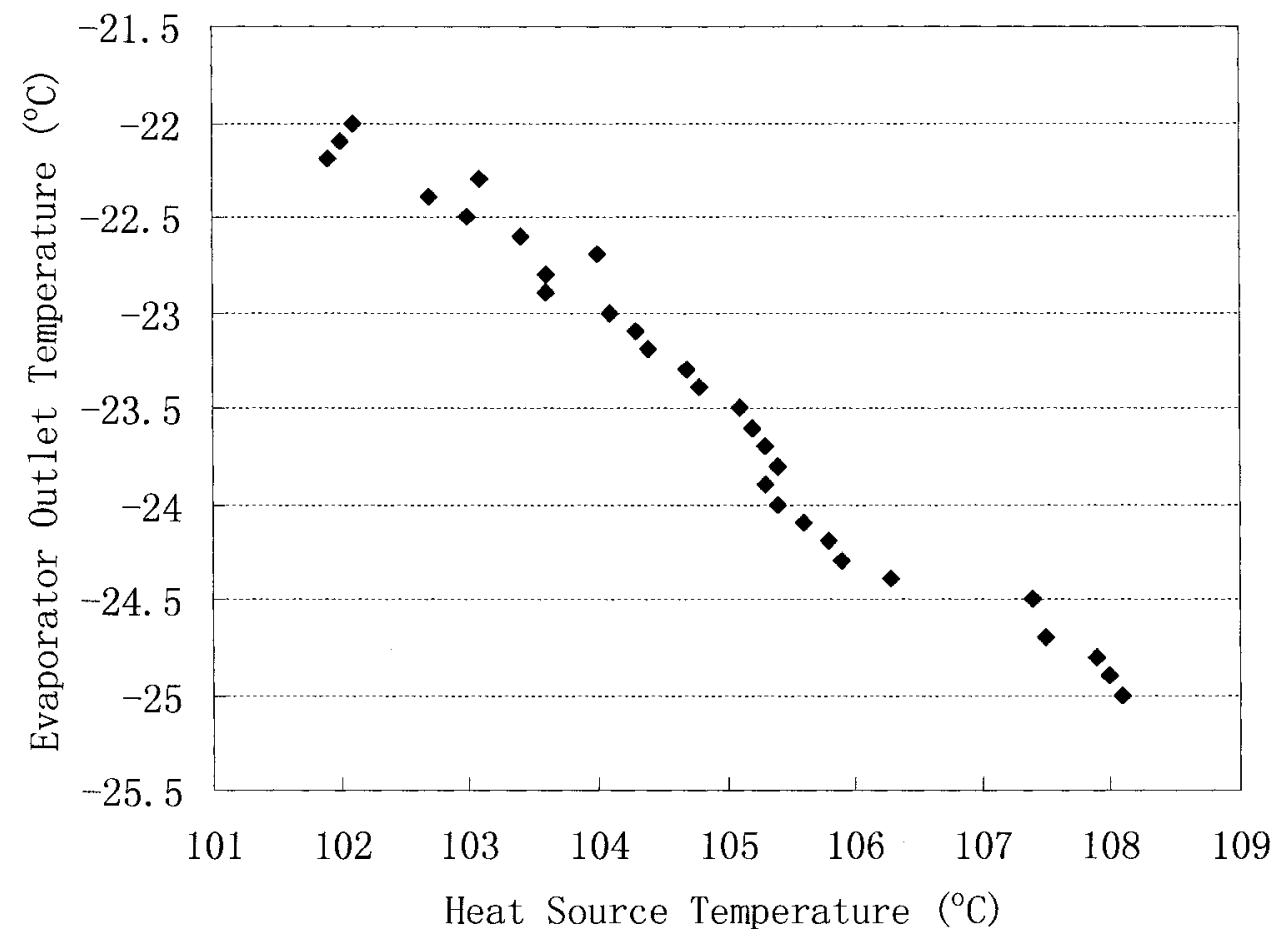

Figure 4.12 The relation between evaporator outlet temperature and heat source temperature (Super-cooling working conditions) 


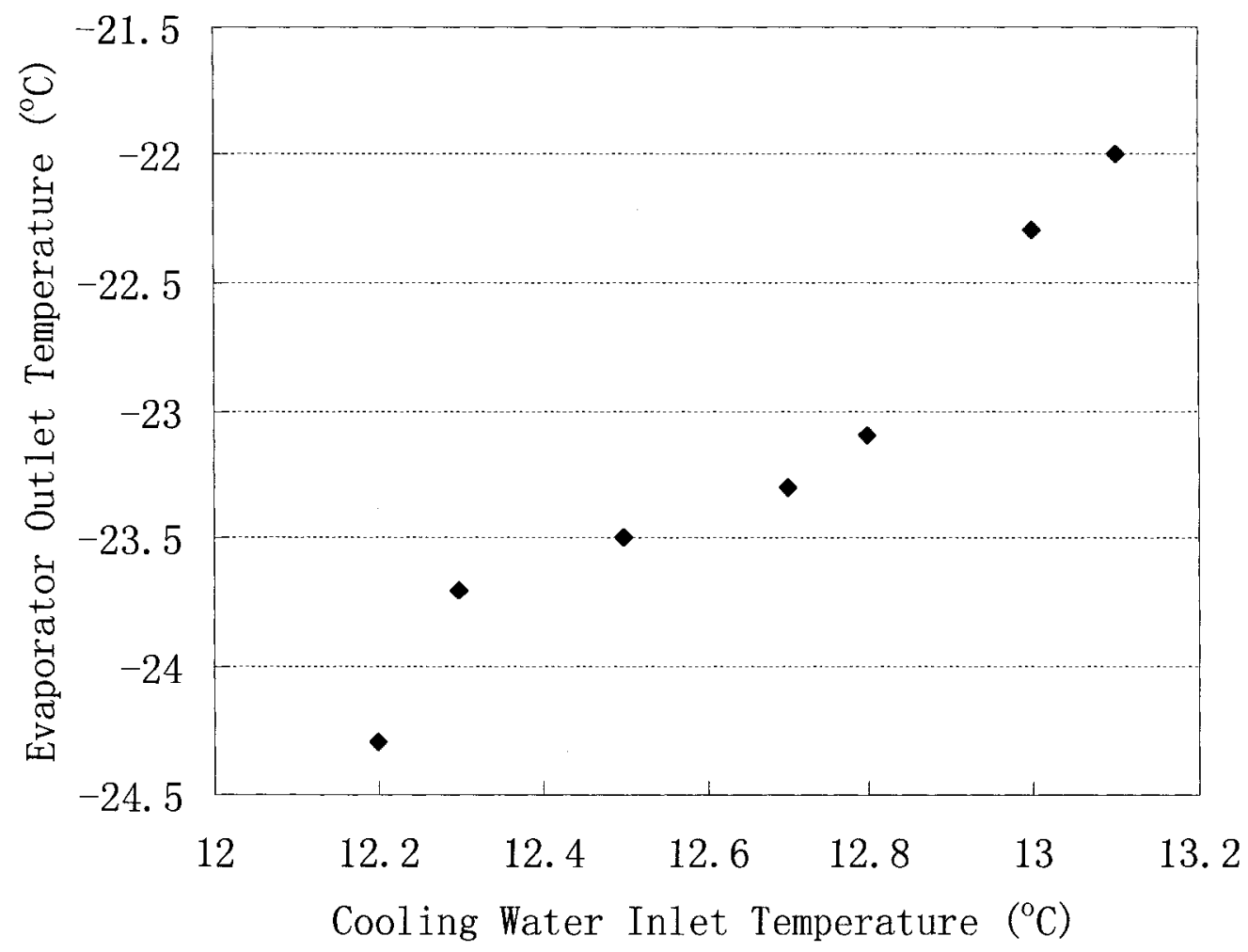

Figure 4.13 The relation between evaporator outlet temperature and cooling water inlet temperature (Super-cooling working condition)

\subsection{Chapter closure}

The experimental results have been analyzed qualitatively. Generally, results are consistent with our predictions. However, there are still some unexpected results, and some phenomena need further inquiry. 


\section{Chapter 5}

\section{Conclusions and recommendations}

\subsection{Summary and conclusion}

\section{Basic properties research}

According to the initial design, the DMSR system uses $\mathrm{NaSCN}$ and $\mathrm{NH}_{3}$ as sorption pair. Compared to other absorption refrigeration system working pairs, this working pair has high solubility, low viscosity and high specific heat and high conductivity, and no corrosion to the steel.

From literatures, the basic thermal properties of the $\mathrm{NaSCN}-\mathrm{NH}_{3}$ working pair were collected, compared and formulated, which include enthalpy, viscosity, density, thermal conductivity, specific heat and the crystallization line. The relationship between the solution crystallization temperature and solution concentration was investigated.

\section{Theoretical modeling of the DMSR system}

According to the initial design, the preliminary DMSR model was built. Based on the parameters, such as the ambient temperature, heater temperature and the concentration of solution, this model can be used to predict the basic operation conditions of the system. The model was able to find: the equations for the maximum and minimum concentration of the solution; the circulation ratio; and the temperature, 
flow rate and enthalpy of the solutions at the inlet and outlet of the heat exchangers.

Based on this theoretical model, two computational programs were built to simulate the components and overall system performance, separately. The system COP, cooling capacity, heating load, circulation ratio and solution concentration of DMSR system against various generator, condenser, evaporator, absorber and solution heat exchanger situations are simulated and compared. Simulation data will be used to analyse the system theoretic characteristic and improve the system performance and will contribute to the design of the second DMSR system prototype.

\section{The DMSR system performance testing}

With the scope of this thesis work, the performance testing mainly consisted of steady-state operating tests. Based on the characteristics of the DMSR system, two kinds of operating conditions were employed: normal working conditions, the evaporating temperature is about $-10^{\circ} \mathrm{C}$; and super-cooling working conditions, the evaporating temperature is almost reaching $-30^{\circ} \mathrm{C}$.

The directly measurable factors of the experimental work are the temperatures, especially at the inlet and outlet of every heat exchanger, components. Other factors such as heat flux, pressure, enthalpy and solution concentration can be obtained through temperature analyses combining thermal physical and thermodynamic correlations. The experimental results were collected to establish the relationship among the generator heat source and outlet temperature, condenser cooling water inlet and outlet temperature, generator inlet and outlet temperature, absorber cooling water 
inlet and outlet temperature, system circulation ratio, cooling capacity, heating load, system COP and solution concentration, and to validate the simulation results and improve the theoretical model.

\subsection{Contributions}

The contributions made during this thesis work are summarized as follow:

\section{The first working prototype built at Carleton University}

From April 2005 to October 2005, supported by an "Interact Project" from Materials and Manufacturing Ontario and DY Refrigeration, the first DMSR working prototype was built at Carleton University and it demonstrated a good performance. Thus, it lays the foundation for future research and development such as the improvement of system performance and the building of next generation prototype.

\section{Theoretical analysis on DMSR system performance}

The basic thermal properties of the working pair and liquid or vapor ammonia were collected, compared and formulated, which include the enthalpy, viscosity, density, thermal conductivity, specific heat and the crystallization line. The relationships among the temperature, solution concentration and other thermal properties were investigated.

Based on the thermodynamic properties of the working solution, this thesis built two computational models to simulate the components influence and overall system 
performance separately. This is a successful application because it not only described the influence of different components on system performance but also display the relationships between different components. This will benefit the future research and the design of next generation prototype.

\section{Experimental data}

This thesis work conducted experimental investigations on the DMSR system steady state performance. It acquired large amount of thermal data based on experimental work. This data covered different generating temperature, cooling water temperature and other different testing conditions. It is a helpful reference for current and future applications.

\subsection{Recommendations for future work}

There are certain areas that can be further investigated and improved, which are summarized as follows.

\section{The Improvement of theoretical analysis method}

The existing computational model plays a very important role in the theoretical analysis process, and the basic system performance and every components working condition can be described by this model. But it is still not perfect; several updates should be applied to it in the future. For example, the mass transfer resistance of 
expansion gas and the size of every component has not been calculated in current model and should be considered in the future work, the pressure difference caused by solution pump should also take into account.

\section{Further experimental data}

In current testing process, large amount of temperature data were acquired, that covers almost all inlet and outlet temperature values for every heat exchanger and component, and the basic system performance can be speculated from these data, but there are still some necessary data, such as the specific heat of antifreeze fluid and the exact mass flow rates for the strong and the weak solution, that are needed to be acquired accurately in the experiment process. This will greatly benefit the test data analysis and system optimization.

\section{Comparison of experimental data and simulation}

Because of the time limit, the comparison of experimental data and simulation results is short. Further data analysis and simulation will lead to comparison of the results in a wide operation range. The results will be used for modifications of the DMSR system and individual components.

\section{The improvement of testing data acquisition system}

The existing data acquisition system plays a very important role in the experiments, but there are still some disadvantages, such as low test accuracy, poor 
interactive group communication ability, and only few types of sensor can be used together with this data acquisition system. We recommend using the new advanced data acquisition device to replace the old one, and using innovatory software, such as Labview, to acquire data. This will increase the test accuracy and decrease the test complicacy. Furthermore, more in-line pressure sensors should be implemented. 


\section{Appendix}

\section{Appendix I: The computational simulation programs}

\section{Program I.1 The single components simulation program 1 (Matlab)}

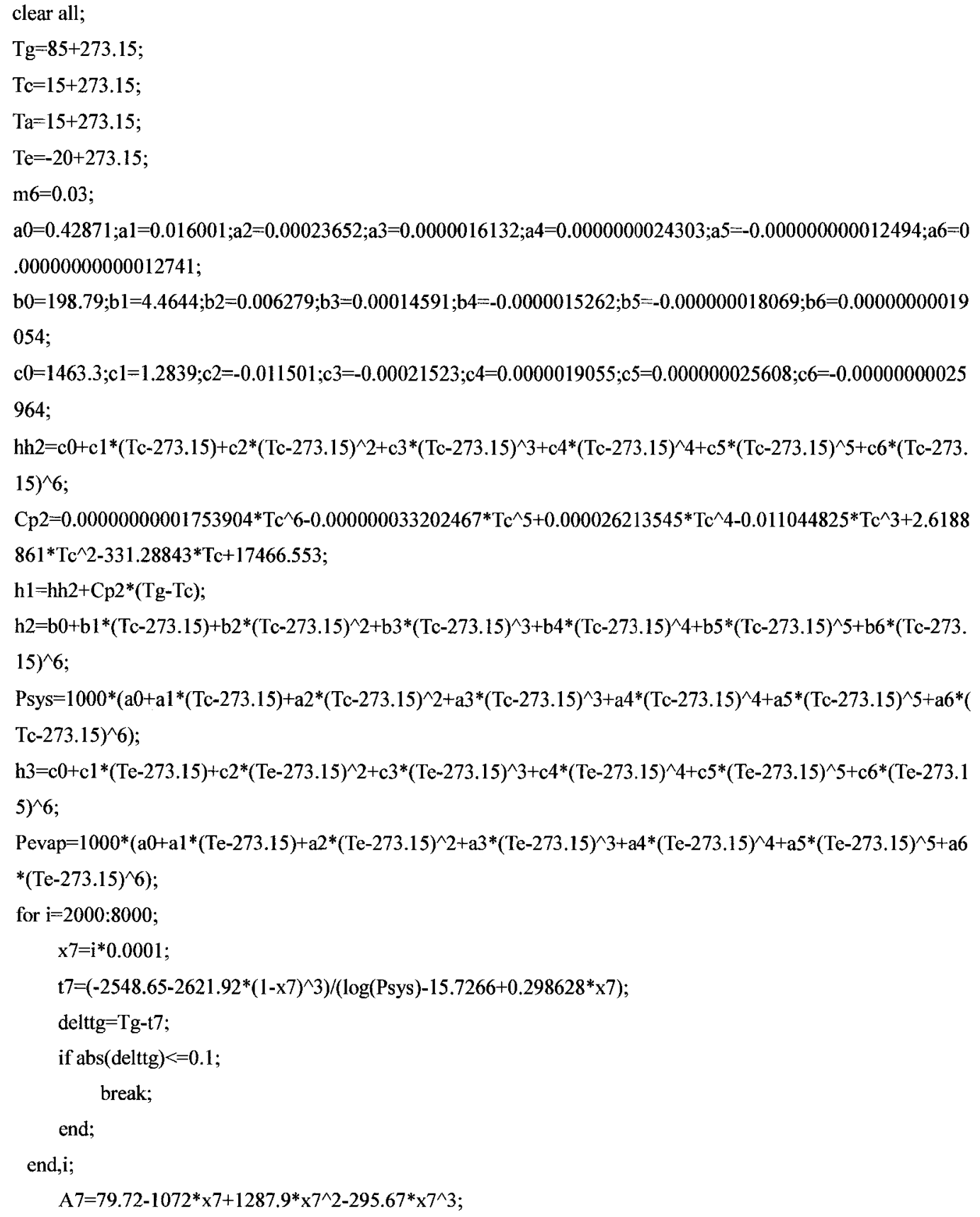




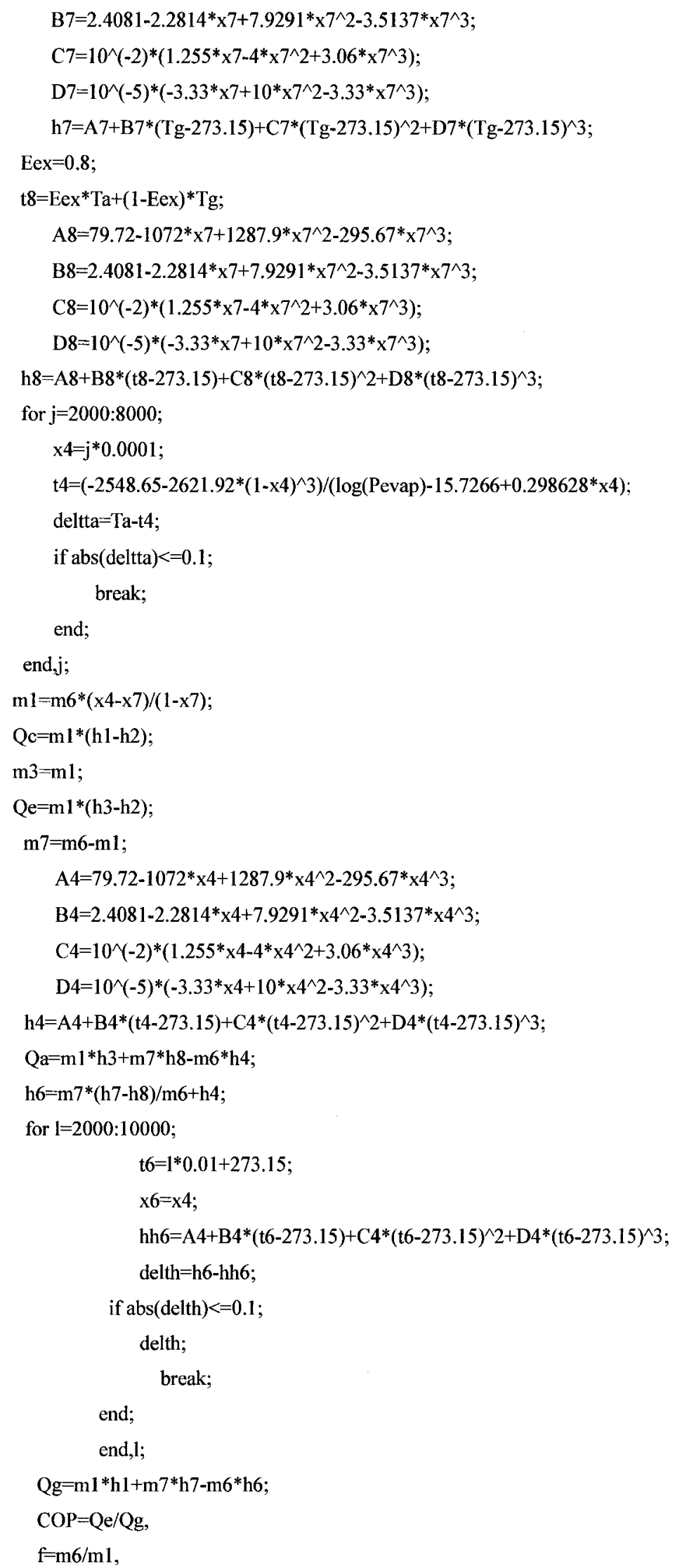


Qe,Qg,Qa

\section{Program I.2 The overall system performance simulation program 2}

\section{(Matlab)}

clear all;

$\mathrm{m} 6=0.03$;

Wexge $=3 ;$ Texge $=95+273.15 ;$ Texco $=15+273.15 ; \mathrm{t} 3=-10+273.15 ; \mathrm{Texab}=15+273.15$;

for $\mathrm{k}=161: 161$

$\mathrm{t} 2=\mathrm{k} * 0.1+273.15$,

$\mathrm{a} 0=0.42871 ; \mathrm{a} 1=0.016001 ; \mathrm{a} 2=0.00023652 ; \mathrm{a} 3=0.0000016132 ; \mathrm{a} 4=0.0000000024303 ; \mathrm{a} 5=-0.000000000012494 ;$ a6 $=0.00000000000012741$;

$\mathrm{b} 0=198.79 ; \mathrm{b} 1=4.4644 ; \mathrm{b} 2=0.006279 ; \mathrm{b} 3=0.00014591 ; \mathrm{b} 4=-0.0000015262 ; \mathrm{b} 5=-0.000000018069 ; \mathrm{b} 6=0.0000000$ 0019054 ;

$\mathrm{c} 0=1463.3 ; \mathrm{cl}=1.2839 ; \mathrm{c} 2=-0.011501 ; \mathrm{c} 3=-0.00021523 ; \mathrm{c} 4=0.0000019055 ; \mathrm{c} 5=0.000000025608 ; \mathrm{c} 6=-0.0000000$ 0025964;

$\mathrm{h} 2=\mathrm{b} 0+\mathrm{b} 1^{*}(\mathrm{t} 2-273.15)+\mathrm{b} 2 *(\mathrm{t} 2-273.15)^{\wedge} 2+\mathrm{b} 3 *(\mathrm{t} 2-273.15)^{\wedge} 3+\mathrm{b} 4^{*}(\mathrm{t} 2-273.15)^{\wedge} 4+\mathrm{b} 5^{*}(\mathrm{t} 2-273.15)^{\wedge} 5+\mathrm{b} 6^{*}(\mathrm{t} 2-27$ $3.15)^{\wedge} 6$;

Psys $=1000 *\left(a 0+a 1 *(t 2-273.15)+a 2 *(t 2-273.15)^{\wedge} 2+a 3^{*}(t 2-273.15)^{\wedge} 3+a 4^{*}(t 2-273.15)^{\wedge} 4+a 5 *(t 2-273.15)^{\wedge} 5+a\right.$ $\left.6^{*}(\mathrm{t} 2-273.15)^{\wedge} 6\right)$

Pevap $=1000 *\left(a 0+a 1^{*}(\mathrm{t} 3-273.15)+\mathrm{a} 2 *(\mathrm{t} 3-273.15)^{\wedge} 2+\mathrm{a} 3 *(\mathrm{t} 3-273.15)^{\wedge} 3+\mathrm{a} 4 *(\mathrm{t} 3-273.15)^{\wedge} 4+\mathrm{a} 5^{*}(\mathrm{t} 3-273.15)^{\wedge} 5+\right.$ a6*(t3-273.15)^ 6$)$;

$\mathrm{h} 3=\mathrm{c} 0+\mathrm{c} 1^{*}(\mathrm{t} 3-273.15)+\mathrm{c} 2 *(\mathrm{t} 3-273.15)^{\wedge} 2+\mathrm{c} 3^{*}(\mathrm{t} 3-273.15)^{\wedge} 3+\mathrm{c} 4^{*}(\mathrm{t} 3-273.15)^{\wedge} 4+\mathrm{c} 5^{*}(\mathrm{t} 3-273.15)^{\wedge} 5+\mathrm{c} 6^{*}(\mathrm{t} 3-273$ $.15)^{\wedge} 6$

Eex $=0.8$;

for $\mathrm{i}=200: 800$;

$\mathrm{x} 7=\mathrm{i} * 0.001$

$\mathrm{t} 7=\left(-2548.65-2621.92 *(1-\mathrm{x} 7)^{\wedge} 3\right) /(\log ($ Psys $)-15.7266+0.298628 * x 7)$;

$\mathrm{A} 7=79.72-1072^{*} \times 7+1287.9^{*} \times 7^{\wedge} 2-295.67^{*} \times 7^{\wedge} 3$;

$\mathrm{B} 7=2.4081-2.2814^{*} \times 7+7.9291 * \mathrm{x} 7^{\wedge} 2-3.5137^{*} \times 7^{\wedge} 3$;

$\mathrm{C} 7=10^{\wedge}(-2)^{*}\left(1.255^{*} \times 7-4^{*} \times 7^{\wedge} 2+3.06 * x 7^{\wedge} 3\right)$;

D $7=10^{\wedge}(-5)^{*}\left(-3.33^{*} \times 7+10^{*} \times 7^{\wedge} 2-3.33^{*} \times 7^{\wedge} 3\right)$;

$\mathrm{h} 7=\mathrm{A} 7+\mathrm{B} 7 *(\mathrm{t} 7-273.15)+\mathrm{C} 7^{*}(\mathrm{t} 7-273.15)^{\wedge} 2+\mathrm{D} 7 *(\mathrm{t} 7-273.15)^{\wedge} 3$;

for $\mathrm{j}=100: 800$;

$\mathrm{t} 5=\mathrm{j} * 0.1+273.15$

$\mathrm{t} 8=\mathrm{Eex}^{*} \mathrm{t} 6+(1-\mathrm{Eex}) * \mathrm{t} 7$

$\mathrm{h} 8=\mathrm{A} 7+\mathrm{B} 7 *(\mathrm{t} 8-273.15)+\mathrm{C} 7 *(\mathrm{t} 8-273.15)^{\wedge} 2+\mathrm{D} 7^{*}(\mathrm{t} 8-273.15)^{\wedge} 3$

$\mathrm{x} 8=\mathrm{x} 7$;

$\mathrm{Wexab}=3$;

$\mathrm{t} 4=\mathrm{t} 5$;

167

Reproduced with permission of the copyright owner. Further reproduction prohibited without permission. 


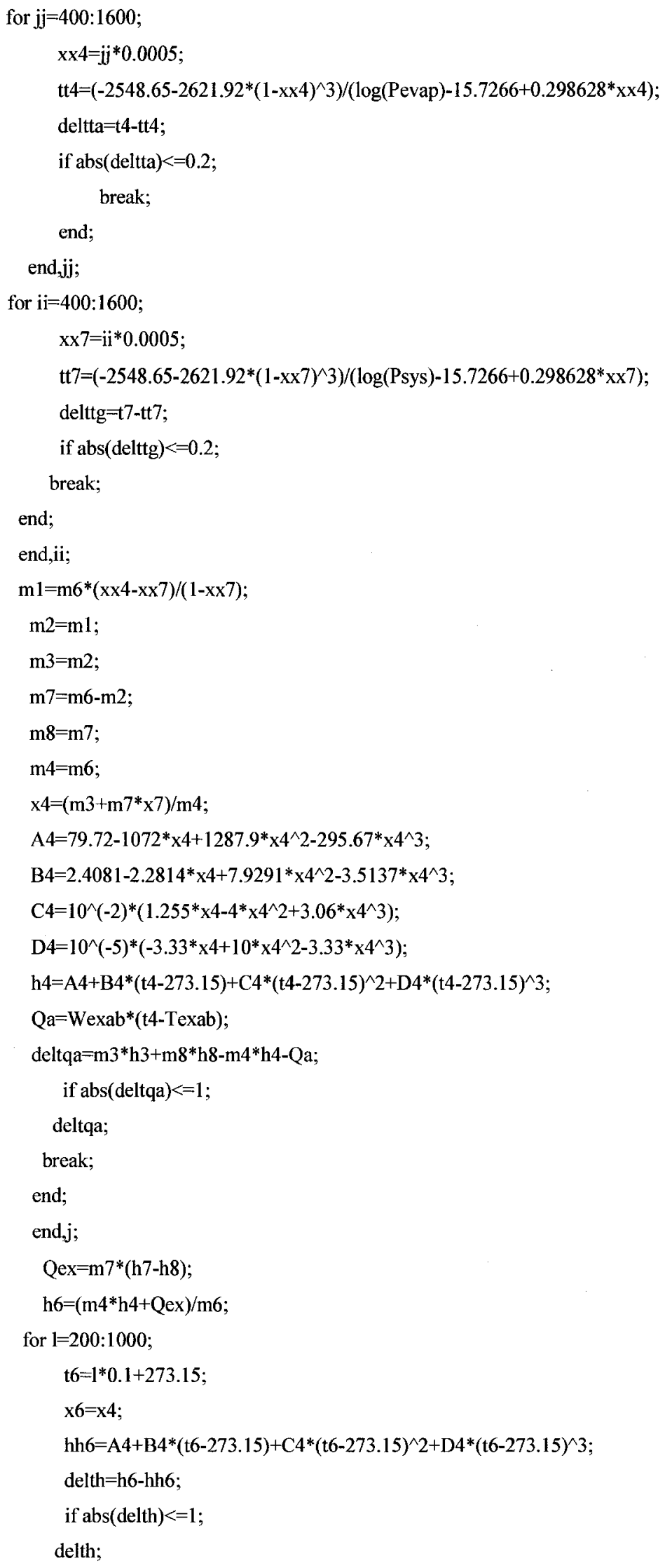




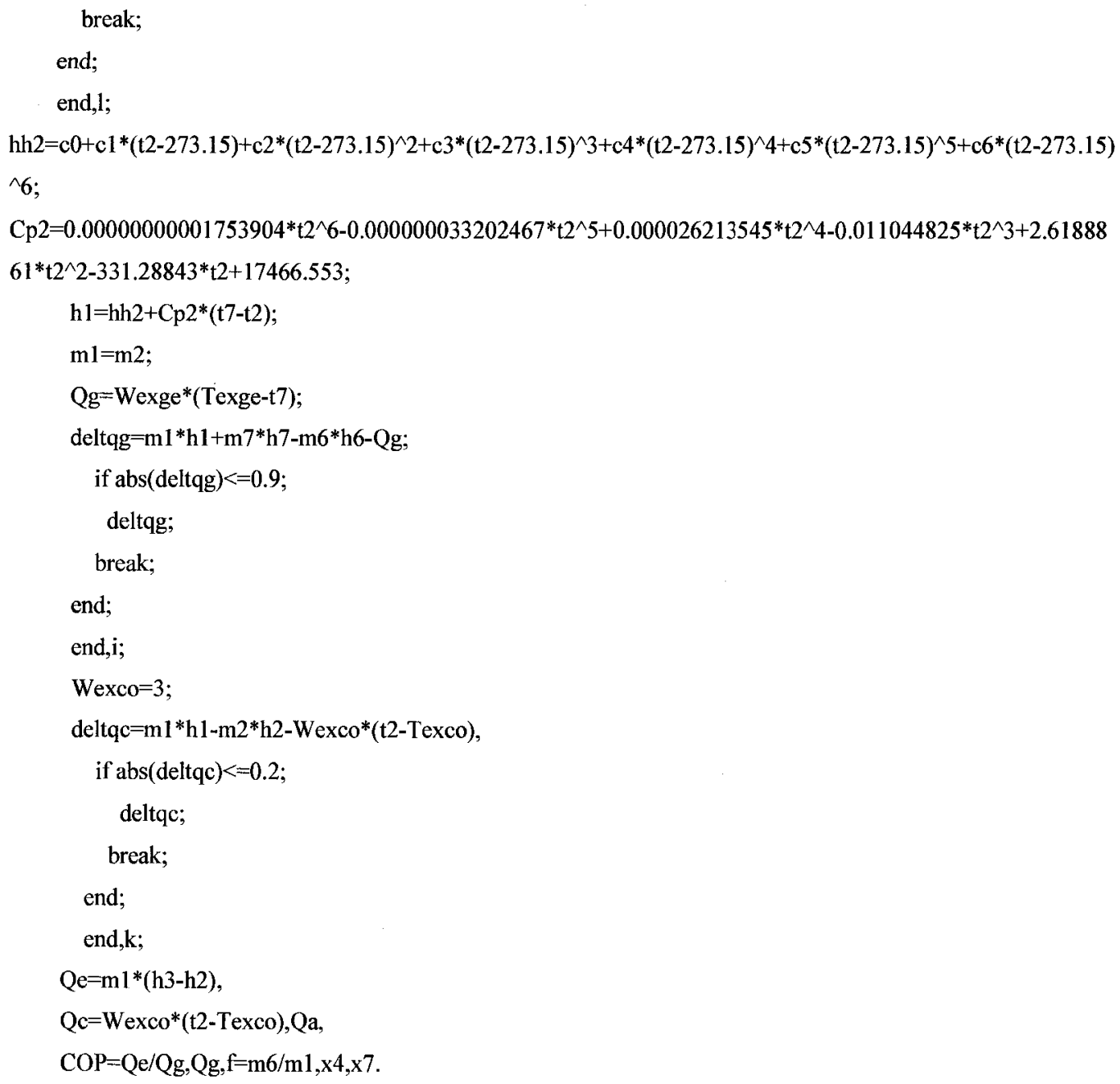




\section{Appendix II: The experimental result recordings}

Table II.1 Experimental result for normal refrigeration working conditions

\begin{tabular}{|c|c|c|c|c|c|}
\hline $\mathbf{T}_{\mathbf{G i}}\left({ }^{\circ} \mathbf{C}\right)$ & $\mathbf{T}_{\mathbf{G o}}\left({ }^{\circ} \mathbf{C}\right)$ & $\left.\mathbf{T}_{\text {Eoo }}{ }^{\circ} \mathbf{C}\right)$ & $\mathbf{T}_{\mathbf{C i}}\left({ }^{\circ} \mathbf{C}\right)$ & $\mathbf{T}_{\mathbf{A o}}\left({ }^{\circ} \mathbf{C}\right)$ & $\mathbf{T}_{\mathbf{C O}}\left({ }^{\circ} \mathbf{C}\right)$ \\
\hline 87.9 & 57.1 & -7.1 & 11.1 & 12.8 & 12.1 \\
\hline 88 & 57.3 & -7.1 & 11.2 & 12.9 & 12.1 \\
\hline 88.1 & 57.4 & -7.1 & 11.2 & 12.9 & 12 \\
\hline 88.3 & 57.6 & -7.1 & 11.2 & 12.9 & 12.1 \\
\hline 88.5 & 57.9 & -7.1 & 11.3 & 12.9 & 12 \\
\hline 88.6 & 57.9 & -7.5 & 11.2 & 12.8 & 11.9 \\
\hline 88.8 & 58 & -7.7 & 11.2 & 12.8 & 11.9 \\
\hline 88.9 & 58.1 & -7.8 & 11.3 & 12.7 & 12 \\
\hline 89.1 & 58.4 & -8 & 11.3 & 13.1 & 12.2 \\
\hline 89.2 & 58.5 & -8.3 & 11.4 & 13.4 & 12.7 \\
\hline 89.4 & 58.4 & -8.4 & 11.4 & 13.5 & 12.7 \\
\hline 89.5 & 58.3 & -8.5 & 11.4 & 13.6 & 12.8 \\
\hline 89.6 & 58.4 & -8.6 & 11.4 & 13.7 & 12.8 \\
\hline 89.8 & 58.4 & -8.6 & 11.5 & 13.7 & 12.9 \\
\hline 89.9 & 58.5 & -8.7 & 11.5 & 13.7 & 12.8 \\
\hline 90 & 58.6 & -8.8 & 11.6 & 13.7 & 12.8 \\
\hline 90.1 & 58.7 & -8.9 & 11.5 & 13.7 & 12.7 \\
\hline 90.2 & 58.7 & -8.9 & 11.6 & 13.7 & 12.8 \\
\hline 90.3 & 58.8 & -9.1 & 11.7 & 13.7 & 12.8 \\
\hline 90.5 & 59.1 & -9.1 & 11.7 & 13.9 & 12.9 \\
\hline 90.7 & 59.3 & -9.2 & 11.8 & 13.9 & 13 \\
\hline 91 & 59.4 & -9.3 & 11.8 & 14 & 13.1 \\
\hline 91.1 & 59.7 & -9.4 & 11.9 & 14.2 & 13.3 \\
\hline 91.3 & 59.9 & -9.6 & 12 & 14.3 & 13.3 \\
\hline 91.4 & 60.1 & -9.6 & 12 & 14.4 & 13.4 \\
\hline 91.7 & 60.7 & -10 & 12.2 & 14.3 & 13.4 \\
\hline 91.8 & 60.8 & -10 & 12.2 & 14.5 & 13.5 \\
\hline 91.9 & 60.9 & -10.1 & 12.3 & 14.5 & 13.5 \\
\hline 92 & 60.9 & -10.2 & 12.3 & 14.5 & 13.6 \\
\hline & & & & & \\
\hline
\end{tabular}




\begin{tabular}{|c|c|c|c|c|c|}
\hline 92.1 & 61 & -10.2 & 12.3 & 14.7 & 13.7 \\
\hline 92.2 & 61 & -10.3 & 12.4 & 14.7 & 13.7 \\
\hline 92.3 & 61.1 & -10.4 & 12.5 & 14.8 & 13.8 \\
\hline 92.4 & 61.1 & -10.4 & 12.5 & 14.8 & 13.8 \\
\hline 92.5 & 61.4 & -10.6 & 12.6 & 14.8 & 13.8 \\
\hline 92.6 & 61.6 & -10.6 & 12.7 & 14.8 & 13.9 \\
\hline 92.7 & 61.9 & -10.7 & 12.7 & 15.1 & 14.1 \\
\hline 92.8 & 62 & -10.8 & 12.7 & 15.1 & 14.1 \\
\hline 92.9 & 62.1 & -10.9 & 12.9 & 15. 3 & 14.2 \\
\hline 93 & 62.1 & -11 & 12.9 & 15.3 & 14.2 \\
\hline 93.1 & 62.5 & -11.2 & 12.9 & 15.2 & 14.2 \\
\hline 93.2 & 62.6 & -11.3 & 13 & 15.2 & 14.2 \\
\hline 93.4 & 62.6 & -11.5 & 13 & 15.3 & 14.3 \\
\hline 93.5 & 62.5 & -11.6 & 13.1 & 15.2 & 14.3 \\
\hline 93.6 & 62.2 & -11.8 & 13.1 & 15.7 & 14.6 \\
\hline 93.7 & 62.1 & -12 & 13.1 & 15.5 & 14.3 \\
\hline 93.8 & 62.4 & -12.1 & 13.2 & 15.4 & 14.4 \\
\hline 93.9 & 62.8 & -12.3 & 13.2 & 15.6 & 14.6 \\
\hline 94 & 62.8 & -12.3 & 13.2 & 15.6 & 14. 7 \\
\hline 94.1 & 62.6 & -12.4 & 13.2 & 15.7 & 14.6 \\
\hline 94.2 & 62.6 & -12.5 & 13.2 & 15.7 & 14.7 \\
\hline 94.3 & 62.8 & -12.5 & 13.2 & 15.8 & 14.6 \\
\hline 94.4 & 62.7 & -12.6 & 13.3 & 15.6 & 14.6 \\
\hline 94.5 & 62.9 & -12.7 & 13.4 & 15.7 & 14.8 \\
\hline 94.6 & 63 & -12.8 & 13.5 & 16 & 14.9 \\
\hline 94.7 & 62.8 & -12.9 & 13.5 & 15.8 & 14.8 \\
\hline 94.8 & 62.8 & -13 & 13.5 & 15.9 & 14.9 \\
\hline 94.9 & 62.8 & -13.1 & 13.7 & 16 & 15.1 \\
\hline 95 & 62.8 & -13.3 & 13.7 & 16 & 15 \\
\hline 95.1 & 62.7 & -13.4 & 13.7 & 16 & 15 \\
\hline 95.2 & 62.7 & -13.5 & 13.7 & 16. 1 & 15.1 \\
\hline 95.3 & 62.8 & -13.5 & 13.8 & 16 & 15.1 \\
\hline 95.4 & 62.8 & -13.6 & 13.9 & 16.2 & 15.4 \\
\hline 95.5 & 62.6 & -13.7 & 13.9 & 16.2 & 15.3 \\
\hline 95.6 & 62.6 & -13.8 & 13.9 & 16.3 & 15.3 \\
\hline 95.7 & 62.7 & -13.9 & 13.9 & 16.3 & 15.3 \\
\hline 95.8 & 62.8 & -13.9 & 13.9 & 16.4 & 15.5 \\
\hline 95.9 & 62.9 & -14 & 13.9 & 16.4 & 15.5 \\
\hline 96 & 62.8 & -14.1 & 14 & 16.4 & 15.5 \\
\hline
\end{tabular}




\begin{tabular}{|c|c|c|c|c|c|}
\hline 96.1 & 62.7 & -14.1 & 13.9 & 16.4 & 15.5 \\
\hline 96.2 & 62.7 & -14.3 & 13.9 & 16.4 & 15.5 \\
\hline 96.3 & 62.7 & -14.2 & 14 & 16.4 & 15.5 \\
\hline 96.4 & 63 & -14.5 & 14.1 & 16.3 & 15.4 \\
\hline 96.5 & 63.2 & -14.6 & 14.2 & 16.4 & 15.4 \\
\hline 96.6 & 62.6 & -14.9 & 14.3 & 17.1 & 16.1 \\
\hline 96.7 & 62.9 & -15 & 14.3 & 17.1 & 16.1 \\
\hline 96.8 & 64.6 & -15.2 & 14.4 & 16.7 & 15. 7 \\
\hline 97 & 64.3 & -15.3 & 14.5 & 16.7 & 15.7 \\
\hline 97.1 & 64 & -15.2 & 14.5 & 16.8 & 16 \\
\hline 97.2 & 63.5 & -15.4 & 14.6 & 17 & 16.1 \\
\hline 97.3 & 63.4 & -15.4 & 14.5 & 17 & 16.1 \\
\hline 97.4 & 64.1 & -15.6 & 14.6 & 16.8 & 15.9 \\
\hline 97.5 & 64.3 & -15.6 & 14.6 & 16.7 & 15.9 \\
\hline 97.6 & 64.5 & -15.7 & 14.6 & 16.8 & 16 \\
\hline 97.7 & 64.7 & -15.7 & 14.6 & 16.8 & 16.1 \\
\hline 97.8 & 65.1 & -16 & 14.5 & 17 & 16.1 \\
\hline 97.9 & 65.3 & -16 & 14.6 & 16.9 & 16 \\
\hline 98 & 65.1 & -16.2 & 14.6 & 16.8 & 16 \\
\hline 98.1 & 64.9 & -16.2 & 14.7 & 16.8 & 16 \\
\hline 98.2 & 63.7 & -16.4 & 14.8 & 17.5 & 16.6 \\
\hline 98.3 & 64.1 & -16.4 & 14.8 & 17.4 & 16.5 \\
\hline 98.4 & 64.5 & -16.4 & 14.7 & 17.3 & 16.3 \\
\hline 98.5 & 64.8 & -16.7 & 14.9 & 17.1 & 16.4 \\
\hline 98.6 & 64.7 & -16.7 & 14.8 & 17.2 & 16.5 \\
\hline 98.7 & 64.4 & -16.9 & 14.9 & 17.4 & 16.5 \\
\hline 98.8 & 64.7 & -16.9 & 14.9 & 17.4 & 16.4 \\
\hline 98.9 & 65 & -16.9 & 14.9 & 17.3 & 16.3 \\
\hline 99 & 65.5 & -17.2 & 14.9 & 17.2 & 16.5 \\
\hline 99.1 & 65.4 & -17.1 & 14.9 & 17.3 & 16.6 \\
\hline 99.2 & 65.3 & -17.1 & 14.9 & 17.3 & 16.6 \\
\hline 99.4 & 64.8 & -17.3 & 14.8 & 17.2 & 16.7 \\
\hline 99.5 & 64.7 & -17.3 & 14.8 & 17.2 & 16.6 \\
\hline 99.6 & 66 & -17.6 & 14.9 & 17 & 16.2 \\
\hline 99.7 & 65.8 & -17.7 & 15 & 17 & 16.2 \\
\hline 99.8 & 65.6 & -17.7 & 14.9 & 16.9 & 16.2 \\
\hline 99.9 & 65.7 & -17.9 & 14.9 & 17.5 & 16.6 \\
\hline 100 & 65.6 & -17.9 & 14.8 & 17.5 & 16.5 \\
\hline
\end{tabular}


Table II.2 Experimental result for super-cooling working conditions

\begin{tabular}{|c|c|c|c|c|}
\hline $\mathbf{T}_{\mathbf{G i}}$ & $\mathbf{T}_{\mathbf{G o}}$ & $\mathbf{T}_{\mathbf{E O}}$ & $\mathbf{T}_{\mathbf{W i}}$ & $\mathbf{T}_{\text {Ao }}$ \\
\hline 102.1 & 80.2 & -22 & 13.1 & 15.1 \\
\hline 102 & 80 & -22.1 & 13.1 & 15 \\
\hline 101.9 & 77.5 & -22.2 & 13.1 & 15. 1 \\
\hline 103.1 & 80 & -22.3 & 13 & 14.8 \\
\hline 102.7 & 79.9 & -22.4 & 13 & 14.9 \\
\hline 103 & 77.8 & -22.5 & 12.7 & 14.7 \\
\hline 103.4 & 78.8 & -22.6 & 12.7 & 14.5 \\
\hline 104 & 82.2 & -22.7 & 12.8 & 14.8 \\
\hline 103.6 & 80.7 & -22.8 & 13.1 & 14.9 \\
\hline 103.6 & 80.7 & -22.9 & 13.1 & 14.9 \\
\hline 104.1 & 84.3 & -23 & 13 & 15 \\
\hline 104.3 & 87.7 & -23.1 & 12.8 & 14.7 \\
\hline 104.4 & 85 & -23.2 & 12.8 & 14.7 \\
\hline 104.7 & 89.2 & -23.3 & 12.7 & 14.5 \\
\hline 104.8 & 89.2 & -23.4 & 12.7 & 14.5 \\
\hline 105.1 & 89 & -23.5 & 12.5 & 14.4 \\
\hline 105.2 & 92 & -23.6 & 12.5 & 14. 4 \\
\hline 105.3 & 94.7 & -23.7 & 12.3 & 14.2 \\
\hline 105.4 & 91.4 & -23.8 & 12.3 & 14.2 \\
\hline 105.3 & 91.8 & -23.9 & 12.3 & 14.3 \\
\hline 105.4 & 89.1 & -24 & 12.3 & 14.2 \\
\hline 105.6 & 94.2 & -24.1 & 12.3 & 14. 1 \\
\hline 105.8 & 89.4 & -24.2 & 12.1 & 14.1 \\
\hline 105.9 & 97.6 & -24.3 & 12.2 & 14. 1 \\
\hline 106.3 & 88.8 & -24.4 & 12.2 & 14. 2 \\
\hline 107.4 & 95.2 & -24.5 & 12.4 & 14.3 \\
\hline 107.5 & 92.9 & -24.7 & 12.4 & 14. 3 \\
\hline 107.9 & 88.8 & -24.8 & 12.4 & 14.2 \\
\hline 108 & 88.8 & -24.9 & 12.2 & 14. 1 \\
\hline 108.1 & 89.7 & -25 & 12.2 & 14.1 \\
\hline
\end{tabular}




\section{Reference}

[1]. Pongsid Srikhirin, Satha Aphornratana, Supachart Chungpaibulpatana, A review of absorption refrigeration technologies, Renewable and sustainable energy reviews, Vol 5, pp. 343-372, 2001.

[2]. Herold KE, Radermacher L. Absorption heat pump, Mechanical engineering, pp.68-73, 1989.

[3]. Gosney WB., Principle of refrigeration. Cambridge University Press, 1982.

[4]. [1]. Billiard F. The Kyoto Protocol. Bulletin de l'Institut International du Froid, 98(2): VI-XII, 1998.

[5]. Keith E. Herold, Reinhard Radermacher, Sanford A. Klein, Absorption chillers and heat pumps, CRC press, 1996.

[6]. Da-wen Sun, Comparison of the performances of $\mathrm{NH}_{3}-\mathrm{H}_{2} \mathrm{O}, \mathrm{NH}_{3}-\mathrm{LiNO}_{3}$ and $\mathrm{NH}_{3}-\mathrm{NaSCN}$ absorption refrigeration systems, Energy conversion management, Vol. 39, pp. 357-368, 1998.

[7]. Rogdakis, E. D., Antonopoulos, K. A., Performance of a low-temperature $\mathrm{NH}_{3}-\mathrm{H}_{2} \mathrm{O}$ absorption-refrigeration system, Energy, Vol.17, pp. 477-484, 1992.

[8]. Bulgan, A. T., Optimization of the thermodynamic model of aqua-ammonia absorption refrigeration systems, Energy conversion and management, Vol. 36, pp. 135-143, 1995.

[9]. Da-wen Sun, Thermodynamic design data and optimum design maps for absorption refrigeration systems, Applied thermal engineering, Vol. 17, pp. 211-221, 1996.

[10]. Bogart, M., Ammonia absorption refrigeration in inderstrial processes. Gulf, Houston, 1981.

[11]. D. Butz, K. Stephan, Dynamic behaviour of an absorption heat pump, International journal of refrigeration, Vol. 12, pp. 204-212, 1989.

[12]. Rogdakis, E. D., Antonopoulos, K. A., Thermodynamic cycle, correlations and nomograph for $\mathrm{NH}_{3}-\mathrm{NaSCN}$ absorption refrigeration systems, Heat recovery systems \& CHP, Vol. 15, pp. 591-599, 1995.

[13]. Rogdakis, E. D., Antonopoulos, K. A., Performance of solar-driven ammonia-lithium nitrate and ammonia-sodium thiocyanate absorption systems 
operating as coolers or heat pumps in Athens, Applied thermal engineering, Vol. 16, pp. 127-147, 1996.

[14]. G. C. Blytas, F. Daniels, Concentrated solutions of $\mathrm{NaSCN}$ in liquid ammonia: solubility, density, vapor pressure, viscocity. thermal conductance, heat of solution, and heat capacity, Journal of the American chemical society, Vol. 84, pp. 1075-1083, 1962.

[15]. S. L. Sargent, W. A. Beckman, Theoretical performance of an ammonia-sodium thiocyanate intermittent absorption refrigeration cycle. Solar Energy, Vol. 12, pp. 137-146, 1968.

[16]. K. P. Tyagi, Ammonia-salts vapour absorption refrigeration systems. Heat Recovery Systems, Vol. 4, pp. 427-431, 1984.

[17]. M. K. Aggarawal, R. S. Aggarawal and Y. V. S. R. Sastry, Solid absorbents for solar-powered refrigeration systems, Energy, Vol. 34, pp. 423-426, 1985.

[18]. C. A. Infante Ferreira, Thermodynamic and physical property data equations for ammonia-lithium nitrate and ammonia-sodium thiocyanate solutions, Solar Energy, Vol. 32, pp. 231-236, 1984.

[19]. P. Bourseau, R. Bugarel, Refrigeration par cycle a absorption-diffusion: comparaison des performances des systemes $\mathrm{NH}_{3}-\mathrm{H}_{2} \mathrm{O}$ et $\mathrm{NH}_{3}-\mathrm{NaSCN}$. International journal of refrigeration, Vol. 9, pp. 206-214, 1986.

[20]. Gearoid Foley, The future of absorption technology in America, Advanced building systems-2000 conference, 2000.

[21]. Perez-Blanco H, Absorption heat pump performance for different types of solution. International journal of refrigeration, Vol 7, pp. 115-122, 1984.

[22]. Holmberg P, Berntsson T., Alternative working fluids in heat transformers. ASHRAE Trans, Vol. 96, pp. 1582-1589, 1990.

[23]. Marcriss RA, Gutraj JM, Zawacki TS., Absorption fluid data survey: final report on worldwide data, ORLN/sub/8447989/3, Inst. Gas Tech., 1988.

[24]. Park YM, Sonntag RE., Thermodynamic properties of ammonia-water mixtures: a generalized equation-of-state approach. ASHRAE Trans, Vol. 96, pp. 150-159, 1990.

[25]. Ziegler B, Trepp C., Equation of state for ammonia-water mixtures. International journal of refrigeration, Vol. 7, pp. 101-106, 1984. 
[26]. Herold KE, Han K, Moran MJ. AMMWAT, A computer program for calculating the thermodynamic properties of ammonia and water mixtures using a Gibbs free energy formulation. ASME Pub AES, Vol. 4, pp. 65-75, 1988.

[27]. Berestneff AA., Absorption refrigeration. Mechanical Engineering, Vol. 72, pp. 216-220, 1949.

[28]. McNeely LA., Thermodynamic properties of aqueous solutions of lithium bromide, ASHRAE Trans, Vol. 85, pp. 413-434, 1979.

[29]. Patterson MR, Perez-Blanco H., Numerical fits of properties of lithium-bromide water solutions. ASHRAE Trans, Vol. 94, pp. 2059-2077, 1988.

[30]. Lee RJ, DiGuilio RM, Jeteter SM, Teja AS., Properties of lithium bromide-water solutions at high temperatures and concentrations-part II: density and viscosity, ASHRAE Trans, Vol. 96, pp.709-714, 1990.

[31]. Jeter SM, Moran JP, Teja AS. Properties of lithium bromide-water solutions at high temperatures and concentrations-part III: specific heat. ASHRAE Trans, Vol. 98, pp.134-149, 1992.

[32]. Lenard JLY, Jeter SM, Teja AS. Properties of lithium bromide-water solutions at high temperatures and concentrations-part IV: vapor pressure. ASHRAE Trans, Vol. 98, pp.167-172, 1992.

[33]. Modahl RJ, Lynch PJ. Arsenic trioxide corrosion inhibitor for absorption refrigeration system, US Patent No. 3609086, 1971.

[34]. Verma SK, Mekhjian MS, Sandor GR, Nakada N. Corrosion inhibitor in lithium bromide absorption fluid for advanced and current absorption cycle machines. ASHRAE Trans, Vol. 105, pp. 813-815, 1999.

[35]. Albertson CE, Krueger RH., Heat transfer additives for absorbent solution, US Patent No. 3580759, 1971.

[36]. Chang WC, Marcriss RA, Rush WF. Secondary alcohol additives for lithium bromide-water absorption refrigeration system, US Patent No. 3609087, 1971.

[37]. Elkassabgi YM, Perez-Blanco H., Experimental study of the effects of alcohol additives in lithium bromide/water pool absorber. ASHRAE Trans, Vol.97, pp. 403-405, 1991.

[38]. Daiguji H, Hihara E, Saito T., Mechanism of absorption enhancement by 
surfactant. International journal of heat and mass transfer, Vol. 40, pp. $1743-1752,1997$.

[39]. Hihara E, Saito T., Effect of surfactant on falling film absorption, International journal of refrigeration. Vol. 16, pp. 339-346, 1993.

[40]. Agarwal RS, Bapat SL., Solubility characteristics of R22-DMF refrigerant-absorbent combination, International journal of refrigeration, Vol. 8, pp. 70-74, 1985.

[41]. Ando E, Takeshita I., Residential gas-fired absorption heat pump based on R22-DEGDME pairpart I: thermodynamic properties of the R22-DEGDME pair, International journal of refrigeration, Vol.7, pp. 181-185, 1984.

[42]. Bhaduri SC, Verma HK., P-T-X behavior of R22 with five different absorbents. International journal of refrigeration, Vol. 9, pp. 362-366, 1986.

[43]. Bhaduri SC, Verma HK., Heat of mixing of R22-absorbent mixture. International journal of refrigeration, Vol. 11, pp. 92-95, 1988.

[44]. Fatouh M, Murthy SS. Comparison of R22-absorbent pairs for vapour absorption heat transformers based on P-T-X-H data. Heat Recovery Systems \& CHP, Vol. 13, pp. 33-48, 1993.

[45]. Murphy KP, Phillips BA., Development of residential gas absorption heat pump, International journal of refrigeration, Vol. 7, pp. 56-58, 1984.

[46]. Best R, Holland FA., A study of the operating characteristics of an experimental absorption cooler using ternary systems. International journal of energy research, Vol. 14, pp. 553-561, 1990.

[47]. Idema PD., Real process simulation of a $\mathrm{LiBr} / \mathrm{ZnBr}_{2} / \mathrm{CH}_{3} \mathrm{OH}$ absorption heat pump. ASHRAE Trans, Vol. 93, pp. 562-574, 1987.

[48]. Herold KE, Radermacher R, Howe L, Erickson DC. Development of an absorption heat pump water heater using an aqueous ternary hydroxide working fluid. International journal of refrigeration, Vol. 14, pp. 156-167, 1991.

[49]. Barragan RM, Arellano VM, Heard CL, Best R. Experimental performance of ternary solution in an absorption heat transfer. International journal of energy research, Vol. 22,pp. 73-83, 1998.

[50]. Wang S.G. and Wang R.Z., Recent development of refrigeration technology in fishing vessels, Renewable Energy, Vol. 30, pp. 589-600, 2005. 
[51]. Antonopoulos KA, Rogdakis ED., Nomographs for optimum solar pond driven $\mathrm{LiBr} / \mathrm{ZnBr}_{2} / \mathrm{CH}_{3} \mathrm{OH}$ absorption refrigeration system. International journal of energy research, Vol. 16, pp. 413-429,1992.

[52]. George JM, Murthy SS. Influence of heat exchanger effectiveness on performance of vapour absorption heat transformers. International journal of energy research, Vol. 13, pp. 455-457,1989.

[53]. George JM, Murthy SS. Influence of absorber effectiveness on performance of vapour absorption heat transformers. International journal of energy research, Vol. 13, pp. 629-638,1989.

[54]. George JM, Murthy SS. Influence of generator effectiveness on performance of vapour absorption heat transformers. International journal of energy research, Vol. 13, pp. 687-699, 1989.

[55]. Vliet GC, Lawson MB, Lithgow RA, Water-lithium bromide double-effect absorption cooling cycle analysis. ASHRAE Trans. Vol. 88, pp. 811-822, 1982.

[56]. Kandlikar SG A new absorber heat recovery cycle to improve COP of aqua-ammonia absorption refrigeration system. ASHRAE Trans, Vol. 88, pp. 141-158, 1982.

[57]. Kaushik SC, Kumar R. A comparative study of an absorber heat recovery cycl for solar refrigeration using NH3-refrigerant with liquid/solid absorbents. Energy research, Vol. 11, pp. 123-132, 1987.

[58]. Groll EA. Current status of absorption/compression cycle technology. ASHRAE Trans., Vol. 103, 1997;103.

[59]. Machienlsen CHM. Research activities on absorption systems for heating. Cooling and industrial use. ASHRAE Trans., Vol. 96, pp. 1577-1581, 1990.

[60]. Rane MV, Radermacher R. Two-stage vapor compression heat pump with solution circuits: performance enhancement with a bleed line, Proceedings of Absorption Heat Pump Conference, pp. 97-102, Tokyo, 1991.

[61]. Rane MV, Amrane K, Radermacher R., Performance enhancement of a two-stage vapor compression heat pump with solution circuits by eliminating the rectifier. International journal of refrigeration, Vol. 16, pp. 247-257, 1993.

[62]. Caccoila G, Restuccia G, Rizzo G. Theoretical performance of an absorption heat pump using ammonia-water-potassium hydroxide solution. Heat recovery system and 
CHP, Vol. 10, pp. 177-185, 1990.

[63]. Groll EA, Radermacher R. Vapor compression heat pump with solution circuit and desorber/absorber heat exchange, Proceedings of the Absorption Heat Pump Conference, pp.463-469, New Orleans, 1994.

[64]. Kuhlenschmidt D., Absorption refrigeration system with multiple generator stages, US Patent No. 3717007, 1973.

[65]. Chung H, Huor MH, Prevost M, Bugarel R. Domestic heating application of an absorption heat pump, Directly fired heat pumps, Procsess of international conderence, paper 2.2, University of Bristol, 1984.

[66]. Chen LT., A new ejector-absorber cycle to improve the COP of an absorption refrigeration system, Applied energy, Vol. 30, pp. 37-51, 1988.

[67]. Aphornratana S, Eames IW., Experimental investigation of a combined ejector-absorption refrigerator. International journal of energy research, Vol. 22, pp. 195-207,1998.

[68]. Wu S, Eames IW., A novel absorption-recompression refrigeration cycle. Applied thermal engineering, Vol. 20, pp. 721-736, 2000.

[69]. Eames IW, Wu S., Experimental proof-of-concept testing of an innovative heat-powered vapour recompression-absorption refrigerator cycle, Applied thermal engineering, Vol. 18, pp. 1149-1157, 1998.

[70]. Zerweck G. Ein-oder mehrstufige Absorptionswärmepumpe, German Patent No DE $3009820 \mathrm{~A} 1,1980$.

[71]. Eriksson K, Jernquist A., Heat Transformers with self-circulation: design and preliminary operational data. International journal of refrigeration, Vol. 12, pp. 15-20, 1989.

[72]. Platen BCV, Munters CG. Refrigerator, US Patent No. 1,685,764, 1928.

[73]. Chen J, Kim KJ, Herold KE, Performance enhancement of a diffusion-absorption refrigerator, International journal of refrigeration, Vol. 19, pp. 208-218, 1996.

[74]. Steirlin H, Ferguson JR. Diffusion Absorption Heat Pump (DAHP). ASHRAE Trans, Vol. 96, pp. 3319-3328, 1990.

[75]. Wang L, Herold KE. Diffusion-Absorption Heat Pump, Annual Report to Gas 
Research Institute, GRI-92/0262, 1992.

[76]. Kouremenos DA, Sagia AS, Use of helium instead of hydrogen in inert gas absorption refrigeration, International journal of refrigeration, Vol. 11, pp. 336-341, 1988.

[77]. Narayankhedlar KG, Maiya MP. Investigation of triple fluid vapor absorption refrigerator, International journal of refrigeration, Vol. 8, pp. 335-342, 1985.

[78]. Properties of R-717 (anhydrous ammonia), Industrial refrigeration consortium, University of Wisconsin, Madison, WI, USA.

[79]. Khalid A. Joudi, Ali H. Lafta, Simulation of a simple absorption refrigeration system, Energy conversion and management, Vol. 42, pp. 1575-1605, 2001.

[80]. Felix Ziegler, Recent developments and future prospects of sorption heat pump systems, International journal of thermal science, Vol. 38, pp. 191-208, 1999.

[81]. K. P. Tyagi, Second law analysis of NH3-NASCN absorption refrigeration cycle, Heat recovery systems, Vol. 6, pp. 73-82, 1986.

[82]. M. K. Aggarwal, R. S. Agarwal, Solid absorbents for solar powered refrigeration systems, Solar energy, Vol. 34, pp. 423-426,1985.

[83]. R. Best, W. Rivera, J. Hernandea, A. Oskam, Thermodynamic design data for absorption heat pump systems operating on ammonia-sodium thiocyanaye- $\mathrm{I}$. Cooling, Heat recovery systems \& CHP, Vol. 13, pp. 1-9, 1993.

[84]. Frank Schubach, Gary Schubach, Chiller heating assembly, US Patent No. $5724829,1998$.

[85]. F. S. Brandt, P. M. A. Broers, Th. W. de Loos, High pressure phase equilibria in the systems ammonia + potassium iodide, + sodium iodide, + sodium bromide, and + sodium thiocyanate: solid-liquid-vapor and liquid-liquid-vapor equilibria, International journal of thermophusics, Vol. 22, pp. 1045-1055, 2001.

[86]. M. Pons, F. Meunier, G. Cacciola, R. E. Critoph, M. Groll, L. Puigjaner, B. Spinner, F. Ziegler, Thermodynamic based comparison of sorption systems for cooling and heat pumping, International journal of refrigeration, Vol. 22, pp. 5-17, 1999.

[87]. M. Altamush Siddiqui, Economic analyses of absorption systems : part A Design amd cost evaluation, Energy convversion, Vol. 38, pp. 889-904, 1997. 
[88]. I. Horuz, T. M. S. Callander, Experimental investigation of a vapor absorption refrigeration system, International journal of refrigeration, Vol. 27, pp. 10-16, 2004. 